TITLE:

\title{
The Ascidians of the Japan Sea. II
}

AUTHOR(S):

Nishikawa, Teruaki

CITATION:

Nishikawa, Teruaki. The Ascidians of the Japan Sea. II. PUBLICATIONS OF THE SETO MARINE BIOLOGICAL LABORATORY 1991, 35(1-3): 25-170

ISSUE DATE:

1991-03-31

URL:

http://hdl.handle.net/2433/176172

RIGHT: 


\title{
The Ascidians of the Japan Sea. $\mathrm{II}^{1)}$
}

\author{
Teruaki Nishikawa \\ Biological Laboratory, College of General Education, Nagoya University, \\ Chikusa-ku, Nagoya 464-01, Japan
}

With Text-figures 10-40 and Tables 5-6

Family Cionidae

55. Rhopalaea crassa (Herdman, 1880)

(Fig. 10)

Ecteinascidia crassa Herdman, 1880, p. 723.

Rhopalaea crassa: Beneden, 1887, p. 26.

Rhopalaea sagamiana Oka, 1927d, pp. 681-683, figs A-B. (listed as a synonym of $R$. crassa by Tokioka, 1953c)

Rhopalaea macrothorax Tokioka, 1953c, pp. 212-213, pl. 29, figs 1-5. (listed as a synonym of $R$. crassa by Kott \& Goodbody, 1980)

Rhopalopsis defecta Sluiter: Hartmeyer, 1906, p. 26.

For other synonyms see Tokioka (1953c) and Kott \& Goodbody (1980).

Doubtful synonym:

Rhopalaea mutuensis Oka, 1927d, p. 683.

Material examined: A (Toyama Bay): Stns 21 and 28, a single individual respectively; St. 29, 2 individuals, thoracic part more or less deteriorated; St. 30, 19 individuals, some attaching to one another by their posterior end or nearly by the whole abdominal part, thoracic part much deteriorated. E-1 (Wakasa Bay): 2 individuals, thorax deteriorated. I-1 (Tsukumo Bay): 4 individuals, firmly attached to fragments of fishing net. I-2 (Tsukumo Bay): about 90, also attached to fishing net. N (Oki): several, already listed by Nishikawa (1986b).

Description. In the present material, the collections A (Stns 29 and 30), E, I-2 (part) and N (part) contain the "usual" specimens provided with well developed thorax (see Fig. 10, A), while in the specimens of collections A (Stns 21 and 28), I-1 and I-2 (part), thorax, probably in the initial stages of regeneration, much smaller than abdomen (see Fig. 10, $\mathrm{G}$ and $\mathrm{E}$ ). In some specimens of $\mathrm{N}$ the test mass includes abdominal part only. In the usual specimens, body roughly cylindrical and up to $91 \mathrm{~mm}$ long, but markedly constricted between thoracic and abdominal regions; the two regions may separate rather easily when handled roughly. Thoracic region 1.5 to 1.6 times as long as the abdominal, except in a $43.5 \mathrm{~mm}$ long specimen from $\mathrm{N}$ having the thoracic region 2.2 times as long as the abdominal, and further in much deteriorated specimens of $\mathrm{A}$, the thoracic region up to $66 \mathrm{~mm}$ and the ab-

1) This is the second of serial papers that are published in this journal as parts of the author's thesis.

Publ. Seto Mar. Biol. Lab., 35(1/3), 25-170, 1991.

(Article 4) 


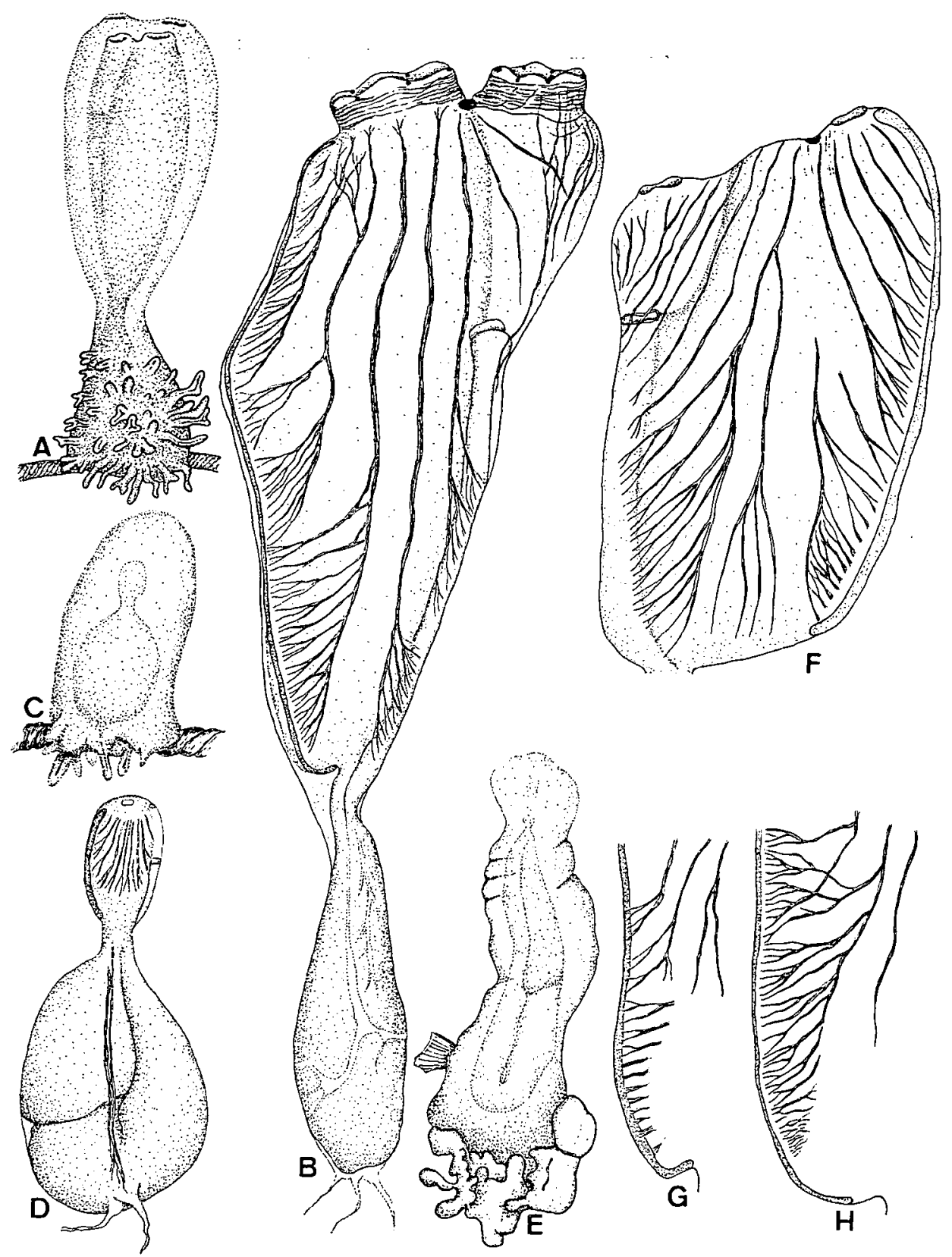

Fig. 10. Rhopalaea crassa (Herdman). A-D. from Tsukumo Bay, Noto Pen. (Collection I-2); E-F. from Tsukumo Bay (I-1); G-H. from Toyama Bay (A, St. 30). A. a typical individual, $52 \mathrm{~mm}$ long; B. left side of the same individual as Fig. A, removed from test; $\mathrm{C}$. an individual with regenerating thorax, $10 \mathrm{~mm}$ long; D. left side of the same individual as Fig. C; E. individual with regenerating thorax, $36 \mathrm{~mm}$ long; F. right side of thorax of the same individual as Fig. E; G-H. left side of posteroventral part of thorax of normal individual, $47 \mathrm{~mm}$ (G) and $42 \mathrm{~mm}(\mathrm{H})$ long, showing disconnected thoracic muscles. 
dominal to $21 \mathrm{~mm}$ in length. In diameter, thoracic region up to $15 \mathrm{~mm}$ or more, while the abdominal to $10 \mathrm{~mm}$. The specimens with regenerating thorax ranging in total length from 10 to $36 \mathrm{~mm}$, though the thoracic part occupying only 2 to 10 $\mathrm{mm}$, except in a specimen of A (St. 28) which is represented by the columnar test mass, $78 \mathrm{~mm}$ long and about $10 \mathrm{~mm}$ thick, containing anteriorly a zooid of $6.5 \mathrm{~mm}$ thorax and $16 \mathrm{~mm}$ long abdomen. All the specimens in the present material attached to substratum by their posterior end. In living specimens dredged in Tsukumo Bay (I-2), test almost transparent and colorless, while in the mantle pure white pigment granules found very densely along the dorsomedian line and the peripharyngeal band (sometimes absent from ventral part), and sometimes in the anterior part of ventromedian line. Eyespots around apertures, the mantle over dorsal ganglion, and anal lobes brilliant yellow; stomach dark red. In formalin, white pigment almost disappears, but yellowish coloration remains discernible in the above-mentioned specimens, as well as in those of $\mathrm{A}, \mathrm{E}$ and $\mathrm{N}$.

The test enclosing thorax more or less thin, soft, gelatinous, transparent and colorless, with the surface quite smooth, while the test covering abdomen somewhat tough, translucent to nearly opaque and white, and the surface sometimes provided with a few to many protuberances, each of which contains a terminal swelling of test vessel (Fig. 10, A). Each aperture 6-lobed with one eyespot between each two adjacent lobe, and opening on short siphon situated terminally. In the usual specimens, thoracic musculature consisting on each side of 7 to 9 logitudinal muscles, converging to the branchial siphon and well ramified posteriorly, and a few fine muscles to the atrial (Fig. 14, B). In some specimens from Toyama Bay, the ramified part of longitudinal muscle(s) along the posterior part of endostyle appear disconnected from the stem part of muscle(s) (Fig. 10, G-H), as observed, though more extensively, by Millar (1975, p. 263, fig, 44a) in the specimens of $R$. crassa from the West Pacific. About 20 tentacles; larger and smaller ones alternating regularly. Ciliated groove an oval slit elongated longitudinally. Inner longitudinal vessels almost complete and supported by simple processes without any projections beyond the vessels: 41 on the left and 42 on the right in a $52 \mathrm{~mm}$ long specimen, while 37 and 38 respectively in a $32 \mathrm{~mm}$ one, both from Tsukumo Bay; about 110 stigmatal rows in the $52 \mathrm{~mm}$ long one, 65 in the $32 \mathrm{~mm}$ long one. Three to 5 stigmata per mesh. Anus bi-lobed, located at the level of the 28th stigmatal row counted from anterior in a $52 \mathrm{~mm}$ long specimen mentioned above, while opening at the 45 th row in an 87 $\mathrm{mm}$ long one from Toyama Bay with about 120 stigmatal rows. In the specimens with regenerating thorax, the thoracic musculature consisting of 8 to 11 longitudinal muscles on each side (Fig. 10, D and F), with their posterior end ramified even in a $1.8 \mathrm{~mm}$ long thorax; a $2.5 \mathrm{~mm}$ long thorax of a specimen from Tsukumo Bay furnished with 9 dorsal languets and about 40 transverse vessels, and 25 (?) papillae (instead of longitudinal vessels) born on each half of the vessels, while a $6.5 \mathrm{~mm}$ long one from Toyama Bay having about 80 stigmatal rows. Abdomen usually covered thickly with mesenchymal tissue over the whole surface in the specimens whether their thorax is well developed or not; stomach occupying nearly the anterior 
half of abdomen, and furnished with 25 to 80 internal longitudinal plications. Gonad indiscernible at all.

Remarks. In the external appearance, the existence of yellow pigment on the dorsal ganglion and anal lobes, and in the numbers of thoracic longitudinal muscles and of inner longitudinal vessels, the present specimens with well developed thorax are quite similar to Rhopalaea macrothorax Tokioka so far recorded only once from Sagami Bay at a depth of 78-400 m. According to the original description, however, this species may be unique in having "many short transverse muscles arranged in a row along the endostyle", seemingly utterly independent of longitudinal muscles. To clarify the nature of these "transverse muscles", reexamination of the type material was made. The material, deposited at BLIH, consists of 4 samples (Proto. Nos. 197, 216, 250 and 251, corresponding to Nos. 102, 119, 148 and 149 in the original description, respectively), containing 8 individuals in all; the body is 31 to 87 $\mathrm{mm}$ long, the thoracic part roughly 1.6 to 2.7 times as long as the abdominal. As a result, the "transverse muscles" in $R$. macrothorax were proved to be the ramified part of the longitudinal muscles disconnected from their stem part. Thus, the present specimens from the Japan Sea can be regarded conspecific with this species. In these 8 individuals, thoracic longitudinal muscles are thick and usually ramified posteriorly along dorso- and ventromedian lines. The "transverse muscles" are distinctly discernible only in the 3 individuals of No. 25l, in which the muscles are confined to the posterior part of thorax, along the posterior half to two-fifths of the whole length of the endostyle and the dorsomedian line. These muscles are arranged in quite the same manner as, though far more extensively than, the ramified part of longitudinal muscles of the specimens from the Japan Sea and described just above (see Fig. 13, G-H).

The thoracic test in the specimens from the Japan Sea, that is delicate, almost completely transparent and colorless, is reminiscent of the specimens collected probably in Australia and identified as $R$. crassa by Kott \& Goodbody (1980, p. 507). The Japan Sea specimens are similar to the Australian ones also in the living color pattern of mantle; the eyespots and the intersiphonal spot over the dorsal ganlion are yellow, while the area along the endostyle and the peripharyngeal band are white (in the Japan Sea specimens) or blue (in the Australian ones). These specimens, and the above-mentioned specimens from Sagami Bay, that have delicate and colorless thoracic test, are consistent with most of previous descriptions of $R$. crassa in most features except the test color and thickness. However, $R$. crassa is variable both in the test thickness (see, for example, Van Name, 1918, p. 127) and its coloration (see Kott \& Goodbody, 1980, p. 507). Even in the "crassus" (=fleshy) specimens referable undoubtedly to this species, the test enclosing the thorax tends to be thinner and softer than that covering the abdomen (see, for example, Tokioka, 1953c, p. 210). Consequently, the above-mentioned specimens with delicate and colorless thoracic test, that is, macrothorax-like external appearance, can be assigned to $R$. crassa. $R$. macrothorax should sink into a junior synonym of $R$. crassa here, as already treated 
by Kott \& Goodbody (1980). It is noteworthy that in the Japan Sea only the macrothorax-like form of $R$. crassa has been so far collected, while the typical (fleshy and stout) form of the species has been recorded in Japan exculsively from the Pacific coasts. In the specimens of the typical form from the western coast of Kii Pen. (listed by Nishikawa, 1980b), the test after preservation is colored dull yellow or greenish yellow, as is usually known in that form.

My reexamination of the two individuals collected from Enoshima, Sagami Bay, about $200 \mathrm{~m}$ deep and referred to Rhopalopsis defecta Sluiter by Hartmeyer (1906, p. 26) proved that these specimens are assignable to $R$. crassa. These specimens are deposited at MNB (ZMB No. 2239); the body stout, never constricted off anywhere, and $24 \mathrm{~mm}$ long $\times 10 \mathrm{~mm}$ in diameter and $20 \mathrm{~mm} \times 10.5 \mathrm{~mm}$ respectively. Test thin anteriorly, while rather thick posteriorly; rather tough, translucent and white as a whole. The larger specimen lacks the abdominal part; the thorax about $10 \mathrm{~mm}$ long and provided with the musculature consisting on each side of 6 muscles converging to the branchial siphon, 5 to the intersiphonal area and 3 (?) to the atrial; longitudinal vessels incomplete, about 30 in number on either side, and about 2 stigmata in a mesh. In the smaller, apparently intact specimen, thorax is about 6 $\mathrm{mm}$ and abdomen $14.5 \mathrm{~mm}$ long; the thoracic musculature consists of 5 muscles converging to the branchial siphon and 3 to the intersiphonal area (those to the atrial hard to count due to injury); about 50 tentacles fine and slender; ciliated groove as a longitudinal slit; longitudinal vessels nearly complete, about 35 on the left and 30 on the right, and 2 or 3 stigmata per mesh; the stomach occupies nearly the middle one-third of abdomen, furnished with about 40 internal longitudinal plications. The longitudinal muscles in both specimens are ramified posteriorly, but the ramified part never disconnected from the stem part, as just seen in those of $R$. crassa illustrated by Tokioka (1953c). The above-mentioned features in Hartmeyer's specimens may fall within the variation range of $R$. crassa, especially that of its typical form rather than the macrothorax-like form, and therefore the specimens can be considered as conspecific with $R$. crassa.

Rhopalaea sagamiana Oka, established on the specimens from Sagami Bay, 150$300 \mathrm{~m}$ deep by Oka (1927d), has been regarded as a synonym of $R$. crassa by Tokioka (1953c) and Kott \& Goodbody (1980). This treatment was affirmed by my reexamination of the two samples deposited at OCUT, registered as Nos. 58-1 (M208) and 339(M482) respectively and identified as $R$. sagamiana by Oka himself. Althouth the localiites of the samples are unavailable, as no other specimens referred to this species by Oka are found at OCUT, so these two samples can be considered as the type series. The material consists of 22 individuals in all, 24 to $87 \mathrm{~mm}$ long; no constriction of body is seen between the thoracic and abdominal parts, as is noted in Oka's original description. In the 3 well-preserved individuals, 34 to $87 \mathrm{~mm}$ long, the thoracic musculature consists of 13 to 21 muscles on each side; inner longitudinal vessels on each side about 60 (in $34 \mathrm{~mm}$ and $63 \mathrm{~mm}$ long individuals) or 80 (in a $87 \mathrm{~mm}$ long one) in number. In the number of thoracic muscles, these individuals fall within the variation range of $R$. crassa, given for example by Kott \& Goodbody 
(1980) as 10 to 36 muslces on each side. On the other hand, the number of longitudinal vessels in these individuals (60 to 80 ) is more than in any previous records (at most 50, according to Van Name and Kott \& Goodbody). This difference can be regarded as of little taxonomic significance, and therefore, $R$. sagamiana is here treated as conspecific with $R$. crassa. At the same time when the former species was established, $R$. mutuensis Oka was also proposed for the specimens collected from east of Shiriya-zaki on the Pacific coast of Shimokita Pen., $104 \mathrm{~m}$ deep. R. mutuensis was, according to its original description (Oka, 1927d, p. 683), distinguished from $R$. sagamiana by such features of $R$. mutuensis as: the cone-shaped external form, opaque and white test, the "neck" region in the middle of mantle body much longer than in $R$. sagamiana, apparently complete absence of longitudinal vessels, and 2 stigmata per mesh. These features are, however, never reliable in distinguishing one species from another in Rhopalaea, and therefore, $R$. mutuensis might be regarded as conspecific with $R$. sagamiana or its senior synonym $R$. crassa. A reexamination of the type material of $R$. mutuensis was not possible, because the material, deposited at OCUT and registered as No. 258(M498), had dried up. The locality of $R$. mutuensis seems influenced more remarkably by boreal waters than any localities of the specimens safely referable to $R$. crassa, so the possibility cannot be ruled out that the former may represent a good species distinct from the latter. Thus, $R$. mutuensis is considered here as a doubtful synonym of $R$. crassa.

Lastly, it was shown in the present study for the first time in $R$. crassa of the family Cionidae that the thorax may be reproduced asexually from the abdomen. Similar cases have been shown in Diazona violacea Savigny by Berrill (1935, pp. 331335) and suggested in Syndiazona grandis by Tokioka (1953c, p. 215), as well as reported in Clavelina lepadiformis Müller by Brien (1970a, b, c, d).

Distribution in Japan Sea. Toyama Bay, 45-1410 m; Tsukumo Bay, 15-40 m; Obama, Wakasa Bay (in the present study); Oki Isls, 47-55 m (Nishikawa, 1986b; in the present study); Tsushima Strait, $101 \mathrm{~m}$ (Millar, 1975).

Distribution outside Japan Sea. ?East of Shiriya-zaki, Shimokita Pen., $104 \mathrm{~m}$ (Oka, 1927d); Sagami Bay, 78-400 m (Hartmeyer, 1906; Oka, 1927d; Tokioka, 1953c); western coast of Kii Pen., 3-100 m (Nishikawa, 1980b); off Goto Isls, Kyushu, 17-20 m (Millar, 1975); Hong Kong, 10-12 m (Kott \& Goodbody, 1980); Philippines, 10-80 fms (Van Name, 1918; Millar, 1975); Banda Sea, 1-129 fms (Herdman, 1882; Sluiter, 1904; Millar, 1975); Flores Sea, down to $521 \mathrm{~m}$ (Sluiter, 1904); NW Australia, Great Barrier Reef and SE Queensland (Kott \& Goodbody, 1980); Sri Lanka (Herdman, 1906).

\section{Syndiazona grandis Oka, 1926}

Syndiazona grandis Oka, 1926a, pp. 133-135, figs a-b.

Material examined: E-2 (Fukui): a single colony of $55 \mathrm{~mm}$ long corona and $60 \mathrm{~mm}$ long peduncle. 
Remarks. The present specimen from off Fukui agrees with descriptions of $S$. grandis. In the specimens collected from Cheju Is., Korea Strait, and allotted to this species by Rho (1975), the thoracic musculature is, according to Rho's personal communication, composed of both longitudinal and transverse muscles, and therefore, her specimens are $S$. grandis, not $S$. chinensis (see below).

Distribution in Japan Sea. Off Fukui Pref. (in the present study); Tsushima Strait, $85 \mathrm{~m}$ deep (Tokioka, 1959b); Cheju Is., Korea Strait (Rho, 1975).

Distribution outside Japan Sea. Tateyama (Oka, 1906); Sagami Bay, 50-140 m (Oka, 1906; Tokioka, 1953c); off Omai-zaki, 34-37 fms (Tokioka, 1967c); western coast of Kii Pen., down to $100 \mathrm{~m}$ (Tokioka, 1949b, 1959a; Nishikawa, 1980b); East China Sea, $93 \mathrm{~m}$ (Tokioka, 1955).

\section{Syndiazona chinensis Tokioka, 1955}

Syndiazona chinensis Tokioka, 1955, pp. 206-208, pl. 11, figs A-E, text-fig. 1; Millar, 1975, pp. 259-262, figs 42-43; Nishikawa, 1980b, tab. 1 .

Material examined: L-3 (Shimane): a single colony from the lower surface of an overhanging rock, $15 \mathrm{~m}$ deep.

Description. Colony discoid in external appearance, $150 \mathrm{~mm}$ in diameter and 25-35 mm thick. In life, test translucent and slightly grayish white, and yellowish white zooids seen through test. Numerous zooids embedded evenly in test; thorax 2.5 to $4 \mathrm{~mm}$ and abdomen up to $5 \mathrm{~mm}$ long; the neck region between these two parts very narrow. A vascular prolongation, up to $12 \mathrm{~mm}$ or longer and up to 1 $\mathrm{mm}$ thick, issuing from the posterior end of abdomen. Both apertures 6-lobed. Thoracic musculature only longitudinal; on each side of an examined thorax, 6 muscles converging to the branchial siphon and ramified posteriorly along the entire length of endostyle, while 7 muscles to the intersiphonal area, some of which ramified near the posterior end of thorax, but others united into a thick bundle near the neck region; the bundle running posteriorly along the abdomen and further into the vascular prolongation. Additionally, a few fine longitudinal muscles in the anterodorsal part of thorax, converging to the atrial siphon. About 12 tentacles; ciliated groove an oval slit elongated longitudinally. In a representative zooid, 46 stigmatal rows, and the inner longitudinal vessels 36 on the left and 34 on the right; 2 stigmata per mesh. Anus bi-lobed, situated at the level of the 14th stigmatal row counted from anterior in a zooid with $3.5 \mathrm{~mm}$ long thorax. Apertures of oviduct and vas deferens close to the anus. Abdomen covered with mesenchymal tissue, and provided with a pair of longitudinal muscle bundles. Stomach occupying roughly the anterior half of abdomen, and with about 40 inner longitudinal plications. Numerous eggs, up to $150 \mu \mathrm{m}$ in diameter, discernible in many zooids on a side of abdomen along nearly its whole length; the eggs apparently included within the expanded oviduct. Eggs of various sizes in the mesenchymal tissue also recognizable in some zooids, filling nearly the whole length of the vascular prolongation. Ovary located around, or just posterior to, the posterior end of intestinal 
loop. Numerous small testicular follicles spreading over intestinal surface, and usually embedded in the mesenchymal tissue; vas deferens nearly straight and filled with sperm. Heart situated along the posterior half of intestinal loop.

Remarks. The present specimen agrees with previous descriptions of Syndiazona chinensis, except that the vascular prolongation sometimes contains eggs of variable sizes in this specimen. The existence of eggs in the prolongation may be an artifact, caused by the strong shrinkage of alimentary system and gonad with some eggs left behind in or pressed toward the prolongation, and therefore, the mentioned difference may be of no taxonomic significance.

Recently Millar (1975, p. 262) stated that Polycitor renziwadai Tokioka from the Arafura Sea "may be $S$. chinensis". However, my reexamination of the holotype colony of P. renziwadai, deposited at SMBL (Type No. 109), revealed that the zooids have neither inner longitudinal vessels nor branchial papillae, and therefore this species cannot be Syndiazona.

Distribution in Japan Sea. Off Cape Hinomisaki, Shimane Pref., $15 \mathrm{~m}$ deep (in the present study).

Distribution outside Japan Sea. Off Shirahama-cho, western coast of Kii Pen., 100$120 \mathrm{~m}$ (Nishikawa, 1980b); East China Sea, $93 \mathrm{~m}$ (Tokioka, 1955); off Mindanao, the Philippines, $64 \mathrm{~m}$ (Millar, 1975); Kei Isls, 30-100 m (do.).

58. Ciona intestinalis (Linné, 1767)

Ascidia intestinalis Linné, 1767, p. 1087.

For synonyms see Hoshino \& Nishikawa (1985, pp. 63-64).

Material examined: E-1 (Wakasa Bay): a $34 \mathrm{~mm}$ long specimen.

Description. Test soft, but rather tough. Endostylar appendage present, and a pair of pharyngeo-epicardiac openings situated near the appendage. About 50 tentacles; inner longitudinal vessels 28 on the left and 25 on the right. Genital aperture opening near the base of atrial siphon; distal end of vas deferens pigmented reddish orange and provided with 22 apertures.

Remarks. There has been some confusion in the taxonomy of the genus Ciona around the Japanese waters, which, however, now appears to be clarified by the revisional work of Hoshino \& Nishikawa (1985). The present specimen conforms very well to the description of $C$. intestinalis given by them. Further, by the courtesy of Rho, I examined the two specimens she collected from Yong-do on the Korean coast facing Korea Strait and identified as C. intestinalis (see Rho, 1971). The two specimens, $90 \mathrm{~mm}$ and $55 \mathrm{~mm}$ long, proved identical with the description of this species given by Hoshino \& Nishikawa. Some morphological notes of the specimens are: about 55 tentacles in the larger specimen, and 35 ones in the smaller; 28 longitudinal vessels on each side in the larger, while 25 in the smaller; the genital 
apertures near the atrial siphon in the larger, while near the anus in the smaller; the anus situated nearly in the middle of branchial sac.

The following references have been made to " $C$. intestinalis" on the basis of the specimens collected in the Japan Sea, but lack information enough to differentiate between $C$. intestinalis and $C$. savignyi (see below): Redikorzev (1941, p. 206; Peter the Great Bay) and Tokioka (1959a, p. 226, Wakasa Bay; 1962a, pp. 8-9, Sado; 1967b, p. 243, Sado). These records are excluded from the list of localities of either species.

Distribution in Japan Sea. Mutsu Bay (Tsuchiya \& Osanai, 1978); Tsukumo Bay (Hoshino \& Nishikawa, 1985); Obama, Wakasa Bay, shallow water (in the present study); Korean coastal waters facing Korea Strait (Rho, 1971; in the present study).

Distribution outside Japan Sea. According to Hoshino \& Nishikawa (1985), Miyagi Pref., Yokohama, around Kii Pen., Osaka Bay and Seto Inland Sea, Japan; Australia; New Zealand; California; East Port, Atlantic coast of North America; Argentina; Rio de Janeiro; cold temperate to warm temperate waters of Europe.

\section{Ciona savignyi Herdman, 1882}

Ciona savignyi Herdman, 1882, pp. 236-237, pl. 35, figs 1-2.

For other synonyms see Hoshino \& Nishikawa (1985, p. 69).

Material examined: C-2 (Mutsu Bay): two specimens from buoys set off Moura, $42 \mathrm{~mm}$ and $43 \mathrm{~mm}$ long respectively. $\mathrm{M}(\mathrm{Oga})$ : four specimens, $6.5-38 \mathrm{~mm}$ long.

Remarks. The present specimens are consistent with the description of this species given by Hoshino \& Nishikawa (1985). The number of longitudinal vessels is 30 on each side in a $38 \mathrm{~mm}$ long specimen, while 25 on the left and 24 on the right in a $20 \mathrm{~mm}$ long one.

Distribution in Japan Sea. Mutsu Bay (Oka, 1935; Hoshino \& Nishikawa, 1985; in the present study); Oga Pen., 0-1 $\mathrm{m}$ (Nishikawa, 1984b; in the present study); Tsukumo Bay, several-25 m (Hoshino \& Nishikawa, 1985); Wakasa Bay, $50 \mathrm{~m}$ (do.).

Distribution outside Japan Sea. According to Hoshino \& Nishikawa (1985), Miyagi Pref., Tateyama, Suruga Bay, Kii Pen., Osaka Bay (8-50 fms) and Seto Inland Sea, Japan; Loring, Alaska and British Columbia, Pacific coast of North America; Argentina. Further, the present species has been collected from Long Beach, California (Nishikawa's unpublished data).

Family Perophoridae

60. Perophora japonica Oka, 1927

(Fig. 11)

Perophora japonica Oka, 1927b, pp. 558-560, figs A-B.

Material examined: A (Toyama Bay): St. 24, 12 individuals, up to $3 \mathrm{~mm}$ long, on Styela clava, lacking mantle body in all examined individuals. B: No. 142 (M705), identified with $P$. japonica by Oka, collected at Ooura, near Asamushi, Mutsu Bay on May 17, '32, many individuals attached to 
two fragments of rock, too much deteriorated to be completely examined; No. 163 (M538), identified with $P$. japonica by Oka, collected in Hekurajima Is. on July 8, '28, many individuals wholly dried up completely. C-2 (Mutsu Bay): from buoys off Moura, many individuals, up to $6 \mathrm{~mm}$ long, on Styela clava and Mytilus galloprovincialis; from undersurface of boulders in the mediolittoral zone of Ooura, near Asamushi, many individuals up to $4 \mathrm{~mm}$ long.

Description. In the zooids of collection A, mantle body more or less deteriorated: on each side of mantle, only 8 to 10 short fine oblique or transverse fibers discernible around the intersiphonal area. About 20 stigmata in each half of 4 rows; inner longitudinal vessels incomplete, about 10 in number on each side; gonad empty. The specimens in collection $\mathrm{C}-2$ are well preserved; individuals connected only by thin stolons. Mantle almost always reticulated more or less densely with pale greenish corpuscular cells; musculature consisting on each side of about 20 very fine fibers exclusively around the siphons, 10 of which converge to the branchial, 5 to the atrial and 5 crossing over the intersiphonal area (Fig. 11, A). About 20 tentacles; ciliated groove an oval slit elongated transversely; 3 dorsal languets. Longitudinal vessels incomplete, 9 on the left and 8 or 9 on the right; about 26 to 30 stigmata in each half row. Gonad mature in some zooids (Fig. 11, A-C), composed of 3 to 7 or more testicular follicles, each of which often lobed to various degrees, arranged roughly in the shape of fan, and an ovary situated at the pivot of the testicular fan or just dorsal to the follicle mass; ovarian eggs up to $400 \mu \mathrm{m}$ in diameter. In a $4.7 \mathrm{~mm}$ long individual from $\mathrm{C}-2,6$ embryos in the distal end of the oviduct on the right side.

Remarks. The present specimens except those of collection B (that had dried up) are similar to Perophora japonica especially in the number of longitudinal vessels and stigmata in each row, gonadal structure and mantle nusculature, although the zooids of collection $\mathrm{A}$ are provided with fewer mantle muscles confined to the intersiphonal

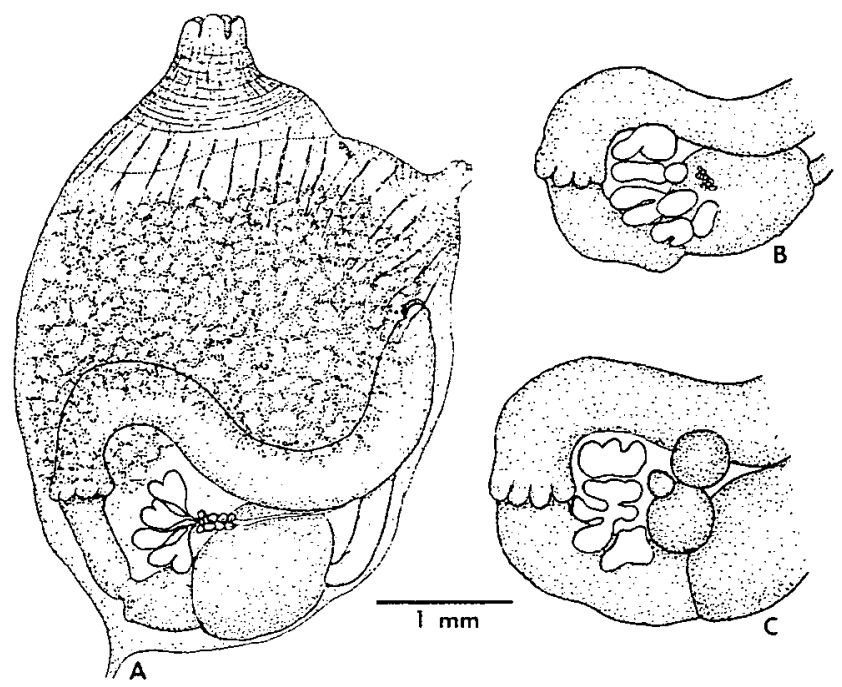

Fig. 11. Perophora japonica Oka from Mutsu Bay (Collection C-2). A. whole left side of mantle body; B-C. left side of a part of intestinal loop, showing the gonad. 
area. This difference may be due to deterioration of the mantle. For the close relationship of this species with $P$. annectens see the remarks given for $P$. annectens.

Distribution in Japañ Sea. Otaru (Tokioka, 1951a); Mutsu Bay, shallow waters (in the present study); Sado (Tokioka, 1967b); Toyama Bay, 74-81 m and Hekurajima Is. (in the present study); Korean coastal waters facing Korea Strait (Rho, 1975).

Distribution outside Japan Sea. Akkeshi, Hokkaido (Tokioka, 195la); Tateyama and Misaki (Oka, 1927b); Sagami Bay, down to $55 \mathrm{fms}$ (Tokioka, 1953c); Tokushima, Shikoku (Oka, 1927b).

\section{Perophora annectens Ritter, 1893}

(Fig. 12)

Perophora annectens Ritter, 1893, pp. 37-85, pls 1-3.

Doubtful references:

Perophora annectens: Brewin, 1951, pp. 108-109, fig. 4; Millar, 1982b, pp. 59 and 61 .

Material examined: None.

Remarks. Redikorzev (1941, pp. 204-205) recorded this species in the Japan Sea from Peter the Great Bay and Possjet Bay, 0-10 m deep. According to his description, the zooids are usually embedded to various degrees, though never completely, in the membraneous common test, each with up to 32 stigmata in each half row, and 5 to 10 testicular follicles. He stated that the morphological similarity between $P$. annectens and $P$. japonica suggests their possible conspecificity of these two.

Previous descriptions of $P$. annectens from the Pacific coasts of North America from Ucluelet (British Columbia) to San Diego, mediolittoral to $30 \mathrm{~m}$ deep (Abbott \& Newberry, 1980), are consistent with those of $P$. japonica from around Japan (sec above), especially in the mantle musculature and the structures of branchial sac and gonad, except that the colony in $P$. annectens may sometimes be of "compound" structure in the specimens from Monterey Bay, California (see Ritter, 1893; Van Name, 1945), while $P$. japonica is apparently always social and never compound. I examined the paratype material of $P$. annectens sent by Ritter himself to ZMA and now registered as TU No. 730 (see Spoel, 1969). The material is represented by a single fragment of colony, roughly $8 \mathrm{~mm} \times 3-4 \mathrm{~mm}$ in extent, comprising about a dozen zooids, up to $1.5 \mathrm{~mm}$ long, and many small buds issuing from the test vessels, all embedded nearly completely in the common test (Fig. 12, A). Mantle muscle fibers are too fine and obscured by the mantle wall, yellowish and nearly opaque, to be described exactly; about 10 tentacles; inner longitudinal vessels incomplete, 6 or 7 on each side; about 20 stigmata in each half of 4 rows; gonad empty. I also examined $P$. annectens deposited at AMNH (No. 1560), collected in Corona Del Mar, California, on July 4, 1939. The material consists of about 20 individuals, 1.5 to 2.5 $\mathrm{mm}$ long, connected by thin stolons; mantle musculature composed of about 16 to 20 very fine muscle fibers on each side (Fig. 12, B), arranged as those of $P$. japonica illustrated in Fig. 14, $\mathrm{A}$ in the present study; 10 to 16 tentacles; longitudinal vessels. 

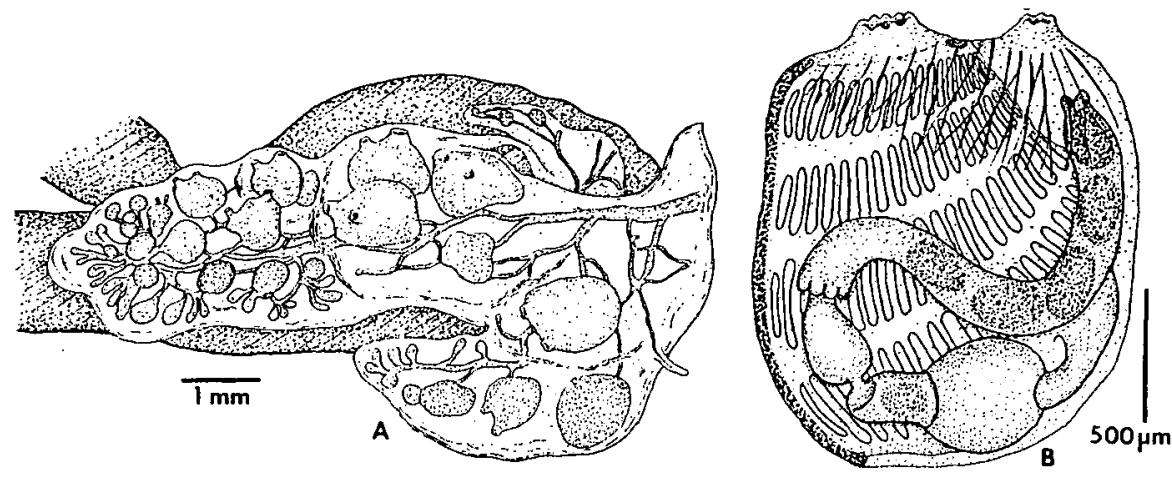

Fig. 12. Perophora annectens Ritter from California. A. a part of the paratype colony (ZAM, TU No. 730), top view; B. left side of mantle body (AMNH, No. 1560).

incomplete, 7-8 on each side; 15-20 stigmata in each half row; gonad indiscernible. The present material is indistinguishable from $P$. japonica inhabiting Japan and adjacent waters.

I recently examined a mass of social perophorid; collected by $\mathrm{M}$. Fukumoto in 1981 in Friday Harbor, Washington, and comprising about 20 individuals, up to $4.2 \mathrm{~mm}$ long. These specimens resemble $P$. annectens, and therefore, $P$. japonica, especially in the mantle musculature (consisting in these specimens of about 15 to 20 very fine fibers on each side, arranged as described in Fig. 15, B in the present paper), the number of inner longitudinal vessels ( 7 to 8 , or rarely 9 incomplete ones on each in the specimens), 15 to 24 stigmata in each half row and 6 to 12 testicular follicles arranged more or less in the shape of fan. The only exception is the existence of "the fifth" stigmatal row in Fukumoto's specimens. In these specimens, the fourth stigmatal row on either or both sides often contains up to 8 adjacent stigmata divided into anterior and posterior halves by a small piece of the branchial wall elongated transversely; the piece bearing 1 to 3 branchial papillae without vessels. Sometimes a fifth row of smaller and fewer stigmata than usual is found below the fourth normal row; branchial papillae may be present or absent between the fourth and fifth rows. Dorsal languets always 3 in number; along each interval of their bases is very rarely discerned a low membraneous longitudinal fold. The occurrence of the fifth complete row, even though rarely, in specimens from Friday Harbor is reminiscent of the specimens collected in the mediolittoral zone of Hauraki Gulf, New Zealand, and referred to $P$. annectens by Brewin (1951); in these specimens, the zooids are embedded completely in the test, 20 to 24 stigmata in each half of 5 rows, and 2 to 7 testicular follicles converging to the proximal end of sperm duct. In the "compound" structure of colony, the specimens from New Zealand are close to some colonies of $P$. annectens, while in the existence of 5 stigmatal rows, the New Zealand specimens are similar to $P$. hutchisoni Macdonald from Australia and New Zealand (Michaelsen \& Hartmeyer, 1928, Millar, 1966). Millar (1982b) suggests - that Brewin's $P$. annectens may be a new species. 
North American $P$. annectens is regarded variable in colony structure and, if the specimens from Friday Harbor described above are assignable to this species, also in the structure of branchial sac. On the other hand, $P$. japonica is apparently always social and furnished with only 4 stigmatal rows, so it is treated here as a good species, rather than amalgamated with $P$. annectens. Thus, $P$. annectens of Redikorzev mentioned above, whose colony is usually compound, is probably $P$. annectens, rather than $P$. japonica, though Redikorzev's records are closer geographically to the latter species.

Distribution in Japan Sea. Peter the Great Bay and Possjet Bay, 0-10 m deep (Redikorzev, 1941).

Distribution outside Japan Sea. Ucluelet (in Vancouver Is., British Columbia) to San Diego, Pacific coasts of North America (Abbott \& Newberry, 1980); ?New Zealand (Brewin, 1951).

62. Perophora sagamiensis Tokioka, 1953

(Fig. 13)

Perophora sagamiensis Tokioka, 1953c, pp. 217-218, pl. 31, fig. 6 .

Material examined: C-8 (Oki): Kuniga, Nishinoshima Is., 1-4m, 12 individuals found on the surface of a botryllid colony.

Description. Zooids isolated completely from one another except for the thin stolons, nearly spherical and 750 to $1250 \mu \mathrm{m}$ long. About 12 fine oblique or longitudinal muscles over the whole right side, and on the anterior half of the left side of mantle body (Fig. 13, A-B); 7 or 8 of them converging to the branchial siphon, while about 4 to the atrial. The muscles usually ramified posteriorly, or rarely anastomosed. About 12 tentacles; 14 to 16 stigmata in each half of 4 rows. Inner longitudinal vessels complete or not; 7 to 9 branchial papillae on each half of transverse vessels. Gonad indiscernible.

Remarks. The present specimens fall well within the variation range of $P$. sagamiensis shown by Tokioka (1953c) and Nishikawa (1984a), except that the mantle muscles reach the posterior end of mantle body in the specimens from Oki, while they are confined to its anterior half in the previous descriptions of $P$. sagamiensis. However, my reexamination of the type material deposited at BLIH (Proto. No. 108) revealed that the mantle is often provided wholly with muscies on the right side and, sometimes on the left. Thus, the present specimens from the Japan Sea belong to this species. These specimens are similar to those from Tanabe Bay in the mantle musculature stated above, as well as in the number of stigmata in each row and that of longitudinal vessels (for the morphology of the specimens from Tanabe Bay see Nishikawa, 1984a, p. 125).

Distribution in Japan Sea. Oki Isls, 1-4 m (in the present study).

Distribution outside Japan Sea. Sagami Bay, 4 fms (Tokioka, 1953c) and Tanabe 


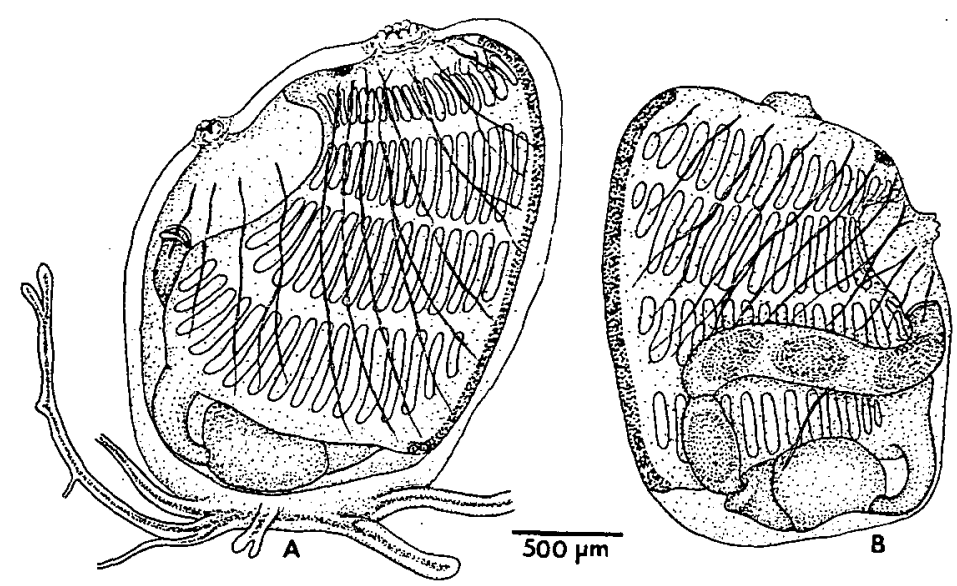

Fig. 13. Perophora sagamiensis Tokioka from Oki Isls (Collection C-8). A. an individual, right side; $B$. left side of mantle body of the same individual.

Bay, $0 \mathrm{~m}$ (Nishikawa, 1980b), Japan; Truk, Ponape and Majuro, Micronesia, 0-7 m (Nishikawa, 1984a).

\section{Perophora multiclathrata (Sluiter, 1904)}

Ecteinascidia multiclathrata Sluiter, 1904, pp. 12-13, pl. 3, figs 6-8.

Perophora multiclathrata: Nishikawa, 1984a, p. 123; Kott, 1985, pp. 106-107, fig. 46.

For synonyms see Nishikawa (1984a).

Material examined: None.

Distribution in Japan Sea. Sado (Tokioka, 1962a).

Distribution outside Japan Sea. Misaki (Ärnbäck-Christie-Linde, 1935), Sagami Bay (Tokioka, 1953c), Kii Pen. (Nishikawa, 1980b), Usa, Kochi Pref. (Nakauchi, 1973), Tokara Isls (Tokioka, 1954a), and Amami Isls (Nishikawa \& Tokioka, 1976a), Japan; Peng-hu (=Pescadores) Isls, Taiwan (Oka, 193la); Palau, 3-20 fms (Tokioka, 1950, 1967c); Truk, Ponape and Majuro, Micronesia, $0 \mathrm{~m}$ (Nishikawa, 1984a); Wake (Tokioka, 1967c); Fiji (Kott, 1981); SE coast of Australia (Kott, 1952, 1964, 1985); Madagascar (Vasseur, 1968); Bermudas (Berrill, 1932; Van Name, 1945; C. Monniot, 1972a); Florida and Puerto Rico, down to $9.5 \mathrm{fms}$ (Van Name, 1945); Guadeloupe, West Indies (C. Monniot, 1983a); Brazil (Millar, 1958; Rodorigues, 1962); Senegal (Pérès, 1949); Gold Coast (Millar, 1953).

\section{Family Ascidiidae}

\section{Ascidia sydneiensis Stimpson, 1885}

Limited Synonymy:

Ascidia sydneiensis Stimpson, 1885, p. 387; Van Name, 1945, pp. 189-190, fig. 101; Millar, 1975, p. 272 ; Kott, 1985, pp. 54-56, fig. 21, pl. Id. 
Ascidia sydneiensis samea: Tokioka, 1953c, pp. 226-227, pl. 34, figs 6-10, pl. 35, figs 1-10, pl. 36, figs $1-10$; 1959a, pp. 226-227, pl. 14, figs 7-8; 1960a, p. 200, pl. 25, figs 36-37; 1961, pp. 108110, fig. 4; 1962a, pp. 10-11, pl. 3, fig. 20;1967c, pp. 138-140, fig. 50; 1970, p. 87, fig. 4, 14; Nishikawa \& Tokioka, 1975, pp. 220-221, fig. 2; 1976a, p. 388, fig. 4, 24-25; Nishikawa, 1980b, tab. 1; 1982b, p. 204; 1984a, p. 126;1984b, p. 150;1986b, p. 176.

Ascidia samea Oka 1935, pp. 461-463, figs 31-32.

Ascidia sydneiensis divisa: Tokioka, 1953c, p. 225, pl. 34, figs 1-5; 1954c, p. 84, pl. 6, fig. 17; Rho, 1971, p. 111; 1975, p. 131; Nishikawa, 1980b, tab. 1.

Ascidia donnani Herdman, 1906, pp. 303-305, pl. 2, figs 1-9.

For other synonyms and references see Van Name (1945), Tokioka (1953c) and Kott (1985).

Doubtful reference:

Phallusia longitubis Traustedt: Traustedt, 1885, p. 16.

Material examined: B: labeled Ascidia samea by Oka: No. 343 (M355), collected from Oshoro, near Otaru, Hokkaido, 11 individuals, 26-55 mm long; No. 306 (M393), collected on the east coast of Yunoshima Is., Mutsu Bay, by Hozawa and Takatsuki on Aug. 5, '26, a $52 \mathrm{~mm}$ long individual, obviously one of the type series of Ascidia samea. C-1 (Hokkaido): Senposhi, Rishiri Is., 2-4 m deep, 4 individuals, 42-52 mm long; Kutsugata-misaki, Rishiri Is., 1 $-4 \mathrm{~m}$, a $40 \mathrm{~mm}$ long individual; in front of the Marine Biological Station of Sapporo Medical College, Oshidomari, Rishiri Is., a $23 \mathrm{~mm}$ long individual; from the undersurface of boulders at a depth of $1 \mathrm{~m}$, Kamomejima Is., Esashi, 4 individuals, 19-34 mm long. C-2 (Mutsu Bay): from buoys off Moura, a $63 \mathrm{~mm}$ long one; Kaizaki, SW end of Shimokita Pen., 15-20 m, a $51 \mathrm{~mm}$ long individual. C-6 (Anamizu Bay): from undersurface of a boulder, a $14 \mathrm{~mm}$ long individual. D (Tottori): 8 individuals, $11-30 \mathrm{~mm}$ long. G-2 (Ishikawa): 2 individuals, $24.5 \mathrm{~mm}$ and $37 \mathrm{~mm}$ long. $\mathrm{M}$ (Oga): from undersurface of boulders in the mediolittoral zone of Daishima, 2 individuals, $26 \mathrm{~mm}$ and $32 \mathrm{~mm}$ long, already listed by Nishikawa (1984b). N (Oki) : a $19 \mathrm{~mm}$ long individual, already listed by Nishikawa (1986b).

Remarks. All the specimens in the present material have "sydneiensis"-type mantle musculature. They were divided here only tentatively into the following 3 groups by the different position of anterior margin of alimentary canal in relation to the atrial siphon of mantle: the group I consists of the specimens with the margin situated anteriorly beyond the siphonal base, the group II of those with the margin at the level between the anterior and posterior bases of the siphon, and the group III of the specimens with the margin below the siphonal base. Following the criteria proposed by Tokioka (1953c, pp. 223-224; 1967a, pp. 399-400), the specimens of group I are referable to $A$. sydneiensis divisa Sluiter, and those of groups II and III to $A$. sydneiensis samea Oka. As a result, 20 specimens were assigned to the group I, 19 to. II and 2 to III. Some are on the borderline between the groups I and II, or II and III. Of the 11 specimens collected together in Oshoro (collection B, No. 343), 6 are allotable to the group I, 4 to II and 1 to III. These facts may demonstrate that the above-mentioned differences in the relative position of the anterior margin of alimentary canal can be regarded as a series of individual variations. Thus, the subspecific taxa samea and divisa are abolished and merged into the species A. sydneiensis Stimpson. However, the present treatment does not mean to deny the possibility of the speciation occurring in this species. Careful examination of this possibility is highly expected in the future from various points of view.

A. pacifica Tokioka resembles $A$. sydneiensis, differing only in that the ciliated groove is simple U-shaped even in the larger specimens in $A$. pacifica, while the groove "increases in complexity with increasing size" (Kott \& Goodbody, 1980, p. 529) in 
A. sydneiensis, as stated by Van Name (1945, p. 189) and Millar (1975, p. 272). A small $17 \mathrm{~mm}$ long specimen, collected from Osaka Bay and referred to A. sydneiensis divisa by Tokioka (1945c, p. 84), "the ciliated groove describes a very complex configuration". In $A$. pacifica, however, a $55 \mathrm{~mm}$ long specimen has simple groove (see Tokioka, 1967a, p. 399). This difference might possibly be of taxonomic significance, which is the reason why $A$. pacifica is here excluded from the synonymy of $A$. sydneiensis. The specimens from Hong Kong and identified as $A$. sydneiensis by Kott \& Goodbody (1980, pp. 526-529) are also excuded from the synonymy, because these specimens, 35 to $55 \mathrm{~mm}$ long, each have a simple U-shaped ciliated groove. The validity of $A$. pacifica may be an open question.

Phallusia longitubis Traustedt has been regarded as a junior synonym of $A$. sydneiensis (see, for example, Hartmeyer \& Michaelsen, 1928, p. 285; Van Name, 1945, p. 189). Traustedt (1885) recorded $P$. longitubis from Hakodate, Hokkaido. I attempted to clarify its identification by examination of the specimen(s) originally deposited at "Berlins Museum", but in vain, because the present day successor of this museum (MNB) does not have the specimen(s) (Kühlmann's personal communication). Therefore, Traustedt's record mentioned above is cited as an uncertain locality in the present study.

Distribution in Japan Sea. Rishiri Is., down to $4 \mathrm{~m}$, Oshoro and Esashi, $1 \mathrm{~m}$, Hokkaido (in the present study); Hakodate (?Traustedt, 1885; Hartmeyer, 1906); Mutsu Bay, down to $20 \mathrm{~m}$ (Oka, 1935; in the present study); Oga Pen., $0 \mathrm{~m}$ (Nishikawa, 1984b; in the present study); Sado (Tokioka, 1962a); Anamizu Bay and Uchiura, eastern coast of Noto Pen., to $1 \mathrm{~m}$ (in the present study); Wakasa Bay (Tokioka, 1959a); Tottori, $0 \mathrm{~m}$ (in the present study); Oki Isls, 47-55 m (Nishikawa, 1986b; in the present study); eastern waters of Korea and Korean waters facing Korea Strait (Rho, 1971, 1975).

Distribution outside Japan Sea. The known localities around Japan are: Onagawa Bay (Hartmeyer, 1906); Matsushima Bay (Tokioka, 1960a), Tokyo Bay, $120 \mathrm{~m}$ (Hartmeyer, 1906); Sagami Bay, down to $60 \mathrm{fms}$ (Hartmyer, 1906; Tokioka, 1953c); Shimoda (Nishikawa, 1982b); Mikawa Bay, $0 \mathrm{~m}$ (Nishikawa's unpublished data); Kii Pen., to $80 \mathrm{~m}$ (Nishikawa \& Tokioka, 1975; Nishikawa, 1980b); Osaka Bay (Tokioka, 195lb, 1954c); Seto Inland Sea (Nishikawa's unpublished data); Nagasaki, Kyushu (Hartmeyer, 1906); Amami Isls (Nishikawa \& Tokioka, 1976a); western waters of Korea (Rho, 1975). Widely distributed in the tropical to warm temperate waters around the world.

\section{Ascidia ahodori Oka, 1927}

Ascidia ahodori Oka, 1927e, p. 493, fig. 950; Tokioka, 1953a, pp. 7-10, fig. 5; 1962a, p. 11, pl. 3, fig. 21 ; Nishikawa, 1980b, tab. 1; 1984b, p. 150; Tokioka, 1960b, pp. 208-209, pl. 26, fig. 5 (as "Ascidia ahodori(?)").

A scidia alpha Tokioka, 1953a, pp. 10-11, fig. 6; 1954c, pp. 82-83, pl. 6, fig. 11; Nishikawa \& Tokioka, 1976a, pp. 390-391, fig. 4, 27-29; Nishikawa, 1980b, tab. 1; 1982b, p. 204; 1984b, p. 150.

New Synonymy. 
Material examined: A (Toyama Bay): St. 8, one individual, posterior part of test injured, mantle body $15 \mathrm{~mm}$ long. C-2 (Mutsu Bay): Kaizaki, SW end of Shimokita Pen., 15-20 m deep, a $28 \mathrm{~mm}$ long individual. C-4 (Tsukumo Bay): from undersurface of stones, 4 individuals, 20-45 mm long. C-6 (Anamizu Bay): a $22 \mathrm{~mm}$ long individual. D (Tottori): 3 individuals. H-3 (Tsukumo Bay): 3 individuals, $19-38.5 \mathrm{~mm}$ long. L-1 (Wakasa Bay): 3 individuals, $28-38 \mathrm{~mm}$ long. $\mathrm{M}$ (Oga): from undersurface of boulders in the mediolittoral zone of Daishima, a $34 \mathrm{~mm}$ long individual; Toga, $10 \mathrm{~m}$, 3 individuals, $18.5-41 \mathrm{~mm}$ long; already listed by Nishikawa (1984b).

Remarks. Ascidia ahodori Oka has been distinguished from A. alpha Tokioka by Tokioka (1953a, 1954d, 1960b, 1962a) by the following differences : 1) the atrial aperture opening on the test usually at the level of anterior one-third of body in $A$. ahodori, while the aperture is situated close to the terminal branchial siphon in $A$. alpha; 2) the anterior margin of alimentary canal located beyond anteriorly the level of anterior base of the atrial siphon in $A$. ahodori, while the margin posterior to the anterior base of the siphon in $A$. alpha; and 3 ) the axis of second intestinal loop passing through the stomach in its middle part or near its pyloric end in $A$. ahodori, while the axis passing through the pyloric end of stomach (or, according to my previous observations passing sometimes through the intestine slightly apart from stomach) in $A$. alpha. These two species are identical with each other in other significant morphological features, as well as in the geographical or bathymetrical distribution. Close analysis of 21 specimens of the present material revealed that these three differences are of no taxonomic significance, because the extremities in each of the differences may be linked by intermediate stages of many specimens, and these differences may arise independently. I have had an impression that the stomach tends to be less extensive and more globular in outline in $A$. alpha than in A. ahodori, but my examination of the present material made it clear that the size and shape of stomach may be of little taxonomic significance. These conclusions are also applicable, according to my unpublished data, to the specimens collected from different localities on the Pacific coasts of Japan. Consequently, A. ahodori and A. alpha are regarded as conspecific with each other, $A$. alpha being a junior synonym of $A$. ahodori.

$A$. californica Ritter et Forsyth, established for specimens collected from California (Ritter \& Forsyth, 1917, pp. 454-456), but later regarded as a junior synonym of $A$. ceratodes (Huntsman) by Van Name (1945), seems to fall within the variation range of $A$. ahodori. Crucial comparisons are urged between the Californian and the Japanese specimens.

Distribution in Japan Sea. Mutsu Bay, 15-20 m (in the present study); Oga Pen., 0-10 m (Nishikawa, 1984b; in the present study); Sado (Tokioka, 1962a); Toyama Bay, 22-30 m, Tsukumo Bay and Anamizu Bay, 0-6 m, Wakasa Bay, $0 \mathrm{~m}$, and Tottori, $0 \mathrm{~m}$ (in the present study).

Distribution outside Japan Sea. Shimoda (Nishikawa, 1982b); Mikawa Bay, 0 m (Nishikawa's unpublished data); Kii Pen., down to $3 \mathrm{~m}$ (Nishikawa, 1980b); Osaka Bay, to $1 \mathrm{~m}$ (Tokioka, 1962a; Nishikawa's unpublished data); Seto Inland Sea, $0 \mathrm{~m}$ (Tokioka, 1953a, Nishikawa's unpublished data); Ariake Sea (Tokioka, 1960b); Kagoshima Bay, $0 \mathrm{~m}$ (Nishikawa's unpublished data); Amami Isls, $0 \mathrm{~m}$ (Nishikawa \& Tokioka, 1976a). 
66. Ascidia gemmata Sluiter, 1895

(Fig. 14)

Ascidia gemmata Sluiter, 1895, pp. 177-178, pl. 9, figs 7-9.

Material examined: A (Toyama Bay): St. 29 , a $56 \mathrm{~mm}$ long $\times 33 \mathrm{~mm}$ wide individual, the surface carrying several ascidians such as Cnemidocarpa clara (1 individual), Pyura lepidoderma (4 individuals) and Boltenia echinata iburi (2 ones), some alcyonarians, bryozoan colonies and polychaete tubes. B: No. 245 (M249), labeled Ascidia plata by Oka, collected in Korea (exact locality unknown) by Y. Okada on Mar. 2, '18, a $61 \mathrm{~mm} \times 34 \mathrm{~mm}$ individual. C-2 (Mutsu Bay): Kaizaki, SW end of Shimokita Pen., $15-20 \mathrm{~m}, 3$ individuals, $26 \mathrm{~mm}, 33 \mathrm{~mm}$ and $55 \mathrm{~mm}$ long, respectively; mantle body more or less injured, or missing in the $33 \mathrm{~mm}$ long individual. C-4 (Tsukumo Bay): from undersurface of boulders in the mediolittoral zone, 7 individuals, the largest is $45 \mathrm{~mm}$ long $\times 28 \mathrm{~mm}$ wide, while the smallest $11 \mathrm{~mm} \times 7 \mathrm{~mm}$; some damaged very much.

Description. In the living $45 \mathrm{~mm}$ long specimen of $\mathrm{C}-4$, pale greenish blood was seen oozing from a wounded part of the pale yellow test. In the specimen of collection $A$ and the $45 \mathrm{~mm}$ long specimen of $\mathrm{C}-4$, both siphons short but distinct; the branchial situated terminal, and the atrial near the posterior end of the body and directed posteriorly (Fig. 14, A). In other specimens, the siphons indistinct; the branchial terminal, while the atrial situated roughly at the level of posterior one-third of body. Test more or less thick, except the $61 \mathrm{~mm}$ long specimen whose test is rather thin, hard cartilaginous to soft leathery, translucent to nearly opaque, and yellowish or dull white. Test surface wrinkled in the larger specimens, while nearly smooth in smaller individuals, and all are devoid of projections. Mantle musculature is a dense network of fine bundles. Up to about 80 tentacles, of various

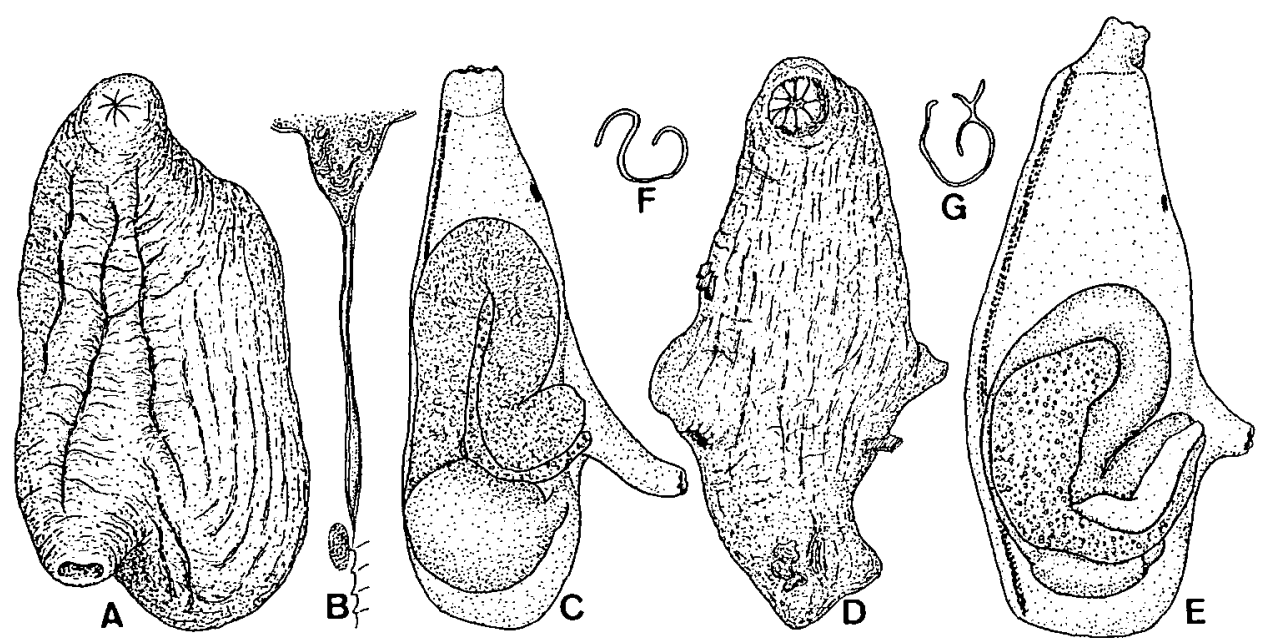

Fig. 14. Ascidia gemmata Sluiter. A \& C. $45 \mathrm{~mm}$ long specimen from Tsukumo Bay, Noto Pen. (Collection C-4); B. $56 \mathrm{~mm}$ long specimen from Toyama Bay (A, St. 29); D-F. $61 \mathrm{~mm}$ long specimen from Korea (B, OCUT No. 245(M249)); G. $55 \mathrm{~mm}$ long specimen from Mutsu Bay (C-2). A \& D. right side; B. complicated configuration of ciliated groove and $5 \mathrm{~mm}$ long narrow groove behind the dorsal tubercle; C \& E. left side of mantle body; F-G. ciliated groove. 
sizes. Prebranchial zone densely covered with evenly spaced minute papillae, except in the $56 \mathrm{~mm}$ long specimen of A which lacks papillae. Ciliated groove simple C-shaped, opening to the anterior in the majority of specimens, but somewhat deformed (Fig. 14, F-G) or cut into several pieces (Fig. 14, B) in some individuals. Dorsal ganlion located at the anterior one-fourth to two-fifths of the intersiphonal area. Narrow groove behind dorsal tubercle extending posteriorly to the level of the ganglion (Fig. 14, B) or ending slightly anterior to it. The relative length of narrow groove to the whole body seems roughly correlated with body length; the value ranging from 0.05 (in a $11 \mathrm{~mm}$ long specimen) to 0.1 (in an individual 61 $\mathrm{mm}$ long). Dorsal lamina ribbed; tip of ribs projecting slightly beyond the margin of the lamina. Numbers of longitudinal and transverse vessels are as follows:

$\begin{array}{ccc}\text { Specimen } & \begin{array}{c}\text { Number of longitudinal } \\ \text { vessels (Left; Right) }\end{array} & \begin{array}{c}\text { Number of transverse } \\ \text { vessels }\end{array} \\ 11 \mathrm{~mm} \text { long (C-3) } & 27 ; 28 & \text { about } 60 \\ 34 \mathrm{~mm} \text { long (C-4) } & 35 ; 40 & \text { about } 160 \\ 45 \mathrm{~mm} \text { long (C-4) } & 42 ; 48 & \text { about } 190 \\ 55 \mathrm{~mm} \text { long (C-2) } & 42 ; 50 & \text { no data } \\ 56 \mathrm{~mm} \text { long (A) } & 65 ; 75 & \text { about } 210 \\ 61 \mathrm{~mm} \text { long (B) } & 57 ; 66 & \text { about } 190\end{array}$

Nearly one branchial plication per mesh; up to 6 stigmata in each mesh. No intermediate papillae. Anterior margin of alimentary canal approaches the anterior third of the distance between bases of both siphons (Fig. 14, C), except the specimens of $\mathrm{B}$ and $\mathrm{C}-2$ in which the margin reaches nearly to the posterior third (Fig. 14, E). Axis of second loop passing through intestine at or slightly behind the pyloric end of stomach. Stomach globular in outline. In the larger specimens the surface of alimentary canal covered densely with testicular follicles; ovarian eggs up to $175 \mu \mathrm{m}$ in diameter found in the specimens of $\mathrm{B}$.

Remarks. The position of atrial siphon and the organization of the alimentary system in the present specimens from the Japan Sea are similar to the original descriptions and most, though not all, subsequent descriptions of Ascidia gemmata Sluiter recorded from the West Pacific. I was fortunately given the chance to reexamine the type material of Ascidia gemmata Sluiter collected from Ambon (Amboina), the Banda Sea, and deposited at ZMA (TU 235; see Spoel, 1969, p. 161), as well as the material from the Siboga Area, 0-13 m deep, referred with a very insufficient description to this species also by Sluiter (1904, p. 29) and kept at ZMA (TU 236-1, -2, $-3,-4$ and -5 ). The Ambon material consists of two specimens fused firmly to each other as shown in the original description; the larger, $33 \mathrm{~mm}$ long, with the rather well preserved mantle body obviously already examined, the smaller individual missing its posterior part and containing only the intact anterior half of mantle body. Several morphological notes are given here for future studies in addition to the original description. These are based mainly on the larger specimen: the atrial aperture 
situated nearly at the posterior one-third of the body including the branchial siphon located terminally; test pale yellowish, with yellowish orange pigment exculsively on the atrial aperture of both specimens; test surface quite smooth and devoid of any papillae; test vessels branched very well; the atrial siphon of the mantle body issuing from the posterior one-third of the body proper excluding the branchial siphon; the mantle musculature as a network of rather thick bundles ramifying densely over the whole right side; tentacles about 50; prebranchial zone papillated minutely but densely; ciliated groove $\mathrm{C}$-shaped opened anteriorly; the narrow groove behind dorsal tubercle $3 \mathrm{~mm}$ long; the distance between the rear end of the tubercle and the anterior end of dorsal ganglion $4 \mathrm{~mm}$; the ganglion located nearly in the middle of the intersiphonal area; long neural duct discernible, without any secondary ciliated grooves; tip of ribs of dorsal lamina projecting markedly beyond its margin; 30 longitudinal vessels on the left and more than 30 ones on the right; no intermediate papillae; the visceral mass occupying more than the posterior half of mantle body proper; the anterior margin of the mass situated at the level somewhat posterior to the dorsal ganglion; the arrangement of alimentary canal as shown in the original description; the intestine much swollen on the bottom part of the second loop, the axis of which passing through the intestine far apart from the pyloric end of stomach that is nearly globular.

On the other hand, the Siboga material consists of 18 specimens, 17 to $48 \mathrm{~mm}$ long, of which the $17 \mathrm{~mm}$ long intact individual of TU 236-1 (collected from Siboga St. 213) and the $28 \mathrm{~mm}$ and $29 \mathrm{~mm}$ long intact ones of Tu 236-4 (Siboga St. 47) may not belong to this species. The other 16 specimens seem basically similar to the type specimens mentioned above, though some variations are noted as follows: test white and without any pigment except in the $46 \mathrm{~mm}$ long specimen of TU 236-5 in which the test of the branchial siphon is pale brown due to the pigment; the atrial aperture on the test almost sessile and situated usually at the posteroir one-third or less of the body, but rarely in its middle; the atrial siphon of mantle body issuing from the level far or slightly posterior to the middle of the body proper; ciliated groove Cor U-shaped, except in the $23.5 \mathrm{~mm}$ long specimen of TU 236-4 and the $46 \mathrm{~mm}$ long one of TU 236-5, in which the groove cut into 2 simple (in the former), or 6 simple or complicated (in the latter) slits; tentacles up to about 100; the narrow groove behind dorsal tubercle $1.2-5.5 \mathrm{~mm}$ long in 17 to $48 \mathrm{~mm}$ long specimens, usually longer in the larger ones; the dorsal ganglion located slightly or far posterior to the rear end of the groove except in the $23.5 \mathrm{~mm}$ long one of $\mathrm{Tu} 236-4$ in that the end of the groove situated along the ganglion; the ganglion located at the anterior one-third to posterior two-fifths of the intersiphonal area; up to 60 or more longitudinal vessels on each side; the anterior margin of visceral mass more or less posterior to the ganglion except in the $26 \mathrm{~mm}$ long specimen of TU 236-4 in which the margin reaching slightly anteriorly beyond the ganglion; the mass occupying less than the posterior half of mantle body proper only in the $46 \mathrm{~mm}$ long specimen of TU 2363 , in which the intestine along the bottom part of second loop is much swollen, and the anterior half of the first loop bent so markedly jorsoposteriad that the axis of 
second loop lies nearly transversely; in other specimens, the swelling is indiscernible, the bend of first loop moderate, and the axis of second loop passing usually around the pyloric end of, or rarely through the intestine slightly behind, the stomach which is globular or somewhat elongated. These variations are regarded due partly to individual variations and partly to allometric growth.

This range of variation seems to coincide with many previous descriptions of A. gemmata except that given by Kott (1972a, pp. 26-27) for the specimen collected from Upper St. Vincent Gulf, in which the atrial siphon is subterminal, while that of the mantle body roughly at the anterior one-third of the body proper, and the anterior margin of the visceral mass located far posterior to the base of the atrial siphon. The occurrence of papillae over the test surface previously noted by Tokioka (1952, p. 103) and Nishikawa (1986a, p. 52) is regarded as an intraspecific variation, whose taxonomic significance remains unsolved. Thus, the specimens from the Japan Sea fall well within the variation range of $A$. gemmata, and therefore, they can be referred to this species. Reexamination of the specimen collected from the mediolittoral zone of Hoza-ura, Nanto-cho on the eastern coast of Kii Pen. and referred to Ascidia ahodori Oka by Nishikawa $(1980$ b, p. 100) revealed that this specimen is well allotable also to this species. Nevertheless, it seems quite peculiar to me that the species in question has so far never been recorded from the warmer waters around Japan, such as the Nansei Archipelago or Sagami Bay.

Distribution in Japan Sea. Mutsu Bay, 15-20 m (in the present study); Toyama Bay, $100 \mathrm{~m}$ (do.); Tsukumo Bay, $0 \mathrm{~m}$ (do.); Korean coastal waters facing Korea Strait (Rho, 1975).

Distribution outside Japan Sea. Eastern coast of Kii Pen., $0 \mathrm{~m}$ (erroneously listed as $A$. ahodori in Nishikawa (1980b); in the present study), Japan; Marianas and Caroline Isls and Wake Is., 9-22 feet (Tokioka, 1967c); Palau (Tokioka, 1950); Ponape and Majuro, 0-1 m (Nishikawa, 1984a); Flores Sea, $0 \mathrm{~m}$ (Sluiter, 1904); Banda Sea, $0 \mathrm{~m}$ (Sluiter, 1895, 1904); Arafura Sea, $13 \mathrm{~m}$ (Sluiter, 1904; Tokioka, 1952); West, South and East Australia, 0-72 feet (Herdman, 1899; Hartmeyer, 1919; Hartmeyer \& Michaelsen, 1928; Kott, 1952, 1966, 1975, 1976, 1985; Millar, 1966); Solomon Isls, 0-1 m (Nishikawa, 1986a).

\section{Ascidia matoya Tokioka, 1949}

(Fig. 15)

Ascidia matova Tokioka, 1949a, pp. 6-7, pl. 3, figs 2-4; Nishikawa, 1986b, p. 176.

Material examined: B: No. 211 (M122), labeled Ascidia mijaz, collected by Izuka in Miyazu Bay of Wakasa Bay on July 8, '03, 2, individuals, $35 \mathrm{~mm}$ long $\times 22 \mathrm{~mm}$ wide, and $33 \mathrm{~mm} \times 21 \mathrm{~mm}$, respectively. $\mathrm{N}$ (Oki) : a $17.5 \mathrm{~mm} \times 12.5 \mathrm{~mm}$ individual, already listed by Nishikawa (1986b).

Description. Entire body oval in outline and flattened laterally. Body surface covered densely with minute papillae, as well as hairy or dendriform projections sometimes sparsely carrying fine sand grains (Fig. 15, A-B) in the specimens from Wakasa 
Bay. The surface of individual from Oki devoid of such papillae or projections, but densely coated, and sometimes also impregnated, with sand grains, shell fragments and other calcareous matters, except siphonal area. Both siphons short but distinct; the brachial terminal, and the atrial situated close to it in the Oki specimen, while at the anterior one-third of body in the Wakasa Bay specimen. Test thin but rather tough, transparent and colorless, test vessels well branched and containing brownish pigment. The vessel leading to test vessel system was traced only in the specimen from Oki; it issues from the mantle along the anterior part of ventral branch of first intestinal loop. Mantle musculature is a network of rather thick fibers densely distributed over the whole right side, and much less developed on the left (Fig. 1, C-D). Tentacles about 24 (in the specimen from Oki) to 40 (in those from Wakasa Bay). Peribranchial zone narrow and densely papillated. Ciliated groove simple C-shaped (in smaller two specimens), or C-shaped with both horns rolled outward (in the largest one); all opened anteriorly. Dorsal ganglion very close to the dorsal tubercle, along narrow groove behind it; the groove 1.2 to $2 \mathrm{~mm}$ long. Tip of ribs of dorsal lamina projecting slightly or markedly beyond the margin. Twenty-eight longitudinal vessels on the left and 38 ones on the right in $17.5 \mathrm{~mm}$ long specimen, 29 and 35 ones, respectively in $33 \mathrm{~mm}$ long one, and 33 and 36 ones in $35 \mathrm{~mm}$ long one; up to 95 transverse vessels; no intermediate papillae. Visceral mass occupying roughly the posterior two-thirds of mantle body, the posterior margin of the mass considerably apart from the rear end of the body. First loop very deep and narrow, while the second deep but rather widely opened with the axis passing through the
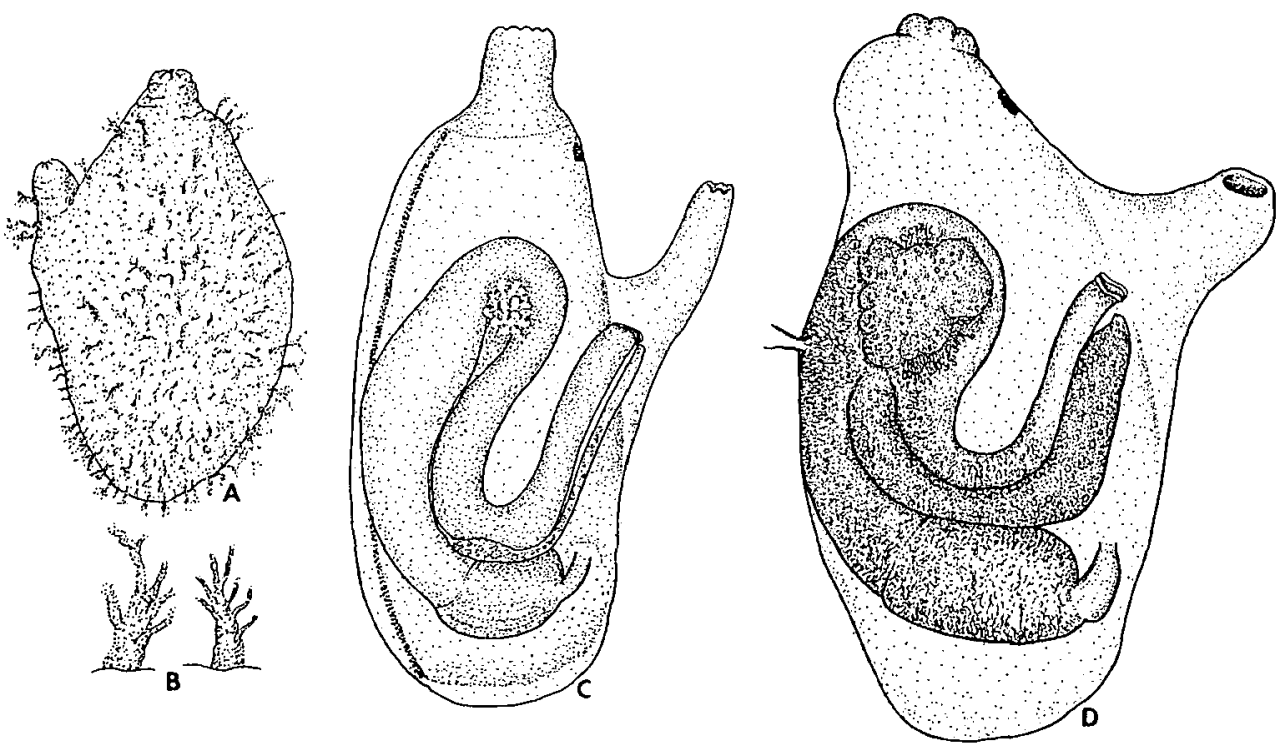

Fig. 15. Ascidia matoya Tokioka. A-C. $33 \mathrm{~mm}$ long specimen from Wakasa Bay (Collection B, OCUT No. 211(M122)); D. $17.5 \mathrm{~mm}$ long specimen from Oki Isls (N) ; A. right side of body; B. two dendroid projections on the test surface, enlarged; C-D. left side of mantle body. 
pyloric end of stomach which is somewhat elongated oval (Fig. 15, C-D). Gonad mature; ovary situated in the first loop, while the testicular follicles spreading over the stomach and intestine in the smallest one.

Remarks. The specimens from Wakasa Bay conform very well to the original and so far only description of $A$. matoya Tokioka, especially in the body surface having hairy processes, and are confidently placed in this taxon. These specimens have a different test surface than the individual from Oki. This difference could be of taxonomic significance, but the general similarity among these specimens is so striking that I will refer to the specimen from Oki as $A$. matoya.

The test surface with the projections described in $A$. matoya, as well as the mantle musculature and the arrangement of alimentary canal seen in this species is similar to the original description of $A$. capillata Sluiter given by Sluiter (1886) on the basis of the single specimen collected form the Bay of Batavia (=Djakarta). However, my reexamination of the holotype of $A$. capillata deposited at ZMA (TU 219; see Spoel, 1969, p. 161) revealed that its surface is quite free from any projections or papillae and the second loop is deep and very narrow. As the mantle body of the holotype is now injured and lacks its anterior part, further detailed comparison is impossible between the holotype and $A$. matoya. Nevertheless, $A$. capillata may well be regarded as distinct from $A$. matoya. Next, the specimen collected from the reef located on NE of Timor, the Banda Sea and labeled A. capillata by Sluiter (1904) was reexamined (ZMA TU 267.4). The mantle musculature and course of alimentary canal of this specimen resembles $A$. matoya mentioned above, but the Banda Sea specimen is distiguishable from $A$. matoya by smooth uniformly chocolate brown test, the dorsal ganglion far apart from the dorsal tubercle, and the visceral mass occupying the posterior half of mantle body in the Banda Sea specimen.

Distribution in Japan Sea. Wakasa Bay (in the present study); Oki Isls, 47-55 m deep (Nishikawa, 1986b; in the present study).

Distribution outside Japan Sea. Matoya Bay, 7-10 m (Tokioka, 1949a).

\section{Ascidia longistriata Hartmeyer, 1906}

(Fig. 16)

Ascidia longistriala Hartmeyer, 1906, pp. 20-21, fig. 12; Tokioka, 1953c, pp. 227-229, pl. 37, figs 1-11, pl. 38, figs 1-5.

Material examined: A (Toyama Bay): St. 8 , a $68 \mathrm{~mm}$ long $\times 30 \mathrm{~mm}$ wide individual, mantle body much injured. B: No. 330 (M197) (part), labeled Ascidia etigo by Oka, without any collection data, but etigo obviously meaning the locality, that represents an old name for the district corresponding to present Niigata Pref., a $87 \mathrm{~mm} \times 40 \mathrm{~mm}$ individual.

Description. Body attached to substratum by the whole left side. Both siphons short but distinct in the smaller specimen, while almost indiscernible in the larger; the branchial situated terminal, while the atrial nearly in the middle of body in the 
smaller individual, or at the level of its posterior one-third in the larger (Fig. 16, A). Test moderately thick (up to $3 \mathrm{~mm}$ in the larger specimen), soft leathery, translucent and white; the surface wrinkled longitudinally in the smaller; and further the surface provided wholly and densely with minute papillae only in the smaller specimen. Mantle very delicate; the musculature as a network of fine bundles in various directions, though transverse muscles predominant in the central part of mantle body on the right side. Tentacles about 36 (in the larger specimen) or 30 (in the smaller); prebranchial zone smooth or papillated, respectively. Ciliated groove C-shaped, with both horns slightly inrolled and opened anteriorly. Dorsal ganglion situated at the anterior one-third of the distance between the bases of both siphons. Narrow groove behind dorsal tubercle very long, extending down to the level slightly anterior to the ganglion in the larger individual, or to the rear end of the ganglion in the smaller. Dorsal lamina ribbed, tip of ribs projecting slightly beyond its margin. Sixtythree longitudinal vessels on the left and 68 ones on the right in the larger specimen, while about 50 and 60 ones in the smaller individual; transverse vessels are 320 and 250 , respectively. No intermediate papillae. Up to 4 or 5 stigmata per mesh in the smaller, but 6 or 7 in the larger. In the larger specimen, visceral mass occupies approximately three-eighths the length of mantle body, leaving the posterior one-eighth unoccupied; the anterior margin of the mass situated at the level of posterior onefifth of the distance between bases of both siphons (Fig. 16, B). The axis of second
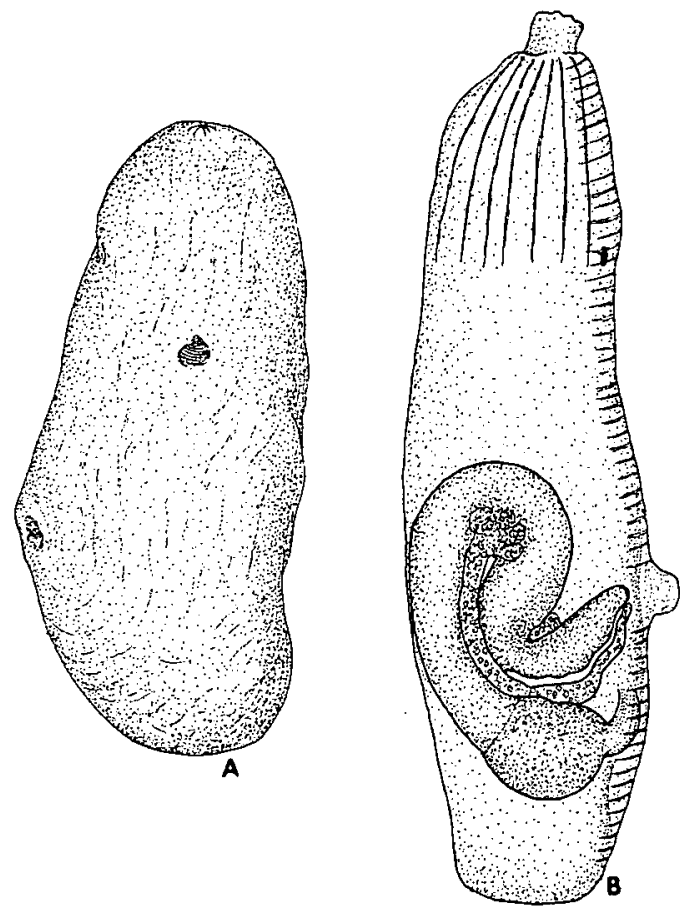

Fig. 16. Ascidia longistriata Hartmeyer from Niigata Pref, $87 \mathrm{~mm}$ long specimen (Collection B, OCUT No. 330(M197)). A. right side of body; B. left side of mantle body. 
intestinal loop passes through the intestine slightly behind the stomach which is globular in outline and provided with internal plications. In the smaller specimens, visceral mass much injured and hardly describable, but seemingly similar to that of the larger specimen. Gonad mature only in the larger specimen; ovarian eggs 150 to $175 \mu \mathrm{m}$ in diameter.

Remarks. The smaller specimen from Toyama Bay falls, though much damaged, well within the variation range of $A$. longistriata Hartmeyer. The larger specimen from Niigata may be unusual for this species in the posterior position of atrial aperture on the test and the axis of second intestinal loop passing through the intestine behind the stomach; in the hitherto known specimens the aperture is situated nearly in the middle of body and the axis across around the middle of stomach. In these two features this specimen resembles $A$. gemmata Sluiter discussed above, but the smallness of the visceral mass in the specimen from Niigata may be enough to distinguish the specimen from $A$. gemmata. Thus, the specimen in question is here referred, though not decidedly, to $A$. longistriata.

Kott \& Goodbody (1980) recorded A. longistriata from Hong Kong. In their specimens the visceral mass occupies approximately the posterior half of mantle body inclusive of the long branchial siphon, leaving almost no space between the posterior margin of the mass and the rear end of mantle body; the visceral mass is much more extensive in the Hong Kong specimens than in the previously known specimens of $A$. longistriata. The form of alimentary canal in the specimens from Hong Kong resembles that of $A$. beta Tokioka previously recorded from the Tokara Isls, Japan (Tokioka, 1954a), rather than that of $A$. longistriata. Therefore, Kott \& Goodbody's record is excluded from the synonymy of this species.

Distribution in Japan Sea. Toyama Bay, 22-30 m, and off Niigata Pref. (in the present study).

Distribution outside Japan Sea. Sagami Bay, down to $350 \mathrm{~m}$ (Hartmeyer, 1906; Tokioka, 1953c); Suruga Bay, $117 \mathrm{~m}$ (Nishikawa's unpublished data).

\section{Ascidia armata Hartmeyer, 1906}

(Fig. 17, A-C)

Ascidia armata Hartmeyer, 1906, pp. 19-20, fig. 11; Tokioka, 1953c, pp. 229-230, pl. 38, figs 6-13, text-fig. 10.

Material examined: A (Toyama Bay): St. 29, a $34 \mathrm{~mm}$ long $\times 18 \mathrm{~mm}$ wide individual. B: No. 347 (M198), labeled Ascidia etigo by Oka, without any collection data, but aligo obviously meaning the locality, representing an old name for present Niigata Pref., 2 individuals, $95 \mathrm{~mm} \times 60 \mathrm{~mm}$ and $65 \mathrm{~mm} \times 44 \mathrm{~mm}$.

Description. Body attached to substratum by the whole left side; rectangular in outline in the $95 \mathrm{~mm}$ and $34 \mathrm{~mm}$ long specimens, while elongated oval in the $65 \mathrm{~mm}$ long one. Both siphons indistinct; the branchial aperture opening on the anterodorsal corner and the atrial at the level of anterior one-third of body. Each 


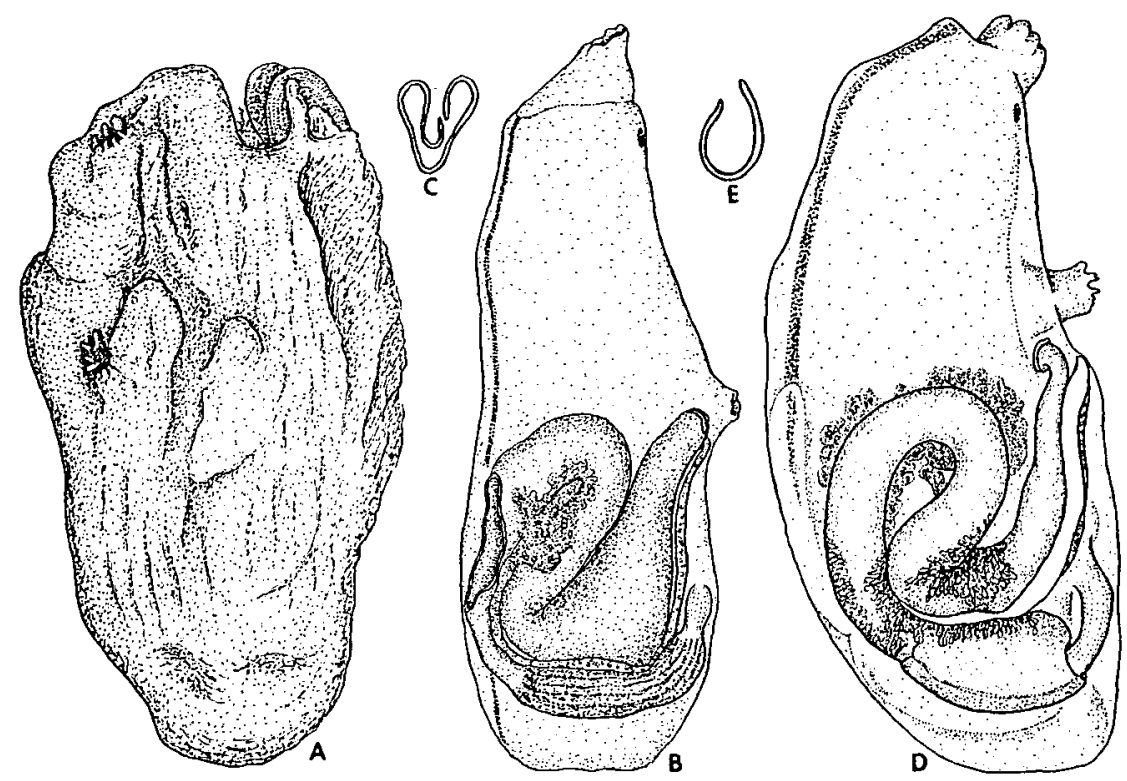

Fig. 17. A-C. Ascidia armata Hartmeyer from Niigata Pref., $95 \mathrm{~mm}$ long specimen (Collection B, OCUT No. 347(M198)); D-E. A. austera Sluiter from Oki Isls, 26 $\mathrm{mm}$ long specimen $(\mathrm{N})$. A. right side of body; B \& $\mathrm{D}$. left side of mantle body; C \& E. ciliated groove.

aperture surrounded by conical protuberances (Fig. 17, A), up to $2 \mathrm{~mm}$ long (in the $95 \mathrm{~mm}$ long specimen), $1.5 \mathrm{~mm}$ (in the $65 \mathrm{~mm}$ long one) or to $1 \mathrm{~mm}$ (in the $34 \mathrm{~mm}$ long one); each receiving a test vessel terminus. Test rather tough but not hard, thick (up to $6 \mathrm{~mm}$ ) in the larger two specimens or thin in the smallest, translucent to almost transparent, and slightly yellowish white; furnished rather densely with vessels. The surface is irregularly wrinkled; and covered rather densely with minute papillae in the anterior half of body in the smallest specimen, which are lacking in the larger two. Mantle very thin, and the musculature as a network of fine bundles. Both siphons short; the branchial terminal, and the atrial nearly in the middle of mantle body. Sixty tentacles in $95 \mathrm{~mm}$ long specimen, 50 in $65 \mathrm{~mm}$ long individual, or 26 in $34 \mathrm{~mm}$ long one. Prebranchial zone covered densely and

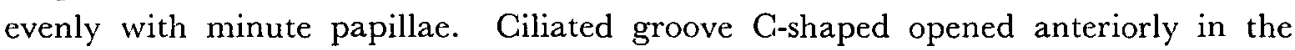
smaller two specimens, while basically C-shaped but with horns arranged more complex (Fig. 17, C) in the largest one. Dorsal ganglion located nearly in the middle between bases of both siphons in the smallest specimen, while more anteriorly in the larger two; the distance between the base of branchial siphon and the posterior end of the ganglion is $4 \mathrm{~mm}$ in $95 \mathrm{~mm}$ long specimen, while $8 \mathrm{~mm}$ in $65 \mathrm{~mm}$ long one. Narrow groove behind the tubercle reaches posteriorly just to the level of the ganglion. Dorsal lamina tall; tip of ribs of the lamina projecting slightly beyond its margin. Number of longitudinal and transverse vessels are: 


$\begin{array}{lcc}\text { Specimen } & \begin{array}{c}\text { Number of longitudinal } \\ \text { vessels (Left; Right) }\end{array} & \begin{array}{c}\text { Number of transverse } \\ \text { vessels }\end{array} \\ 95 \mathrm{~mm} \text { long } & 76 ; 90 & 210 \\ 65 \mathrm{~mm} \text { long } & 56 ; 65 & 200 \\ 34 \mathrm{~mm} \text { long } & 50 ; 60 & 80\end{array}$

Intermediate papillae discernible only on the posterior part of the sac in the smallest specimen. Three to 4 (in the smallest specimen), or up to 6 or 7 stigmata per mesh. Anterior margin of alimentary canal extends to the level of atrial siphon (Fig. 17, B) in the larger two specimens, but is more posterior in the smallest. Posterior margin of visceral mass distant from the rear end of mantle body. The axis of second intestinal loop passes through the intestine behind the stomach which is elongated cylindrical and furnished with 8 or more internal plications on its left side. Proximal part of dorsal branch of second loop is swollen remarkably. Anal margin smooth. Gonad mature in the larger two specimens.

Remarks. These specimens from the Japan Sea conform very well to the previous descriptions of Ascidia armata from Sagami Bay by Hartmeyer and Tokioka, especially in the test armature around each aperture, the general structure of branchial sac and the position and arrangement of alimentary canal. The Japan Sea specimens are, however, different from the previous descriptions of this species mainly in : 1) the papillated prebranchial zone in these specimens (instead of unpapillated in Tokioka's description), 2) the fewer transverse vessels (80 to 210 in 34 to $95 \mathrm{~mm}$ long specimens from the Japan Sea, instead of 180 to 300 in 40 to $98 \mathrm{~mm}$ long ones from Sagami Bay), and 3) the far more anterior position of dorsal ganglion in the specimens from Niigata than in the previous descriptions (but in that from Toyama Bay the position of the ganglion is similar to the descriptions). Among these differences, the last one can be regarded as an individual variation, though further examinations would be necessary for the crucial conclusion. The first two variations could be of taxonomic significance. On the other hand, it is equally possible that the differences in question represent individual variations. Detailed considerations on this problem are highly expected in future on the basis of a good number of specimens from different localities, but here the present specimens from the Japan Sea are referred to $A$. armata.

Distribution in Japan Sea. Toyama Bay, $100 \mathrm{~m}$ deep and off Niigata Pref. (in the present study).

Distribution outside Japan Sea. Sagami Bay, down to $180 \mathrm{~m}$ (Hartmeyer, 1906; Tokioka, 1953c).

\section{Ascidia zyogasima Tokioka, 1962}

Ascidia zyogasima Tokioka, 1962b, pp. 278-280, fig. 11; Rho, 1971, p. 111.

Doubtful synonym:

Phallusia koreana Traustedt, 1885, pp. 14-15, 49-50, pl. 2, fig. 15, text-figs 3-4. 
Material examined: None.

Remarks. Rho (1971) recorded this species in the Japan Sea from Cheju Is., Korea Strait, but no further reports have yet been made. Rho's specimens are consistent well with the original description of the species given by Tokioka (1962b) especially in the anterior position of atrial siphon, the large number of longitudinal vessels, the position and arrangement of alimentary canal, and the globular stomach, and therefore the specimens are clearly conspecific with Tokioka's material.

Traustedt (1885) established the species Phallusia koreana for specimens collected from the Korean coast at a depth of 60 to $100 \mathrm{fms}$. This species was later synonymized tentatively with Ascidia callosa Stimpson by Hartmeyer (1924). P. koreana resembles $A$. zyogasima in the position of atrial siphon, the existence of intermediate papillae on the branchial sac, and the position and arrangement of alimentary canal. $P$. koreana differs from $A$. zyogasima in the existence of short and pointed protuberances around the apertures on the test only in $P$. koreana and that of the secondary serrations born on the margin of dorsal lamina between prominently projected tips of ribs beyond it also only in $P$. koreana. As the original description of $P$. koreana lacks a description of the number of longitudinal or transverse vessels, and the detailed morphology of alimentary canal, reexamination of the type material was planned, but in vain, because it has been unfortunately missing for a long time at UZMK (E. Rasmussen's personal communiaction). Indeed, in the serrated margin of dorsal lamina $P$. koreana resembles $A$. callosa, but in $A$. callosa the visceral mass occupies far larger part of mantle body than in $P$. koreana. This difference seems to be of taxonomic significance. Thus, $P$. koreana may better be regarded, though somewhat doubtfully, as conspecific with $A$. zyogasima, rather than with $A$. callosa previously from the arctic and boreal waters.

Distribution in Japan Sea. Cheju Is., Korea Strait (Rho, 1971); ?Korean coast, 60-100 fms (Traustedt, 1885).

Distribution outside Japan Sea. Sagami Bay, 300-450 m (Tokioka, 1962b).

71. Ascidia zara Oka, 1935

(Tab. 5)

Ascidia zara Oka, 1935, pp. 463-464, figs 33-34.

Doubtful synonyms:

Ascidia ?zara: Millar, 1975, pp. 272-273, fig. 54.

Phallusia suensonii Traustedt, 1885, pp. 13-14, 49, pl. 2, fig. 14, text-figs 1-2.

Material examined: B: No. 192 (M433), collected on the east coast of Yunoshima Is., near Asamushi, Mutsu Bay by Hozawa and Takatsuki on Aug. 8, '26, a $21 \mathrm{~mm}$ long individual; No. 159 (M352), labeled Ascidia usuefa by Oka, collected in Oshoro, near Otaru, Hokkaido, a $20 \mathrm{~mm}$ long individual, dried up completely and detailed examination impossible, but the papillae discernible over the test surface. C-1 (Hokkaido): from undersurface of boulders in the mediolittoral zone of Kutsugata-misaki, Rishiri Is., 7 individuals, 13 $24 \mathrm{~mm}$ long; Kabuka $\mathrm{Hbr}$, Rebun Is., $5 \mathrm{~m}$, a $24 \mathrm{~mm}$ long individual; from undersurface of stones, $1 \mathrm{~m}$, Kamomejima Is., Esashi, a $20 \mathrm{~mm}$ long individual. D (Tottori): a $8.5 \mathrm{~mm}$ long individual, collected on Dec. '78. H-2 (Tsukumo Bay): from seawater tank 
of Noto Marine Biological Station, 10 individuals, 28-39 mm long. I-2 (Tsukumo Bay): 6 individuals found attached to balanoid shells, fishing nets or plastic sheets, $6.8-14 \mathrm{~mm}$ long. $\mathrm{J}-2$ (Tsuruga Bay): a $32 \mathrm{~mm}$ long individual. $M$ (Oga): from undersurface of stones in the mediolittoral zone of Daishima, 14 individuals, 12-57 mm long; already listed by Nishikawa (1984b).

Remarks. All the specimens examined in the present study fall within the previously known range of variation of $A$. zara. For future studies, several morphological features are noted as follows: the papillae over the test surface variable in size and arrangement; the length ranging from 100 or less to $500 \mu \mathrm{m}$, or rarely up to 1 $\mathrm{mm}$ long (often much longer around apertures), and the papillae usually distributed evenly and densely over the whole surface, but sometimes confined exclusively to the peripheral or anterior part, and in some individuals they are very sparse; both siphons almost always indiscernible; the atrial aperture situated at the level slightly anterior to, or just in the middle of body; number of longitudinal vessels and the length of narrow groove behind dorsal tubercle shown in Tab. 5; dorsal ganglion usually located near the rear end of the groove, but also found sometimes along its middle part; up to about 100 tentacles in the largest specimen; ciliated groove C- or U-shaped opened anteriorly; prebranchial zone almost always densely papillated, but quite smooth in a few individuals; no intermediate papillae; the anterior margin of alimentary canal usually extending anteriorly beyond the anterior base of atrial siphon on the mantle body, though in some individuals it does not reach this for; the axis of

Table 5. Characteristics of Ascidia zara Oka from the Japan Sea

\begin{tabular}{|c|c|c|c|}
\hline Material & $\begin{array}{l}\text { Body length } \\
\text { (mm) }\end{array}$ & $\begin{array}{l}\text { Number of } \\
\text { longitudinal vessels }\end{array}$ & $\begin{array}{l}\text { Length of narrow groove } \\
\text { behind the dorsal tubercle (mm) }\end{array}$ \\
\hline B & 21 & $28(\mathrm{~L}) ; 35(\mathrm{R})$ & 2.9 \\
\hline \multirow{6}{*}{$\mathrm{C}-1$} & 15 & $25 ; 32$ & 2.2 \\
\hline & 17 & $26 ; 34$ & 2.3 \\
\hline & 17 & $25 ; 30$ & 1.9 \\
\hline & 18 & $22 ; 30$ & 3.0 \\
\hline & 22 & $28 ; 33$ & 2.5 \\
\hline & 24 & $27 ; 35$ & 2.5 \\
\hline \multirow[t]{2}{*}{ D } & 8.5 & $18 ; 20$ & 一 \\
\hline & 28 & $50 ; 50$ & 3.6 \\
\hline \multirow[t]{3}{*}{$\mathrm{H}-2$} & 35 & $45 ; 44$ & 2.4 \\
\hline & 35 & $46 ; 45$ & 2.7 \\
\hline & 13 & $29 ; 36$ & 1.1 \\
\hline \multirow[t]{2}{*}{$1-2$} & 14 & $33 ; 35$ & 0.9 \\
\hline & 14 & $31 ; 37$ & 1.3 \\
\hline \multirow[t]{2}{*}{$J-2$} & 32 & $40(?) ; 46(?)$ & 3.3 \\
\hline & 19 & $26 ; 34$ & 2.2 \\
\hline \multirow[t]{2}{*}{$\mathbf{M}$} & 36 & $22 ; 35$ & 5.3 \\
\hline & 57 & $35 ; 38$ & 5.5 \\
\hline
\end{tabular}


second intestinal loop usually passes through the intestine just behind the stomach, or through its pyloric end, but rarely passes through the middle of stomach as seen in some specimens of $\mathrm{C}-1$; stomach globular in outline, but not extensive; many specimens mature, even the $12 \mathrm{~mm}$ long individual of $\mathrm{M}$; in a $20 \mathrm{~mm}$ long one from Esashi, numerous eggs in the peribranchial cavity, that are up to $170 \mu \mathrm{m}$ in diameter including the chorion.

Millar (1975) referred two specimens from off Goto Isls, Kyushu, 249-366 m deep, doubtfully to $A$. zara. The specimens fall well within the variation range of this species, differing only in that the mantle musculature on the right side consists mainly of oblique bundles confined only to the anterior half of mantle body in the specimens from Kyushu, but a network of fine muscles over the whole side in $A$. zara. This difference may be of taxonomic significance, so Millar's record is here included in the synonym of this species with some doubt.

The papillated test of $A$. zara resembles Phallusia suensonii Traustedt established by Traustedt (1885) on material collected from the eastern coast of Korea, $45 \mathrm{fms}$ deep; $P$. suensonii was then synonymized only uncertainly with Ascidia callosa Stimpson by Hartmeyer (1924). Also the arrangement of alimentary canal of $P$. suensonii resembles some specimens of $A$. zara. Fortunately I had a chance to examine the type material of $P$. suensonii deposited at UZMK, consisting of two specimens, $35 \mathrm{~mm}$ long $\times 25 \mathrm{~mm}$ wide and $33 \mathrm{~mm} \times 25 \mathrm{~mm}$. Their features are: test surface furnished with minute papillae, up to $40 \mu \mathrm{m}$ long, mainly in peripheral part of body, and in the smaller specimen with some hydrozoans and a chitinous nest tube of a polychaete; test very thin but tough, translucent and pale brown; both siphons low but distinct, and the branchial terminal, with the atrial situated slightly anterior to the middle of body; mantle body nearly missing, and only the 4 small fragments of branchial sac remain, of which 2 pieces kept in each of 2 small glass tubes; in the fragments, about 10 to 12 stigmata were counted per mesh, intermediate papillae seen, and the margin of tall dorsal lamina serrated complicatedly just as shown in the figure II on page 13 of the original description. Unfortunately, now missing are such diagnostic taxonomic features as the position of dorsal ganglion, the number of longitudinal and transverse vessels and the actual appearance of the stomach, which were not discussed in the original description. Luckily, an important message was entered on a card signed by Hartmeyer, accompanied by the type material and dated in V. 1922, saying that "Vom Weichkörper war nur ein Stücken Kiemensack (in einem besondern Gläschen) erhalten--". Thus it appears that Hartmeyer's (1924) opinion cited above was not based on the accurate anatomy of the whole mantle body of the specimens concerned. I would like to provisionally regard $P$. suensonii as conspecific with $A$. zara, on the basis of the similarities seen between these two species in the papillated test and the arrangement of alimentary system, although $P$. suensonii seems different from $A$. zara in the existence of secondary serrations between the tips of ribs on the margin of dorsal lamina. According to the orginal description of $P$. suensonii, "zona praebranchialis levis" (= the prebranchial zone is smooth), but the same feature is also observable in some specimens of $A$. zara. 
The papillated test of $A$. zara also resembles Ascidiopsis columbiana Huntsman recorded from British Columbia, 0-20 fms deep, by Huntsman (1912) and from Kamchatka, $20 \mathrm{~m}$ deep, by Ärnbäck-Christie-Linde (1934), and of Ascidiopsis nanaimoensis Huntsman from British Columbia, 20-30 fms deep, by Huntsman (1912). Later, A. columbiana was synonymized with Ascidia callosa Stimpson, while $A$. nanaimoensis with Ascidia prunum O. F. Müller (see, for example, Van Name, 1945, pp. 175 and 178). In the number of longitudinal vessels and the arrangement of alimentary canal, $A$. columbiana and $A$. nanaimoensis apparently fall within the variation range of A. zara. Closer comparisons among these species are desirable in future.

Distribution in Japan Sea. Rishiri and Rebun Isls, 0-5 m, Oshoro, and Esashi, about $1 \mathrm{~m}$, Hokkaido (in the present study; Oka (1935) already referred, as the locality, to Hokkaido, but further detailed geographical information unavailable); Mutsu Bay (Oka, 1935; in the present study); Oga Pen., $0 \mathrm{~m}$ (Nishikawa, 1984b; in the present study); Sado (Tokioka, 1967b); Tsukumo Bay, 0-25 m and Tsuruga Bay, $50 \mathrm{~m}$ (in the present study); Wakasa Bay (Tokioka, 1959a); Tottori, $0 \mathrm{~m}$ (in the present study); ?eastern waters of Korea, $37^{\circ} \mathrm{N}$ and $129^{\circ} 35^{\prime} \mathrm{E}, 45$ fms (Traustedt, 1885).

Distribution outside Japan Sea. Kesen, Miyagi Pref. (Oka, 1935); Matsushima Bay (Tokioka, 1960a); Tokyo Bay (Nishikawa's unpublished data); Sagami Bay, 100-140 m (Tokioka, 1953c); Shimoda (Nishikawa, 1982b); Ise Bay (Nishikawa's unpublished data); Kii Pen. (Tokioka, 1953c; Nishikawa, 1980b); Osaka Bay (Tokioka, 1954c); Seto Inland Sea (Tokioka, 1953a); ?off Goto Isls, 249-366 m (Millar, 1975).

\section{Ascidia austera Sluiter, 1904}

(Fig. 17, D-E)

Ascidia austera Sluiter, 1904, pp. 39-40, pl. 6, figs 6-8.

Material examined: $\mathrm{N}$ (Oki) : a $26 \mathrm{~mm}$ long individual, previously listed by Nishikawa (1986b).

Description. Body roughly rectangular in outline, elongated longitudinally and flattened laterally, attached firmly to dead brachiopod shell by the whole left side. Both siphons short but distinct; the branchial nearly terminal, with the atrial roughly in the middle of body. Test surface somewhat wrinkled, and sparsely impregnated with sand grains but only in the posterior peripheral part; the surface around apertures and near the base of both siphons covered rather densely with low conical papillae, up to $50 \mu \mathrm{m}$ long. Test soft, up to $1 \mathrm{~mm}$ thick, tough, translucent, and chocolate brown due to dark brown granules of less than $5 \mu \mathrm{m}$ in diameter, distributed wholly and very densely especially in the dorsal part of body on the free side; test on the attachment side very thin and colorless. The dark brown granules confined to the outer three-fourths of test on the cut surface. Test vessels branched; no such granules therein. Mantle fairly thick and pale yellow; the musculature as a network of fine fibers densely covering the whole right side, but 
much less developed on the left. Tentacles about 24 and of various sizes; prebranchial zone narrow and papillated densely. Ciliated groove C-shaped opened anteriorly (Fig. 17, E); dorsal ganglion very close to the tubercle; narrow groove behind it is $2 \mathrm{~mm}$ long. Dorsal lamina ribbed; tip of ribs projecting markedly beyond the lamina. Thirty-four longitudinal vessels on the left and 41 on the right. About 80 transverse vessels, intermediate papillae lacking; 4 stigmata per mesh. Visceral mass occupies roughly posterior half of mantle body; the anterior margin never reaching the posterior base of atrial siphon (Fig. 17, D). First intestinal loop deep, rather wide on its bottom and bent somewhat dorsad, while the second deep and narrow, with the axis passing through the intestine slightly behind the pyloric end of stomach. Stomach moderately elongated and lacking obvious internal longitudinal plications. Gonad fully mature; ovary protruding anteriorly far from first intestinal loop, while testicular follicles spreading over the intestine (Fig. 17, D).

Remarks. This specimen falls well within the variation range of Ascidia austera Sluiter previously recorded from the Moluccas and Australia, 0-5.5 m deep. Thus the specimen is safely referable to this species. The arrangement of alimentary canal in the present specimen is somewhat reminiscent of Ascidia armata Hartmeyer previously recorded from Sagami Bay, down to $180 \mathrm{~m}$ deep, by Hartmeyer (1906) and Tokioka (1953c). The specimen from the Japan Sea is easily distinguishable from this species by the test appearance (pale yellow and provided on the surface with conspicuous projections around apertures) and the much swollen rectum in $A$. armata.

Very recently Kott (1985) regarded $A$. austera as a junior synonym of $A$. capillata Sluiter, 1887. A. capillata in her sense "is a unique species, in which the test becomes rather intimately associated with the body wall, partially isolating the gut and gonad from the remainder of the body wall" (p. 31). In A. austera at least from the Japan Sea, however, the mentioned isolation is undetectable, and therefore Kott's synonymy will not be followed here.

Distribution in Japan Sea. Oki Isls, 47-55 m deep (Nishikawa, 1986b; in the present study).

Distribution outside Japan Sea. The Moluccas, $0 \mathrm{~m}$ (Sluiter, 1904); North, East and SW Australia, 0-5.5 m (Hartmeyer \& Michaelsen, 1928; Kott, 1952, 1964, 1966).

73. Ascidia callosa Stimpson, 1852

Ascidia callosa Stimpson, 1852, p. 228.

Material examined: None.

Remarks. The first and hitherto the only record of this species in the Japan Sea was given by Skalkin (1959, p. 246) from the western coast of South Sakhalin, but without any anatomical information. Hartmeyer (1924) synonymized Phallusia suensonii and $P$. koreana with Ascidia callosa, but this was not followed in the present study; for $P$. suensonii see the section of $A$. zara and for $P$. koreana see that of $A$. 
zyogasima. A. callosa has been known from the arctic and boreal waters of both hemispheres, 0-270 m deep (Van Name, 1945; Ärnbäck-Christie-Linde, 1952; Abbott, 1961), and therefore, it may be of some biogeographical significance to clarify in the future the actual horizontal and bathymetric distribution of this species in the Japan Sea.

\section{Ascidia sp. aff. obiliqua Alder, 1863}

Ascidia aff. obliqua: Beniaminson, 1971, p. 319.

Material examined: None.

Remarks. As Beniaminson's (1971) present record from Possjet Bay lacks the description completely, it is impossible here to make detailed reference to the exact affilation of his record.

Family Plurellidae

75. Microgastra granosa (Sluiter, 1904)

Ascidia granosa Sluiter, 1904, p. 36, pl. 5, figs 11-14.

Ascidia(?) aenigmatica Nishikawa, 1986b, pp. 177-181, fig. 1. New Synonymy.

For other synonyms see Kott (1985), except Ascidia polytrema Herdman.

Material examined: None.

Remarks. Nishikawa (1986b) established Ascidia(?) aenigmatica on the specimens dredged off the Oki Isls, that was then regarded conspecific with the material collected from Hakodate and referred previously to Ascidia granosa Sluiter by Hartmeyer (1906) on the basis of my reexamination of the material. Very recently I noticed that Kott (1985) erected a new gepus Microgastra of the family Plurellidae, its type species being Ascidia granosa Sluiter. Her detailed description of $M$. granosa (Sluiter) based mainly on the material from Queensland, NE Australia, is quite consistent with the above-mentioned specimens of Ascidia(?) aenigmatica from the Japan Sea in many important features including the presence of the gonad completely embedded in the test. Further, $M$. granosa resembles well $A$. (?) aenigmatica also in the following features overlooked in the original description of $A$.(?) aenigmatica but confirmed through the reexamination of its paratypes from Oki deposited at NSMT (No. Pc 683) and the specimens of $A$. granosa from Hakodate and housed at MNB as: the test across the ventral surface separated into 2 layers, the inner one consisting of a thin but tough membrane of test (free from any foreign matters) extending across beneath the mantle body to enclose a space bounded on the outside by a brittle outer layer that is impregnated densely with sand grains. The dorsal ganglion is embedded in the inner surface of test just anterior to the base of the atrial siphon, and the base furnished around with a velum composed of a low and tough projection of test. Only the specimens from Oki have many "ciliated pits on narrow ducts" 
(Kott, p. 72), 30 to $50 \mu \mathrm{m}$ in diameter clearly discernible microscopically in each of a few fragments of mantle wall found attached firmly to the test along its dorsomedian line. In the specimens from Hakodate the gonad consists of 1(?) to 4 ovaries accompanied posteriorly by a single mass of testicular follicles. Kott's description of $M$. granosa differs from the Japanese specimens of $A$.(?) aenigmatica in: 1) the body usually has a "strong, root-like process about halfway along the ventral border" (p. 70) in $M$. granosa, while no such process is discerned in $A$. (?) aenigmatica, 2) that the visceral mass is situated "in the dorsal part of the left side of the body adjacent to the oesophageal opening" (p. 72) in $M$. granosa, while "sited quite on the ventral side opposite the atrial siphon" (Nishikawa, p. 179) in $A$.(?) aenigmatica, 3) that the remarkable approach of the dorsal lamina of the branchial sac to the endostyle only in $A$.(?) aenigmatica, and 4) further that there is always a single ovary in the former, while 1-4 ones in the latter. These differences, especially the last one, are of taxonomic significance, but the general resemblance between these two is so striking that they can be considered in the present study to be conspecific with each other. Thus, $A$.(?) aenigmatica is sunk into a junior synonym of $M$. granosa.

My reexamination of the type specimens of Ascidia mikrenterica Sluiter collected in the Banda Sea, described by Sluiter (1904) and deposited at ZMA (No. TU 254), and the specimens from the Holothurian Bank, NW Australia and from Great Barrier Reef, referred to Ascidia granosa by Hastings (1931) and now housed at BMNH (Nos. 1892-1-29-402 and 1930-12-17-22, respecitvely), proved the validity of Kott's (1985) synonymization of these specimens with $M$. granosa; the specimens are quite similar to her description of this species, in so far as the features then confirmable in them are concerned, including those of the dorsal ganglion embedded in the test and the gonad composed of a single ovary and a testis, as well as in the existence of the ciliated pits only in Hastings' specimens. The only exception is that all the examined specimens lack the root-like process on the body. In the rather well preserved specimen registered as BMNH 1892-1-29-402, the branchial fold on the left side is not so conspicuous, and therefore the dorsal lamina does not approach the endostyle.

The reexamination of the specimen from Sri Lanka and referred to Ascidia granosa by Herdman (1906) was planned, but in vain, for the specimen is now (tentatively?) lost at BMNH (G. Paterson's personal communication); and therefore, in the present study this record is somewhat doubtfully included in the synonymy of $M$. granosa, following Kott's (1985) treatment. Unfortunately, also, the specimens collected from Sagami Bay and assigned to $A$. granosa by Hartmeyer (1906) are now missing from MNB (personal communication of Kühlmann), so this record is also included in the synonymy but somewhat uncertainly. However, Kott's synonymization of Ascidia polytrema Herdman, 1906 with $M$. granosa was proved incorrect by my reexamination of the holotype of $A$. polytrema. In the holotype specimen, about $30 \mathrm{~mm}$ long, collected in Sri Lanka and deposited at BMNH (No. 1907-8-30-6), the mantle body was represented by only a few fragments, one of which includes a piece of mantle having a longitudinal row of short transverse muscle bundles along 
the dorsomedian line, with the atrial aperture opening on the line. The piece is also accompanied by the oesophagus, stomach, distal part of sperm duct, and the small testicular follicles spreading over a part of stomach, all organized as is usually seen in Ascidiidae. According to the original description, "about 20 supplementary ciliated funnels --- opening into the peribranchial cavity" (p. 307). Consequently, the holotype specimen is clearly assignable to the genus Phallusia of the family Ascidiidae, but not to Microgastra of Plurellidae.

Distribution in Japan Sea. Hakodate (Hartmeyer, 1906); Oki Isls, 40-55 m (Nishikawa, 1986b).

Distribution outside Japan Sea. ?Sagami Bay, $180 \mathrm{~m}$ (Hartmeyer, 1906); Moluccas, $45 \mathrm{~m}$ (Sluiter, 1904); Banda Sea, $0 \mathrm{~m}$ and $204 \mathrm{~m}$ (Sluiter, 1904); Flores Sea, $73 \mathrm{~m}$ (Sluiter, 1904); NW Australia, $62.2 \mathrm{~m}$ (Hastings, 1931); Great Barrier Reef, NE Australia, $34.8 \mathrm{~m}$ (Hastings, 1931); Queensland, NE Australia (Kott, 1985); ?Sri Lanka (Herdman, 1906).

Family Agnesiidae

76. Agnesia himeboja Oka, 1915

Agnesia himeboja Oka, 1915, pp. 1-6, figs 1-3; Tokioka, 1949a, p. 6, pl. 3, fig. 1; Nishikawa, 1980b, tab. 1.

Agnesia sabulosa Oka, 1929b, pp. 152-154, figs A-B. New Synonymy.

Material examined: B: No. 150 (M236), labeled Agnesia sabulosa by Oka, collected in Hakodate by N. Sasaki on July 5, '17, 6 individuals; representing obviously the type specimens, but dried up completely and hard to examine.

Remarks. The original description of $A$. sabulosa resembles strongly the previous descriptions of $A$. himeboja, inclusive of the original one, in terms of mantle musculature, branchial structure such as represented by the arrangement and number of transverse rows of infundibula, and the alimentary system. However, the test surface is furnished wholly and densely with fine hair-like processes carrying sand grains and shell fragments thickly in $A$. sabulosa, while the surface is devoid completely of any such processes in the descriptions of $A$. himeboja. Also, in my reexamination of the type material of $A$. himeboja deposited at OCUT (No. 46(M39)) I found many specimens whose posterior part of body was covered by many fine filamentous processes of test, sometimes carrying some sand grains. Thus, $A$. sabulosa is conspecific with $A$. himeboja, and therefore, $A$, sabulosa is sunk into a junior synonym of $A$. himeboja.

Distribution in Japan Sea. Hakodate, 10-15 fms (Oka, 1929b); Nanao Bay, 5$39 \mathrm{~m}$ (Tokioka, 1949a).

Distribution outside Japan Sea. Tateyama, 5-7 fms (Oka, 1915); Matoya Bay, 8-16 m (Tokioka, 1949a); Tanabe Bay, 10 m (Nishikawa, 1980b); Kagoshima Bay (Nishikawa's unpublished data). 


\section{Agnesia orthenteron Redikorzev, 1941}

Agnesia orthenteron Redikorzev, 1941, pp. 199-202, 212, figs 17-18.

Material examined: None.

Remarks. This species was established by Redikorzev on a single $11 \mathrm{~mm}$ long and $5 \mathrm{~mm}$ wide specimen collected in the Japan Sea at a depth of 1900-2090 m (further detailed location of collecting site unknown); no other reports of this species have been recorded. According to the original and hitherto the only description, the features of this species are: the body rectangular and the surface smooth; mantle musculature consists of circular muscles on the siphons, fine radial muscles diverging from the siphons but disappearing near the central part of mantle body, and of 4 longitudinal series of short transverse bundles one on each side along the dorso- or ventromedian lines; the bundles along dorsomedian line is somewhat oblique in direction, and finer but longer than those along the ventromedian; about 36 tentacles; 5 dorsal languets; 5 transverse vessels, each of which bearing 9 branchial papillae on either side; 14 transverse rows of infundibula, though apparently 12, according to my understanding of the description; two rows between two adjacent transverse vessels; each half row containing 13 infundibula; each infundibulum comprising a single stigma coiling I to 3 times; radial parastigmatic vessels present; alimentary system situated on the left side of the branchial sac, and forming a simple U-shaped loop; gonad located within the loop, and consisting of well-ramified testis surrounding the ovary; oviduct and vas deferens running parallel with each other along the rectum. The longitudinal series of short transverse muscles along each side of dorsoand ventromedian lines of mantle body and the occurrence of 5 transverse vessels in this species is reminiscent of $A$. himeboja Oka described just above, but $A$. orthenteron is distinguishable from $A$. himeboja by the number of branchial papillae in each transverse vessel on either side ( 9 in the former, instead of 3 to 6 in the latter, according to Nishinawa's unpublished data) and the course of alimentary canal (simple Ushaped, instead of having the obvious second intestinal loop). In terms of the simple U-shaped alimentary system, on the contrary, $A$. orthenteron resembles $A$. atlantica Monniot et Monniot thus far known from the Atlantic, $1392-4680 \mathrm{~m}$ deep by Monniot \& Monniot $(1973,1974)$ and Millar (1982a), and A. celtica Monniot et Monniot from the North Atlantic, 4100-4737 m deep by Monniot \& Monniot (1974) and the Argentina basin at a depth of 3906-3917 $\mathrm{m}$ by Monniot \& Monniot (1976). However, $A$. orthenteron differs from these two species in that it has the series of short transverse muscles along the median line of mantle body, but $A$. atlantica and $A$. celtica lack the series, and in the structure of branchial sac which bears only 6 transverse rows of infundibula in $A$. atlantica, each row in between two adjacent transverse vessels; and in $A$. celtica with the branchial papillae born on each transverse vessel almost equal in number to the infundibula along the vessel. Thus, $A$. orthenteron appears to be a good species, so far endemic to the deep water of the Japan Sea. 


\section{Adagnesia vesiculiphora Nishikawa, 1982}

Adagnesia vesiculiphora Nishikawa, 1982a, pp. 155-163, figs 1-5.

Material examined: None.

Remarks. This species was established for specimens dredged off Noto Ogi on the eastern coast of Noto Pen., $37^{\circ} 20.6^{\prime} \mathrm{N}$ and $137^{\circ} 16.8^{\prime} \mathrm{E}, 20 \mathrm{~m}$ deep; and since then, not obtained in the Japan Sea. Recently, however, many specimens obviously referable to this species were collected on the Pacific coast of Japan from off Namiecho, Fukushima Pref., about $45 \mathrm{~m}$ deep (Nishikawa's unpublished data).

\section{Family Corellidae}

\section{Rhodosoma turcicum (Savigny, 1816)}

(Fig. 18)

Phallusia turcisa Savigny 1816, pp. 102-105, pl. 10, fig. 1.

Rhodosoma turcicum: Van Name, 1930, p. 471, fig. 43.

For other synonyms sec Van Name (1945).

Material examined: $\mathrm{C}-1$ (Hokkaido): Chazu, Bikuni, 3-5 m, 2 individuals, $10 \mathrm{~mm}$ and 11.5 mm long, respectively. C-2 (Mutsu Bay): Kaizaki, SW end of Shimokita Pen., 15-20 m, an individual of $18 \mathrm{~mm}$ long body and $1 \mathrm{Imm}$ long posterior extension. $\mathrm{C}-5$ (Noto): 2 individuals, $11 \mathrm{~mm}$ and $6.5 \mathrm{~mm}$ long. D (Tottori) : a $22 \mathrm{~mm}$ long individual collected in Dec. '78. F-1: No. Iv-947, 2 individuals, $33 \mathrm{~mm}$ and $34.5 \mathrm{~mm}$ long. $\mathrm{I}-2$ : a $13 \mathrm{~mm}$ long individual. $\mathrm{N}$ (Oki): 2 individuals, $3 \mathrm{~mm}$ and $5.5 \mathrm{~mm}$ long, already listed by Nishikawa (1986b).

Remarks. In the specimen of I-2, the anterior margin of the body on the right side of the siphons is slightly protuberant and covered densely with papillae (Fig. 18 , A), instead of bearing the cleft concealing the siphons laterally, that is characteristic to $R$. turcicum. In the internal features, however, the present specimen is consistent with the previous descriptions of the species, and therefore, the specimen of I-2 can be regarded only as a somewhat deformed individual of the latter species. All the other specimens in the present material fall within the variation range of this species. For future studies, the number of longitudinal and transverse vessels in the specimens examined are recorded as follows:

$\begin{array}{lcc}\text { Specimen } & \begin{array}{c}\text { Number of longitudinal } \\ \text { vessels (Left; Right) }\end{array} & \begin{array}{c}\text { Number of transverse } \\ \text { vessels }\end{array} \\ 6.5 \mathrm{~mm} \text { long (C-5) } & 34 ; 36 & 44 \\ 11 \mathrm{~mm} \text { long (C-5) } & 40 ; 41 & 48 \\ 13 \mathrm{~mm} \text { long (I-2) } & 26 ; 24 & 37 \\ 18 \mathrm{~mm} \text { long (C-2) } & 46 ; 48(?) & \text { injured } \\ 33 \mathrm{~mm} \text { long (F-1) } & 52 ; 48(?) & \text { about } 100 \\ 34.5 \mathrm{~mm} \text { long (F-1) } & 50 ; 53 & 110\end{array}$

Pérès (1956, 1960) adopted Rhodosoma verecundum Ehrenberg, 1828, instead of 

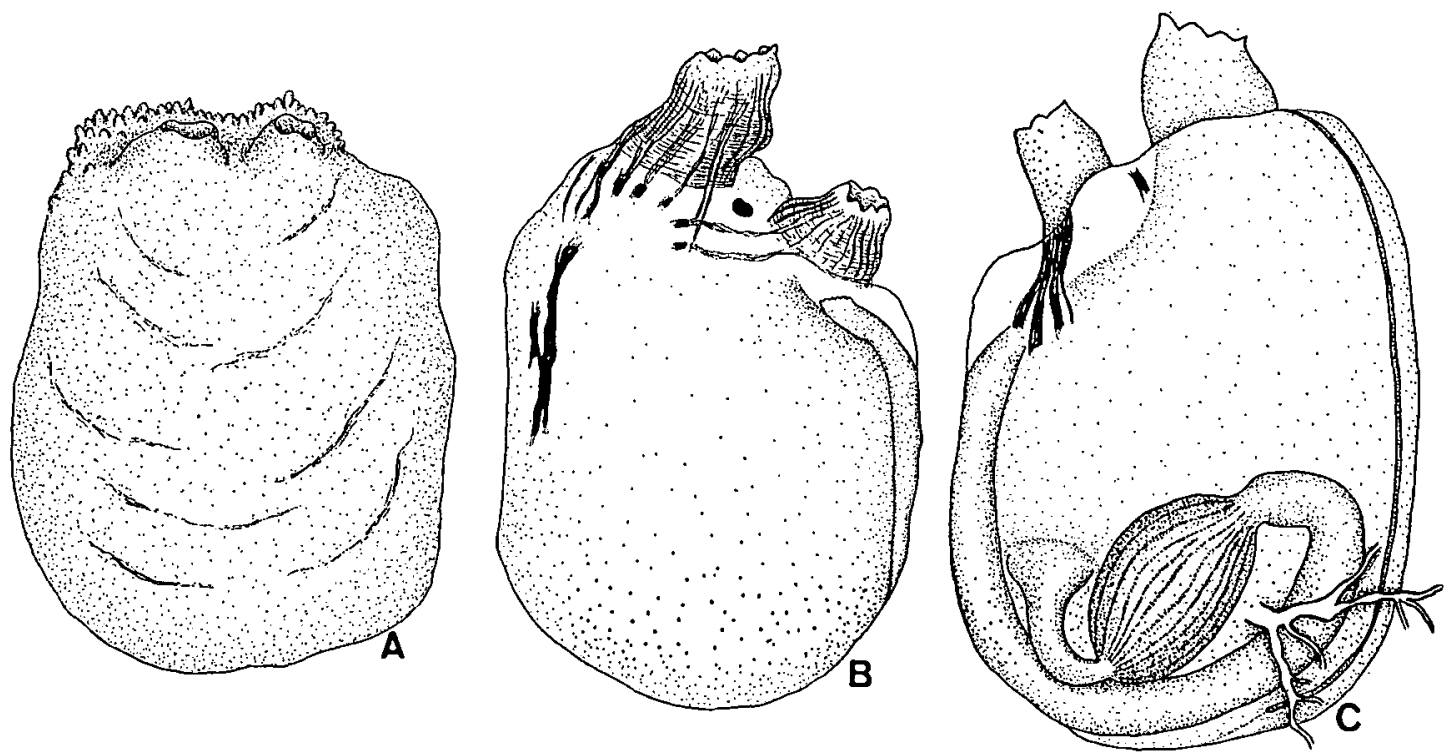

Fig. 18. Rhodosoma turcicum (Savigny) from Tsukumo Bay, Noto Pen., $13 \mathrm{~mm}$ long specimen (Collection I-2). A. whole body; $B$. left side of mantle body; $C$. right side of mantle body. 
Phallusia turcica Savigny, 1816, as the valid specific name for the sole good species of the genus Rhodosoma. He insists that the existence of "couvercle si caractéristique des Rhodosoma" cannot be verified by the original description of Phallusia turcica given by Savigny. Yet, I rather follow the prevailing opinion that $R$. verecundum is a junior synonym of $R$. turcicum.

Distribution in Japan Sea. Bikuni, Hokkaido, 3-5 $\mathrm{m}$ (in the present study); Mutsu Bay, down to $20 \mathrm{~m}$ (Tsuchiya \& Osanai, 1978; in the present study); Notohime, 0-2.5 $\mathrm{m}$ and Tsukumo Bay, $25 \mathrm{~m}$, off Amino-cho, Kyoto Pref., 30-122 m, and Tottori, $0 \mathrm{~m}$ (in the present study); Oki Isls, 40-55 m (Nishikawa, 1986b; in the present study); Korean coastal waters facing Korea Strait (Rho, 1971, 1975).

Distribution outside Japan Sea. Japan: Tokyo Bay, and Uraga Channel, $80 \mathrm{~m}$ (Hartmeyer, 1906) ; Sagami Bay, 100-145 m (Hartmeyer, 1906; Oka, 1932c; Tokioka, 1953c); Kii Pen., down to $3 \mathrm{~m}$ (Nishikawa \& Tokioka, 1975; Nishikawa, 1980b); Tosa Bay (Oka, 1932c); Kagoshima Pref. (do.); and Ariake Sea (Tokioka, 1960b). Other localities: according to Van Name (1945) and Kott (1972a), this species has so far been recorded from the tropical to warm temperate waters of such various regions in the world as the West Pacific, around Australia, Sri Lanka, Red Sea, Mediterranean, Florida, Carribean, West Indies and California; and further Kott (1954) recorded this species from the cold temperate water off Tasmania, 155-174 m deep, though later (1985) excluded this record from those of $R$. turcicum without giving any justification.

\section{Corella japonica Herdman, 1880}

(Fig. 19)

Corella japonica Herdman, 1880, p. 472.

Corella japonica var. asamusi Oka, 1931b, pp. 198-200, figs A-B; 1935, pp. 458-460, fig. 29; Tokioka, 1960 a, p. 201 ; 1967c, p. 149, fig. 57. New Synonymy.

Material examined: A (Toyama Bay): St. 15, 3 individuals, 25-30 mm long, St. 28, 10 individuals, $18.3-33 \mathrm{~mm}$. B (Mutsu Bay): No. 43(M403), collected off Asamushi Mar. Biol. Stat., St. 27, by Takatsuki on Sept. 8, '26, 2 individuals, $32 \mathrm{~mm}$ and $27 \mathrm{~mm}$ long; No. 94(M453), off Yunoshima Is., by Hozawa and Takatsuki on Aug. 29, '27, 15 individuals, 11-37 mm long; No. 248(M405), S off Wakinosawa by Hozawa and Kokubo on Aug. 9, '26, a $35.5 \mathrm{~mm}$ long individual; No. N20(M455), off Itasaki by the same two researchers as No. 248 on Aug. 10, '27, 8 individuals, 32.5-42.5 mm long; the samples except that of No. 248 were identified with Corella japonica var. asamusi by Oka (1935). $\mathrm{F}-1$ (Kyoto): 2 individuals, $21 \mathrm{~mm}$ and $24 \mathrm{~mm}$ long. G-4 (Wakasa Bay): a $28 \mathrm{~mm}$ long individual. I-2 (Tsukurno Bay): 4 individuals, $7-28 \mathrm{~mm}$ long. $\mathrm{M}$ (Oga): a $33 \mathrm{~mm}$ long individual, already listed by Nishikawa (1984b). N (Oki): a $8 \mathrm{~mm}$ long individual, attached to the algae Caulerpa fergusoni Murray(?), already listed by Nishikawa (1986b).

Description. Distribution of rooty processes on the test surface varies among individuals, even those of the same local population. In an extreme case the processes are distributed very densely over the whole right (=attachment) side and marginal area of body (Fig. 19, A), while in others, they are confined to the midventral region or the posterior end of body but rather sparsely so. Of 8 specimens of collection $B$ 

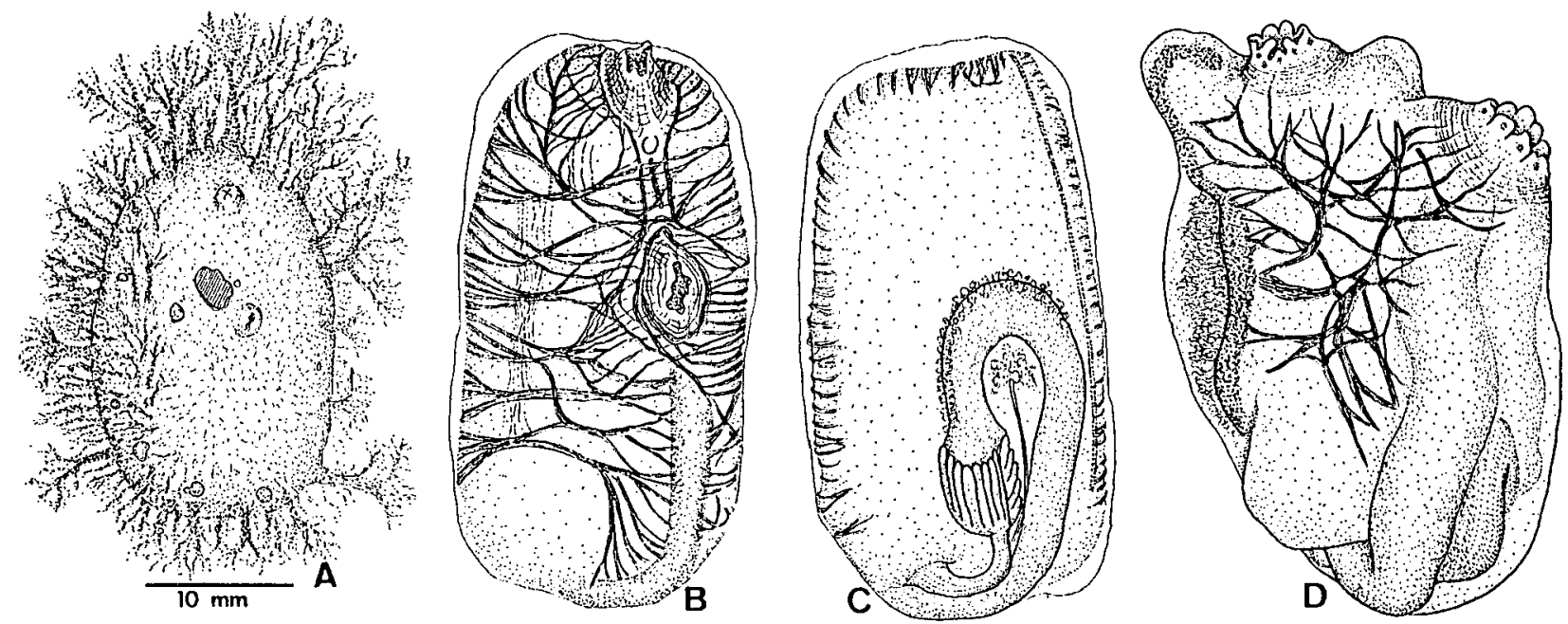

Fig. 19. Corella japonica Herdman. A-C. $24 \mathrm{~mm}$ long specimen from off Amino-cho, Kyoto Pref. (Collection F-1); D. 8 $\mathrm{mm}$ long specimen from Oki Isls (N). A. left side of the whole body; B \& D. left side of mantle body; C. right side of mantle body. 
(No. N20), for example, the processes found on the whole right side of body in 4 specimens, but confined to the posterior end in the remaining 4. Apparently, the specimens from Mutsu Bay tend to be less densely covered by the processes than those from other localities; the exceptions are the smallest 3 specimens $(7.0 \mathrm{~mm}$, $8.0 \mathrm{~mm}$ and $9.5 \mathrm{~mm}$ long, respectively) of I-2 (Tsukumo Bay) and the $8 \mathrm{~mm}$ long one of $\mathrm{N}$ (Oki) where the whole surface has minute simple papillae. In all the specimens examined, the left side of body always covered by minute papillae, up to $500 \mu \mathrm{m}$ long. These processes and papillae sometimes carrying sand grains. Mantle slightly pigmented reddish brown or orange in some specimens of F-1 and I-2. Mantle musculature consists of left bundles running mostly transversely and wellramified along the left margin of mantle body; these bundles white or pale pink. Thickness and arrangement of the bundles various; the 23 specimens of this study fall into 2 groups, in 15 individuals the bundles distributed nearly over the entire left mantle wall (Type I), while in the other 8 they are lacking roughly in the posterior one-fourth or less of that side (Type II) (Fig. 19, B-D). Allotment of the specimens concerned in respective collections is:

$\begin{array}{ccc}\text { Collection } & \begin{array}{c}\text { Number of specimens assignable to } \\ \text { Type I }\end{array} & \begin{array}{c}\text { Type II } \\ \text { A }\end{array} \\ \text { B } & 9 & 4 \\ \text { F-1 } & 5 & 0 \\ \text { G-4 } & 0 & 2 \\ \text { M } & 1 & 0 \\ \text { N } & 0 & 1 \\ & 0 & 1\end{array}$

The bundles generally not so thick in the examined specimens except the two individuals of $\mathrm{B}$ (No. 43) in which the bundles are as thick as in the original description of C. japonica var. asamusi given by Oka (1931b, fig. B). No correlation between the distribution of rooty test processes and the arrangement of mantle muscle bundles. Ciliated groove C-shaped opened anteriorly; about 50 or more tentacles, usually roughly of two sizes alternating fairly regularly. Number of inner longitudinal vessels and transverse rows of infundibula in some specimens are:

$\begin{array}{lcc}\text { Body length } & \text { Number of vessels } & \begin{array}{c}\text { Number of rows of } \\ \text { infundibula } \\ \text { unknown }\end{array} \\ 7 \mathrm{~mm}(\mathrm{I}-2) & 21(\mathrm{~L}) ; 22(\mathrm{R}) & \text { do. } \\ 8 \mathrm{~mm}(\mathrm{~N}) & 28 ; 25 & \text { do. } \\ 9.5 \mathrm{~mm}(\mathrm{I}-2) & 23(?) ; 26 & \text { do. } \\ 18.3 \mathrm{~mm} \text { (A) } & 28 ; 30 & 26 \\ 21 \mathrm{~mm}(\mathrm{~F}-1) & 25 ; 27 & \text { about } 30 \\ 27 \mathrm{~mm} \text { (B) } & 26 ; 28 & 27 \\ 28 \mathrm{~mm} \text { (I-2) } & 27 ; 29 & \text { unknown } \\ 31 \mathrm{~mm} \text { (A) } & 29 ; 31 & \end{array}$




$\begin{array}{llr}37 \mathrm{~mm} \mathrm{(A)} & 26 ; 30 & \text { about } 33 \\ 42.5 \mathrm{~mm}(\mathrm{~B}) & 32 ; 34 & \text {. about } 30\end{array}$

Remarks. Oka (1931b) established a new local variety asamusi of Corella japonica on the specimens from Mutsu Bay; the distinguishing features of this variety are the larger body (up to $45 \mathrm{~mm}$ long), the branched projections of test well developed, the subterminal branchial aperture, the beautifully orange red mantle on the left side, and the very well developed mantle musculature (consisting of much thicker bundles). Of the mentioned features, only those of the test projections and the mantle musculature seem significant taxonomically and therefore, reconsidered in the present study. As described above, the test projections are highly varied even among different specimens from Mutsu Bay, and the muscle bundles are not always so thick as given in the original description of var. asamusi even in the specimens from the bay. Nevertheless, according to Herdman's (1882) detailed description of the type specimens of the nominotypical form collected from off Kobe and Yokohama, Japan, as well as from Hong Kong, these specimens also have "hair-like branched processes -- here and there at the edges and the lower surface" of test ( $p$. 191 ; also see fig. 1 of pl. 26), and the "extraordinarily developed" mantle musculature over the whole left side and on the intersiphonal area (p. 191; fig. 2 of pl. 2). The musculature of Herdman's specimens is similar to those from Hakodate and described and figured as C. japonica by Ritter (1913) or as C. japonica var. asamusi by Tokioka $(1967 \mathrm{c})$, and probably also to those from Matsushima Bay and described as C. japonica var. asamusi by Tokioka (1960a). Thus, the local variety asamusi is amalgamated into the nominotypical form of $C$. japonica.

As described above, in the specimens from localities outside Mutsu Bay and Wakasa Bay, the posterior part of the left mantle wall often completely lacks muscle bundles (see Fig. 19, B). According to Nishikawa's unpublished data, based upon numerous specimens dredged in Tokyo Bay, the posterior one-third of mantle body is usually devoid of muscle bundles; in these specimens, the test surface has only minute papillae carrying some sand grains, but lacks the prominent rooty processes seen in those from other localities around Japan (see above). The mantle musculature of the specimens from Tokyo Bay is similar to Tokioka's (1953c) specimens from Sagami Bay (except the smallest one of them); in his specimens "a few groups of muscle bands run transversely or obliquely in the anterior half on the left side of the body" (p. 232). Such a sparse distribution of mantle muscles is also seen in the specimens from Suruga Bay and Ise Bay described by Tokioka (1967c) and from off Goto Isls by Millar (1975), in contrast to the above-mentioned dense musculature in the specimens from Hakodate, Mutsu Bay, Toyama Bay (in some specimens), Wakasa Bay, Matsushima Bay, Yokohama and off Kobe, Japan, and from Hong Kong. Thus, $C$. japonica may have a tendency that the mantle musculature becomes reduced especially in the posterior part of the body in individuals inhabiting warmer waters, as already suggested by Tokioka \& Nishikawa $(1975$, p. 334) and Nishikawa \& Tokoika (1976a, p. 393). 
Distribution in Japan Sea. Hakodate, 11.5-15.5 fms (Ritter, 1913; Tokioka, 1967c); Mutsu Bay (Oka, 1931b, 1935; in the present study); Oga Pen., 89-90 m (Nishikawa, 1984b; in the present study); Toyama Bay, 36-45 $\mathrm{m}$ and Tsukumo Bay, $25 \mathrm{~m}$ (in the present study); Wakasa Bay, 70-160 m (Hartmeyer, 1906; in the present study); off Amino-cho, Kyoto Pref., 30-122 m (in the present study); Oki Isls, 35-45 m (Nishikawa, 1986b; in the present study).

Distribution outside Japan Sea. Japan: Onagawa Bay, 5-10 m (Hartmeyer, 1906); Matsushima Bay (Tokioka, 1960a); Tokyo Bay, $20 \mathrm{~m}$ (Hartmeyer, 1906; Nishikawa's unpublished data); Yokohama (Herdman, 1882; Traustedt \& Weltner, 1894); Sagami Bay, 4 fms-120 m (Tokioka, 1953c); off Ose-zaki, Suruga Bay, 48$60 \mathrm{fms}$ and off Noma-saki, Ise Bay, $13 \mathrm{fms}$ (Tokioka, 1967c); Sugashima Is., Ise Bay (Nishikawa, 1980b); Kobe, Osaka Bay, 8-50 fms (Herdman, 1882); off Goto Isls, $32^{\circ} 21^{\prime} \mathrm{N}$ and $128^{\circ} 71^{\prime} \mathrm{E}, 174-201 \mathrm{~m}$ (Millar, 1975); Amami Isls, 3-5 m (Nishikawa \& Tokioka, 1976a); Ishigaki Is., about $1 \mathrm{~m}$ (Tokioka \& Nishikawa, 1975); Hong Kong, 10 fms (Herdman, 1882); Tonking Bay (Gurjanova, 1972); Gulf of Thailand (Dawydoff, 1952); Bay of Batavia (=Djakarta), 12 fms (Sluiter, 1890); New Caledonia (Vasseur, 1967a); Ponape Is., $0 \mathrm{~m}$ (Nishikawa, 1984a); Fiji (Kott, 1981); Sansibar (Traustedt \& Weltner, 1894; for the validity see Michaelsen, 1918).

\section{Chelyosoma siboja Oka, 1906}

(Fig. 20, A-B; Tab. 6)

Chelyosoma siboja Oka, 1906, pp. 51-52; 1928b, fig. D; 1935, pp. 460-461, fig. 30; Nishikawa, 1984b, p. 150.

Chelyosoma dofleini: Rho, 1971, p. 112; 1975, p. 133.

Tokioka's (1967c) Chelyosoma siboja is excluded, moved to the synonymy of C. dofleini.

Material examined: B: No. 110(M502), collected from Seogwipo, Cheju Is., Korea Strait on Aug. 12, '13, two individuals, $70 \mathrm{~mm}$ and $60 \mathrm{~mm}$ in disk length; No. N21, collected at Zenibako, Hokkaido, on Mar. 23, '12, an individual, $58 \mathrm{~mm}$ in disk length. C-1 (Hokkaido): Senposhi, Rishiri Is., 2-4 $\mathrm{m}$ deep, 2 individuals, $66 \mathrm{~mm}$ and $68 \mathrm{~mm}$ in disk length; Ofuyu, 1-3 $\mathrm{m}$, an individual, 50 $\mathrm{mm}$ in disk length; Shukutsu, Otaru, 1-4 m, 23 individuals, 14-54 mm in disk length. C-2 (Mutsu Bay): Kaizaki, SW end of Shimokita Pen., 15-20 m, 27 individuals, 4.5-75 $\mathrm{mm}$ in disk length, smaller ones on the surface of larger ones; from buoys off Moura, an individual, $9 \mathrm{~mm}$ in disk length. E-1 (Wakasa Bay): an individual, $27 \mathrm{~mm}$ in disk length. $\mathrm{M}$ (Oga): St. A-12, 48-52 $\mathrm{m}$, an individual, $16.5 \mathrm{~mm}$ in disk length; already listed by Nishikawa (1984b).

Remarks. In the general features the present specimens are consistent weil with the previous descriptions of this species, except that given by Tokioka (1967c) based on a single specimen collected from Otaru, which should be referred to C. dofleini Hartmeyer (see below). Thus, the specimens examined in the present study are identified with C. siboja Oka. C. dofleini of Rho $(1971,1975)$ is undoubtedly assignable to $C$. siboja, because her specimens bear the horny plates on the disk (=siphonal area) arranged in the manner characteristic of $C$. siboja; in her specimens with a single central plate, up to 7 intermediate ones and 21-22 marginal ones. 

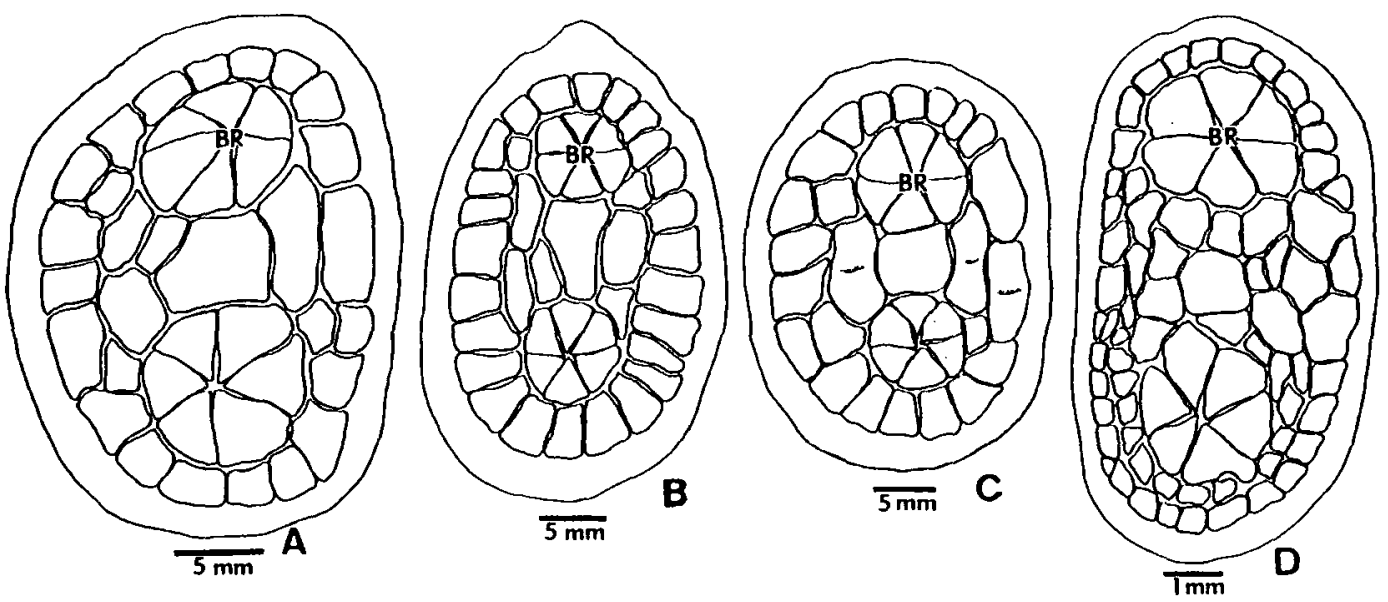

Fig. 20. Siphonal areas of Chelyosoma spp., top view. A-B. C. siboja Oka; C. C. yezoense Oka; D. Chelyosoma species. A. from Wakasa Bay (Collection E-1); B. from Otaru, Hokkaido (C-1); C. from Rishiri Is. (C-1); D. from Esashi, Hokkaido $(\mathrm{C}-1)$. BR: branchial aperture.

The patterns taken by the horny plates may be noteworthy among the specimens examined in the present study. The commonest and therefore typical pattern consists of a single rectangular central plate (abbreviated here as CP) located between the siphons which each armored with 6 triangular siphonal plates (SPs), 4 larger intermediate plates (LIPs), 2 plates on each side of CP, 0-3 small intermediate plates (SIPs) set in each of 4 deformed triangular areas surrounded by SPs, LIPs and some marginal plates, and a single row of marginal plates (17?-25 in total number). This pattern is the same as that figured by Oka (1928b, fig. D). In some specimens, however, the pattern may deviate slightly from the typical one as follows: (a) two LIPs on the right side of CP fused into a single plate, and/or (b) the CP divided into two pieces, one is much larger than the other that is almost always cornered (Fig. $20, \mathrm{~A}-\mathrm{B})$. The percentage of deviated specimens in each collection is: $0 \%$ in $\mathbf{B}$, $12 \%$ in $\mathrm{C}-1,21 \%$ in $\mathrm{C}-2,100 \%$ in $\mathrm{E}-1$, and $0 \%$ in $\mathrm{M}$. The patterns of plate arrangement in some of the examined specimens are shown in Tab. 6.

The deviated form-(a) resembles C. yezoense, if two LIPs on the left side in the former were also fused into a single plate, while the form-(b) is seemingly similar to C. dofleini, if the CP in this form were divided more equally into two longitudinally elongated pieces (for either species see below). This suggests that C. siboja, C. yezoense and $C$. dofleini are very closely related to, or possibly conspecific with one another. However, these three species are distinguishable clearly from all the other known species of this genus. Further discussions on this problem remain pending for future studies.

Distribution in Japan Sea. Rishiri Is., 2-4 $\mathrm{m}$ and Ofuyu, 1-3 $\mathrm{m}$ (in the present study); Otaru, 1-4 $\mathrm{m}$ and Zenibako (Oka, 1906; in the present study); Mutsu Bay, down to $20 \mathrm{~m}$ (Oka, 1906, 1935; in the present study); Oga Pen., 48-52 m (Nishikawa, 1984b; in the present study); Wakasa Bay, shallow (in the present study); 
Table 6. Variations in horny plate arrangement around the siphonal area in Chelyosoma siboja Oka from the Japan Sea

\begin{tabular}{|c|c|c|c|c|c|c|c|}
\hline \multirow[t]{2}{*}{ Material } & \multirow{2}{*}{$\begin{array}{c}\text { Disk } \\
\text { Length } \\
(\mathrm{mm})\end{array}$} & \multicolumn{4}{|c|}{ Number of SIPs* on } & \multirow{2}{*}{$\begin{array}{c}\text { Number of } \\
\text { marginal } \\
\text { plates }\end{array}$} & \multirow{2}{*}{ Pattern** } \\
\hline & & $\begin{array}{l}\text { left side } \\
\text { of } B R^{*}\end{array}$ & $\begin{array}{l}\text { right side } \\
\text { of BR* }\end{array}$ & $\begin{array}{l}\text { left side } \\
\text { of AT* }\end{array}$ & $\begin{array}{l}\text { right side } \\
\text { of } \mathrm{AT}^{*}\end{array}$ & & \\
\hline B & 58 & 1 & 0 & 0 & 0 & 20 & $N$ \\
\hline \multirow{11}{*}{$\mathrm{C}-1$} & 14 & 0 & 1 & 0 & 0 & $25(?)$ & $\mathrm{N}$ \\
\hline & 17 & 0 & 2 & 0 & 1 & $23(?)$ & $\mathbf{N}$ \\
\hline & 29 & 1 & 1 & 1 & 0 & $17(?)$ & $\mathrm{N}$ \\
\hline & 30 & 1 & 1 & 0 & 0 & 22 & $\mathbf{N}$ \\
\hline & 36 & 1 & 0 & 0 & 1 & 20 & $N$ \\
\hline & 37 & 1 & 1 & 0 & 1 & 25 & $D-(a)(b)$ \\
\hline & 40 & 0 & 0 & 0 & 0 & 19 & $\mathrm{~N}$ \\
\hline & 45 & 0 & 1 & 0 & 0 & 22 & $\mathrm{~N}$ \\
\hline & 50 & 1 & 0 & 1 & 1 & 20 & $\mathrm{~N}$ \\
\hline & 54 & 0 & 0 & 1 & 1 & 21 & D-(a) \\
\hline & 66 & 1 & 0 & 1 & 1 & 24 & $\mathrm{~N}$ \\
\hline \multirow{11}{*}{$\mathrm{C}-2$} & 7 & 1 & 1 & 0 & 1 & $24(?)$ & D-(b) \\
\hline & 7 & 1 & 1 & 1 & 1 & 24 & D-(b) \\
\hline & 7.5 & 1 & 0 & 0 & 0 & 24 & $D \cdot(b)$ \\
\hline & 9 & 1 & 0 & 0 & 0 & 24 & $\mathrm{~N}$ \\
\hline & 11 & 1 & 0 . & 1 & 1 & 21 & $\mathrm{~N}$ \\
\hline & 45 & 0 & 0 & 0 & 0 & $21(?)$ & $\mathbf{N}$ \\
\hline & 47 & 0 & 0 & 0 & 0 & 20 & D-(a) \\
\hline & 50 & 1 & 1 & 1 & 1 & 22 & $\mathrm{~N}$ \\
\hline & 56 & 1 & 1 & 0 & 1 & 24 & D-(a) \\
\hline & 60 & 1 & 0 & 0 & 1 & 24 & $\mathbf{N}$ \\
\hline & 7.5 & 3 & 1 & 2 & 2 & 23 & $\mathrm{~N}$ \\
\hline $\mathrm{E}-1$ & 27 & 1 & 0 & 1 & 1 & 20 & $\mathrm{D}-(\mathrm{a})(\mathrm{b})$ \\
\hline $\mathrm{M}$ & 16.5 & 0 & 0 & 0 & 0 & 21 & $\mathrm{~N}$ \\
\hline
\end{tabular}

*) SIP: small intermediate plate, BR: branchial siphon and AT: atrial siphon.

**) $\mathrm{N}$ means normal and D deviated; for detail see the text.

eastern coast of Korea and Korean coastal waters facing Korea Strait (Rho, 1971, 1975); Cheju Is. (in the present study).

Distribution outside Japan Sea. Unknown.

\section{Chelyosoma dofleini Hartmeyer, 1906}

Chelvosoma dofleini Hartmeyer, 1906, pp. 22-24; Oka, 1928b, fig. F; Tokioka, 1953c, pp. 234-235, pl. 40, figs 4-6, text-fig. 13.

Chelyosoma siboja: Tokioka, 1967c, p. 150, fig. 58.

Rho's (1971, 1975) C. dofleini is moved to the synonymy of $C$. siboja. 
Material examined: C-1 (Hokkaido): Shukutsu, Otaru, 1-4 $\mathrm{m}$ deep, 2 individuals, $13 \mathrm{~mm}$ and $29 \mathrm{~mm}$ in disk length. C-2 (Mutsu Bay): Kaizaki, SW end of Shimokita Pen., 15-20 m, 2 individuals, $7.5 \mathrm{~mm}$ and $57 \mathrm{~mm}$ in disk length, the smaller attached to the test surface of $C$. siboja.

Remarks. These specimens, especially the largest, were, at a glance, indistinguishable from $C$. siboja, but the detailed examination revealed that the specimens are quite different from $C$. siboja in the arrangement of horny plates on the disk. Arrangements in the present specimens are: in the specimen of $7.5 \mathrm{~mm}$ in disk length, 2 central plates (CPs) +4 (on the left side) -3 (on the right) intermediate plates (IPs), of which two plates are much larger than the rest on each side +25 marginal plates (MPs); in the specimen with $13 \mathrm{~mm}$ long disk, $2 \mathrm{CPs}+3-2 \mathrm{IPs}+25 \mathrm{MPs}$; in the specimen with $29 \mathrm{~mm}$ long disk, $2 \mathrm{CPs}+3-3 \mathrm{IPs}+24 \mathrm{MPs}$; and in the individual with $57 \mathrm{~mm}$ long disk, 2 CPs +4-3 IPs +21 MPs. Marginal ridge of the siphonal area is distinctly developed even in the smallest specimen. These specimens resemble an individual collected from Otaru and referred to $C$. siboja by Tokioka (1967c); in his specimen the plate arrangement is 2 CPs $+3-3$ IPs +23 MPs. In the paired CPs accompanied on each side by IPs, all the above-mentioned specimens from the Japan Sea are quite similar to the previous descriptions of $C$. dofleini inclusive of the original, on the basis of the specimens from Sagami Bay. However, these Japan Sea specimens are somewhat different from the descriptions of $C$. dofleini in the number of MPs (21 to 25 in these specimens, instead of 15 to 19 in the descriptions) and in the development of marginal ridge (remarkable, instead of indistinct, according to the figs 4-6 of pl. 40 of Tokioka, 1953c), as well as in the bathymetrical distribution (down to $20 \mathrm{~m}$, instead of about $100 \mathrm{fms}-350 \mathrm{~m}$ ). These differences might suggest the possible occurrence of some differentiation of the Japan Sea population from that of the Pacific coast of Japan, but further considerations may be left pending here for the future studies on the basis of more specimens from different localities. In the present study, the present specimens from the Japan Sea are assigned to $C$. dofleini, based on the general similarity in the plate arrangement between these two.

Distribution in Japan Sea. Otaru, 1-4 m (Tokioka, 1967c; in the present study); Mutsu Bay, 15-20 m (in the present study).

Distribution oulside Japan Sea. Sagami Bay, about $100 \mathrm{fms}-350 \mathrm{~m}$ (Hartmeyer, 1906; Tokioka, 1953c).

\section{Chelyosoma yezoense Oka, 1928}

(Fig. 20, C)

Chelyosoma yezoense Oka, 1928b, pp. 397-399, fig. C.

Material examined: C-1 (Hokkaido): Senposhi, Rishiri Is., 2-4 m, an individual of $60 \mathrm{~mm}$ long in disk length; Kutsugata-misaki, Rishiri Is., $1-4 \mathrm{~m}$, an individual, $32 \mathrm{~mm}$ in disk length; Shukutsu, Otaru, 1-4 $\mathrm{m}$, an individual, $45 \mathrm{~mm}$ in disk length.

Remarks. The arrangement of horny plates on the siphonal area in the larger 
two specimens is 1 central plate (CP) +2 intermediate plates (IPs) $+18-19$ marginal ones (MPs), two of the MPs along respective IPs are larger than the rest, while in the smallest specimen, the plates composed of $1 \mathrm{CP}+3$ (on the left) or 2 (on the right) IPs +19 MPs (Fig. 20, G). In the last-mentioned specimen, 2 larger plates of 5 IPs and the MP along the right IPs are furnished each with a short transverse furrow in the center of respective plates (Fig. 20, C). The larger two specimens in the present material are consistent with the original description of $C$. yezoense, while the smallest differs from that mainly in the existence of additional (small) IPs only in the former specimen. This difference may, however, be of little taxonomic significance, as shown above in the variation of plate arrangment of $C$. siboja. Thus, all the three specimens from the Japan Sea are safely referable to C. yezoense.

Distribution in Japan Sea. Rishiri Is., 1-4 m and Otaru, 1-4 m, Hokkaido (in the present study).

Distribution outside Japan Sea. Iburi District, Pacific coast of Hokkaido (Oka, $1928 \mathrm{~b})$.

84. Chelyosoma orientale Redikorzev, 1911

Chelyosoma orientale Redikorzev, 191 1b, pp. 146-150, figs 5-7 and 9; 1941, p. 198; Hartmeyer, 1924, p. 9.

Material examined: None.

Distribution in Japan Sea. Mamiya (=Tatarskiy) Strait, 62-80 m deep (Redidorzev, 1911b, 1941).

Distribution outside Japan Sea. Sea of Okhotsk, 20-182 m deep, Bering Sea, 36$53 \mathrm{~m}$ and Chukchi Sea, 18-45 m (Redikorzev, 1941); SE end of Sakhalin, $52 \mathrm{fms}$ (Nishikawa's unpublished data).

85. Chelyosoma macleayanum Broderip et Sowerby, 1830

Chelyosoma macleayanum Broderip \& Sowerby, 1830, p. 46, pl. 3, figs 4-6.

For other synonyms see Van Name (1945).

Material examined: None.

Distribution in Japan Sea. Sovetskaya Gavan', Mamiya (=-Tatarskiy) Strait (Redikorzev, 1941).

Distribution outside Japan Sea. Arctic to boreal waters in the world, 1-565 m deep (see Huus \& Knudsen, 1950, p. 11).

\section{Chelyosoma sp.}

(Fig. 20, D)

Material examined: C-1 (Hokkaido): Kamomejima Is., Esashi, an individual found attached 
to undersurface of stone, $1 \mathrm{~m}$ deep; siphonal area is $9 \mathrm{~mm} \times 5 \mathrm{~mm}$ in extent, the body $6.5 \mathrm{~mm}$ tall.

Remarks. The arrangement of horny plates on the siphonal area is shown in Fig. 20, D. Longitudinal vessels complete; 28 ones on the left and 31 on the right. Gonad immature. This specimen is unique in the larger number of plates and their complicated arrangement, and therefore, might possibly represent a new species, though treated here merely as Chelyosoma sp. Detailed considerations on the affiliation of this specimen is kept pending in the present study for future studies until more specimens are obtained.

Distribution in Japan Sea. Esashi, Hokkaido, about $1 \mathrm{~m}$ (in the present study). No other localities are yet known.

Family Octacnemidae

\section{Megalodicopia hians Oka, 1918}

Megalodicopia hians Oka, 1918, pp. 399-406, figs 1-2; Tokioka, 1953c, pp. 235-236, pl. 41, figs 1-7, text-fig. 14; Kott, 1969b, pp. 88-89, figs 117-118.

Material examined: None.

Distribution in Japan Sea. NE off Sado Is., $38^{\circ} 35^{\prime} \mathrm{N}$ and $138^{\circ} 41^{\prime} \mathrm{E}, 200 \mathrm{fms}$ deep (Oka, 1918).

Distribution outside Japan Sea. Sagami Bay, $350 \mathrm{~m}$ (Tokioka, 1953c); Weddell Sea in the Antarctic, 810-1555 m (Kott, 1969b); and ?Peru-Chile Trench, 5325 $\mathrm{m}$ (do.).

Family Botryllidae

88. Botryllus primigenus Oka, 1928

Botryllus primigemus Oka, 1928a, pp. 303-305, figs A-B; Tokioka, 195la, pp. 7-8, fig. 5; 1953c, pp. 236-237, pl. 42, figs 1-4; 1954d, p. 84; 1967c, p. 151; Millar, 1958b, p. 505; Rho, 1971, p. 113 ; Nishikawa, 1980b, tab. 1.

Van Name's (1931, 1945) Botryllus primigenus excluded, moved to the synonymy of $B$. tuheratus.

Material examined: D (Tottori): several small colonies collected in Aug., '78, zooids deteriorated.

Remarks. The features of the material are: zooids brownish, up to $7 \mathrm{~mm}$ long; each siphon opening directly on the colony surface; 4 stigmatal rows on each side. Botryllus primigenus Oka has been distinguished from $B$. tuberatus Ritter et Forsyth (see below) solely by the atrial apertures always opening directly on the colony surface. The present specimens are thus assignable to $B$. primigenus. The colonies referred to $B$. primigenus by Van Name $(1931,1945)$ should be, according to his own descriptions, identified as B. tuberatus, already treated as such by C. Monniot (1983b, pp. 426-428). These two species may be conspecific, the occasional system-free zooids in $B$. tuberatus representing an intermediate state between them (see Tokioka, 1953c, 
p. 238). Some botryllids that resemble one another in colony morphology and zooids have different life histories (see, for example, Saito \& Watanabe, 1985). A taxonomic revision of these species must remain pending until comparative studies are made on their life histories; that of $B$. primigenus has been accumulated by Watanabe and his coworkers in Shimoda, while that of $B$. tuberatus doesn't seem to have been pursued. At present, Van Name's records mentioned above are excluded from the synonymy of $B$. primigenus, and transferred to that of $B$. tuberatus (see below).

Distribution in Japan Sea. Tottori, $0 \mathrm{~m}$ (in the present study); Japan Sea coast of Korea and Korean coastal waters facing Korea Strait (Rho, 1971).

Distribution outside Japan Sea. Akkeshi, Hokkaido (Tokioka, 1951a); Tateyama (Oka, 1928a); Sagami Bay (Tokioka, 1953c); Ise Bay (Nishikawa's unpublished data); Kii Peninsula (Nishikawa, 1980b); Osaka Bay (Tokioka, 1954c); Usa, Kochi Pref. (Nakauchi, 1973); Amoy, China (Tokioka, 1967c); Palao (do.); Brazil (Millar, 1958).

\section{Botryllus tuberatus Ritter et Forsyth, 1917}

Botryllus tuberatus Ritter \& Forsyth, 1917, p. 461, pl. 39, figs 10 \& 12, pl. 40, fig. 22.

Botrylloides eligulatum Beniaminson, 1975, pp. 41-42, figs 6-8; 1976, p. 124, fig. 286. New Synonymy.

For other synonyms see C. Monniot (1983b).

Material examined: C-1 (Hokkaido): Ofuyu, 1-3 m, 9 colonies; Shukutsu, Otaru, 1-4 m, 3 colonies; Chazu, Bikuni, 3-5 m, 4 colonies; Yobetsu, 1-3 m, 2 colonies; Muenjima coast and Yaemonmisaki, Okushirijima Is., 2-3 m, 10 colonies; Kamomejima, Esashi, 1-7 m, 6 colonies. C-2 (Mutsu Bay): Kaizaki, SW end of Shimokita Pen., 15-20 m, 1 colony; Oura, near Asamushi, $0 \mathrm{~m}, 1$ colony. C-8 (Oki): Ooku, Dogo Is., $3 \mathrm{~m}, 2$ colonies.

Remarks. The features of the present material are: in life the ventral half or more of the anterior part of zooids facing colony surface pigmented dark brown, while the remaining half pale or bright yellow, except in the zooids from Ofuyu that appeared uniformly yellowish; after preservation, the whole zooid dark brown, or rarely pale yellow; the largest colony is approximately $65 \mathrm{~mm} \times 25 \mathrm{~mm}$ in extent and up to $1.3 \mathrm{~mm}$ thick; systems usually distinct, consisting of up to a dozen or more zooids; in mature colonies from Bikuni the ovary containing a single ovum, up to 350 $\mu \mathrm{m}$ in diameter, while the testis comprising a single oval or roundish follicle, as illustrated by Tokioka (1951 b, fig. 3).

Botrylloides eligulatum Beniaminson collected from $1.5 \mathrm{~m}$ in Possjet Bay, Peter the Great Bay, is, according to the original description, characterized as follows: zooids arranged in stellate or oval systems around common cloacal apertures; atrial siphon formed completely and remarkably, without any languet; 4 stigmatal rows; pyloric coecum prominent; rectum fairly long; a single large egg in the prominent incubatory pouch on each side; testis undescribed. In these features except for the elongated rectum, the present species resemble Botryllus tuberatus. The elongated rectum in Beniaminson's species is unique among the botryllids with 4 stigmatal rows, but this feature doesn't seem to me very significant taxonomically. Though in $B$. 
tuberatus an incubatory pouch has been reported only very rarely (see, for example, C. Monniot, 1983b), it is well known in the closely related $B$. primigenus (see, for example, Mukai \& Watanabe, 1976, p. 339). If the testis can be observed in Beniaminson's species, its relative position to the ovary may prove the valid affiliation of the present species to the genus Botryllus. Consequently $B$. eligulatum is here included in the synonymy of $B$. tuberatus.

Distribution in Japan Sea. Peter the Great Bay, 0-75 m (Redikorzev, 1941; Beniaminson, 1975, 1976); western coast of South Sakhalin (Skalkin, 1959); Ofuyu, Otaru, Bikuni, Yobetsu, Okushirijima Is. and Esashi, Hokkaido, 1-7 m and Mutsu Bay, down to $20 \mathrm{~m}$ (in the present study); Sado (Tokioka, 1962a); Oki Isls, $3 \mathrm{~m}$ (in the present study); Japan Sea coast of Korea and Korean coastal waters facing Korea Strait (Rho, 1971, 1975).

Distribution outside Jafian Sea. Akkeshi, Hokkaido (Tokioka, 195la), Sagami Bay, down to 3-5 fms (Tokioka, 1953c), around Kii Pen., to $4 \mathrm{~m}$ (Nishikawa, 1980b), Osaka Bay (Tokioka, 195lb, 1954c), Seto Inland Sea (Tokioka, 1953a) and Usa, Kochi Pref. (Nakauchi, 1973), Japan; Korean shores facing the Yellow Sea (Rho, 1971, 1975); Jiaozou Bay (Ger \& Zan, 1983) and probably Amoy (Tokioka, 1967c), China; Palao and Gilbert (Tokioka, 1967c); Truk, 1-7 m (Nishikawa, 1984a); Banda Sea, $20 \mathrm{~m}$ (Millar, 1975); W and NE Australia (Kott, 1985); Southern California (Ritter \& Forsyth, 1917; Van Name, 1945); Florida, very shallow waters (Van Name, 1931, 1945); Guadeloupe, West Indies (C. Monniot, 1983b).

\section{Botryllus schlosseri (Pallas, 1766)}

Alcyonium schlosseri Pallas, 1766, p. 355.

Botryllus schlosseri: Savigny, 1816, p. 200, pl. 20, fig. 5.

For other synonyms see Van Name (1945).

Material examined: C-2 (Mutsu Bay): from buoys off Moura, 6 colonies, the largest $45 \mathrm{~mm} \times$ $25 \mathrm{~mm}$ in extent and $2 \mathrm{~mm}$ thick, some from surface of Styela clava.

Description. Systems stellate, consisting of about 12 zooids $2 \mathrm{~mm}$ long and pale brownish. A dozen(?) tentacles. Seven stigmatal rows on the left and 8 on the right; second row incomplete. Stigmata arranged between 3 longitudinal vessels on each side as: D. 8-4-4-3 or 4 V. Stomach with 8 plications; pyloric coecum prominent. Second loop very shallow and wide; rectum short. In each side of peribranchial cavity 3 or 4 embryos are present dorsal to rather extensive testis situated near the endostyle and composed of 5 to 8 follicles; ovidual cups discernible. Sometimes several tailed larvae also in the cavity; about $400 \mu \mathrm{m}$ in trunk length and with 8 ampullae.

Remarks. The present specimens resemble the previous descriptions of $B$. schlosseri especially in the stellate arrangement of zooids, the existence of ovidual cups and 8 larval ampullae. By these features, this species is distinguishable from $B$. sexiens Saito et Watanabe and B. scalaris Saito et Mukai (see Saito, Mukai \& Watanabe, 
1981a). As shown below, B. schlosseri has very wide geographic distribution, so the present species may actually consist of two or more different taxa.

Distribution in Japan Sea. Peter the Great Bay, 15 m (Redikorzev, 1941); western coast of South Sakhalin (Skalkin, 1959); Otaru, Hokkaido (Tokioka, 1951a); Mutsu Bay, $0 \mathrm{~m}$ (Saito, Mukai \& Watanabe, 1981a; in the present study); Sado Is. (Tokioka, 1967b); Cheju Is., Korea Strait (Rho, 1971).

Distribution outside Japan Sea. Akkeshi, Hokkaido (Tokioka, 195la); Sagami Bay (Tokioka, 1953c); Mikawa Bay, $0 \mathrm{~m}$ (Nishikawa's unpublished data); Tanabe Bay, Kii Pen., down to $1 \mathrm{~m}$ (Nishikawa, 1980b) ; Jiaozou Bay (Ger \& Zan, 1983) and Hong Kong, $2 \mathrm{~m}$ (Kott \& Goodbody, 1980), China; Australia (Kott, 1952, 1972a, b, 1985); New Zealand (Brewin, 1946, 1948; Millar, 1982b); Indian coast of Africa (Millar, 1955); Chile (Van Name, 1954); Atlantic coast of USA (Van Name, 1945); Atlantic coast of Africa (Pérès, 1949, 1951); "Widely distributed in European waters, from the Faeroe Islands and western and southern Norway to the Mediterranean, Adriatic and Black Seas" (Berrill, 1950, p. 217; many subsequent records from that region are omitted here for brevity).

\section{Botryllus magnicoecus (Hartmeyer, 1912)}

Botrylloides nigrum var. magnicoecum Hartmeyer, 1912, p. 271, pl. 41, fig. 11.

Botryllus magnicoecus: Michaelsen, 1915, p. 419.

Psammobotrus purpureus Oka, 1932a, pp. 102-104, figs A-B. New Synonymy.

For other synonyms see Tokioka (1967c) and Nishikawa (1984a); Kott's (1985) Botryllus purpureus and Kott's (1985) Botrylloides magnicoecum are excluded.

Material examined: B: No. 188, labeled Snabotrus purpureus by Oka, collected in Oma, NW end of Shimokita Pen., facing Tsugaru Strait, by Hozawa, Takatsuki and Sato, on Aug. 18, '27, a single colony, $25 \mathrm{~mm} \times 15 \mathrm{~mm}$ in extent and up to $3 \mathrm{~mm}$ thick, on Amphiroa sp.

Description. Test rather tough, somewhat leathery, translucent and white; the surface densely coated, though never impregnated with, sand grains. Zooids up to $3.5 \mathrm{~mm}$ long, provided densely with reddish purple pigment, and arranged in stellate systems. Eleven to 13 stigmatal rows; second row complete. Stomach furnished with 12 plications; pyloric coecum curved and prominent. Second intestinal loop wide and shallow; rectum elongated. In larger zooids, 1 or 2 tailed but unhatched larvae, up to $250 \mu \mathrm{m}$ in long diameter, rarely seen anterior to the testis that is very extensive, occupying roughly the whole second loop and consisting of about 7 follicles; ovidual cups indiscernible. In much smaller zooids, about $700 \mu \mathrm{m}$ long, up to 5 eggs discerned anterior to the testis on each side.

Remarks. The present specimen is identical with $B$. magnicoecus especially in the rather thick colony, the stellate arrangment of zooids, elongated rectum and extensive testis (see, for example, Tokioka, 1967c, pp. 153-155). These features, except the last-mentioned one, resemble the original description of Psammobotrus purpureus Oka established on the colonies from Tateyama, Japan; the description lacking the 
detailed information about the testis. My reexamination of material probably representing the type series, deposited at OCUT (Nos. 56 (S197), 171(S397), 172(S402) and $255(\mathrm{~S} 408)$ ), revealed that $P$. purpureus may be regarded as a junior synonym of B. magnicoecus. The material No. 56 consists of 4 colonies (the collection data unknown); Nos. 171 and 172 respectively of a single colony collected in Tateyama on Apr. 14-27, 1913 and No. 255 comprising a single colony from Tateyama on May $3-10,1928$. The features of these materials are: the largest colony $80 \mathrm{~mm} \times 46$ $\mathrm{mm}$ in extent and $8 \mathrm{~mm}$ thick; the thickest up to $13 \mathrm{~mm}$ thick; test sparsely or moderately coated over the whole surface, and sometimes sparsely impregnated with sand grains; 13 to 16 stigmatal rows, though only 12 ones in the original description of $P$. purpureus; second row complete; 10 to 12 stomach plications; in the larger zooids, testis very small and immature, while in very small ones, less than $1 \mathrm{~mm}$ long, testis composed of about 7 follicles occupying nearly the whole second intestinal loop; in the latter zooids, a single ovum also discerned anterior to the testis. Clearly the examined specimens of $P$. purpureus fall within the variation range of $B$. magnicoccus.

Kott (1985) identified the material from West Australia as Botryllus purpureus (Oka). Her material seems different from the probable type specimens of Psammobotrus purpureus mentioned above especially in the test ("full of embedded sand" in the former, instead of sometimes impregnated sparsely with sand in the latter) and in the number of stigmatal rows (7, instead of 13 to 16). These differences might be of taxonomic significance, and therefore it is tentatively excluded here from the synonymy of $B$. magnicoecus.

Botrylloides magnicoecum Hartmeyer reported by Kott (1985) from Australia resembles Botryllus magnicoecus in the present study in many significant features inclusive of those seen in the branchial and gonadal structures. However, in Kott's material, "as the colonies develop, the common cloacal apertures are raised on the top of large conical elevations--" (Kott, p. 276), which may be peculiar to the Australian population as noted by Kott (p. 277). This remarkable peculiarity makes me reluctant to include this record in the synonymy of Botryllus magnicoecus.

Distribution in Japan Sea. Tsugaru Strait (in the present study); Korean coastal waters facing Korea Strait (Rho, 1971, 1975).

Distribution outside Japan Sea. Tateyama (Oka, 1932), Sagami Bay, down to 3$5 \mathrm{fms}$ (Tokioka, 1953c) and the western coast of Kii Pen., 0-4 m (Nishikawa, 1980), Japan; further, according to Nishikawa (1984a), China, Truk and Majuro, to $15 \mathrm{~m}$, Australia, New Zealand, India, as well as East, South and SW Africa.

\section{* Botryllus sp.}

Botrillus [sic] sp.: Beniaminson, 1971, p. 319.

Recorded by Beniaminson from Possjet Bay; its exact affiliation is not possible for the complete lack of description. 


\title{
92. Botrylloides violaceus Oka, 1927
}

\author{
sensu Saito, Mukai et Watanabe, 1981
}

\begin{abstract}
Limited synonymy: Since the work of Saito, Mukai \& Watanabe (1981b) appeared, taxonomic accounts now always try to include life history and larval morphology. Thus, many previous records of "Botrylloides violaceus" must be excluded here, whose descriptions lack information about these diagnostic features.

Botrylloides violaceus: Tokioka, 1953c, pp. 241-243, pl. 3, figs 1-2, pl. 44, figs 1-5, pl. 45, figs 1-4; 1962a, pp. 12-13, pl. 3, fig. 22 (part); 1967b, p. 243; Takeuchi, 1980, pp. 1-5, pls 1-2; Nishikawa, 1980b, p. 108 (part); Saito, Mukai \& Watanabe, 198lb, pp. 360-364, figs 3-4, 5, b; Ger \& Zan , 1983, pp. 93-94, fig. 1 .
\end{abstract}

Material examined: B: No. 59(S339), labeled Botrylloides promiscuum by Oka, 2 colonies collected off Nakago, Mutsu Bay by Takatsuki and Sato on July 24, '27, encrusting stems of Sargassum sp. C-1 (Hokkaido): Kutsugata-misaki, Rishiri Is., 1-4 m, 3 colonies; 4 from Nishiuedomari, Rebun Is., 1-8 m; Ofuyu, 1-3 m, 4 colonies; 4 from Shukutsu, Otaru, 1-4 m; Chazu, Bikuni, 0.5-1 m, 11 colonies; Yobetsu, 1-3 m, 9; Kamomejima, Esashi, 1-7 m, 8; Yaemon-misaki, Okushiri Is., 2-3 m, 3. C-2 (Mutsu Bay): from buoys off Moura near Asamushi, 12 colonies. C-6 (Anamizu Bay): 2 colonies attached to Sargasstm sp. C-7 (Maizuru Bay): an extensive colony covering Styela clava. L-7 (Mutsu Bay): one colony.

Description. In life, the zooids reddish purple, or rarely pale yellow or white in the material from $\mathrm{C}-1$, yellowish orange in that of $\mathrm{C}-2$, or dark red in that of $\mathrm{C}-6$; usually reddish orange but rarely black in that of $\mathrm{C}-7$. The largest colony being about $200 \mathrm{~mm} \times 20 \mathrm{~mm}$ in extent; up to $4 \mathrm{~mm}$ thick. Zooids arranged in ladder systems, between which the test surface sometimes slightly elevated. Test rather soft, nearly transparent and white or dull white. Twelve to 15 stigmatal rows in the colonies from Hokkaido, 10 to 13 in those from Mutsu Bay, 12 to 14 in those from Anamizu Bay and 12 in that from Maizuru; second row incomplete. Nine to 12 stomach plications; pyloric coecum present but small. In some specimens, one or two ova, about $100 \mu \mathrm{m}$ in diameter, situated dorsoposterior to the compact testis consisting of several (in the colonies from Hokkaido and Mutsu Bay), up to 9 (in those from Anamizu), or 10 to 16 (in that from Maizuru) follicles on each side in some zooids. Many unhatched larvae included in the test of all the colonies examined; 750 to $1250 \mu \mathrm{m}$ in trunk length and provided with 24 to 35 ampullae, except in the colonies from Esashi $(\mathrm{C}-1)$ and Mutsu Bay (C-2) in which the unhatched larvae up to $750 \mu \mathrm{m}$ in trunk length and with 20 to 22 ampullae. Oozooid and precocious buds are discernible at least in larger larvae.

Remarks. Recentiy Saito ei al. (1981b) and Saito \& Watanabe (1985) reveaied that detailed observations on life history of the living colonies is indispensable for the precise classification of Botrylloides species. However, I have always had to examine dead specimens. Even under such circumstances, on the basis of the similarity in diagnostic features such as larval size and number of larval ampullae, the present specimens except those from Esashi $(\mathrm{C}-1)$ and Mutsu Bay $(\mathrm{C}-2)$ are referred to $B$. violaceus Oka sensu Saito et al. (1981b). Larval size and number of ampullae in the specimens from Esashi and Mutsu Bay mentioned above may be somewhat reminis- 
cent of $B$. lenis Saito et Watanabe that has larvae, $700 \mu \mathrm{m}$ in trunk length and having 14 to 24 ampullae (see Saito \& Watanabe, 1985, pp. 234-237 and tab. 1). With regard to these features, the specimens in question may be an intermediate form between $B$. violaceus and $B$. lenis. At present the specimens are assinged tentatively to $B$. violaceus, because they differ from $B$. lenis in the number of stigmatal rows (11 to 13 in the specimens, instead of 8 to 9 in $B$. lenis).

Distribution in Japan Sea. Rishiri and Rebun Isls, Ofuyu, Otaru, Bikuni, Yobetsu, Esashi and Okushiri Is., $0.5-8 \mathrm{~m}$ (in the present study) and Oshoro, low intertidal (Takeuchi, 1980), Hokkaido; Mutsu Bay, shallow (Saito et al., 1981b; in the present study); Sado (Tokioka, 1962a, 1967b); Anamizu Bay ,down to $1 \mathrm{~m}$ (in the present study); Maizuru, Wakasa Bay, $0 \mathrm{~m}$ (in the present study). The following records are omitted here: Hakodate (Tokioka, 1967c, pp. 158-160), Wakasa Bay (Tokioka, 1959a, p. 227) and Korean coastal waters facing Korea Strait (Rho, 1971, pp. 115-116; 1975, pp. 134-135).

Distribution outside Japan Sea. Akkeshi, Hokkaido (Tokioka, 1953c; Saito et al., 1981b); Mikawa Bay, $0 \mathrm{~m}$ (Nishikawa's unpublished data); Toshijima Is., $0 \mathrm{~m}$ (Nishikawa, 1980b; erroneously described as about $370 \mu \mathrm{m}$ in trunk length and 8 larval ampullae, but really $750 \mu \mathrm{m}$ in that length and 20 to 24 ampullae, and 11 stigmatal rows) and Iwaya, Osaka Bay (Nishikawa's unpublished data), Japan; Jiaozou Bay, Chin (Ger \& Zan, 1983).

\section{Botrylloides simodensis Saito et Watanabe, 1981}

Botrylloides sinıdensis Saito et Watanabe in Saito, Mukai \& Watanabe, 1981b, pp. 358-360, figs 1, 2, 5 a.

Material examined: B: No. 194 (S348), labeled as Botrylloides tenue by Oka, a single colony collected off Oma, NW end of Shimokita Pen., facing Tsugaru Strait, on Aug. 18, '27 by Hozawa, Takatsuki and Sato; No. 236(S326), as Botrylloides violaceus by Oka, a single small one collected in front of En-musubi-jizo, near Asamushi on July 14, '26 by Hozawa and Ito. C-1 (Hokkaido): Kamomejima, Esashi, about $1 \mathrm{~m}$, many colonies or fragments. C-8 (Oki): Tsuma, Dogo Is., 2-4 m, a colony encrusting stems of Sargassum sp.; Izanaki-ura, Nishinoshima Is., 1-3 m, 5 colonies, one of which covering Polycarpa cryptocarpa kroboja.

Description. In life the zooids orange to pale or reddish purple, and sometimes sprinkled with white pigment; after preservation, colored pinkish or purplish. The largest colony being $90 \mathrm{~mm} \times 25 \mathrm{~mm}$ in extent; up to $3 \mathrm{~mm}$ thick. Zooids up to $2.5 \mathrm{~mm}$ long, arranged in ladder systems. Eight tentacles; the larger and smaller ones alternating regularly. Twelve or 13 stigmatal rows in the colonies from Mutsu Bay, 11 or 12 in those from Esashi, 9 or 10 in those from Tsugaru Strait and Dogo, and 10 or 11 in those from Nishinoshima; second row always incomplete. Seven or 8 stomach plications except 10 in the colony from Mutsu Bay; pyloric coecum present but small. A single embryo, tailed or not, in the incubatory pouch of parent zooid on each side, situated dorsoposterior to the testis comprising up to 24 follicles; tailed embryos found only in specimens from Tsuma (C-8) and Esashi (C-1); up to $500 \mu \mathrm{m}$ and to $400 \mu \mathrm{m}$ in diameter respectively, while the untailed 200 to $250 \mu \mathrm{m}$ 
(B, No. 236), 250 to $300 \mu \mathrm{m}$ (B, No. 194), up to $280 \mu \mathrm{m}(\mathrm{C}-1)$, or $300 \mu \mathrm{m}$ (C-8). Many hatched larvae in the common cloacal cavity in colonies from $\mathrm{C}-1$, about 500 $\mu \mathrm{m}$ in trunk length and with 8 larval ampullae.

Remarks. The present specimens agree with the original description of $B$. simodensis especially in larval size and number of ampullae, though the maximal embryo size in the incubatory pouch in these specimens (up to $500 \mu \mathrm{m}$ in diameter) is larger than that in $B$. simodensis (to about $300 \mu \mathrm{m}$ ). In colonies from Esashi, embryos attain a hatched size of $500 \mu \mathrm{m}$ in trunk length, though never $800 \mu \mathrm{m}$ as in $B$. lentus Saito et Watanabe (Saito \& Watanabe, 1985, pp. 228-230). The present specimens are distinguishable from $B$. lenis also by the number of stigmatal rows (9 to 12 in the specimens, instead of 15 to 18 in $B$. lenis). Consequently the present specimens are here referred to $B$. simodensis.

Distribution in Japan Sea. Esashi, Hokkaido, about $1 \mathrm{~m}$; Tsugaru Strait; Mutsu Bay; Oki Isls, 1-4 m (in the present study); Mutsu Bay (Saito et al., 1981b).

Distribution outside Japan Sea. According to Saito et al. (1981b), Akkeshi, Misaki, Shimoda, Shirahama and Mukaishima, low intertidal. Additionally, Shirahama, Tanabe Bay, $0 \mathrm{~m}$ (Nishikawa, 1980b; erroneously described as the larva about 750 $\mu \mathrm{m}$ in trunk length and having 20 to 24 ampullae, but really about $370 \mu \mathrm{m}$ in that length and 8 ampullae), Mikawa Bay, $0 \mathrm{~m}$ (Nishikawa's unpublished data) and Usa, Kochi Pref. (do.), Japan; Jiaozou Bay (Ger \& Zan, 1983); Trunk, Ponape and Majuro, 0-13 m (Nishikawa, 1984a).

\section{Botrylloides lateritium Beniaminson, 1975}

Botrylloides lateritium Beniaminson, 1975, pp. 39-40, figs 1-5.

Material examined: None.

Remarks. According to the original and so far the sole description, this species may be characterized as follows: zooids arranged in ladder systems (but sometimes in stellate ones, judging from his figures); atrial siphon distinct and with a languet; 9 stigmatal rows; 12 stomach plications; a single small ovum in the pouch of parent zooid, situated posterior to the testis comprising about 10 follicles packed tightly (see his fig. 4). The taxonomic relationship of the present species with the Japanese species of the genus cannot be determined, because Beniaminson's description lacks complete information.

Distribution in Japan Sea. Possjet Bay, Peter the Great Bay, $1.5 \mathrm{~m}$ (Beniaminson, 1975).

Distribution outside Japan Sea. Unknown.

95. Botrylloides aureum Sars, 1851 sensu Skalkin, 1959

Botrylloides aureum: Skalkin, 1959, p. 246.

Material examined: None. 
Remarks. Skalkin (1959) listed Botrylloides aureum from the western coast of South Sakhalin, without any description. The present species has been recorded from the Atlantic arctic and subarctic waters, and doubtfully also from the Alaskan waters (Van Name, 1945, p. 227). Thus, Skalkin's record is far apart from all the other known localities of this species. As the morphological information of his material is unavailable now, its exact affiliation are left open here.

\section{* Botrylloides sp.}

Botrylloides sp.: Hartmeyer, 1906, p. 27.

Remarks. Hartmeyer recorded Botrylloides sp. from Hakodate, without any description. I have not examined this material.

Nishikawa (1984b, p. 150) recorded Botryllid sp. from Oga Pen., and further, the material examined in the present study contains many specimens assignable only to the family Botryllidae, for the lack of gonads, larvae or other diagnostic structures. All such specimens and records are omitted here.

Family Styelidae

96. Symplegma reptans (Oka, 1927)

(Fig. 21)

Synstyela reptans Oka, 1927e, p. 496, fig. 956.

Symplegma reptans: Tokioka, 1949b, pp. 49-51, text-fig. 7, pl. 8, fig. 2; 1951, p. 173; 1953c, pp. $243-245$, pl. 46 , figs $1-5$, text-fig. 16 ; 1959a, p. 227.

Symplegma sp.: Nishikawa, 1982b, pp. 208-209, fig. 1, C-F.

Kott's (1985) Symplegma reptans is excluded with some doubt.

Doubtful reference:

Symplegma reptans: Kott \& Goodbody, 1980, pp. 529 and 531, fig. 15.

Material examined: B (Mutsu Bay): No. 286(S314), labeled Synstyela aomori by Oka, collected about $1500 \mathrm{~m}$ off Jyogasawa, near Oominato, by Hozawa and Kokubo on Aug. 11, '26, 5 fragments encrusting Zostera sp. C-2 (Mutsu Bay): from buoys off Moura, near Asamushi, 5 colonies or fragments, some from Styela clava, the largest colony $70 \times 60 \mathrm{~mm}$ in extent; Hadakajima Islet, in front of Asamushi Mar. Biol. St., 1-4 m deep, 3 colonies. D (Tottori): several collected in Dec. '77, and Aug. and Dec. ' $78,43 \mathrm{~mm} \times 23 \mathrm{~mm}$ in extent in the largest.

Description. Colony up to $2 \mathrm{~mm}$ thick. Test thin but very tough, nearly transparent and colorless. Zooids, up to $4 \mathrm{~mm}$ long, compressed dorsoventrally, and greyish or pinkish purple, due to spherules. Twelve tentacles; the larger and smaller ones alternating almost regularly. Ciliated groove an oval slit elongated longitudinally. Four inner longitudinal vessels on each side; the dorsal two on the left converging posteriorly to the dorsal lamina, though the rest of vessels reaching the posterior end of branchial sac. Stigmata arranged as D. 6-5-5-5-6 V. in a $4 \mathrm{~mm}$ long zooid. Eight or 9 stigmatal rows on each side in the specimens from $D$, 9 or 10 on the right and 10 on the left in those from $\mathrm{C}-2$, and $10-11$ on each side 
in those from B; second row always incomplete; the posterior-most one often more or less rudimentary. Number of stomach plications is 9 to 10 or 10 to 11 in the specimens from $\mathrm{D}$ or $\mathrm{B}$, respectively, usually a single plication on the left side of typhlosole never reaching the cardiac margin of stomach; in those from $\mathrm{C}-2,12$ or 13 plications discernible of which 1 to 3 plications on the left side, and rarely a single one on the right, of typhlosole never reaching that margin (Fig. 21, A-C). The plications except those along the typhlosole almost always occupying the entire length of stomach, though very rarely not so (see Fig. 21, B). Pyloric coecum of moderate size, curved only slightly. A thin or thick vessel, filled with minute spherules (probably blood cells), running along the outer margin of the coecum, issues from near the proximal end of the coecum as a single vessel toward rectum, branching off midway one or very rarely two short projections leading to mantle wall, and distally bifurcated into a branch to the wall and the other branch bridging between the distal part of coecum and the bottom of intestinal loop, ending on the intestinal wall further bifurcated, though sometimes unclearly (Fig. 21, A-C). Pyloric duct sometimes detectable along the vessel running from the rectum along the outer margin of pyloric coecum to the intestine (Fig. 21, D). Gonads partly mature, testis consisting of a pair of follicles simple in outline, or cleft two or three times, and sperm duct often somewhat elongated (Fig. 21, E); ovary containing at most 3 or 4 eggs, up to $400 \mu \mathrm{m}$ in diameter. In some zooids from $\mathrm{C}-2$, about 5 embryos in each side of
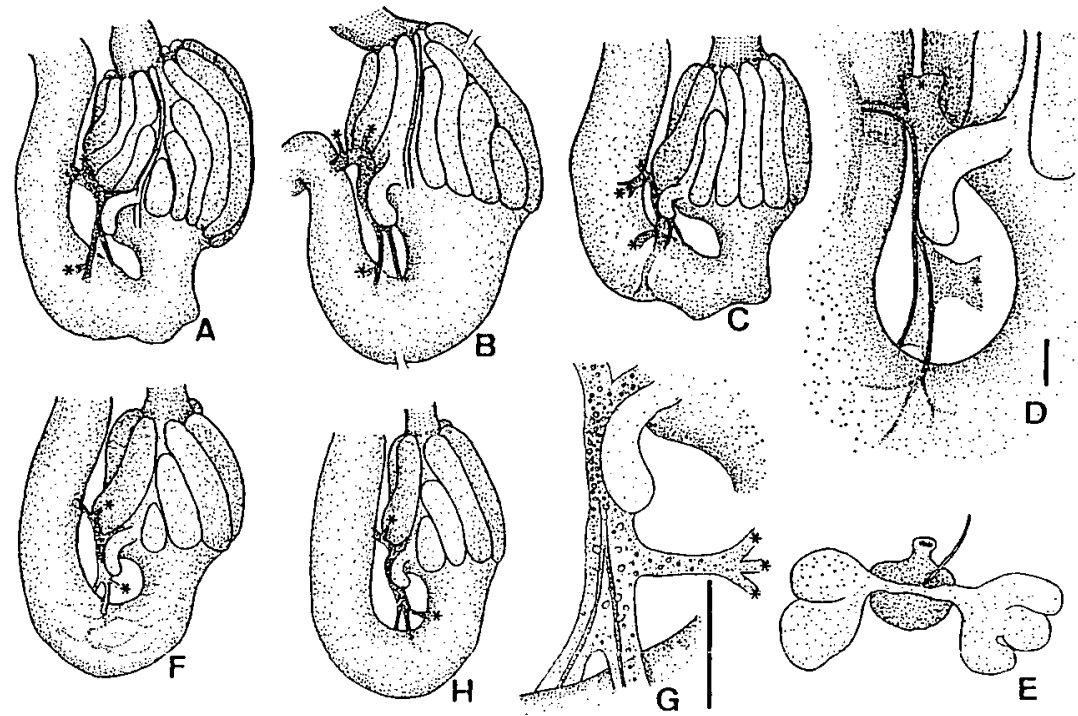

Fig. 21. Symplegma reptans (Oka). A-B. zooids of a colony from Mutsu Bay (Collection C-2); C-E. zooids of colony fragments from Mutsu Bay (B, OCUT No. 286 (S314)); F-G. zooids of the lectotype colony from Tateyama (B, OCUT No. 14(S230)); H. a zooid of the paralectotype colony from Tateyama (B, OCUT No. 318(S291)). A-C, F \& H. left side of alimentary system; D \& G. pyloric coecum and accompanying vessels, enlarged; E. a gonad, showing elongated sperm duct. Vessels marked with asterisks are those leading to the mantle wall. Scales indicate $100 \mu \mathrm{m}$. 
peribranchial cavity.

Remarks. Synstyela reptans Oka was established with very insufficient description and without any reference to the exact type locality and what specimens constitute the type series. Later, Tokioka (1949b) correctly changed the generic name of the species from Synstyela to Symplegma, and redefined the species on the basis of the colonies collected at Seto, Tanabe Bay, on the western coast of Kii Pen.; those colonies are missing now from SMBL holding. Fortunately, I recently found the specimens attributable to the type series of Symplegma reptans, out of the specimens deposited at OCUT. Among them, only the following specimens are labeled Synstyela reptans obviously by Oka: No. 14(S230), collected in Tateyama by Oka on Apr. 21, '21; No. 284(S240), without data; No. 318(S291), in Tateyama on May 4, '26; No. 319(S6), in Tateyama in Apr., 1898; and No. N22(S276), without data. The specimens registered as Nos. 284, 319 and N22 had already dried up, while those of Nos. 14 and 318 are still in good condition; the latter comprising each a single colony or its fragment investing Sargassum sp., just as illustrated by Oka in the figure 956 of the original description. Consequently the latter specimens, collected before the establishment of the species in question, can be regarded as belonging to the type series. Here the specimens Nos. 14 and 318 are designated as the lectotype and paralectotype, respectively. The lectotype is about $55 \mathrm{~mm} \times 25 \mathrm{~mm}$ in extent, while the paralectotype $55 \mathrm{~mm} \times 45 \mathrm{~mm}$; both about $1 \mathrm{~mm}$ thick. The features of the type series are: zooids up to $2.8 \mathrm{~mm}$ long, much depressed dorsoventrally; 12 tentacles, the larger and smaller ones alternating regularly; ciliated groove an oval slit, more or less elongated longitudinally; 4 inner longitudinal vessels on each side, 2 dorsal ones on the left converging to the dorsomedian line; 8 stigmatal rows on each in the lectotype colony, while 8 or 9 ones in the paralectotype; second row always incomplete; stigmata arranged as D 4-3-4-4-5 V in a zooid of the lectotype; 8 or 9 stomach plications, of which one or two on the left side of typhlosole never reaching the cardiac end of stomach (Fig. 21, F and $\mathrm{H}$ ); pyloric coecum of moderate size and curved slightly; the accompanying vessel and duct arranged as in the specimens from the Japan Sea described above (Fig. 21, F-H); gonad mature only in the lectotype; margin of each testicular follicle smooth or cleft shallowly two or three times; eggs up to $325 \mu \mathrm{m}$ in diameter; sperm duct short or somewhat elongated, though not so remarkably as shown in Fig. 21, E; no hatched larvae discernible. The present type series is quite similar to specimens from the Japan Sea especially in the shape and size of pyloric coecum and the arrangement of its accompanying vessel, though in the type series the zooid is provided sometimes with fewer stigmatal rows and stomach plications than in the Japan Sea specimens. This difference may not be significant. Thus, the specimens from the Japan Sea are referable to $S$. reptans. The type series mentioned above conform to the description of Symplegma sp. given by Nishikawa (1982b) on the specimens from Shimoda, Sagami Bay, so this record is here included in the synonymy of $S$. reptans.

The descriptions of $S$. reptans given by Tokioka (1949b) and Tokioka (1953c) 
on the specimens from Tanabe Bay and Sagami Bay, respectively, may apparently be different from the type series mentioned above in the shape of pyloric coecum and the arrangement of its accompanying vessel (see fig. 7, 2-3 and figs 3-4 of plate 46 in Tokioka's respective descriptions), so a reexamination of the materials concerned was made. Though the specimen from Tanabe Bay is now not kept at SMBL as stated above, those from Sagami Bay were fortunately examined, deposited at BLIH (Proto. Nos. 36, 69, 70 and 71). It was verified that they are S. reptans, because they resemble the type series in the features of pyloric coccum and accompanying vessel, as well as in the testicular follicle with smooth or somewhat lobulated margin, though unlike Tokioka's (1953c) figures. This may mean that Tokioka's (1949b) record, and further those of $S$. reptans given by Tokioka (1951b, 1959a) from Osaka Bay and Wakasa Bay respectively without references to the mentioned diagnostic features, can be included in the records of $S$. reptans delimited here. On the other hand, the shape of pyloric coecum in Kott \& Goodbody's (1980) S. reptans collected from Hong Kong is reminiscent of Tokioka's (1949b, 1953c) descriptions (but never the specimens themselves), while somewhat different from that shape of the species redefined in the present study. Therefore, their record is here included in the synonymy of the species only doubtfully.

Recently Kott (1985) assigned the colonies from Queensland, Australia, to Symplegma reptans (Oka). In these colonies, however, the zooids are "arranged in circles" with "the atrial apertures opening in the centre" (p. 258) and the "internal longitudinal vessels extend the whole length of the branchial sac" (p. 259). These two features are never shared with the Japanese $S$. reptans. The mentioned differences seems to be of taxonomic significance, and therefore Kott's record is excluded from the synonymy of $S$. reptans with some doubt.

Distribution in Japan Sea. Mutsu Bay, several meters (in the present study); Wakasa Bay (Tokioka, 1959a); Tottori, $0 \mathrm{~m}$ (in the present study).

Distribution outside Japan Sea. Tateyama, SW end of Boso Pen. (the type locality; in the present study); Sagami Bay (Tokioka, 1953c; Nishikawa, 1982b); Mikawa Bay (Nishikawa's unpulished data); Tanaba Bay (Tokioka, 1949b); Osaka Bay (Tokioka, 1951b); Usa, Kochi Pref. (Nakauchi, 1973; the life history was described by Sugimoto \& Nakauchi (1974); I examined their material; it clearly belongs to S. reptans defined in the present study); ?Hong Kong (Kott \& Goodbody, 1980).

\section{Symplegma japonica Tokioka, 1962}

Symplegma japonica Tokioka, 1962a, p. 13-15, fig. 4; Nishikawa, 1980b, tab. 1; 1984a, p. 13; 1984b, p. 151.

Material examined: M (Oga): Daishima, $0 \mathrm{~m}$, many small fragmental colonies from undersurface of boulders, already listed by Nishikawa (1984b).

Remarks. The features of the material are: living zooids pale yellow; the colony composed of a few zooids, up to $2.5 \mathrm{~mm}$ long; 8 tentacles, the larger and smaller 
ones alternating almost regularly; ciliated groove inverted U-shaped with both horns rolled out; 8 to 10 stigmatal rows; second row complete; about 20 stomach plications, of which 4 or 5 converging in their cardiac ends to each side of typhlosole; pyloric coecum and its accompanying vessel same as in original description; gonad indiscernible. The present specimens agree with the original and subsequent descriptions of S. japonica. Recently C. Monniot (1983b, p. 431) claimed that $S$. japonica may be a juvenile form of $S$. reptans. $S$. japonica is distinguishable from $S$. reptans by the colony shape (fragmentary masses, each containing only a few zooids in $S$. japonica, as compared with an extensive sheet with numerous zooids in $S$. reptans), the shape of ciliated groove (inverted U- or V-shaped, instead of oval elongated longitudinally), the second stigmatal row (complete, instead of incomplete), the number of stomach plications and that of the plications converging to the typhlosole (up to 20 or more and 8 to 10 , respectively, instead of only about 10 and 1 to 3), and by the arrangement of vessel accompanying pyloric coecum (bridging the alimentary canal only on the rectum, instead of on the rectum and the bottom of the first intestinal loop). Therefore, $S$. japonica is regarded as a good species.

Distribution in Japan Sea. Oga Pen., $0 \mathrm{~m}$ (Nishikawa, 1984b; in the present study); Sado (Tokioka, 1962a).

Distribution outside Japan Sea. Western coast of Kii Pen., down to $3 \mathrm{~m}$ (Nishikawa, 1980b); Ponape Is., $0 \mathrm{~m}$ (Nishikawa, 1984a).

\section{Polyzoa vesiculiphora Tokioka, 1951}

Polyzoa vesiculiphora Tokioka, 1951a, pp. 11-12, text-fig. 9, pl. 2, figs 1-2; Nishikawa, 1980b, tab. 1. Polyzoa vesiculiphora race $2 l-5 r$ Watanabe \& Tokioka, 1972, pp. 328-334, figs 1-3.

Material examined: D (Tottori): a single mass, $17 \mathrm{~mm} \times 10 \mathrm{~mm}$ in extent and up to $4 \mathrm{~mm}$ thick, consisting of about 15 individuals, attached to one another very firmly, collected in Dec. '78.

Description. Body rounded, 3.5 to $5 \mathrm{~mm}$ long. Test very thin but tough; the surface coated densely with sand grains. A thin vessel to the test issuing from the posteroventral part of mantle body. Mantle brownish; a large elongate vesicular endocarp present on its inner surface on each side. Many fine atrial tentacles on the velum. Up to about 40 branchial tentacles, the larger and smaller ones alternating. Ciliated groove as an oval slit elongated longitudinally. Three inner longitudinal vessels on each side; the stigmata arranged as D 8-7-8-16 V on the left, while D 12-7-8-20 V on the right in a $5 \mathrm{~mm}$ long specimen. Nine stigmatal rows, of which the posterior-most two being rudimentary and not accompanied by parastigmatic vessels in a $3.5 \mathrm{~mm}$ long specimen; 7 and 10 stigmatal rows, all with parastigmatic vessels in $4.2 \mathrm{~mm}$ and $5 \mathrm{~mm}$ long specimens, respectively. Anterior margin of alimentary canal reaches beyond the anterior base of atrial siphon situated roughly in the middle of mantle body. Second intestinal loop rather deep and wide. Stomach occupying slightly less than the posterior half of the ventral branch of first intestinal loop; 13 to 15 plications, of which 2 or 3 converging in their cardiac ends 
to typhlosole on respective sides. Pyloric coecum prominent, though not so remarkably as illustrated in fig. 1, C of Watanabe \& Tokioka (1972); the vessel along the outer margin of the coecum arranged just as illustrated in the same figure. Gonads usually mature; 2 on the left and 6 on the right in a $5 \mathrm{~mm}$ long specimen, 5 on each side in a $4.2 \mathrm{~mm}$ long one, or 7 on the left and 6 on the right in a $3.5 \mathrm{~mm}$ long animal. Testis in each gonad forming a round mass, situated usually anterior to, but rarely posterior to, the ovary containing many eggs, up to $325 \mu \mathrm{m}$ in diameter. Rarely the embryos, up to $375 \mu \mathrm{m}$ in diameter, found free in the peribranchial cavity. Two hatched larvae in the cavity in a $3.5 \mathrm{~mm}$ long specimen; $480 \mu \mathrm{m}$ in trunk length and $300 \mu \mathrm{m}$ in width; ampullae indiscernible. The present specimens fall within the variation range of $P$. vesiculiphora.

Distribution in Japan Sea. Tottori, $0 \mathrm{~m}$ (in the present study).

Distribution outside Japan Sea. Akkeshi, Hokkaido (Tokioka, 1951a); near the Misaki Mar. Biol. Lab., Sagami Bay (Watanabe \& Tokioka, 1972); Ise Bay, 0 m, and western coast of Kii Pen. (Nishikawa, 1980b); Ushimado, Seto Inland Sea (Nishikawa's unpublished data).

\section{Polyzoa pacifica Tokioka, 1951}

Polyzoa pacifica Tokioka, 1951b, pp. 173-175, fig. 4; 1962a, pp. 15-16, pl. 3, fig. 31; Rho, 1971, p. 116.

Material examined: None.

Remarks. The present species is distinguishable from the closely related $P$. vesiculiphora solely by the number of stigmatal rows (about 12 in $P$. pacifica, while at most 10 in $P$. vesiculiphora). In this feature as well as many other diagnostic ones $P$. pacifica resembles $P$. translucida Ritter et Forsyth recorded from San Diego Bay, southern California by Ritter \& Forsyth (1917).

Distribution in Japan Sea. Sado (Tokioka, 1962a); Korean coastal waters facing Korea Strait (Rho, 1971).

Distribution outside Japan Sea. Shimoda, Sagami Bay (Nishikawa's unpublished data); Osaka Bay (Tokioka, 1951b).

\section{Polyandrocarpa (P.) sp. cf. maxima (Sluiter, 1904)}

(Fig. 22)

Material examined: L-8 (Oki): a nearly spherical colony, about $45 \mathrm{~mm}$ in long diameter.

Description. The colony composed of many zooids, fused to one another completely except their anterior part bearing stout but distinct siphons, distributed over nearly the whole surface of colony. Zooids $16 \mathrm{~mm}$ or longer. Test thin, leathery, opaque and dull white; the surface sometimes coated with sand grains. In the mantle body, the branchial siphon situated terminal, while the atrial nearly in, or 
slightly posterior to, the middle of body. About 24 tentacles, the larger and smaller ones alternating; additionally in some zooids, a few to many papillae between the tentacles. Ciliated groove simple U- or C-shaped opening anteriorly, or rarely consisting of two slits as seen in a $12 \mathrm{~mm}$ long mantle body (Fig. 22, D). Four branchial plications on each side; the formula in a $12 \mathrm{~mm}$ long mantle body is:

$$
\begin{aligned}
& \text { L. D. } 4 \text { (9) } 4 \text { (11) } 4 \text { (12) } 4 \text { (10) } 4 \mathrm{~V} \text {. } \\
& \text { R. D. } 1 \text { (12) } 4 \text { (11) } 5 \text { (12) } 4 \text { (11) } 5 \mathrm{~V} \text {. }
\end{aligned}
$$

About 4 stigmata in a mesh. The alimentary system occupying the posterior half or more of mantle body; second loop shallow (Fig. 22, A) or deep (Fig. 22, C), its axis passing through the middle or pyloric end of stomach. Stomach globular in outline and occupying nearly the half of ventral branch of first intestinal loop; surface furnished with many longitudinal plications; no pyloric coecum. The surface of alimentary system provided sparsely with minute papillae containing white pigment. Anal margin cut into many lobules. No endocarps. Gonads more or less elongated, and about a dozen on the right and fewer on the left (Fig. 22, A-C), each attached to the mantle wall by a thin and low membrane along the whole length. Gonads confined to near the bottom of first loop on the left, while distributed rather extensively on the right. Each gonad immature, though many empty testicular follicles arranged in a double row on attachment side.

Remarks. Polyandrocarpa (P.) sagamiensis Tokioka is the only species of this subgenus so far recorded from Japanese waters, collected from Sagami Bay, $15 \mathrm{~m}$ by Tokioka (1953c). The present colony from Oki is distinguishable from this species by the complete absence of pyloric coecum in this colony (instead of the existence of "a minute but distinct" ones in $P$. sagamiensis), and the number and arrangement of gonads (up to about a dozen arranged randomly, instad of about 16 on the left and

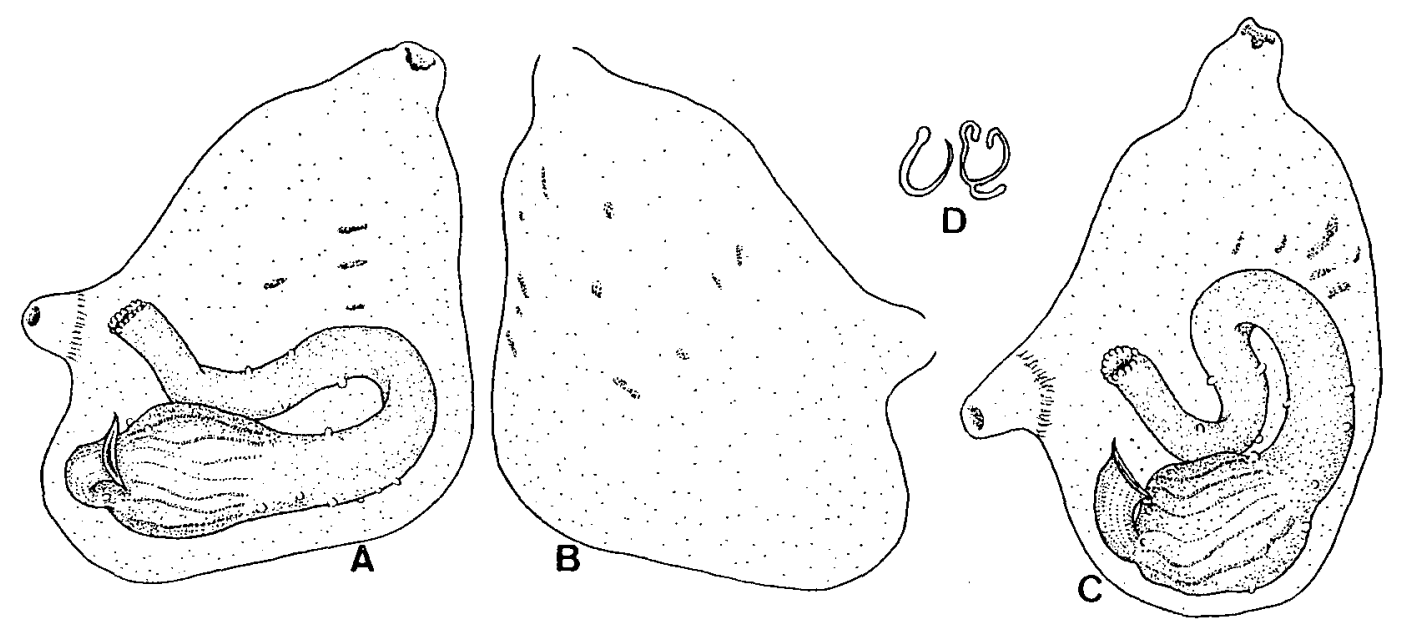

Fig. 22. Polyandrocarpa (P.) sp. cf. maxima (Sluiter) from Oki Isls (Collection L-8). AB. $12.5 \mathrm{~mm}$ long mantle body; G-D. $12 \mathrm{~mm}$ long mantle body. A \& C. left inner side of mantle body; B. right inner side of mantle body; D. ciliated groove. 
about 50 on the right, "all arranged along the ventral margin on each side"). In the small number of gonads the present colony is similar to $P$. (P.) maxima (Sluiter) recorded from the Philippines (Sluiter, 1904; Van Name, 1918). As the present colony from Oki is immature, its exact assignment is not possible; it is here identified as $P$. (P.) sp. cf. maxima.

\section{1: Polycarpa cryptocarpa kroboja (Oka, 1906)}

(Fig. 23)

Styela kroboja Oka, 1906, p. 50.

Polycarpa cryptocarpa var. kroboja: Tokioka, 1953c, pp. 251-254, pl. 52, figs 1-7, pl. 53, figs 1-6; 1959a, p. 229, pl. 15, figs 21-22; 1962a, p. 16, pl. 1, fig. 8, pl. 3, fig. 32; Nishikawa \& Tokioka, 1975 , p. 221 ; Nishikawa, 1980 b, tab. $1 ; 1982$ b, p. $204 ; 1984$ b, p. 151.

Polycarpa cryptocarpa kroboja: Nishikawa, 1986b, p. 176.

Polycarpa cryptocarpa: Hartmeyer, 1906, p. 17.

Pandocia (Polycarpa) japonica Michaelsen, 1911, pp. 153-158, figs 15-16. New Synonymy.

Material examined: C-8 (Oki): Dogo Is.: Kamio, 3-4 m deep, 4 individuals, 46.5-64 mm long; Okino-ura, 3-6 m, 5 individuals, 25.5-47.5 mm; Jyodoga-ura, 3-8 m, 8 individuals, 31.5-53 $\mathrm{mm}$; Ooku, $3 \mathrm{~m}, 15$ individuals, 28-56 mm. Nishinoshima Is.: Mimimimi-ura, 1-3 m, 8 individuals, 25-77 mm; Izanaki-ura, 1-3 m, 23 individuals, 20.5-70 mm; Chinzaki, 1-6 m, 5 individuals, 33.5$98 \mathrm{~mm}$; Kuniga, 1-4 m, 6 individuals, 29.5-57.5 mm. E-2 (Fukui): a $65 \mathrm{~mm}$ long individual collected on Sept. 29, '68. H-3 (Noto): a $60 \mathrm{~mm}$ long individual. L-2 (Kyoto): 6 individuals, 25.5$60 \mathrm{~mm}$ long. L-6 (Noto): 2 individuals, $69 \mathrm{~mm}$ and $55 \mathrm{~mm}$ long. M (Oga): a $55 \mathrm{~mm}$ long individual, listed already by Nishikawa (1984b). N (Oki): 4 individuals dredged at a depth of 30-55 $\mathrm{m}, 41-77 \mathrm{~mm}$ long, listed by Nishikawa (1986b).

Remarks. The present specimens share the following significant features: test very dark brown or nearly black; mantle and viscera chocolate brown; ciliated groove usually simple $\mathrm{C}$-shaped, often with horns either rolled in or out, rarely somewhat branched, while rather rarely the groove comprising several simple or curved slits (Fig. 22, A-G); a rudimentary branchial fold present, though sometimes obscure anteriorly, between the dorsal lamina and dorsal-most branchial fold on the right side, consisting of up to 6 inner longitudinal vessels; the deep first intestinal loop filled usually with 3 endocarps arranged along its axis, of which the largest is the dorsal (inner-most) rounded one, while the smallest is an inconspicuous thin membranous projection, situated between the dorsal and ventral ones, or rarely with only two endocarps; no others discernible on the inner surface of mantle; numerous gonads
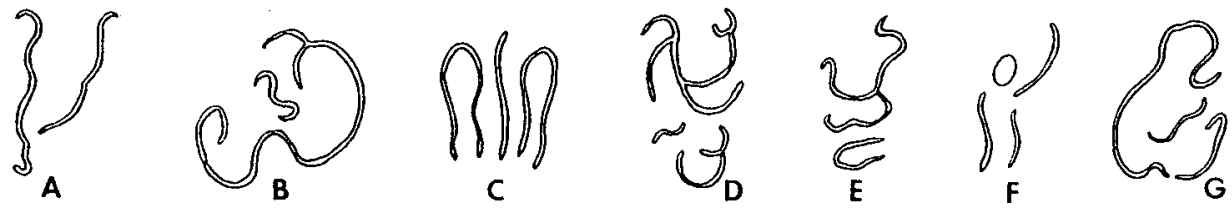

Fig. 23. Polycarpa cryplocarpa kroboja (Oka) from Oki Isis (Collection C-8). Ciliated grooves. A. $48 \mathrm{~mm}$ long specimen; B. $64 \mathrm{~mm}$ long specimen; C. $40 \mathrm{~mm}$ long specimen; D. $46 \mathrm{~mm}$ long specimen; E. $42.8 \mathrm{~mm}$ long specimen; F. $54.5 \mathrm{~mm}$ long specimen; G. $98 \mathrm{~mm}$ long specimen. 
embedded completely in the mantle. As these features are shared with Styela kroboja Oka, thus far called as Polycarpa cryptocarpa var. kroboja (Oka), recorded from the Japanese waters, the present specimens are identified with this variety. Reexamination of the material collected from Enoshima and referred to P. cryptocarpa (Sluiter) by Hartmeyer (1906), that consists of 2 specimens, $35 \mathrm{~mm}$ and $57 \mathrm{~mm}$ long, respectively, and deposited at MNB (No. ZMB 2234), revealed that they are also this variety. Hartmeyer (1906) also recorded P. cryptocarpa from near "Jagoshima" (= Jyogashima Is.) and Ito, Sagami Bay; this record is referable to the variety, though I have not yet examined the specimens concerned. One of the three type specimens of Pandocia (Polycarpa) japonica Michaelsen was also reexamined, that were collected from Siza-hama(exact location unknown), Satsuma (==western part of Kagoshima Pref.), described by Michaelsen (1911) and deposited at ZMH (No. T 144). The features of the specimen, $64 \mathrm{~mm}$ long and already dissected, are: test dark brown; mantle chocolate brown; ciliated groove simple as illustrated in fig. 15 (right) of the original description; the rudimentary fold clearly discernible in the posterior half of the sac; alimentary system missing completely; and the gonad embedded completely in the mantle. The present specimen is quite similar to the variety kroboja, except that the first intestinal loop is occupied only by a single large endocarp. This feature in Michaelsen's specimen resembles some specimens of the nominotypical form of $P$. cryptocarpa as shown below. The number of endocarps in the loop ranges from 2 to 4 in the variety kroboja, and therefore, a single endocarp in a specimen may be somewhat peculiar. However, the existence of a distinct rudimentary fold and the simple ciliated groove in the present specimen as large as $64 \mathrm{~mm}$ long justifies its identification with this variety. Thus, Pandocia (Polycarpa) japonica Michaelsen is regarded as a junior synonym of $S$. kroboja Oka by the Principle of Priority.

The nominotypical form of $P$. cryptocarpa (Sluiter, 1885) is distinguishable morphologically from the variety kroboja only by the complicated ciliated groove (cut into many or numerous pieces in the larger specimens, though quite simple in the smaller) and the complete absence of the rudimentary branchial fold in the former. With regard to the latter feature, accroding to Nishikawa's unpublished data, in only a few out of many specimens collected in the Truk Islands and referred to the nominotypical form, the rudimentary fold is slightly discerned posteriorly. The tendency may be pointed out that the test color is usually pale brown, more or less paler in the nominotypical form than in the variety, though sometimes as deep as brownish black also in the nominotypical form. In some specimens of the variety kroboja from Tanabe Bay, Kii Pen., the test is dull orange, or yellowish orange with a slight tint of brown, but the rudimentary fold is clearly discernible and the ciliated groove quite simple (Nishikawa, unpublished). As for the number of endocarps in the loop, only a single one is described or illustrated in the nominotypical form by Sluiter (1885, fig. 1 of pl. 7), Kott (1957, p. 146), Tokioka (1961, p. 123) and Millar (1975, pp. 284-285), though the existence of 2 or 3 ones is recorded by Tokioka (1950, fig. 16; 1970b, fig. 7) and Nishikawa \& Tokioka (1976a, p. 394), as well as by Nishikawa's unpublished data on the basis of the specimens collected from Truk, Ponape and Ma- 
juro (see Nishikawa, 1984a, p. 133) and those from Singapore; on the other hand, the single endocarp is very rarely recorded in the variety kroboja (see above). Consequently, there seems only a minor, but usually rather distinct morphological gap between the nominotypical form and the variety, that is represented by the ciliated groove simple or complicated in the larger specimens. The three specimens collected from Siza-hama, Satsuma, the same locality as Pandocia japonica (see above) and referred to Pandocia (Polycarpa) cryptocarpa by Michaelsen(1911) were reexamined, that are deposited at ZMH (No. T 143). In these specimens, 36 to $45 \mathrm{~mm}$ long, test is "schmutzig gelbbraun bis schwarzbraun", ciliated groove cut into many pieces, the rudimentary fold barely discernible and 2 to 4 endocarps in the loop. They are within the variation range of the nominotypical form of $P$. cryptocarpa.

Previous records indicate that the population of the nominotypical form occupies the Indo-West Pacific region, while that of the variety exclusively around the Japanese main islands excluding Hokkado and Shikoku; these two populations may overlap each other geographically only in Satsuma, southern end of Kyushu Island. Under such circumstances, the taxon Styela kroboja Oka can be ranked as a subspecies of $P$. cryptocarpa (for the definition of subspecies see, for example, Mayr, 1963). Thus, so-called $P$. cryptocarpa represents the nominotypical subspecies $P$. cryptocarpa cryptocarpa (Sluiter, 1885).

Recently P. cryptocarpa (Sluiter) was considered by Kott (1985, pp. 177-179) to be a junior synonym of $P$. obscura Heller, and further, some specimens referred to $P$. cryptocarpa were renamed by her $P$. pigmentata (Herdman, 1906). More considerations are necessary for me to decide for or against these opinions.

Distribution in Japan Sea. Oga Pen., $10 \mathrm{~m}$ (Nishikawa, 1984b) ; Sado (Tokioka, 1962a); Tsukumo Bay, 5-10 m (in the present study); off Echizen-cho, Fukui Pref. (do.); Wakasa Bay (Tokioka, 1959a); off Amino-cho, Kyoto Pref., down to $10 \mathrm{~m}$ (in the present study); Oki Isls, 1-55 m (Nishikawa, 1986b; in the present study).

Distribution outside Japan Sea. Shikine Is. (Tokioka, 1962a); Sagami Bay, down to $150 \mathrm{~m}$ (Oka, 1906; Hartmeyer, 1906; Tokioka, 1953c); Shimoda (Nishikawa, 1982b); around Kii Pen., 1-80 m (Oka, 1906; Nishikawa \& Tokioka, 1975; Nishikawa, 1980b); Kagoshima Pref. (Michaelsen, 1911).

\section{Polycarpa doederleini Hartmeyer, 1906}

Polycarpa doederleini Hartmeyer, 1906, pp. 15-16, fig. 9.

Polycarpa doederleini var. siranuli Tokioka, 1960b, pp. 209-2i i, pi. 26, figs $7-10$, pi. 27, figs 11-15; Rho, 1975, pp. 135-136, pl. 5, figs 6-9; Nishikawa, 1980b, tab. 1; 1986b, p. 176. New Synonymy.

Material examined: A (Toyama Bay): a $54 \mathrm{~mm}$ long individual. K-1 (Tsushima Strait): 2 individuals, $48 \mathrm{~mm}$ and $50 \mathrm{~mm}$ long respectively. $\mathrm{N}$ (Oki): 4 individuals, 31-63 mm long, already listed by Nishikawa (1986b).

Description. Body elongated and compressed laterally; test impregnated densely with foreign matter; test surface with hairy processes gathering sand grains. Atrial 
velum well developed, with the margin bearing fine atrial tentacles. Branchial tentacles about 12 to 40 , of various lengths. Dorsal tubercle divided into 8 (in 56 $\mathrm{mm}$ long specimen of collection $\mathrm{N}$ ) to 18 (in $63 \mathrm{~mm}$ long one in the same collection) small pieces, each containing a straight, $\mathrm{G}$ - or $\mathrm{U}$ - shaped ciliated groove. Only 3 branchial folds on the right, while 4 ones on the left; the formula in the largest ( 63 $\mathrm{mm}$ long) specimen is:

$$
\begin{aligned}
& \text { L. D. } 0(30) 25(40) 12(26) 18(22) 15 \mathrm{~V} . \\
& \text { R. D. } 48(35) 15(30) 17(24) 22 \mathrm{~V} .
\end{aligned}
$$

Intestine nearly straight; one-fourth to one-sixth occupied by globular or oval stomach. Many endocarps over inner surface of mantle. Up to 20 or more gonads distributed roughly in a single row along each side of endostyle; they are elongated dorsoventrally and attached to mantle by wide lateral side; testicular follicles arranged in a double row on the attachment side.

Remarks. Polycarpa doederleini Hartmeyer was established for specimens collected in Sagami Bay at a depth of 100-200 m (according to the original description). Tokioka (1960b) proposed a new variety siranuhi for the specimens dredged in the Ariake Sea of Kyushu. He distinguished the variety from the nominotypical form by the larger number of divided pieces of dorsal tubercle in the variety siranuti (11 to 26 ones, instead of only about 5 in the nominotypical form) and the existence of only 3 (instead of 4 in the latter) branchial folds on the right side. Rho (1975) attributed the specimens from Korea to the variety, describing as with 11 to 17 pieces of the tubercle and 3 folds on the right. The specimens from the Japan Sea examined in the present study are consistent with the original description of the variety, and therefore, safely referred to it. Then in this variety, the subdivided pieces of dorsal tubercle are highly variable in number, ranging from 8 to 26.

My reexamination of the type material of the nominotypical form revealed that Hartmeyer's original description was incorrect in the features of dorsal tubercle and branchial plications. The material collected at a depth of 100-200 fms (following the label therein) and deposited at MNB (ZMB No. 2232), consists of 2 ascidians, 35 $\mathrm{mm}$ and $47 \mathrm{~mm}$ long respectively, as well as a $44 \mathrm{~mm}$ long anthozoan; all are already dissected. Though the mantle body was so deteriorated and fragile that detailed examination was impossible, the dorsal tubercle is divided into 8 pieces in the $47 \mathrm{~mm}$ long specimen or 10(?) in the $35 \mathrm{~mm}$ long one, each of which contains a straight or rarely U-shaped ciliated groove, and the branchial sac is furnished with 4 folds on the left, and only 3 on the right. The branchial formulae are:

in $47 \mathrm{~mm}$ long specimen

L. D. 0 (20?) 10 (20?) 12 (20) 9 (20?) $12 \mathrm{~V}$.

R. D. more than 32 (20?) 10 (22) 7 (20?) $13 \mathrm{~V}$.

in $35 \mathrm{~mm}$ long specimen

L. 0 (20?) 12? (more than 20) 8 (20?) 12 (20?) 10? V.

R. 33 (30?) 10 (20?) 12 (12) $13 \mathrm{~V}$. 
In the mentioned features, these type specimens are similar to the variety siranuhi. Also in other diagnostic features, these specimens resemble the specimens from the Japan Sea. Consequently, the variety siranuhi should be amalgamated into the nominotypical form.

In the 3 specimens collected from Tanabe Bay, $30-80 \mathrm{~m}$ and referred to the variety siranuhi by Nishikawa (1980b), the $14 \mathrm{~mm}$ long one is provided with 6 pieces of dorsal tubercle, $20 \mathrm{~mm}$ long one with 8 pieces and $26 \mathrm{~mm}$ long one with 10 pieces. And there are only 3 branchial plications on the right side only, except in the smallest specimen that has 4 plications on each side, though the dorsal-most one on the right is rather rudimentary; the formula in this specimen is:

$$
\begin{aligned}
& \text { L. D. } 0 \text { (12) } 6 \text { (17) } 4 \text { (16) } 4 \text { (15) } 9 \mathrm{~V} \text {. } \\
& \text { R. D. } 5 \text { (12) } 4 \text { (20) } 5 \text { (15) } 4 \text { (16) } 9 \mathrm{~V} \text {. }
\end{aligned}
$$

In other features, the specimens are consistent well to $P$. doederleini defined above. The smallest specimen with only 6 pieces of the tubercle and 4 branchial folds on each side may well be regarded as an extremity of wide variation range seen in this taxon.

The features of most specimens of $P$. doederleini delimited above, such as the elongated and laterally flattened body, the sand-encrusted and fragile test, the existence of only 3 branchial plications on the right side, the simple straight intestine and the gonad arranged in a single row along each side of endostyle, are highly reminiscent of Polycarpa procera (Sluiter, 1885). This species has been recorded from Billiton Is., Java Sea, 6 fms deep by Sluiter (1885; for the number of branchial plications see Hartmeyer, 1919a, p. 56), the Sulu Archipelago, $15 \mathrm{~m}$ and the Java Sea, $82 \mathrm{~m}$ by Sluiter (1904; do.), from Cape Jaubert, NW Australia, 38-72 fms deep by Hartmeyer (1919a), from the Great Barrier Reef by Hastings (1931), and from Singapore by Millar (1975). Hartmeyer (1919a) mentioned that the "recht Kiemensackhälfte" is provided with 4 plications, while the "Links" with only 3 ones, which was, however, construed as above in the present study. In $P$. procera, however, the dorsal tubercle is usually simple or sometimes divided into 2 to 6 pieces, while always divided into 6 to 26 in $P$. doederleini. Apparently, this difference may be of certain taxonomic significance, and therefore these two species are here treated as distinct from each other.

In the external appearance, as well as the arrangement of alimentary system and gonads, $P$. doederleini and $P$. procera resemble $P$. tinctor (Quoy et Gaimard, 1834) inhabiting around Australia (Kott, 1952, 1973a; Mililar, 1963). The first two are, however, distinguishable from $P$. tinctor by its ubiquitous occurrence of the simple ciliated groove and 4 well-marked branchial folds on each side (see Herdman, 1882, pp. 170-171; 1899, p. 51; Kott, 1972b, p. 186; 1975, p. 13; other than above-mentioned literature). Thus, the synonymization of these 3 species with one another given by Kott (1964, pp. 134-136) is not adopted in the present study; for further considerations see Millar (1975, pp. 282-283).

Distribution in Japan Sea. Toyama Bay, $45 \mathrm{~m}$ and Tsushima Strait, $37 \mathrm{~m}$ (in the 
present study); Oki Isls, 30-55 m (Nishikawa, 1986b; in the present study); Cheju Is., Korea Strait (Rho, 1975).

Distribution outside Japan Sea. Sagami Bay, 100-200 m (or fms) (Hartmeyer, 1906); Tanabe Bay, 30-80 m (Nishikawa, 1980b); Ariake Bay (Tokioka, 1960b).

\section{Polycarpa aurita (Sluiter, 1890)}

(Fig. 24, A-C)

Styela aurita Sluiter, 1890, pp. 338-340, pl. 2, figs 12-13.

Polycarpa aurita: Sluiter, 1919, p. 3.

Material examined: $N(\mathrm{Oki}): 2$ individuals, $23 \mathrm{~mm}$ long body with a $10 \mathrm{~mm}$ long thin posterior extension of test, and $33 \mathrm{~mm}$ long, respectively; listed by Nishikawa (1986b).

Description. Body oval; surface nearly smooth, coated wholly and densely with sand grains. Both siphons indistinct. Test thin, soft but tough, transparent to translucent and dull yellow. Fine atrial tentacles arranged in a single ring. Branchial tentacles 16 (in the larger specimen) or 20 (in the smaller), the larger and smaller tentacles alternating; additionally several minute ones. Ciliated groove Cshaped, opening laterally (Fig. 24, B-C). Branchial formulae are:

in $23 \mathrm{~mm}$ long specimen

L. D. 4 (48) 8 (38) 12 (38) $12(20) 8 \mathrm{~V}$.

R. D. 4 (38) 6 (39) 10 (32) 15 (26) $10 \mathrm{~V}$.

in $33 \mathrm{~mm}$ long specimen

L. D. $0(52) 10(45) 10(39) 10(40) 6 \mathrm{~V}$.

R. D. 4 (45) 7 (42) 10 (45) 10 (44) $10 \mathrm{~V}$.

Up to 5 stigmata per mesh in between the folds. Posterior end of endostyle curled. Visceral mass occupies posterior one-third of mantle body. Stomach globular; surface quite smooth, though many inner longitudinal plications discernible. First intestinal loop very deep and closed, containing about 3 elongated endocarps; second loop shallow and widely opened. Rectum elongated. Many gonads spread densely over nearly the whole inner surface of mantle on each side, anastomosing frequently; a large number of gonoducts over them (Fig. 24, A). Each gonad attached firmly to, but never embedded in, the mantle by wide lateral side; partly mature. Many small endocarps distributed among the gonads.

Remarks. The present specimens are consistent with the original and subsequent descriptions of $P$. aurita (Sluiter).

Distribution in Japan Sea. Oki Isls, 35-55 m (Nishikawa, 1986b; in the present study).

Distribution outside Japan Sea. Truk Isls, 2-3 m (Nishikawa, 1984a); west off New Guinea, 18-32 m (Sluiter, 1904); Banda Sea (Pizon, 1908); Flores Sea, to $36 \mathrm{~m}$ (Sluiter, 1904); Java Sea, 10-18 fms (Sluiter, 1890, 1919); Arafura Sea (Tokioka, 


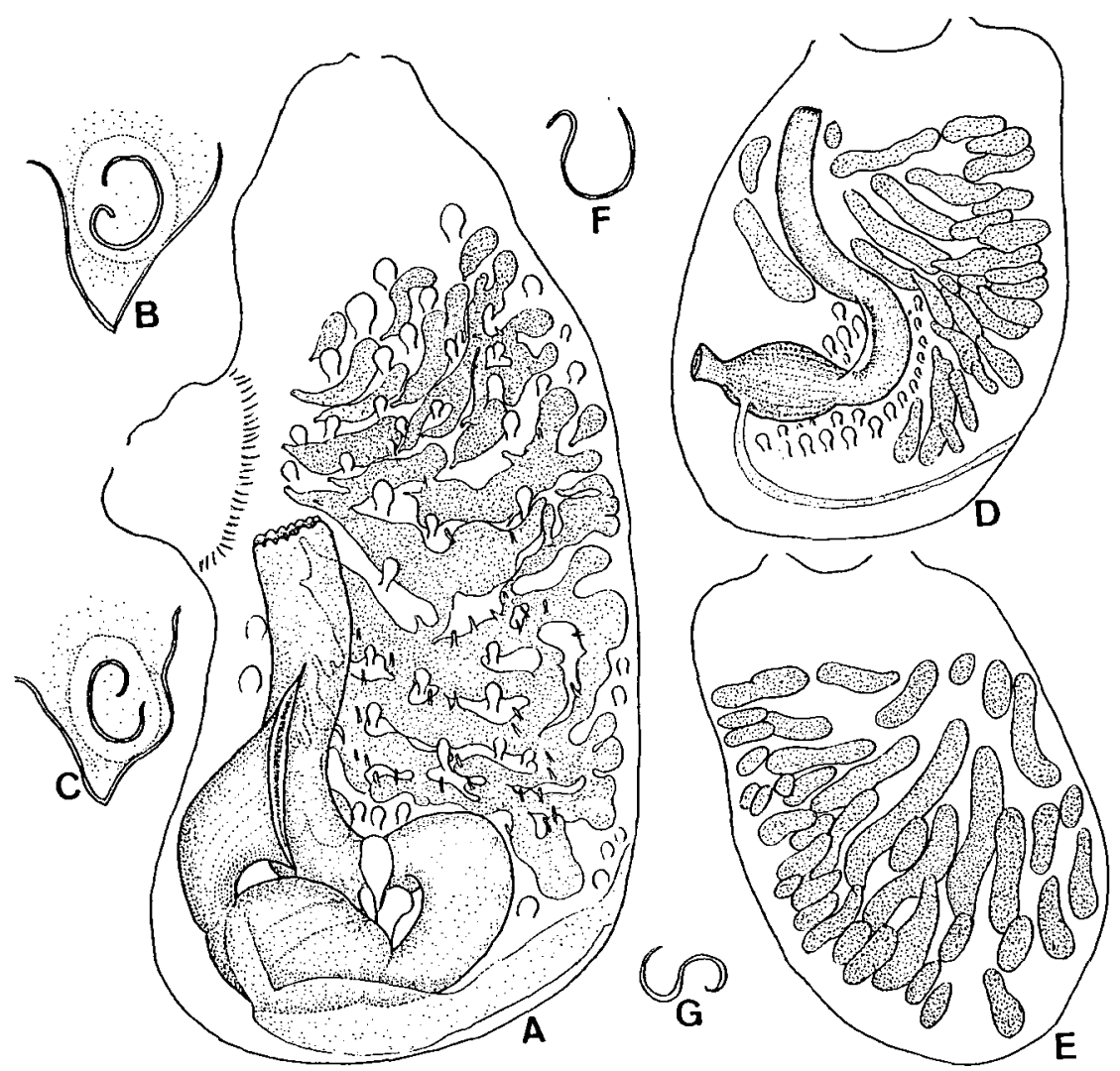

Fig. 24. A-C. Polycarpa aurita (Sluiter) from Oki Isls (Collection N); D-G. P. psammotesta Tokioka from Wakasa Bay (G-4). A-B. $33 \mathrm{~mm}$ long specimen; C. 23 $\mathrm{mm}$ long one; D-F. $27.3 \mathrm{~mm}$ long one; G. $19.5 \mathrm{~mm}$ long. A \& D. left inner side of mantle body; B, C, F \& G. ciliated groove; E. right inner side of mantle body.

1952); North Australia, 60-72 feet (Hartmeyer, 1919); Great Barrier Reef (Hastings, 1931); Arabian Sea, $38 \mathrm{~m}$ (Kott, 1957).

\section{Polycarpa maculata Hartmeyer, 1906}

Polycarpa maculata Hartmeyer, 1906, pp. 17-18, fig. 10.

Material examined: A (Toyama Bay): 2 individuals, $33 \mathrm{~mm}$ and $39 \mathrm{~mm}$ long, respectively. E-1 (Wakasa Bay): 5 individuals, $18-30 \mathrm{~mm}$ long. $\mathrm{E}-2$ (Fukui): 4 individuals $16-28 \mathrm{~mm}$ long. F-2: 2 individuals, $22 \mathrm{~mm}$ and $26.5 \mathrm{~mm}$ long. G-4 (Wakasa Bay): 11 individuals, $16.5-27 \mathrm{~mm}$ long. M (Oga): a $22 \mathrm{~mm}$ long individual, already listed by Nishikawa (1984b). N (Oki): 5 individuals, $16-36 \mathrm{~mm}$ long, listed by Nishikawa (1986b).

Remarks. The present specimens agree with $P$. maculata. The significant features in the specimens are: test soft leathery and pale or dark brown; surface wrinkled and coated, and rarely also impregnated with foreign matter, sometimes provided with fine short test filaments carrying the matter; mantle and viscera chocolate 
brown, or sometimes orangish brown; ciliated groove usually inverted S-shaped, or sometimes simple C-shaped opening in various directions, but very rarely composed of two curved pieces; up to 17 longitudinal vessels on each fold and 0 to 4 , or rarely 5 ones in the interspace; stomach cylindrical in outline, occupying half or more of the ventral branch of first loop; only a single large roundish endocarp in the loop; no other endocarps; 20 to 30 gonads, ranging from 10 to 52 on the left and from $13($ ?) to 60 on the right, distributed nearly evenly over each side; they are elongated oval and more or less flattened laterally, attached to mantle by a very narrow end opposite the genital apertures, or a few cases, by a rather thick membrane along the proximal one-third or less of the gonad; testicular follicles, if discernible, almost simple oval in outline and up to 14 ones arranged in two rows in each gonad; eggs up to $180 \mu \mathrm{m}$ in diameter.

Polycarpa maculata resembles $P$. reniformis (Sluiter) recorded from the Flores Sea by Sluiter (1904) in the attachment manner of gonads, as well as the simple ciliated groove, general arrangement of longitudinal vessels on the branchial sac, the existence of only a single large endocarp in the first intestinal loop, and the number and arrangement of gonads. However, my reexamination of the holotype of $P$. reniformis deposited at ZMA (TU 976.30; see Spoel, 1969, p. 196) revealed that it differs from $P$. maculata in the larger stomach occupying nearly the whole ventral branch of first intestinal loop in $P$. reniformis and the well branched testicular follicles (their number being about 6 pairs).

Distribution in Japan Sea. Off Oga Pen., 59-62 m deep (Nishikawa, 1984b; in the present study); Toyama Bay, 74-81 m (in the present study); off Echizen-cho, Fukui Pref. (do.); Wakasa Bay, down to $110 \mathrm{~m}$ (Tokioka, 1959a; in the present study); off Tango, Kyoto Pref., $80 \mathrm{~m}$ (Hartmeyer, 1906); Oki Isls, 35-55 m (Nishikawa, 1986b; in the present study); Tsushima Strait, 113-118 m (in the present study); Cheju Is., Korea Strait (Rho, 1971, 1975).

Distribution outside Japan Sea. Sagami Bay, $50 \mathrm{fms}$ (Tokioka, 1953c), off the western coast of Kii Pen., about 30-200 m (Nishikawa, 1980b), Amami Isls, shallow (Nishikawa \& Tokioka, 1976a) and Yaeyama Isls, 3-5 m (Nishikawa's unpublished data), Japan; Truk, Ponape and Majuro, 0-14 m (Nishikawa, 1984a); Tasmania, 155-174 m (Kott, 1954).

\section{Polycarpa psammotesta Tokioka, 1953}

(Fig. 24, D-G)

Polycarpa psammotesta Tokioka, 1953c, pp. 249-250, pl. 50, figs 1-8; 1967c, pp. 176-178, fig. 73.

Material examined: G-4 (Wakasa Bay): 9 individuals, $19-31 \mathrm{~mm}$ long.

Description. Body rounded; both siphons indistinct. Test up to $1 \mathrm{~mm}$ thick, and fragile due to wholly and densely impregnated sand grains; test itself transparent and white. Mantle very thin, semi-transparent and orangish. Both siphons indis- 
tinct; branchial aperture terminal, while the atrial subterminal. Twenty to 40 tentacles borne on the margin of moderately developed branchial velum; the larger and smaller ones alternating almost regularly; usually a minute papilla between each. Atrial tentacles present. Ciliated groove simple U-shaped opened anteriorly, sometimes with either or both horns rolled out (Fig. 23, G-D). Branchial formula in a $27.3 \mathrm{~mm}$ long specimen is:

$$
\begin{aligned}
& \text { L. D. } 1(17) 6(25) 4(26) 6(20) 6 \mathrm{~V} . \\
& \text { R. D. } 1 \text { (18) } 5(23) 6(23) 6(11) 8 \mathrm{~V} \text {. }
\end{aligned}
$$

Usually 3 to 5 stigmata oval and not so much elongated in a mesh in the interspace. Visceral mass rather less extensive; first intestinal loop rather deep but opened, while the second more or less shallow (Fig. 23, D), or sometimes barely discernible. Stomach occupying more than half of the proximal (=posteroventral) branch of first intestinal loop; oval in outline and provided with about 20 longitudinal plications over the whole surface, but without pyloric coecum. Rectum elongated; anal margin cut into about 15 lobules. Small endocarps in first loop, as well as along the outer margin of the bottom of the loop on the left side, though no endocarps on the right. Gonads distributed over nearly the whole inner surface on each side; one to several in first loop along the intestine and rectum. Numbers of gonads are:

in $19.0 \mathrm{~mm}$ long specimen

$19.5 \mathrm{~mm}$

$22.0 \mathrm{~mm}$

$23.0 \mathrm{~mm}$

$23.5 \mathrm{~mm}$

$26.5 \mathrm{~mm}$

$26.5 \mathrm{~mm}$

$27.3 \mathrm{~mm}$

$31.0 \mathrm{~mm}$
18 (including 3 in the loop) on the left; 16 on the right,

$11(3) ; 24$,

$23(1) ; 22$,

$20(2) ; 35$,

17 (1); 26,

$26(2) ; 31$,

$22(4) ; 28$,

29 (2); 41,

14 (1); 27.

Gonads elongated, up to $8 \mathrm{~mm}$ long; attached to mantle wall by a thin membrane along nearly their whole length; fully mature. Up to 30 or more testicular follicles arranged in a double row on the attachment side. Eggs up to $200 \mu \mathrm{m}$ in diameter.

Remarks. The present specimens resemble $P$. psammotesta especially in the test appearance, structure of branchial sac, arrangement of alimentary canai, distribution of endocarps, and the number, distribution, shape and structure of gonads. The elongated gonads in this species are reminiscent of $P$. longicarpa Tokioka from Arafura Sea (Tokioka, 1952), but $P$. psammotesta is distinguishable from $P$. longicarpa mainly by the complete absence of gonads in the first intestinal loop in $P$. longicarpa.

Distribution in Japan Sea. Hakodate (Tokioka, 1967c); Wakasa Bay, $110 \mathrm{~m}$ (in the present study).

Distribution outside Japan Sea. Sagami Bay, 100-400 m (Tokioka, 1953c); Suruga 
Bay, 63-100 fms (Tokioka, 1967c).

\section{Polycarpa granosa Tokioka, 1953}

Polycarpa granosa Tokioka, 1953c, pp. 248-249, pl. 49, figs 5-8.

Material examined: None.

Remarks. A single $72 \mathrm{~mm}$ long specimen dredged from Wakasa Bay in the Japan Sea was referred to this species by Tokioka (1959a), remarking that the specimen is different from the type specimen collected from Sagami Bay in the absence of "an accessory fold at each of the second to fourth branchial folds" and that of "a pad-like structure -- in front of the dorsal tubercle" in the former. These features in the specimen from Wakasa Bay are shared in common with the specimens from Tanabe Bay, Kii Peninsula and from Kochi Prefecture, according to Nishikawa's unpublished observations. Therefore, so far as the present state of knowledge is concerned, the above-mentioned differences do not suggest a taxonomic distinctiveness of the population in the Japan Sea from that on the Pacific coasts of Japan.

Distribution in Japan Sea. Wakasa Bay (Tokioka, 1959a).

Distribution outside Japan Sea. Sagami Bay (Tokioka, 1953c); Tanabe Bay, $0 \mathrm{~m}$ (Nishikawa, 1980b); ?Osaka Bay, $0 \mathrm{~m}$ (Nishikawa's unpublished data); Usa, Kochi Pref. (do.).

\section{Polycarpa divisa (Ostroumov et Pavlenko, 1911)}

Pandocia divisa Ostroumov \& Pavlenko, 1911, pp. 24-25, figs 2-3; Redikorzev, 1916, pp. 333-335, fig. $75 ; 1941$, p. 194.

Polycarpa divisa: Hartmeyer, 1923, p. 284.

Material examined: None.

Distribution in Japan Sea. Peter the Great Bay, about 45-84 m deep (Ostroumov \& Pavlenko, 1911; Redikorzev, 1916, 1941), as well as an unknown locality, $68 \mathrm{~m}$ (Redikorzev, 1941), though I have not examined the specimens.

Distribution outside Japan Sea. Okhotsk Sea, 100 m deep (Redikorzev, 1941).

\section{Cnemidocarpa irene (Hartmeyer, 1906)}

Styela irene Hartmeyer, 1906, pp. 7-8, fig. 4.

Styela esther Hartmeyer, 1906, pp. 8-10; Oka, 1935, pp. 445-447, figs 15-16. New Synonymy.

Cnemidocarpa valborg Hartmeyer, 1919, pp. 35-39, pl. 1, figs 14-16; Monniot \& Monniot, 1984, pp. 577-578. New Synonymy.

Cnemidocarpa areolata: Tokioka, 1953a, pp. 14-15, fig. 9; 1953c, pp. 254-256, pl. 54, figs 1-9, pl. 58, figs 5-8; 1954a, pp. 261-262, pl. 35, figs 4-7; 1954c, pp. 85-86, fig. 3; 1959a, pp. 229-230, pl. 15, figs 23-24; 1961, pp. 126-128, fig. 12; 1962a, p. 17; Rho, 1971, pp. 117-118, pl. 5, figs 1-7; 1975, pp. 136-137; Nishikawa, 1980b, tab. 1; 1982b, p. 204; 1984b, p. 151; 1986b, p. 176; Kott, 1985, pp. 122-124, figs 50b, c, 53. (Heller's original description of Styela areolata excluded). For other synonyms and references see Monniot \& Monniot (1984). 
Doubtful reference:

Cnemidoiarpa fertilis: Nishikawa \& Tokioka, 1976a, pp. 397-398, fig. 7.

Material examined: A (Toyama Bay): 4 individuals, $16-28 \mathrm{~mm}$ long. B (Tsugaru Strait): labeled Styela esther by Oka: No. 12(M466), collected off Oma on Aug. 18, '27 by Hozawa, Takatsuki and Sato, a $43 \mathrm{~mm}$ long one; No. 183(M497), the same location and date as No. 12, a $17 \mathrm{~mm}$ long individual with a $28 \mathrm{~mm}$ long extension of test; these specimens clearly representing a part of "seven specimens of Styela esther -- obtained at Oma-simote, August 18, 1927" and described by Oka (1935). C-8 (Oki): Dogo Is.: Jyodoga-ura, 3-8 m deep, 5 individuals, 28-37 mm long; Ooku, $3 \mathrm{~m}, 3,25.3-$ $32.5 \mathrm{~mm}$ long. Nishinoshima Is.: Mimimimi-ura, $1-3 \mathrm{~m}, 2$ individuals, $32.5 \mathrm{~mm}$ and $40.8 \mathrm{~mm}$ long, respectively; Chinzaki, 1-6 m, a $60.5 \mathrm{~mm}$ long individual; Izanaki-ura, $1-3 \mathrm{~m}$, a $31 \mathrm{~mm}$ long individual. D (Tottori): 9 individual collected in Oct. '77 and Aug and Dec. '78, 3-13 mm long. E1 (Wakasa Bay): a $26 \mathrm{~mm}$ long individual. G-2 (Noto): 2 individuals, $10 \mathrm{~mm}$ and $11.5 \mathrm{~mm}$ long. $\mathrm{H}-3$ (Noto) : 2 individuals, $11 \mathrm{~mm}$ and $25 \mathrm{~mm}$ long. L-4: a $12 \mathrm{~mm}$ long individual. L-9 (Kyushu): 4 individuals, $10-15 \mathrm{~mm}$ long. L-10 (Noto): 3 individuals, $30-31 \mathrm{~mm}$ long. $\mathrm{M}$ (Oga): 9 individuals, 15-39 mm long, already listed by Nishikawa (1984b). $\mathrm{N}$ (Oki): 41 individuals, 12.5-44 mm long, already listed by Nishikawa (1986b).

Remarks. The present specimens all have a globular stomach that occupies nearly half the ventral branch of the first intestinal loop; this loop is deep but rather wide and the second loop more or less shallow and wide; the gonads are often branched distally, more or less flattened, attached firmly and directly to mantle by the wide surface, and occupy more or less wide part of mantle on each side; 1 to 4 (usually 2) on the left, elongated roughly dorsoventrally along second loop, while 2 to 7 (usually 3 or 4 ) on the right. These features, as well as those seen in the external appearance and structure of branchial sac, are also shared with "so-called Cnemidocarpa areolata (Heller)". Each gonad is usually provided with a single aperture of sessile or somewhat elongated sperm duct located close to the opening of oviduct, though in the specimens of collection $\mathrm{B}$ and some of those of $\mathrm{N}$, the sperm duct is sometimes furnished with 2 to 4 apertures all close to one another, due to the branching of the orifice end of the duct. The $17 \mathrm{~mm}$ long specimen of $B$ has a single gonad in the first loop along the rectum, in addition to 3 in the second loop, on the left. These anomalies seen in the specimens of $\mathrm{B}$ and $\mathrm{N}$ are here regarded as individual variations. In several specimens of $\mathrm{N}$, the inner surface of branchial siphon is covered with a colonial hydrozoan (see Kubota \& Yamada, 1988).

Recently Monniot \& Monniot's (1984) reexamination of the type specimen of Styela areolata Heller, 1878 revealed that it is distinguishable from "so-called C. areolata (Heller)" by the very deep and narrow second intestinal loop and the short and divided sperm duct opening on a cluster of papillae ("un bouquet de papilles") on the mesial surface of ovary in the former. On the basis of these differences they redefined $C$. areolata sensu stricto, and many previous records of $C$. areolata were moved to $C$. valborg Hartmeyer originated for the specimens from NW Australia. By the courtesy of C. Monniot, I examined his specimen of $C$. areolata sensu stricto collected in India and mounted on a glass slide. According to his personal communication, the mentioned feature of sperm duct in this Indian specimen is shared with the type specimen of $C$. areolata. My examination proved that the abovementioned "bouquet" of papillae of sperm duct is a tuft of 8 to 12 filaments, up to 
about $1 \mathrm{~mm}$ long, issuing from close vicinity to the opening of oviduct, situated on the orifice extremity of each gonad; no other apertures of vas deferens are detectable on the mesial surface of gonads. Thus, the manner of opening of vas deferens in $C$. areolata sensu stricto is distinct markedly from that seen in "so-called $C$. areolata" and even the specimens of the collections B and $\mathrm{N}$ stated above, or from Styela n. sp. (formerly sometimes called Siyela esther; see below). Therefore, I would like to follow Monniot \& Monniot's opinion about the separate status of "socalled C. areolata" from $C$. areolata sensu stricto, though not agreeing with them on the valid name of the former taxon on the following account.

My reexamination of the holotype $16 \mathrm{~mm}$ long specimen of Styela irene Hartmeyer revealed that it is conspecific with "so-called $C$. areolata" and $C$. valborg. The holotype was collected from Miyazu, Wakasa Bay in the Japan Sea, 70-80 m and deposited at MNB (No. ZMB 2230). The following is the additional morphological notes to the original description of $S$. irene: test thin, leathery and white; filamentous atrial tentacles present; ciliated groove simple C-shaped opened anteriorly; branchial formula is :

$$
\begin{aligned}
& \text { L. D. } 2 \text { (10) } 2 \text { (11) } 4 \text { (11) } 4 \text { (10) } 4 \text { V. } \\
& \text { R. D. } 0 \text { (10) } 3 \text { (11) } 3 \text { (10) } 3 \text { (7) } 3 \text { ? V.; }
\end{aligned}
$$

up to 8 stigmata per mesh; dorsal lamina not so tall, smooth-edged; many endocarps borne on the inner surface of mantle; alimentary canal same as in the original description; gonads of Cnemidocarpa-type in structure, attached to mantle by wide surface; only 2 gonads (instead of 3 in the original description) on the left, of which the anterior one bifurcated along nearly its whole length, while on the right 6 (instead of 3) elongated branches of gonads, though the exact number of gonads unknown for the lack of orifice part of the branches. Further, one of the two type specimens of Styela esther Hartmeyer, 1906 was also reexamined, that had been collected from Fukuura, Sagami Bay and now deposited at MNB (No. ZMB 2799); the other specimen is unfortunately absent there (personal communication of $\mathrm{D}$. Kühlmann). The present specimen falls within the variation range of "so-called C. areolata" in nearly all significant features, except that the second intestinal loop is somewhat deep and rather narrow; this difference may be of little taxonomic significance. In this specimen, there are two gonads on each side (as in its original description), which are of Cnemidocarpa-type in structure and attached to mantle by wide surface; each gonad is furnished at its proximal terminal with a single aperture of oviduct accompanied by a single opening of vas deferens. Thus, $S$. irene and $S$. esther are regarded as conspecific with "so-called $C$. areolata", as well as with $C$. valborg in the sense of Monniot \& Monniot (1984). Among the available specific names of the taxon concerned, irene is apparently the oldest (over esther by the position precedence), and therefore considered here the valid name.

Reexamination of the $12 \mathrm{~mm}$ long specimen collected in the Amami Isls and referred to $C$. fertilis (Hartmeyer) by Nishikawa \& Tokioka (1976a) revealed that the gonads in the specimen are attached to mantle by the wide surface, instead of by 
fine filaments always seen in C. fertilis (see below), and that the present specimen is consistent with the previous descriptions of $C$. irene except in the extraordinarily large stomach in the former. This difference is possibly of taxonomic significance, so the present record is here included but rather tentatively in the synonymy of $C$. irene.

Distribution in Japan Sea. Tsugaru Strait (Oka, 1935; in the present study); Oga Pen., 10-33 m (Nishikawa, 1984b; in the present study); Sado (Tokioka, 1962 a); Toyama Bay, 22-36 m (in the present study); Tsukumo Bay (do.); Uchiuracho, NE coast of Noto Pen., $0 \mathrm{~m}$ (do.); Fukuura, W coast of Noto Pen., 5-10 m (do.); Wakasa Bay, 0-80 m (Hartmeyer, 1906; Tokioka, 1959a; in the present study); Oki Isls, 1-55 m (Nishikawa, 1986b; in the present study); Tottori, $0 \mathrm{~m}$ (in the present study); Kokura, $1.5 \mathrm{~m}$ (do.); Korean coasts facing the Japan Sea and Cheju Is., Korea Strait (Rho, 1971, 1975).

Distribution outside Japan Sea. Sagami Bay, down to $16 \mathrm{~m}$ (Hartmeyer, 1906; Tokioka, 1953c), Shimoda (Nishikawa, 1982b), Ise Bay (Nishikawa's unpublished data), around Kii Pen., 0-130 m (Nishikawa, 1980), Osaka Bay (Tokioka, 1954c), Seto Inland Sea, $0 \mathrm{~m}$ (Tokioka, 1953a), Kochi Pref., 4-80 m (Nishikawa's unpublished data), Kagoshima Bay, 0-2 m (do.), Tokara Isls (Tokioka, 1954a) and ?Amami Isls (Nishikawa \& Tokioka, 1976a), Japan; Yellow Sea coast of Korea (Rho, 1975); Hong Kong (Kott \& Goodbody, 1980); Marianas (Tokioka, 1967c); Palau (Tokioka, 1950); around Australia (Hartmeyer, 1919; Hartmeyer \& Michaelsen, 1927, 1928; Hastings, 1931; Kott, 1952, 1964, 1966, 1985); New Caledonia (Tokioka, 1961; Vasseur, 1967a); Fiji (Kott, 1981), all in the West Pacific region. Guadeloupe Is., Caribbean Sea of the Atlantic (C. Monniot, 1983b).

\section{Cnemidocarpa clara (Hartmeyer, 1906)}

(Fig. 25)

Styela clara Hartmeyer, 1906, pp. 13-14, fig. 7; Oka, 1935, pp. 442-444, figs 12-13.

Styela elsa Hartmeyer, 1906, pp. 10-12, fig. 5. New Synonymy.

Styela macrogastra Oka, 1935, pp. 450-451, figs. 20-21. New Synonymy.

Cnemidocarpa macrogastra: Tokioka, 1967c, pp. 183-184, fig. 77, b-e; Rho, 1971, p. 118, pl. 4, figs $2-5 ; 1975$, p. 138 . Nishikawa's (1984b, p. 151) reference excluded.

Azygocarpa mutuensis Oka, 1932f, pp. 391-393, fig. 1; 1935, pp. 455-456, figs 25-26. New Synonymy.

For other references see Tokioka (1967c).

Doubtfui synonyms and references:

Cnemidocarpa clara: Redikorzev, 1941, pp. 191-192, fig. 15; Beniaminson, 1971, p. 319.

Cnemidocarpa heterotentaculata Beniaminson, 1971, pp. 295-297, fig. 1; 1976, p. 123, fig. 284.

Cnemidocarpa monnioti Beniaminson, 1971, pp. 297-299, fig. 2.

Siyela joannae Herdman, 1898, pp. 264-265, pl. 13, figs 5-9.

Cnemidocarpa joannae: Huntsman, 1912, pp. 159-162, pl. 12, fig. 6, pl. 20, figs 2-3.

Cnemidocarpa finmarkiensis joannae: Redikorzev, 1916, pp. 261-265, text-fig. 56, pl. 6, fig. 1 .

Material examined: A (Toyama Bay): 2 individuals, $6.5 \mathrm{~mm}$ and $11 \mathrm{~mm}$ long, respectively, the smaller from Ascidia gemmata. B: No. 4(M416) (part), labeled Azygocarpa mutuensis by Oka, a 20 
$\mathrm{mm}$ long individual collected in the southern coast of Yunoshima Islet, Mutsu Bay on June 21, '26 by Takatsuki; No. 208(M293), labeled Styela platoidea by Oka, a $26 \mathrm{~mm}$ long individual in Hakodate on July 2, '17, mantle body deteriorated very much. C-1 (Hokkaido): Misaki, southern end of Rishiri Is., $2-4 \mathrm{~m}$ deep, a $12.5 \mathrm{~mm}$ individual; in front of Marine Biological Station of Sapporo Medical College, Pon-misaki, 1-6 m, 2 individuals, $9.5 \mathrm{~mm}$ and $14 \mathrm{~mm}$ long; Kabuka, Rebun Is., $2-3 \mathrm{~m}$, on Aug. 6, 4 individuals, 7-13 mm long; Nishiue-domari, Rebun Is., $1-8 \mathrm{~m}, 2$ individuals, $7 \mathrm{~mm}$ and $10 \mathrm{~mm}$; Shukutsu, 1-4 m, a $16 \mathrm{~mm}$ long individual; Chazu, Bikuni, 3-5 m, a $14 \mathrm{~mm}$ long individual; Muenjima coast, Okushiri-jima Is., 2-3 m, a $13 \mathrm{~mm}$ long individual. C-2 (Mutsu Bay): off Kaizaki, SW end of Shimokita Pen., 15-20 m, 3 individuals, 16-23 mm long; Hadakajima Islet, in front of Asamushi Mar. Biol. St., 1-4 m, a $15 \mathrm{~mm}$ long individual; from buoys off Moura, near Asamushi, 2 individuals, $12 \mathrm{~mm}$ and $19 \mathrm{~mm}$ long. $\mathrm{D}$ (Toitori): a $10.8 \mathrm{~mm}$ long individual in June, '78.

Description. The following description is based on the specimens except the specimen No. 4 (part) of material B. In life the animal dark red, if recorded. Body more or less flattened laterally or dorso-ventrally, attached to the substratum by the whole left, or rarely right, side or the wide dorsal side. Test thin, leathery, nearly opaque and white. The surface quite smooth, and, except in the specimens from A, sprinkled usually densely, but sometimes rather sparsely with minute pale yellowish flecks, up to $250 \mu \mathrm{m}$ or more in diameter (Fig. 25, A). Both apertures usually situated close to each other. Ciliated groove C-shaped opening anteriorly; about 24 tentacles. Atrial tentacles present. Dorsal lamina tall and its margin irregularly serrated, as shown by Tokioka (1967c, fig. 77, e). Four branchial folds on each side. Many endocarps over nearly the whole inner surface of mantle. Stomach voluminous and elongated, occupying nearly the whole ventral branch of first intestinal loop, that is deep and narrow. Second intestinal loop usually very deep with its axis passing through the cardiac end of stomach, but rarely rather shallow (Fig. 25, B). Gonads much elongated and more or less sinuous in appearance; 3 to 5 (usually 4 or 5) on the left, one or two situated along the rectum, while the rest more or less ventrally; and 4 to 8 (usually 5 or 6 ) on the right (Fig. 25, A-C). Each

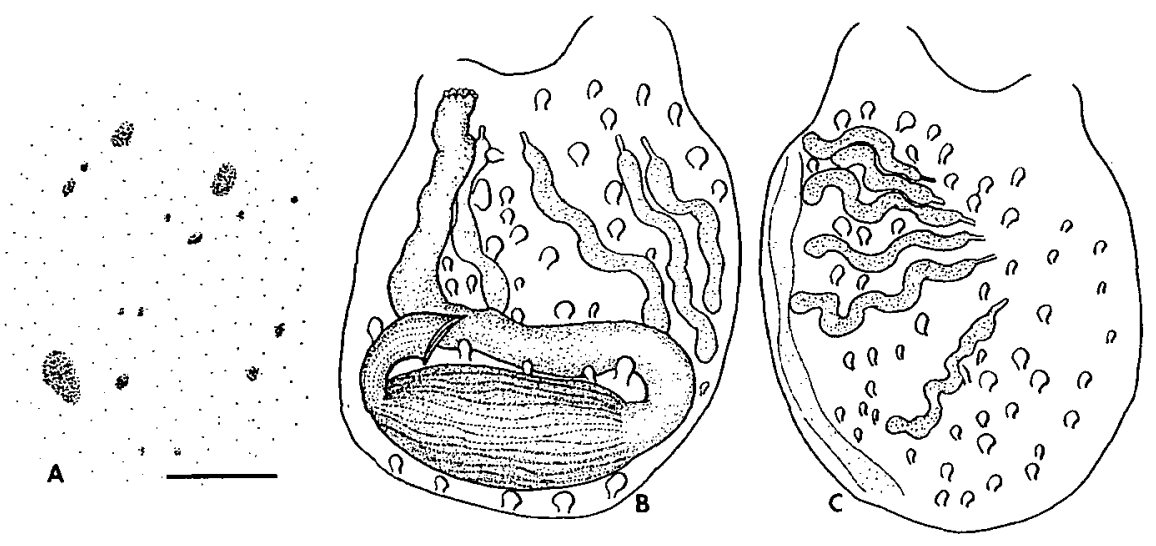

Fig. 25. Cnemidocarpa clara (Hartmeyer), $13 \mathrm{~mm}$ long specimen from Rebun Is., Hokkaido (Collection $\mathrm{C}-1$ ). A. enlarged view of a part of test surface, showing pigment flecks, scale indicates $500 \mu \mathrm{m}$; B. left inner side of mantle body; $\mathrm{C}$. right inner side of mantle body. 
gonad attached to mantle only by several to many very thin but tough fibers; testicular oval follicles in a single row on the attachment side facing mantle.

Remarks. The above-described specimens fall within the variation range of $C$. macrogastra represented by many previous descriptions, so they are regarded as conspecific with it. Further, only a single sample labeled Azygocarpa mutuensis Oka among the specimens of OCUT is reexamined, that was collected on the southern coast of Yunoshima Islet, near Asamushi, Mutsu Bay on June 21, 1926 and registered as No. 4 (M416). The material consists of a $20 \mathrm{~mm}$ long, already dissected specimen and another $11.5 \mathrm{~mm}$ long intact one; examination of the latter proved that it Styela coriacea (see below). Oka's original description of $A$. mutuensis is apparently based on the $20 \mathrm{~mm}$ long specimen. When Oka (1935) later described the same species obviously on the basis of this specimen, he wrote as "one specimen of this curious Styela was obtained on the southern coast of Yunoshima, June 21, 1926. Nothing is known of occurrence of this species elsewhere" (p. 456). Thus, the 20 $\mathrm{mm}$ long specimen reexamined in the present study is regarded as the holotype of A. mutuensis by monotypy (see International Code of Zoological Nomenclature, 3rd ed., Art. 73 (ii)). This holotype of $A$. mutuensis is now regarded as conspecific with all the other specimens described above.

Hartmeyer (1906) established Styela elsa for two specimens from Sagami Bay and Osaka Bay. It has, however, been regarded as a junior synonym of Cnemidocarpa finmarkiensis joannae (Herdman) by Redikorzev (1916), and further, as of C. finmarkiensis by Hartmeyer (1923); the latter treatment was followed by Van Name (1945), Tokioka (1963) and so on. Recently I examined one of the two type specimens collected from Osaka Bay and housed at MNB (No. ZMB 2231), and proved that the specimen, though injured considerably, falls within the variation range of $C$. macrogastra; the other type specimen is now unavailable (personal communication of D. Kühlmann). The examined specimen, $15 \mathrm{~mm}$ long, can be regarded as the paratype, because the original description shows that the "Körper -- $25 \mathrm{~mm}$ lang, $33 \mathrm{~mm}$ hoch, $21 \mathrm{~mm}$ breit --"; the body flattened laterally, the test surface quite smooth and sprinkled wholly with pale brownish pigment flecks, the margin of dorsal lamina undulating and sometimes serrated slightly, the stomach occupying about three-fourths of the ventral branch of first intestinal loop, and the gonads (preserved very incompletely and the number unknown) attached to mantle by fine strands. And also in the same work as above, Hartmeyer (1906) originated a new species Styela clara on the basis of the four type specimens collected from Hakodate by Hilgendorf. My reexamination of all these specimens now deposited at MNB (No. ZMB 1092) in good condition revealed that they are conspecific with $C$. macrogastra. Thus, $S$. elsa, $S$. clara and $C$. macrogastra are considered synonymous, and then, clara is here chosen as a valid specific name of the taxon concerned, though elsa has the position precedence over clara. This is because the holotype specimen of $S$. elsa is now unavailable and its paratype is preserved very poorly as stated above, while the type series of $S$. clara is kept in good condition, and therefore the latter name has the advantage 
of the stability and universality of nomenclature over that of the former. The taxon concerned is therefore called Cnemidocarpa clara (Hartmeyer).

Some taxonomic or morphological notes are given below of the type series of C. clara in addition to its original description. Among the four syntypes, 16, 20, 20 and $22 \mathrm{~mm}$ long respectively, the smallest one is designated here as the lectotype, because this is obviously the specimen on which the illustration in the original description was based. The features of the type series are: body attached to substratum by the wide ventral region, but not depressed dorsoventrally; test surface nearly smooth or wrinkled slightly; yellowish flecks detectable over the surface; ciliated groove C-shaped opening anteriorly; dorsal lamina serrated irregularly, though described originally as "mit glattem Rande"; the branchial formulae are:

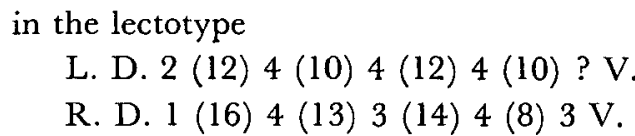

in a $20 \mathrm{~mm}$ long paralectotype

L. D. 3 (24) 4 (16) 7 (14) 6 (13) $4 \mathrm{~V}$.

R. D. 3 (24) 8 (19) 6 (14) 7 (12) $4 \mathrm{~V}$.

Alimentary system and the appearance of gonads quite the same as in the description; 4 gonads on each side in the lectotype, but in the paralectotypes 4 on one side and 5 on another; each gonad attached to mantle by thin filaments; testicular follicles, occupying the attachment side facing the mantle, arranged in a single row or two.

Oka (1935) recorded $S$. clara from Mutsu Bay. I tried to reexamine Oka's specimens, but they had been lost. Judging from his description, however, Oka's specimens may be assigned to $C$. clara delimited above. Further, Redikorzev (1941) also recorded $C$. clara from Possjet Bay, described only as: tentacles 30 to 35 , the smaller papilla-like, while the larger furnished with small side-branches; ciliated groove circular; up to 7 gonads on the left. So far as his brief description is concerned, except the branched tentacles, his specimens fall within the variation range of $C$. clara. In the branched tentacles stated above Redikorzev's material resembles C. heterotentaculata Beniaminson and C. monnioti Beniaminson, both recorded from Possjet Bay by Beniaminson $(1971,1976)$. These two species are quite similar to C. clara in the alimentary system and gonads, and different from this species only in the occasional occurrence of branched tentacles in these two species, instead of their complete absence in $C$. clara. This difference is possibly of certain taxonomic significance, so Beniaminson's two species, as well as Redikorzev's specimens mentioned above, are here included doubtfully in the synonymy of $C$. clara.

The voluminous stomach in $C$. clara reminds me of $C$. joannae (Herdman) recorded from the Oregonian region of the Pacific coast of North America by Herdman (1898) and Huntsman (1912b), as well as of $C$. finmarkiensis joannae from the Okhotsk and the Japan Sea by Redikorzev (1916). C. joannae is similar to C. clara also in the test color (bright, orange red in C. joannae) and appearance of gonads (elongated, 
often sinuous in outline, attached loosely to mantle, and 5 to 12 on the left and 7 to 12 on the right). C. joannae and C. finmarkiensis joannae have been regarded as synonyms of C. finmarkiensis (see, for example, Hartmeyer, 1923, pp. 256-261; Van Name, 1945, pp. 266-268). However, I am inclined to treat the first two taxa as doubtful synonyms of $C$. clara, and as distinct from, though very closely related to, C. finmarkiensis, laying stress on the difference seen in the size of stomach ("short and rounded" (Van Name, 1945, p. 267) in C. finmarkiensis, while voluminous in the first two).

Distribution in Japan Sea. ?Off Sikhote-Alin, $46^{\circ} 12^{\prime} 45^{\prime \prime} \mathrm{N}$ and $138^{\circ} 15^{\prime} \mathrm{E}, 75 \mathrm{~m}$ (Redikorzev, 1916); Rishiri, Rebun and Okushiri Isls, Bikuni and Otaru, Hokkaido, 1-8 $\mathrm{m}$ (Tokioka, 1967c; in the present study); Hakodate (Hartmeyer, 1906; in the present study); Tsugaru Strait (Oka, 1935); Mutsu Bay, 0-20 m (Oka, 1932f, 1935; in the present study); Toyama Bay, 22-100 $\mathrm{m}$ (in the present study); Wakasa Bay (Tokioka, 1953b, 1959a); Tottori, $0 \mathrm{~m}$ (in the present study); Korean coastal waters facing the Japan Sea and Korea Strait (Rho, 1971, 1975); ?Peter the Great Bay, 0.75-5.5 m (Redikorzev, 1941; Beniaminson, 1971, 1976); ?far off the Peter the Great Bay, 99-115 m (Redikorzev, 1916).

Distribution outside Japan Sea. Sagami Bay, 100-140 m (Hartmeyer, 1906; Tokioka, 1953c), Osaka Bay (Hartmeyer, 1906; Tokioka, 1954c) and Seto Inland Sea, down to $120 \mathrm{~m}$ (Tokioka, 1953a; Nishikawa's unpublished data), Japan; ?Sea of Okhotsk, $56^{\circ} 22^{\prime} \mathrm{N}$ and $138^{\circ} 09^{\prime} \mathrm{E}, 55 \mathrm{~m}$ (Redikorzev, 1916); ?coasts of British Columbia and Puget Sound, 0-20 fms (Herdman, 1898; Huntsman, 1912).

\section{0a. Cnemidocarpa fertilis fertilis (Hartmeyer, 1906)}

(Fig. 26)

Styela fertilis Hartmeyer, 1906, p. 16.

Cnemidocarpa fertilis: Tokioka, 1953c, pp. 256-259, pl. 55, figs 1-10, pl. 51, figs 1-9, pl. 57, figs 110; 1969c, p. 183, fig. 77a; Rho, 1975, pp. 137-138, pl. 6, figs 1-11; Millar, 1975, p. 298. Nishikawa \& Tokioka's (1976a, pp. 397-398) reference excluded, moved to $C$. irene.

Material examined: A (Toyama Bay): 5 individuals, 14-39 mm long.

Description. Body rather depressed dorsoventrally and attached to substratum by nearly whole ventral side (Fig. 26, A), or cylindrical and attached by left posterior half (Fig. 26, D). Siphons distinct or not; branchial aperture terminal, while the atrial subterminal or situated at anterior one-third of body. Test surface more or less wrinkled, provided sometimes with low protuberances mainly around apertures. About 30 or more tentacles, including several minute ones. Ciliated groove C-shaped opening anteriorly (Fig. 26, C) or to the left, but rarely somewhat deformed (Fig. 26, G). The branchial formulae are:
in $16 \mathrm{~mm}$ long one
L. D. 4 (22) 5 (22) 4 (21) 2 (18) $4 \mathrm{~V}$.
R. D. 4 (23) 6 (21) 4 (19) 4 (17) $4 \mathrm{~V}$.
in $39 \mathrm{~mm}$ long one L. D. 4 (21) 5 (23) 4 (24) 5 (18) $4 \mathrm{~V}$. 
R. D. 4 (16) 5 (29) 6 (18) 4 (14) 4 V.

Dorsal lamina smoothly margined. Visceral mass occupies roughly posterior half or more of mantle body. Stomach globular (Fig. 26, B and F), in a few cases somewhat elongated (Fig. 26, E), occupying one-third to half of the ventral, or posterior branch of first intestinal loop that is more or less deep and nearly closed. Second intestinal loop deep and narrow (Fig. 26, E-F), except the largest specimen with the loop deep but somewhat widely opened (Fig. 26, B); the axis of the loop passing through the cardiac end or the middle of stomach. Rectum straight or somewhat curved. Many endocarps over the whole inner surface of mantle (Fig. 26, E-F), or around visceral mass on the left side (Fig. 26, B). Gonads mature; elongated and slender but not so voluminous, and sometimes sinuous in appearance; attached to mantle by many thin filaments. Number of gonads is:

$\begin{array}{lc}\text { in } 14 \mathrm{~mm} \text { long specimen } & 4 \text { on the left } ; 5 \text { on the right } \\ 15 \mathrm{~mm} \text { long one } & \text { indiscernible } \\ 16 \mathrm{~mm} \text { long one } & 4 ; 4 \\ 20 \mathrm{~mm} \text { long one } & 4 ; 1 \\ 39 \mathrm{~mm} \text { long one } & 15 ; 16 .\end{array}$

Testicular follicles arranged roughly in a double row on attachment side.

Remarks. As the original description of Styela fertilis Hartmeyer seems insufficient, I examined one of the 3 type specimens, that was collected in Tokyo Bay, $20 \mathrm{~m}$ deep and housed at MNB (No. ZMB 2800). This specimen, $37 \mathrm{~mm}$ long and already dissected, conforms very well to the previous descriptions of Cnemidocarpa fertilis (Hartmeyer), especially that given by Tokioka (1953c) in the external ap-

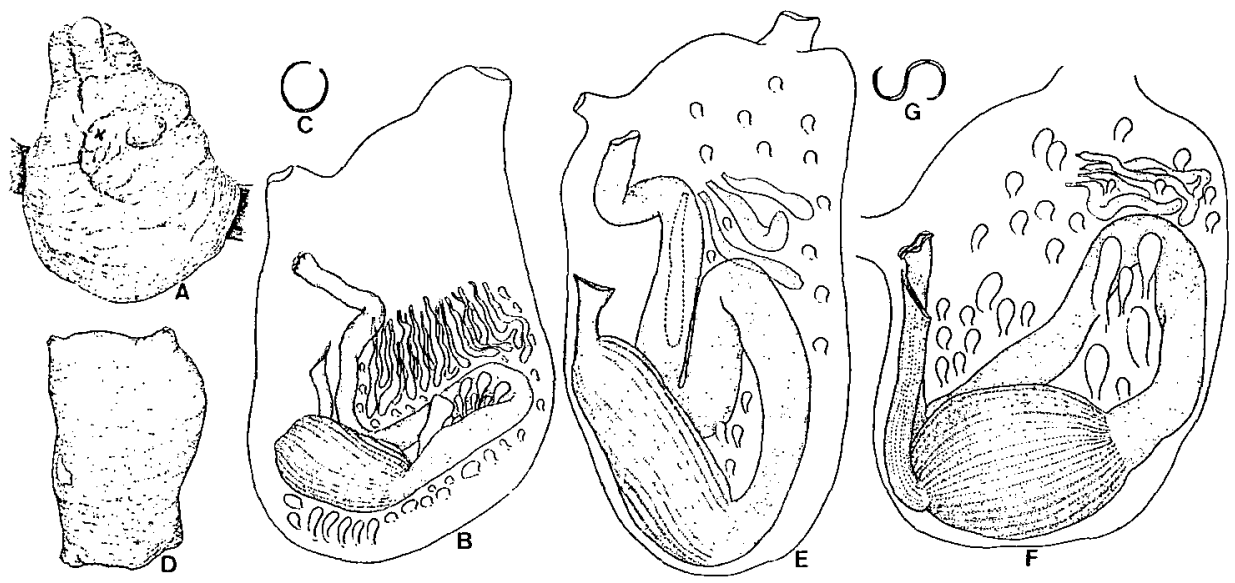

Fig. 26. Cnemidocarpa fertilis fertilis (Hartmeyer) from Toyama Bay (Collection A). AC. $39 \mathrm{~mm}$ long specimen; D-F. $16 \mathrm{~mm}$ long one; F-G. $20 \mathrm{~mm}$ long one. A \& D. whole body; B, E \& F. left inner side of mantle body; C \& G. ciliated groove. 
pearance and the internal features such as the arrangement of intestinal loop and that of gonads. Some morphological features are as follows: the body flattened dorsoventrally; test surface wrinkled and furnished densely with minute protuberances or projections; test itself is rather thick, very tough but not hard, leathery, opaque and dull white; fine atrial tentacles arranged in a single ring; ciliated groove simple C-shaped opening anteriorly; the branchial formula on the left side is D. 2 (20) 1 (16) 4 (15) 4 (14) $3 \mathrm{~L}$., while that on the right is undescribable due to hard injury of the sac; dorsal lamina very low with smooth margin; many endocarps over the inner surface of mantle; stomach injured, but apparently occupying onethird of the ventral branch of the first loop; its bottom sharply bent dorsally; gonads mature, obviously of Cnemidocarpa-type, 19 on the left and 28 on the right; each gonad elongated, sometimes sinuous, branched very rarely, and attached to mantle by long or short fine filaments; a single or double rows of testicular follicles occupying the attachment surface of gonad.

The specimens from the Japan Sea and examined in the present study are consistent with previous descriptions of $C$. fertilis, as well as one of its type specimens mentioned above, except in the smaller number of gonads ( 1 to 5 on each side) in the smaller four (14 to $20 \mathrm{~mm}$ long) specimens of the present material. C. fertilis has been described as furnished with 6 to 30 gonads on each side. The smaller number of gonads in the Japan Sea specimens is highly reminiscent of $C$. fertilis minor (see below), but these specimens are distinguishable from $C$. fertilis minor by the more or less stout and extensive appearance of gonads in the latter. Here, these specimens, as well as the largest one with usual number of gonads, are referred together to $C$. fertilis fertilis, the nominotypical subspecies of C. fertilis. C. fertilis fertilis is quite similar to $C$. finmarkiensis (Kiaer) recorded from the Arctic waters, as well as the boreal coasts of the North Pacific, especially in the features of alimentary system and gonads (see Van Name, 1945, pp. 266-268).

Nishikawa \& Tokioka's (1976a) record of C. fertilis from Amami Islands was proved to be erroneous by the reexamination. of their specimens; the gonads are attached to mantle by the wide surface, instead of by thin filaments as always seen in C. fertilis. This record was transferred into the synonymy of $C$. irene; for further details see its remarks in the foregoing pages.

Distribution in Japan Sea. Toyama Bay, $105-115 \mathrm{~m}$ (in the present study); Korea Strait, down to $117 \mathrm{~m}$ (Rho, 1975; Millar, 1975).

Distribution outside Japan Sea. Tokyo Bay, $20 \mathrm{~m}$ (Hartmeyer, 1906); Uraga Channel, $80 \mathrm{~m}$ (do.); Sagami Bay, to $400 \mathrm{~m}$ (Hartmeyer, 1906; Tokioka, 1953c, 1967c).

110b. Cnemidocarpa fertilis minor Tokioka, 1954

(Fig. 27)

Cnemidocarpa fertilis f. minor Tokioka, 1954c, pp. 87-88, text-fig. 4, pl. 7, fig. 18; 1959a, pp. 230-231, pl. 16, figs 26-29; 1960a, pp. 201-202, pl. 25, figs 39-41; Nishikawa, 1986b, p. 176. 
Cnemidocarpa macrogastra: Nishikawa, 1984b, p. 151.

Material examined: E-2 (Fukui): a $27 \mathrm{~mm}$ long individual, found attached to Pyura sacciformis. M (Oga) : a $11 \mathrm{~mm}$ long individual, listed as Cnemidocarpa macrogastra by Nishikawa (1984b). $N$ (Oki): 8 individuals, 11-18 $\mathrm{mm}$ long, listed by Nishikawa (1986b).

Remarks. The present specimens resemble the previous descriptions of C. fertilis f. minor, and therefore, have been identified with this taxon. Brief morphological notes are as follows: test surface nearly smooth, attached to substratum by the whole right side in the specimens from E-2 and $M$, while covered densely with pebbles and shell fragments except a rather wide area around both apertures; the apertures of test furnished with small protuberances. Dorsal lamina smooth-margined, or serrated very slightly; many endocarps over the inner surface of mantle; second intestinal loop deep, its axis passing through the middle or cardiac end of stomach; stomach elongated and occupying half of ventral branch of the first loop (Fig. 27, A-C and E); gonads fully mature, and stout, voluminous and extensive (Fig. 27, A-F), attached to mantle by many thin fibers; their numbers are:

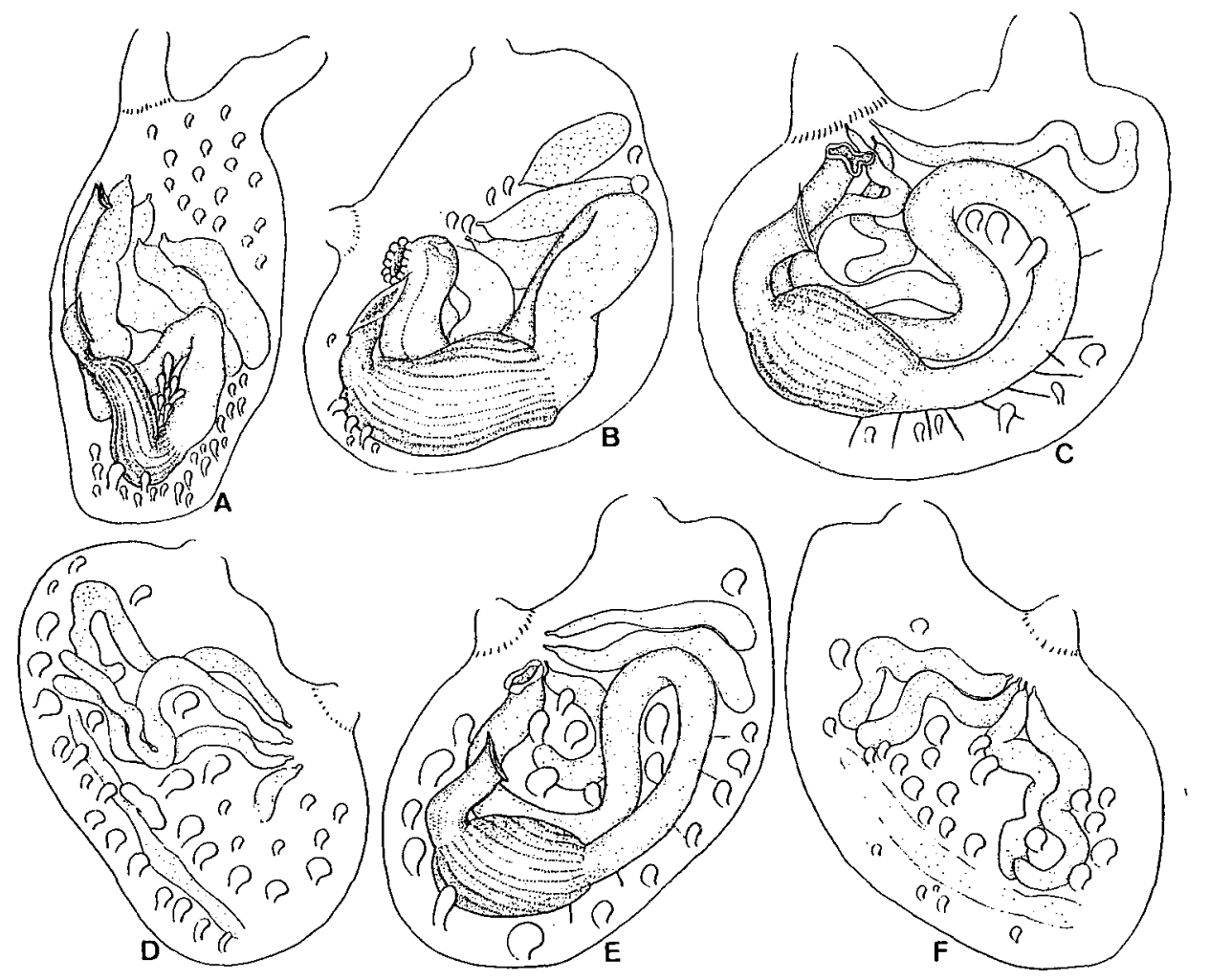

Fig. 27. Cnemidocarpa fertilis ninor Tokioka. A. $27 \mathrm{~mm}$ long specimen from Fukui Pref. (Collection E-2); B. $11 \mathrm{~mm}$ long specimen from off Oga Pen. (M); G-D. 15 $\mathrm{mm}$ long specimen from Oki Isls (N); E-F. $18 \mathrm{~mm}$ long specimen from Oki Isls (N). A-C, \& E. left inner side of mantle body; D \& F. right inner side of mantle body. 


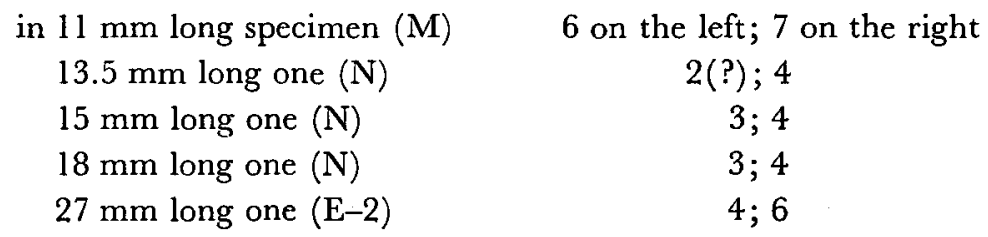

Testicular follicles arranged in one or two rows on the attachment side; ovarian eggs up to $170 \mu \mathrm{m}$ in diameter.

The present taxon is treated as subspecific rank, following the International Code of Zoological Nomenclature (3rd. ed.) Art. 45(g). Further discussions on the validity of the present treatment must await examination of more mature material from different localities.

Distribution in Japan Sea. Off Oga Pen., 59-62 m (Nishikawa, 1984b; in the present study); off Echizen-cho, Fukui Pref. (in the present study); Wakasa Bay (Tokioka, 1959a); off Oki Isls, 30-45 m (Nishikawa, 1986b; in the present study).

Distribution outside Japan Sea. Matsushima Bay (Tokioka, 1960a); ?Sagami Bay, $300 \mathrm{fms}$ (Hartmeyer, 1906); Osaka Bay, down to about $30 \mathrm{~m}$ (?Hartmeyer, 1906; Tokioka, 1954c).

\section{Cnemidocarpa miyadii Tokioka, 1949}

(Fig. 28)

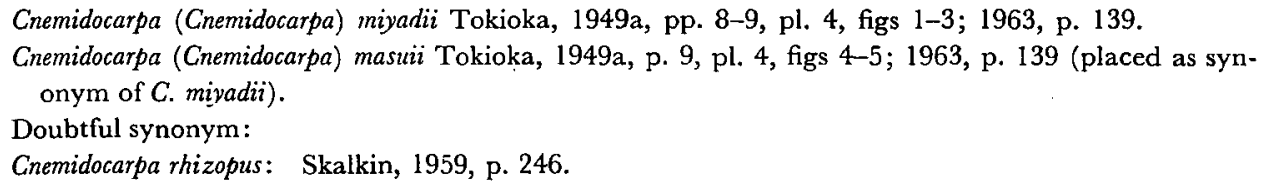

Material examined: J-4 (Wakasa Bay): 5 individuals, 6.5-9.3 mm long.

Description. Body oval or elongated oval in outline and flattened laterally. Several to a dozen or more tufts of filamentous projections of test issuing mainly from peripheral part, and often also other parts of body surface except around apertures (Fig. 2, A and D); each tuft consists of a short stem from which up to about 15 slender projections sprout. Surface also furnished with simple filamentous processes. These projections and processes carry foreign material such as sand grains, foraminiferan or molluscan shell debris and echinoid spines. Test thin but much hardened because of impregnation of foreign matter. Both apertures sessile and terminal. Twelve to 24 tentacles; the larger and smaller ones sometimes alternating regularly. Ciliated groove, if observable, as a transverse slit (Fig. 28, G and I). Branchial plications low and rather indistinct; the formulae are:

in the $7 \mathrm{~mm}$ long specimen

L. D. 0 (6) 1 (9) 0 (8) 0 (6) $0 \mathrm{~V}$.

R. D. 0 (8) $1(6)$ I (10) I (6) $0 \mathrm{~V}$. 
in the $8 \mathrm{~mm}$ long one
L. D. 0 (6) l (5) 2 (9) 1 (5) $2 \mathrm{~V}$.
R. D. $1(10) 0(9) 1(8) 1$ (5) 1 V.

Up to 4 to 6 stigmata per mesh in interspace; transverse vessels all of equal thickness; parastigmatic vessels present. Dorsal lamina tall, with smooth margin. No endocarps over inner surface of mantle. Alimentary system occupies nearly the posterior two-thirds of mantle body. Stomach globular or oval in outline, occupying nearly half of ventral branch of first intestinal loop; the loop deep but rather wide; stomach surface furnished with about 20 longitudinal plications; pyloric coecum indiscernible. Second loop distinct (Fig. 28, B and E) or not (Fig. 28, H); its axis passing through middle of stomach; rectum sometimes elongated. Gonads quite empty, small and stout, somewhat elongated transversely, and firmly attached to mantle directly by their lateral side. Four to 6 gonads on the left and 7 or 8 on

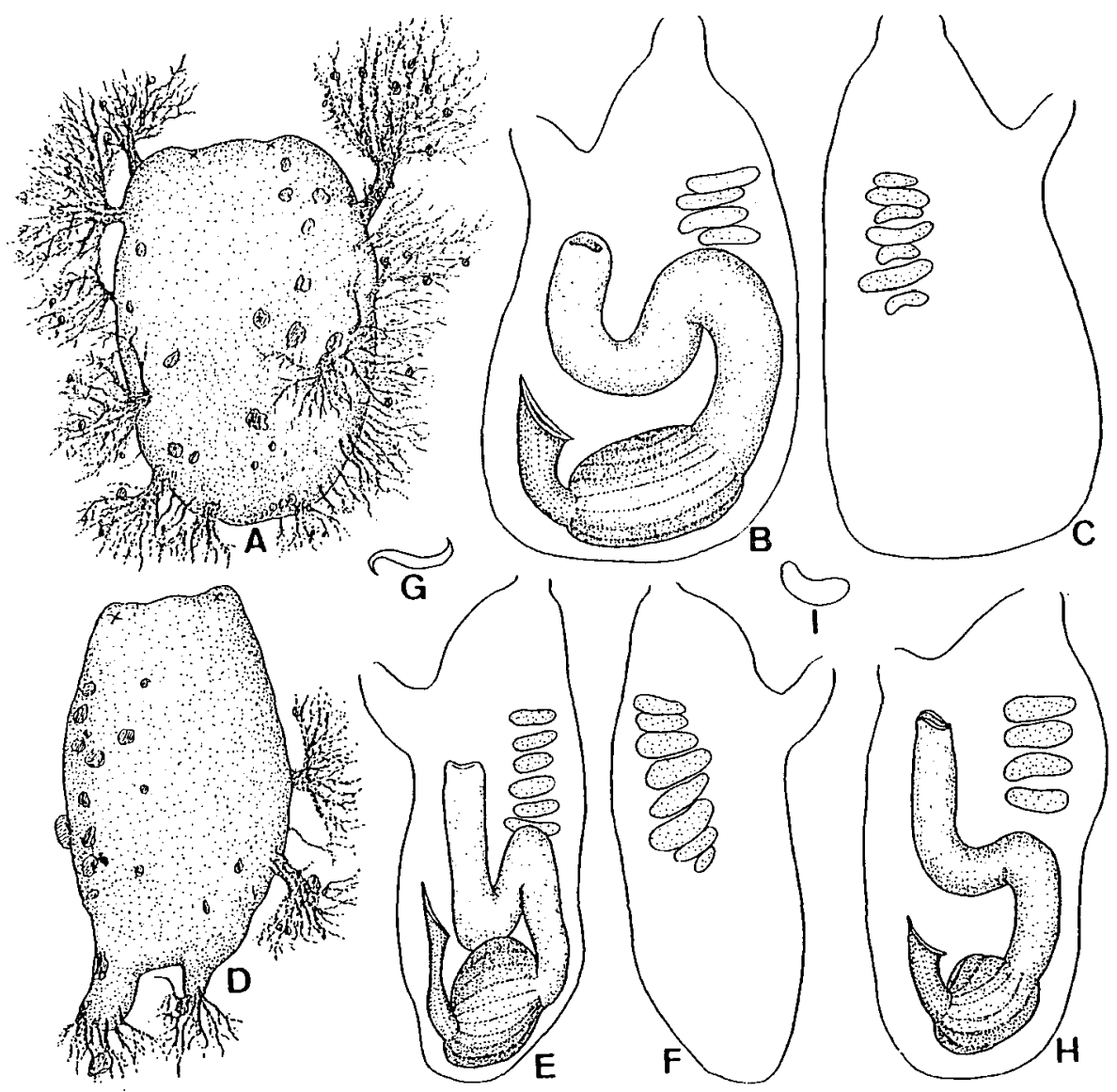

Fig. 28. Cnemidocarpa miyadii Tokioka from Wakasa Bay (Collection J-4). A-C. a $8 \mathrm{~mm}$ long specimen; D-G. $9.3 \mathrm{~mm}$ long specimen; H. $7 \mathrm{~mm}$ long; I. another $8 \mathrm{~mm}$ long. A \& D. whole body; B, E \& H. left inner side of mantle body; C \& F. right inner side of mantle body; G \& I. ciliated groove. 
the right situated anterior to the bottom of first loop and arranged in a single longitudinal row along the ventromedian line.

Remarks. The present specimens are similar to the original description of $C$. miyadii Tokioka on the basis of two specimens from Hakata Bay especially in the body surface being coated with fine sand and provided with "fine long hairy processes along the ventral side of the left (--attachment) side", the branchial structure such as low folds comprising each a small number of vessels, arrangement of alimentary canal, and the number and arrangement of gonads, with the exception of the ciliated groove (a transverse slit in these specimens, instead of C-shaped in C. mijadii). This difference seems to be of little taxonomic significance. The description lacks information regarding the filament tufts on the body surface; to check the possible existence of the tufts, a reexamination of the type material was planned, but it was not registered and could not be found in SMBL. However, the present specimens from Wakasa Bay may be regarded as conspecific with C. miyadii. Tokioka (1963, p. 139) synonimized C. miyadii with C. masuii Tokioka recorded from Matoya Bay, Kii Peninsula; $C$. masuii is provided with the ciliated groove as "a simple groove slightly undulated", as is shown above in the specimens from Wakasa Bay.

The number and arrangement of gonads in $C$. miyadii reminds me of Styela ascidioides Herdman recorded only once from the Gulf of Manaar, 9-26 fms deep by Herdman (1906). The former species is, however, easily distinguishable from the latter by the test structure ("cartilaginous, full of bladder cells and pigment cells (blue, black, red and yellow)" in the latter). Further, the external appearance of C. miyadii resembles C. chinensis Tokioka from China (Tokioka, 1967c) and Vietnam (Millar, 1975). C. miyadii is different from C. chinensis in the arrangement of gonads on the right side (many along the midline both dorsally and ventrally in $C$. chinensis).

C. miyadii may resemble C. rhizopus (Redikorzev) recorded from Arctic and adjacent waters (see Van Name, 1945, p. 265-266) and C. mollis (Stimpson) from the North Atlantic (see Van Name, 1945, pp. 263-264) especially in the external appearance and features of the branchial sac such as indistinct plications, but the first species is somewhat different from the last two in the gonads being elongated transversely and extensively. This difference is of taxonomic significance; consequently, C. miyadii is here regarded as distinct form, though closely related to C. rhizopus or C. mollis. Skalkin (1959) listed C. rhizopus from the western coast of South Sakhalin without any description. Zoogeographically such occurrence of this species may be possible. Another possibility cannot, however, be ruled out that Skaikin's material represents $C$. miyadii. In the present study, I have tentatively assigned Skalkin's $C$. rhizopus to C. miyadii.

Distribution in Japan Sea. ?Western coast of South Sakhalin (Skalkin, 1959); Uchiura Bay of Wakasa Bay, about $25 \mathrm{~m}$ (in the present study); Hakata Bay (Tokioka, 1949a).

Distribution outside Japan Sea. Matoya Bay, 8-10 m (Tokioka, 1949a). 


\section{Cnemidocarpa ramosa $\mathrm{n}$. sp.}

(Fig. 29)

Type series. Ten specimens, preserved more or less well, were chosen as the type series out of 16 individuals dredged by the R/V "Tansei-maru" of the Ocean Research Institute of the University of Tokyo on June 2, 1975 at St. 8, 37 $28.9^{\prime} \mathrm{N}$ and $137^{\circ} 23.4^{\prime} \mathrm{E}, 22-30 \mathrm{~m}$ deep, in Toyama Bay (Collection A). These selected material includes both the largest and smallest specimens. The $14.5 \mathrm{~mm}$ long and $10.5 \mathrm{~mm}$ wide specimen is designated as the holotype, deposited at the Seto Marine Biological Laboratory (SMBL Type No. 368), while the other 9 specimens, 8.5-19 mm long, as the paratypes, housed in the National Science Museum (Nat. Hist.), Tokyo (NSMT Pc No. 1098).

Description. Body stout, roughly cylindrical, attached to substratum by the posterior end; broad posterior extension of test is discerned in some of the paratype specimens (Fig. 29, D). Test surface irregularly wrinkled and provided with low protuberances especially in the anterior part; a conical, usually (but not always) prominent projection found between both apertures, that is often covered with a massive coral-like colony of a bryozoan (Fig. 29, A, D, G). Test itself thin but tough, leathery, opaque and pale brown, with a slight tint of yellowish green anteriorly. Both apertures nearly sessile, situated terminal. Mantle rather thin and pale brown, sometimes with dense white spherules, 50 to $70 \mu \mathrm{m}$ in diameter. Tentacles not well developed, sometimes very short, issuing from the margin of low velum; 13 in number in the holotype, and 9 to 12 in the paratypes. Ciliated groove C-shaped opening anteriorly. Dorsal lamina very tall, with the margin smooth or rarely slightly undulated. The branchial formulae are:

in the $8.5 \mathrm{~mm}$ long paratype

L. D. 3 (15) 4 (10) 4 (12) 4 (10) 3 V.

R. D. 3 (12) 2 (15) 4 (12) 4 (9) $3 \mathrm{~V}$.

in the holotype

L. D. 4 (17) 5 (19) 6 (15) 5 (10) $5 \mathrm{~V}$.

R. D. 5 (13) 7 (18) 5 (17) 5 (15) $6 \mathrm{~V}$.

in the $16 \mathrm{~mm}$ long paratype

L. D. 5 (26) 2 (24) 5 (14) 3 (15) $4 \mathrm{~V}$.

R. D. 9 (23) 4 (23) 3 (20) 4 (21) $6 \mathrm{~V}$.

Up to 5 stigmata per mesh. Many endocarps over the whole inner surface of mantle on each side. Numerous fine atrial tentacles issuing from nearly the whole inner surface of rather wide velum. Visceral mass occupying posterior half or more of mantle body; anterior margin of the mass never reaching anteriorly beyond posterior base of atrial siphon (Fig. 29, B, E, H). First intestinal loop deep but rather opened; most part of posterior (=proximal) branch of the loop occupied by elongated cylindrical stomach. Stomach furnished with about 20 longitudinal plications over the whole surface and with a small indistinct pyloric coecum. Second intestinal loop more or less shallow and opened very widely. Anus bi-lobed. Gonads thin, often sinuous, and elongated extensively, attached firmly to mantle by the wide 

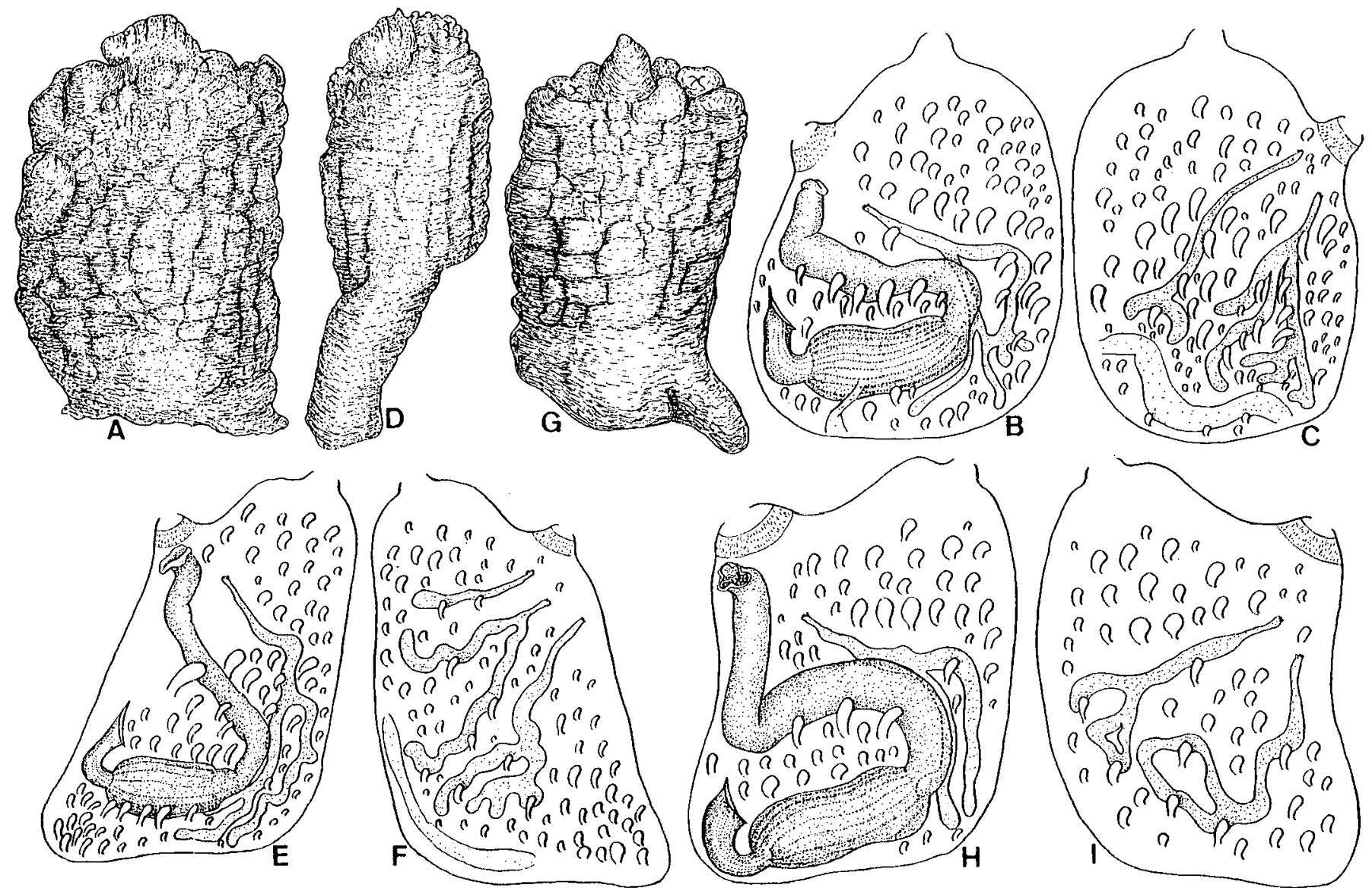

Fig. 29. Cnemidocarpa ramosa n. sp. from Toyama Bay. A-C. holotype, $14.5 \mathrm{~mm}$ long (SMBL Type No. 368); D-F. a paratype specimen, $9.2 \mathrm{~mm}$ long body with $9.3 \mathrm{~mm}$ long posterior extension (NSMT Pc-1098); G. another paratype, $18 \mathrm{~mm}$ long (NSMT Pc-1098); H-I. another paratype, $16 \mathrm{~mm}$ long (NSMT Pc-1098). A, D \& G. whole body; B, E \& H. left inner side of mantle body; C, F \& I. right inner side of mantle body. 
lateral side; branched very frequently, in up to two orders, except the $19 \mathrm{~mm}$ long paratype in which only one of the 4 gonads branched slightly in the distal end; the branches of a gonad sometimes anastomosing (Fig. 29, B, G, E F, H, I). The gonad(s) on the left side situated along the ventral margin of bottom of first intestinal loop and its wide adjacent part (Fig. 29, B, E, H). A single gonad on the left and 2 on the right in the holotype, as well as in $8.5 \mathrm{~mm}, 13.5 \mathrm{~mm}, 14 \mathrm{~mm}, 16 \mathrm{~mm}$ and 18 $\mathrm{mm}$ long paratype specimens; a single gonad on the left and 3 on the right in the $13 \mathrm{~mm}$ long paratype; 2 on each in the $15 \mathrm{~mm}$ and $19 \mathrm{~mm}$ long ones; and one on each side in another $16 \mathrm{~mm}$ long one. Gonads almost empty or partly mature; testicular follicles, if discernible, arranged in two rows over the whole attachment side; overian eggs up to $175 \mu \mathrm{m}$ in diameter in the holotype. Aperture of vas deferens situated very close to opening of oviduct in the anterior end of each gonad.

Remarks. The present specimens from Toyama Bay resemble Styela rustica rustica (Linné) and S. rustica macrenteron Ritter (see Van Name, 1945, pp. 288-290) in their stout shape and the conical projection between the apertures. The present specimens are, however, clearly assignable to the genus Cnemidocarpa, not to Styela. Therefore, the mentioned similarity is of a convergent nature.

In the well branched and rather extensive gonads, as well as the simple ciliated groove and arrangement of the alimentary system, the present specimens from the Japan Sea are quite similar to Cnemidocarpa tinaktae (Van Name) recorded from the Philippines, down to $46 \mathrm{~m}$ deep (Van Name, 1918; Millar, 1975) and Ambon (Millar, 1975), and to C. hartmeyeri Michaelsen from the Red Sea (Michaelsen, 1919). The present specimens may resemble $C$. tinaktae also in having a fewer tentacles (1620 in $C$. tinaktae), but these specimens may be somewhat different from C. tinaktae in the number of gonads (usually 1 or sometimes 2 on the left and usually 2 and sometimes 1 or 3 on the right in the former, while 3 to 10 on each side in the latter). Further, the present Japanese specimens differ from C. hartmeyeri, established for a 25 $\mathrm{mm}$ long specimen, in the number of gonads (3(?) on each side in $C$. hartmeyeri) and the branchial structure (approximately 30 tentacles and the ventral-most fold indistinct, instead of only 9 to 13 tentacles and the fold distinct even in the specimen as small as $8.5 \mathrm{~mm}$ long in the Japanese specimens).

In the small number of gonads and their branching the present specimens also resemble C. stolonifera (Herdman) hitherto recorded from around Australia (see Herdman, 1899, pp. 42-43; Kott, 1952, pp. 215-216; 1966, p. 298; 1972c, pp. 240-241 ; 1985, pp. 138-140; Millar, 1963, p. 728) and C. personata (Herdman) from Port Jackson, E. Australia (see Tokioka, 1967c, pp. 184-186; Kott, 1985, pp. 134-136). The present specimens are distinguishable from these two species by the position of left gonads (enclosed nearly completely by the second loop in these two species, while extending far posteriorly along the bottom of the first loop in the Japanese specimens). Gonadal features such as the number, postion and appearance in the present specimens are shared also with $C$. bifurcata Millar recorded from AcapulcoPanama, Fast Pacific, $3570 \mathrm{~m}$ deep by Millar (1964) and C. cornicula Monniot from 
Kerguelen, 200-1000 $\mathrm{m}$ deep by C. Monniot (1978). In these two species, there is usually a single well-branched gonad on each side. These species are, however, unique in their branchial structure, as is often the case with deep-sea ascidians, and are here considered different from the specimens from the Japan Sea. The specimens may also be similar to Polycarpa pedata Herdman occurring in the West Pacific region including southern Japan, but the specimens are markedly different from $P$. pedata in the position of left gonads (situated anterior to the second loop in $P$. pedata) and the structure of ciliated groove (composed of numberous orifices) (see, for example, Tokioka, 1958, pp. 322-325).

As shown above, the present specimens from the Japan Sea can be safely regarded as a species new to science, for which the specific name ramosa is proposed here after the ramified gonads.

The atrial velum sprinkled with numerous atrial tentacles over the whole surface seen in this new species is not unique; such a feature has been recorded in many species, e.g., C. stewartensis Michaelsen by Brewin (1950c), C. minuta (Herdman) by C. Monniot (1978) and Styela thalassae Monniot by C. Monniot (1969a).

113. Cnemidocarpa sp. cf. javensis Millar, 1975

Cnemidocarpa sp. cf. javensis: Nishikawa, 1986b, pp. 181-183, fig. 2.

Material examined: None.

Distribution in Japan Sea. Off Oki Isls, 30-35 m deep (Nishikawa, 1986b).

Distribution outside Japan Sea. Unknown.

114. Styela plicata (Lesueur, 1823)

Ascidia plicata Lesueur, 1823, pp. 5-6, pl. 3, fig. b.

For synonyms see Kott (1985).

Material examined: C-4 (Tsukumo Bay): a $47 \mathrm{~mm}$ long individual. C-7 (Wakasa Bay): many individuals, up to $55 \mathrm{~mm}$ long. E-1 (Wakasa Bay): 18 individuals, $16-51 \mathrm{~mm}$ long. H-3 (Tsukumo Bay): a $73 \mathrm{~mm}$ long individual. I-2 (Tsukumo Bay): many individuals. L-1 (Wakasa Bay) : 3 individuals, 57-82 $\mathrm{mm}$ long. L-6 (Nanao Bay): 2 individuals, $59 \mathrm{~mm}$ and $61 \mathrm{~mm}$ long.

Remarks. The present specimens are consistent with the previous descriptions of $S$. plicata. The number of gonads in the present specimens is 1 to 2 on the left, with 3 to 8 on the right.

Distribution in Japan Sea. Mutsu Bay (Oka, 1935); Tsukumo Bay, down to 25 $\mathrm{m}$ (in the present study); Nanao Bay, $0.5 \mathrm{~m}$ (do.); Wakasa Bay, to $5 \mathrm{~m}$ (Tokioka, $1953 \mathrm{~b}$; in the present study).

Distribution outside Japan Sea. Tokyo Bay (Traustedt \& Weltner, 1894; Hartmeyer, 1906; Tokioka, 1953c), Ise Bay (Nishikawa's unpublished data), around Kii Pen., down to $80 \mathrm{~m}$ (Nishikawa, 1980), Osaka Bay (Tokioka, 195lb, 1954c), Usa, Kochi Pref. (Nakauchi, 1973); Ariake Sea (Tokioka, 1960b), Nagasaki (Redikorzev, 
1916) and Kagoshima Bay (Nishikawa's unpublished data), Japan. Recorded further from the warm and temperate waters nearly all over the world, though rather rarely in the tropical region.

\section{Styela canopus Savigny, 1816}

Styela canopus Savigny, 1816, pp. 45 \& 154.

For synonyms see Kott \& Goodbody (1980).

Material examined: C-3 (Fukaura): a $9 \mathrm{~mm}$ long individual. D (Tottori) : 2 individuals, $5 \mathrm{~mm}$ and $8 \mathrm{~mm}$ long. E-1 (Wakasa Bay): 12 individuals, $10-22 \mathrm{~mm}$ long. I-1 (Noto): a $13 \mathrm{~mm}$ long individual. I-2 (Tsukumo Bay) : 3 individuals, $8-10 \mathrm{~mm}$ long. $\mathrm{M}$ (Oga) : a $10 \mathrm{~mm}$ long individual, already listed by Nishikawa (1984b).

Remarks. The stomach occupies about one-third to half or more of the ventral branch of the first intestinal loop. Two gonads are found on each side; testicular follicles are situated somewhat apart from the ovary, and not so close to it as seen in S. plicata.

Distribution in Japan Sea. Fukaura, Aomori Pref., 3-7 $\mathrm{m}$ deep (in the present study); Oga Pen., 0 m (Nishikawa, 1984b); Sado (Tokioka, 1962a, 1967b); off NotoOgi, Noto Pen., 15-40 m (in the present study); Tsukumo Bay, $25 \mathrm{~m}$ (do.); Wakasa Bay (do.); Tottori, $0 \mathrm{~m}$ (do.); Korean coastal waters facing Korea Strait (Rho, 1975).

Distribution outside Japan Sea. Tokyo Bay (Oka, 1934a; Nishikawa's unpublished data), Sagami Bay (Tokioka, 1953c), Ise Bay, $0 \mathrm{~m}$ (do.), around Kii Pen. (Nishikawa, 1980b), Osaka Bay (Tokioka, 1951b, 1954c), Seto Inland Sea (Tokioka, 1953 a), Usa, Kochi Pref. (Nishikawa's unpublished data), Ariake Sea (Tokioka, 1960b), Kagoshima Bay (Nishikawa's unpublished data) and Nishinoshima-Shinto Is. (do.), Japan. Further, this species has been recorded from the tropical to warm temperate waters all over the world.

\section{6a. Styela clava clava Herdman, 1881}

Styela clava Herdman, 1881, p. 70; Tokioka, 1959c, p. 462; 1960a, p. 202; 1967c, pp. 190-191, fig. 82; 1967b, p. 244; Millar, 1960b, pp. 509-511, fig. 1; 1975, pp. 302-303, fig. 81a; C. Monniot, 1970, pp. 151-152, fig. 3; Rho, 1971, pp. 119-120, pl. 6, figs $1-4$; Rho, 1975, pp. 140-141; Huwae \& Lavaleye, 1975, pp. 79-81, fig. 1; Beniaminson, 1976, p. 123, fig. 283; Holmes, 1976, pp. 115116 ; Abbott \& Newberry, 1980, pp. 207-208, fig. 12.34; Buizer, 1980, pp. 181-183, figs 1-2; Nishikawa, 1980b, tab. 1: 1984b, p. 151; Christiansen \& Thomsen, 1981, pp. 15-24, figs 1-3; Kott, 1985, pp. 115-116, fig. 49.

Tethyum clava: Ostroumov \& Pavlenko, 1911, pp. 22-23.

Botryorchis clava: Redikorzev, 1941, p. 187.

For other synonyms and references see Tokioka (1959c).

Material examined: B (Mutsu Bay): No. 39(M395), labeled as Styela clava, collected off Yomogida-mura, by the vessel "Aotaka-maru" on July 31, '26, one individual; referred to by Oka (1935). C-1 (Hokkaido): Rishiri Is.: Misaki, Senposhi, 5 individuals; in front of Mar. Biol. St. of Sapporo Medical College, Pon-misaki, 9 individuals; Kutsugata-misaki, 5 individuals. Rebun Is.: Kabuka $\mathrm{Hbr}, 2$ individuals; around Neko-iwa, 10 individuals; Nishiuedomari, 9 individuals. Ofuyu, 5 indi- 
viduals. Chazu, Bikuni, 6 individuals. Kamomejima Islet, Esashi, 8 individuals. C-2 (Mutsu Bay): Kaizaki, SW end of Shimokita Pen., 3 individuals; from buoys off Moura, 14 individuals; Hadakajima Islet, in front of Asamushi Mar. Biol. St., 3 individuals. E-1 (Wakasa Bay): one individual. M (Oga): 26 individuals, already listed by Nishikawa (1984b).

Remarks. The present specimens fall within the variation range of Styela clava given by many previous descriptions. Several features are noted here for future studies as: body surface nearly smooth, or provided with low prominences; percentage of stalk length occupying the whole individual length in well-preserved specimens is $33 \%$ in that of $\mathrm{B}, 0$ to $56 \%$ in those of $\mathrm{C}-1,11$ to $56 \%$ in those of $\mathrm{C}-2$, and 0 to $49 \%$ in those of $\mathrm{M}$; stomach usually occupying one-third or more of the ascending branch of the intestinal loop; number of gonads in the specimens in good condition is 1 to 5 (usually 2 or 3 ) on the left and 2 to 8 (4 to 6 ) on the right in those of $\mathrm{C}-1$, 2 to 6 ( 3 to 4 ) and 4 to 9 ( 5 or 6 ) in those of $\mathrm{C}-2$, or 2 to 5 (3 or 4 ) and 4 to 8 (6 or 7) in those of $M$. In a specimen of $C-1$ with $50 \mathrm{~mm}$ long body and $46 \mathrm{~mm}$ long stalk, and having 4 gonads on the left and 6 on the right, the stomach occupies only nearly one-forth of the branch; this feature is reminiscent of Styela longipedata Tokio$\mathrm{ka}$ (see below), but the specimen is distinguishable from $S$. longipedata by the number of gonads ( 2 on each in the latter). The material of C-1 includes a specimen with only one gonad on the left and 3 on the right, but no specimens with one or two gonads on each side as in Styela clava symmetrica (see below).

Here the so-called Styela clava is denoted as $S$. clava clava as the nominotypical subspecies of $S$. clava, while $S$. clava var. symmetrica as $S$. clava symmetrica, only following the International Gode of Zoological nomenclature (3rd ed.), Art. 45(g). This does not necessarily mean, however, that such subdivision of the species is taxonomically significant; for further discussion see below.

Distribution in Japan Sea. Hokkaido, northerly from Rishiri and Rebun Isls southerly to Esashi, 1-8 $\mathrm{m}$ (in the present study); Hakodate (Traustedt, 1885); Mutsu Bay, down to $20 \mathrm{~m}$ (Oka, 1935; Tokioka, 1967c; in the present study); Oga Pen., to $33 \mathrm{~m}$ (Nishikawa, 1984b; in the present study); Sado (Tokioka, 1967b); Wakasa Bay, to about $70 \mathrm{~m}$ (Hartmeyer, 1906; Tokioka, 1959a, in the present study); Korean coasts facing the Japan Sea and Korea Strait (Redikorzev, 1916; Rho, 1971, 1975); Peter the Great Bay, to $20 \mathrm{~m}$ (Ostroumov \& Pavlenko, 1911; Redikorzev, 1916, 1941; Beniaminson, 1976).

Distribution outside Japan Sea. Pacific: Bering Sea, $0 \mathrm{~m}$ (Redikorzev, 1941); Okhotsk Sea, 25 m (Redikorzev, 1916); Akkeshi Bay, Hokkaido (Tokioka, 195la), Matsushima Bay (Tokioka, î60a), Tokyo Bay (Tokioka, 1953c; Nishikawa's unpublished data), Sagami Bay (Tokioka, 1953c), Ise Bay (Nishikawa's unpublished data), around Kii Pen. (Hartmeyer, 1906; Tokioka, 1967c; Nishikawa, 1980b), Osaka Bay (Herdman, 1882; Tokioka, 1951b, 1954c, 1967c), Seto Inland Sea (Tokioka, 1953a), Nagasaki (Tokioka, 1967c), Japan; Yellow Sea coast of Korea (Rho, 1971, 1975); Yantai (=Chefoo) and Shanghai, Ghina (Tokioka, 1967c); East China Sea, $31^{\circ} \mathrm{N}$ and $125^{\circ} \mathrm{E}, 25 \mathrm{fms}$ (Traustedt, 1885), and $31^{\circ} 16^{\prime} \mathrm{N}$ and $123^{\circ} 35^{\prime} \mathrm{E}$ (Millar, 1975); Port Phillip Bay, SE Australia (Holmes, 1976; Kott, 1985); Californian 
coast (Abbott \& Newberry, 1980). Europe: southern coast of England (Carlisle, 1954b; Millar, 1960b); northern coast of France (C. Monniot, 1970); Netherland (Huwae \& Lavaleye, 1975; Buizer, 1980); Denmark (Christiansen \& Thomsen, 1981).

\title{
116b. Styela clava symmetrica Tokioka, 1959
}

\author{
Styela clava var. symmetrica Tokioka, 1959c, pp. 457-462, fig. 1; 1962a, p. 17; Rho, 1975, p. 141; \\ Nishikawa, 1984b, p. 151; Millar, 1975, pp. 302-303, fig. 81. b-d. \\ Styela clava: Drasche, 1884, p. 379, pl. 6, figs 9-11. \\ Styela longipedata: Rho, 1975, pp. 142-143, pl. 9, figs 1-8.
}

Material examined: A (Toyama Bay): 2 individuals, one is $42 \mathrm{~mm}$ in total length, while the other $61 \mathrm{~mm}$, lacking mantle body. G-1 (Oga): a $40 \mathrm{~mm}$ long individual. $\mathrm{M}$ (Oga): 2 individuals, $31 \mathrm{~mm}$ and $53 \mathrm{~mm}$ long.

Remarks. The features of the present specimens are: stalk occupying 44 to $48 \%$ of total length; test surface furnished conspicuously with conical prominences in the specimens of $M$, but only low protuberances on the rest; stomach more than half (in the specimen of $\mathrm{G}-1$ ), nearly half (in that of $\mathrm{A}$ ), or one-third (in those of $\mathrm{M}$ ) as long as the ascending branch of intestinal loop; two gonads on each side in the specimen of $\mathrm{G}-1$ and the smaller one of $\mathrm{M}$, two on the left and one on the right in that of $\mathrm{A}$, and one on each in the larger specimen of $\mathrm{M}$.

$S$. clava symmetrica was established originally as a variety of $S$. clava on the basis of many specimens collected from Kada, western coast of Kii Pen., distinguished from the nominotypical form mainly by the number of gonads (two on each in the former, while two or more on the left and more than two on the right in the latter). Here the specimens with a total of three or fewer gonads are referred also to the subspecies symmetrica, because there seems no significant morphological gap between such specimens and the usual ones of this subspecies with two gonads on each side. If this is true, the subspecies symmetrica may be linked with the nominotypical subspecies by such specimen with one gonad on the left and three on the right as assigned to the latter in the present study (see above). Conclusive examination on this problem will be done elsewhere in the future, based on ample material from various localities; until then, the present subdivision of $S$. clava on the subspecific level will be regarded as valid.

The specimens collected from Korea and referred to $S$. longipedata Tokioka by Rho (1975) may, according to her figures, be transferred to $S$. clava symmetrica on the basis of large stomach which is nearly half the length of the ascending branch of intestinal loop. Complete comparison between $S$. clava and $S$. longipedala is desirable in future.

Distribution in Japan Sea. Off Oga Pcn., $21 \mathrm{~m}$ (Nishikawa, 1984b; in the present study); Sado (Tokioka, 1962a); Toyama Bay, down to $81 \mathrm{~m}$ (in the present study); Cheju Is., Korea Strait (Rho, 1975).

Distribution outside Japan Sea. Western coast of Kii Pen. (Tokioka, 1959c); off Goto Isls, $32^{\circ} 15^{\prime} \mathrm{N}$ and $128^{\circ} 20^{\prime} \mathrm{E}, 18 \mathrm{~m}$ (Millar, 1975). 


\section{Styela longipedata Tokioka, 1953}

Styela longipedata Tokioka, 1953c, pp. 271-273, pl. 65, figs 1-9; 1953b, p. 28; Nishikawa, 1980b, tab. 1. Rho's (1975) reference excluded, moved to $S$. clava symmetrica.

Material examined: None.

Distribution in Japan Sea. Wakasa Bay (Tokioka, 1953b)

Distribution outside Japan Sea. Sagami Bay, down to $50 \mathrm{fms}$ (Tokioka, 1953c); off the western coast of Kii Pen. (Nishikawa, 1980b).

\section{8a. Styela coriacea coriacea (Alder et Hancock, 1848)}

(Fig. 30)

Cynthia coriacea Alder \& Hancock, 1848, p. 195.

Sivela coriacea: Hartmeyer, 1923, pp. 220-234, fig. 15; Van Name, 1945, pp. 285-287, figs 179F, 181-183; Huus \& Kundscn, 1950, pp. 7-8; Berrill, 1950, pp. 182-184, figs. 56b, 58; Ärnbäck -Christie-Linde, 1952, pp. 26-27; Millar, 1952, p. 24; 1959, pp. 7-11, fig. 4; Tokioka, 1967c, pp. 195-196, fig. 85; Skalkin, 1959, p. 246; C, Monniot, 1969a, pp. 169-171, figs 4-5; Monniot \& Monniot, 1985, p. 29; Nishikawa, 1984b, p. 151; 1986b, p. 176.

Goniocarpa coriacea: Redikorzev, 1941, p. 190, pl. 3, fig. 4.

Stvela plnta Oka, 1930d, pp. 427-430, figs A-C; 1935, pp. 453-454, fig. 24. (placed as a synonym of $S$. coriacea by Tokioka, 1967c)

Styela coreacea litoralis Beniaminson, 1974, pp. 329-330, fig. 7. New Synonymy.

Styela saiebrosa Beniaminson, 1971, pp. 299-301, fig. 3. New Synonymy.

For other synonyms and references see Hartmeyer (1923) and Van Name (1945).

Doubtful synonym:

Styela aomori Oka, 1935, pp. 449-450, figs 18-19.

Material examined: A (Toyama Bay): 2 individuals, $16 \mathrm{~mm}$ and $7 \mathrm{~mm}$ long, respectively, the larger attached to Polycarpa maculata. B (Mutsu Bay): No. 4(M416) (part), collected from the southern coast of Yunoshima Islet on June 21,'26 by Takatsuki, a $11.5 \mathrm{~mm}$ long intact individual; No. 67 (M383), labeled Stysla aomori by Oka, dredged west off Osima, 23 fms deep on July 9, 1926, by Hozawa, 3 dissected individuals, 24-38 mm long and 6 intact ones, $18-32 \mathrm{~mm}$ long, the dissected specimens obviously representing the type series of Styela aomori, but now damaged very much and impossible to examine in detail; No. 305(M398), labeled Styela plata by Oka, off Ozawa, Aug. 9, '26 by Hozawa and Kokubo, 2 intact individuals, $15 \mathrm{~mm}$ and $16 \mathrm{~mm}$ long, never the type of $S$. plata, but already referred to by Oka (1935). M (Oga): 2 individuals, $13.5 \mathrm{~mm}$ and $14 \mathrm{~mm}$ long, already listed by Nishikawa (1984b). N (Oki): 8 individuals, 3-20 mm long, already listed by Nishikawa (1986b).

Description. Body usually flattened dorsoventrally, attached to substratum by wide ventral side (Fig. 30, A), but sometimes more or less elongated anteroposteriorly, becoming cylindrical in several specimens and attached by broad posterior end (Fig. 30. H); very rarely roundish and attached by dorsolateral part (Fig. 30, F). Both apertures almost sessile and nearly terminal. Test surface quite smooth (Fig. 30, F \& H), or somewhat wrinkled (Fig. 30, A); sometimes coated sparsely with sand grains; the surface always paved wholly and very densely with minute bubblelike bodies, up to $125 \mu \mathrm{m}$ in diameter. Test thin, soft to rather hardened, tough, leathery and dull white, pale pink, orangish yellow or pale brownish. Mantle usually thin and delicate; many endocarps over its inner surface; numerous fine atrial 


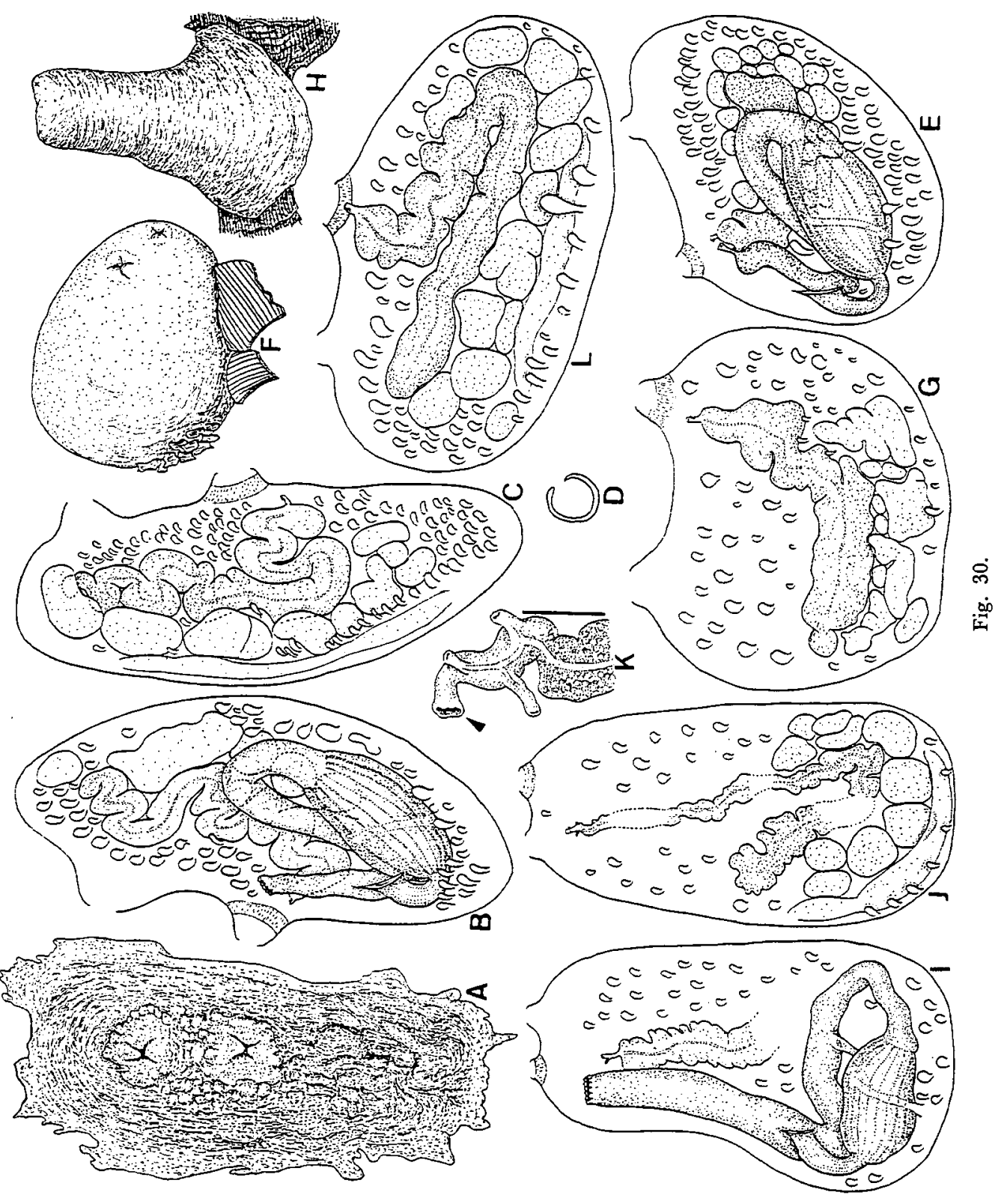


tentacles arranged in several rings over the inner surface of wide velum. Branchial tentacles of various lengths, usually 12 to 24 in number, but up to about 40 in the $32 \mathrm{~mm}$ long specimen of B. Ciliated groove C-shaped opening anteriorly (Fig. $30, \mathrm{D})$ except in the $13.5 \mathrm{~mm}$ long one of $\mathrm{M}$ that is furnished with the groove as a longitudinal slit. The branchial formulae are:

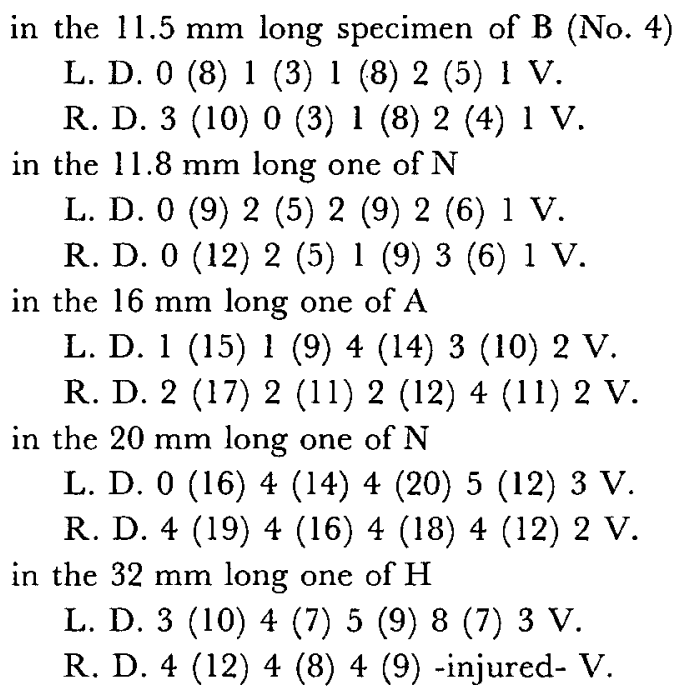

Dorsal lamina smooth-edged. Visceral mass usually occupies posterior half of mantle body, occasionally more than the half; anterior margin of first intestinal loop usually more anterior to the base of atrial siphon, and anterior to anus (Fig. 30, B \& E) in the depressed specimens, while in the cylindrical specimens the margin far posteior to atrial siphon and anus (Fig. 30, I). Stomach elongated, occupying usually the half or more of ventral (or posterior) branch of first intestinal loop (Fig. 30, B \& I), but sometimes nearly its whole length (Fig. 30, E) ; stomach surface with many longitudinal plications; pyloric coecum absent. First intestinal loop very deep and closed; the second usually very deep and narrow with short rectum (Fig. 30, B \& E), but rather shallow and more or less opened with long rectum in the cylindrical specimens (Fig. 30, I). Axis of second intestinal loop passes through cardiac end of stomach. One gonad on each side, very voluminous when mature. Left gonad composed of a nearly straight, tubular ovary situated along the ventral branch of second intestinal loop with proximal (=-antiorifice) end of ovary more or less beyond the bottom of first intestinal loop, and a few to many massive testicular follilces along the ovary on the lateral side facing intestinal loop (Fig. 30, B). In some specimens, a

Fig. 30. Styela coriacea coriacea (Alder et Hancock). A-D. $20 \mathrm{~mm}$ long specimen from Oki Isls (Collection $\mathrm{N}$ ) ; E. $19 \mathrm{~mm}$ long one from Oki Isls (N); F-G. $16 \mathrm{~mm}$ long one from Toyama Bay (A); H-K. $32 \mathrm{~mm}$ long one from Mutsu Bay (B, OCUT No. 67 (M383)); L. $11.5 \mathrm{~mm}$ long one from Mutsu Bay (B, OCUT No. 4(M416)). A, F \& H. whole body, dorsal (A) or side (F \& H) view; B, E \& I. left inner side of mantle body; C, G \& J. right inner side of mantle body; D. ciliated groove; $K$. anterior tip of gonad on the right side, showing a single aperture of oviduct (arrowhead) and 3 openings of vas deferens. Scale indicates $1 \mathrm{~mm}$. 
few to several follicles are also seen on the other side (Fig. 30, E). Right gonad composed of the ovary usually curved more or less conspicuously (Fig. 30, C, J \& L), but rarely almost straight (Fig. 30, G), and many massive testicular follicles found along its ventral side, or outer margin when strongly curved. The ovary, at least its proximal part, lies horizontally in the depressed specimens, but becomes U-shaped opened anteriorly with the shorter horn represented by the proximal part in the cylindrical specimens (Fig. 30, J). Testicular follicles arranged roughly in a single row, but sometimes into 2 or 3 . Ovary opens terminally with a single aperture of vas deferens located close to the opening, except in the $32 \mathrm{~mm}$ long specimen of B (No. 67) in which the right gonad has 3 apertures of vas deferens (Fig. 30, K). Ovarian eggs up to $150 \mu \mathrm{m}$ in diameter.

Remarks. All the present specimens seem to fall well within the variation range of the so-called Styela coriacea (Alder et Hancock), now denoted as the nominotypical subspecies, shown in many previous descriptions, and therefore safely be referred to it. Some of the present specimens in the collections B or N might differ from one another especially in some features of the alimentary canal and gonads. These morphological gaps may, however, be bridged by certain intermediate states, so the differences are safely regarded as individual variations. The cylindrical external appearance, long rectum and U-shaped right gonad in some specimens of the present material resembles Styela rustica (Linné) previously known from the arctic and boreal waters, but these specimens are distinguishable, though rather obscurely, from S. rustica by the structure of gonad (the testicular follicles usually more or less apart from ovary in the latter, while very close to it in the former). Detailed comparison is desirable in future between $S$. coriacea and $S$. rustica.

The present study supports Tokioka's (1967c) synonymization of Styela plata Oka described only inadequately with $S$. coriacea. Though the type material of $S$. flata had been lost, I was able to examine the specimens referred to this species by Oka himself. And as stated above, they are assignable to $S$. coriacea coriacea. Consequently, S. plata is regarded as a junior synonym of $S$. coriacea coriacea. Styela aomori Oka previously recorded only once from Mutsu Bay seems, according to its original description, markedly different from $S$. coriacea in the number of gonads on each side (two in $S$. aomori, instead of one in $S$. coriacea). The specimens allotable to the type series of $S$. aomori still remain at OCUT, but the mantle body unfortunately much damaged and impossible to describe. However, my examination of the specimens regarded by Oka as conspecific with the type series proved that they are clearly referable to $S$. coriacea coriacea as mentioned above; both specimens are, so far as the external appearance is concerned, indistinguishable from each other. Thus, $S$. aomori is here treated as a doubtful junior synonym of $S$. coriacea coriacea.

Recently Beniaminson (1974) established a new subspecies litoralis of $S$. coriacea (then erroneously spelled as coreacea) for the specimens collected from Shimushur Is., Kurile Isls, distinguishing it from the nominotypical form by the unique habitat (mediolittoral zone in the subspecies litoralis), the dorsal lamina with undulated, but 
not serrated, margin, and the existence of a small side-branch in the right ovary. The nominotypical form has, however, been hitherto recorded even from very shallow waters such as 0-4 $\mathrm{m}$ deep in the Faeroes Isls (Hartmeyer, 1923, p. 232), and further, the mentioned differences seen in the lamina and ovary seem to be of little taxonomic significance. The branched ovary in Beniaminson's subspecies resembles $S$. nidrosiensis Ärnbäck-Christie-Linde from Norway, 30-400 m deep by Ärnbäck-Christie-Linde $(1925,1926 \mathrm{~b})$, but later this species was rightly synonymized with $S$. coriacea by C. Monniot (1969a). Consequently, the subspecies litoralis may be amalgamated into the nominotypical subspecies. Styela salebrosa Beniaminson, 1971 from the Possjet Bay, Japan Sea, 17-20 m deep is also similar to $S$. coriacea coriacea in the minutely papillated test and the features of branchial sac, alimentary canal and gonads, so the former is regarded here as a junior synonym of the latter.

Distribution in Japan Sea. Peter the Great Bay, down to $32 \mathrm{~m}$ (Redikorzev, 1911 a, 1916, 1941; Ostroumov \& Pavlenko, 1911; Beniaminson, 1971); western coast of South Sakhalin (Skalkin, 1959); Oshoro (Oka, 1930d) and Otaru (Tokioka, 1967c), Hokkaido; Mutsu Bay, 23 fms (Oka, 1930d, 1935; in the present study); off Oga Pen., 59-62 m (Nishikawa, 1984b; in the present study); Toyama Bay, 74-81 m (in the present study); off Oki Isls, 35-55 m (do.).

Distribution outside Japan Sea. This species is regarded eurythermal and euryhaline, according to Millar (1959, p. 15); widely distributed in the arctic to northern cold temperate waters in both hemisphere, down to about $600 \mathrm{~m}$ deep; and in the Bay of Biscay, 340-662 m (C. Monniot, 1969a).

\section{8b. Styela coriacea hemicaespitosa Ritter, 1913}

(Fig. 31)

Styela hemicaespitosa Ritter, 1913, pp. 471-475, pl. 34, figs 21-23.

Styela coriacea hemicaespitosa: Van Name, 1945, pp. 287-288.

Material examined: A (Toyama Bay): a single individual, $20 \mathrm{~mm}$ long.

Description. Body rounded; whole surface except aperture areas densely covered with hairy processes of test carrying fine sand grains abundantly; the area free from the processes is sprinkled sparsely with the grains (Fig. 31, A). Branchial aperture subterminal, with the atrial situated in the middle of body; both nearly sessile. Test thin but tough, translucent and white. Mantle thin and translucent with a brownish tint anteriorly. A few endocarps present on each side. Twelve rather short tentacles. Giliated groove G-shaped opened anteriorly (Fig. 31, D). Only 3 folds on each; the formula is :

$$
\begin{aligned}
& \text { L. D. } 2 \text { (19) } 10 \text { (18) } 5 \text { (11) } 4 \mathrm{~V} \text {. } \\
& \text { R. D. } 4 \text { (18) } 9 \text { (16) } 8 \text { (10) } 4 \mathrm{~V} \text {. }
\end{aligned}
$$

Thin and thick transverse vessels alternating almost regularly; parastigmatic ones present; 8 to 10 stigmata in a mesh. Dorsal lamina smoothly edged; taller than the 


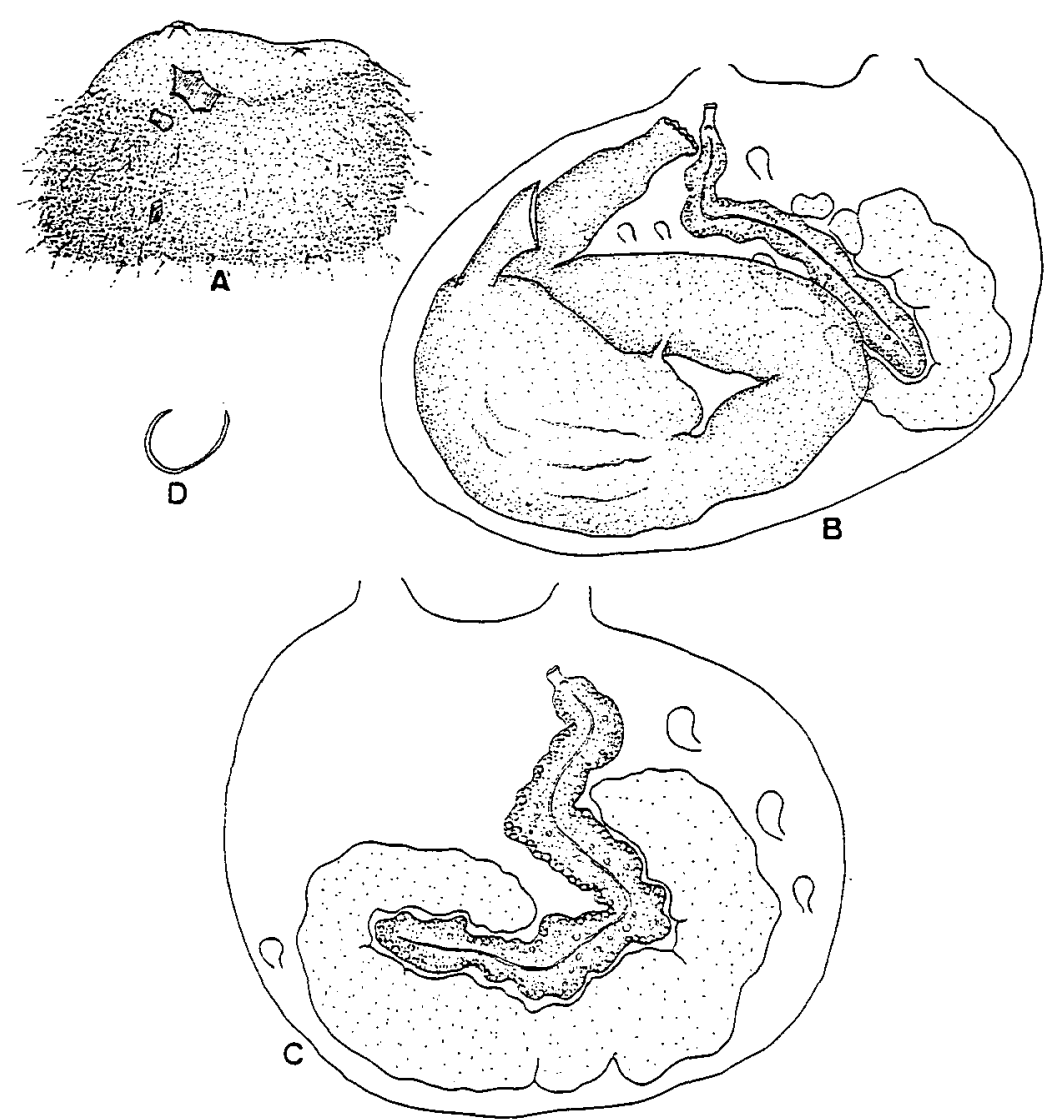

Fig. 31. Styela coriacea hemicaespitosa Ritter from Toyama Bay (Collection A), $20 \mathrm{~mm}$ long specimen. A. whole body; B. left inner side of mantle body; C. right inner side of mantle body; $D$. ciliated groove.

branchial folds near oesophageal opening. Alimentary system voluminous, occupying more than the posterior half of mantle body; both intestinal loops very deep; axis of second loop passing through cardiac end of stomach. Stomach large, occupying two-thirds of ventral branch of first loop; plications indistinct due to deterioration. Rectum short; anal margin divided into 10 lobules. A single gonad, fully mature, on each side; consisting on the left side of an elongated ovary and several massive testicular follicles along the posterior half of ovary, while on the right of the ovary markedly curved and closely bordered proximally with a C-shaped mass of testis. Gonoducts opening terminally.

Remarks. Three branchial folds on each side in the present specimen resemble Tethym (Styela) godeffroyi Michaelsen previously recorded from Australia (Michaelsen, 1911; synonymized with Cnemidocarpa personata (Herdman) by Kott, 1985), but the Japan Sea specimen is different from $T$. godeffroyi in the arrangement of intestinal loop, and the number and structure of gonads. However, in the internal features 
except the branchial sac, this specimen is quite similar to $S$. coriacea coriacea (see above); therefore, the specimen can be safely regarded here as an unusual form of $S$. coriacea coriacea. In the external appearance, this specimen resembles very well $S$. coriacea hemicaespitosa Ritter recognized by Van Name as "a geographic race differing so strikingly from the typical coriacea in appearance" (p. 287) and so far recorded from the Bering Sea and off southern California or Lower California. Consequently the present specimen is referred to this subspecies; its taxonomic rank may leave room for further discussion.

Distribution in Japan Sea. Toyama Bay, $45 \mathrm{~m}$ (in the present study).

Distribution outside Japan Sea. Bering Sea, $225 \mathrm{fms}$ (Ritter, 1913); off the coast of southern California or Lower California, 18-61 fms (Ritter, 1913; Van Name, 1945).

\section{Styela rustica (Linné, 1767)}

Ascidia rustica Linné, 1767, p. 1087.

Vannamea kurilensis Oka, 1932e, pp. 321-32?, figs A-B. (placed as a synonym of S. rustica by Tokioka, 1963, p. 139).

For other synonyms see Van Name (1945).

Material examined: None.

Distribution in Japan Sea. Mamiya (=Tatarskii) Strait, $30 \mathrm{~m}$ (Redikorzev, 1916); western coast of South Sakhalin (Skalkin, 1959); an unknown locality off the coast of Soviet Union, 14-28 m (Redikorzev, 1941).

Distribution outside Japan Sea. Widely distributed in the Arctic and subarctic waters, 0-432 $\mathrm{m}$ deep.

120. Styela monogamica Oka, 1935

Styela monogamica Oka, 1935, pp. 451-453, figs 22-23.

Material examined: None.

Remarks. This species has been hitherto recorded only once from Mutsu Bay by Oka (1935); unfortunately the type and other specimens examined by him had been lost completely. The depressed body with a single gonad on each side reminds me of $S$. coriacea stated above, but $S$. monogamica differs from $S$. coriacea in the structure of gonad (consisting of a tubular or curved ovary fringed mainly ventrally with testicular follicles in the former, while of a large tubular ovary and a slender testis along the dorsal border of ovary in the latter). This difference is of certain taxonomic significance, so $S$. monogamica should be regarded as a good species.

\section{Styela sigma Hartmeyer, 1906}

(Fig. 32, A)

Styela sigma Hartmeyer, 1906, pp. 12-13, fig. 6. 
Styela atlantica: Tokioka, 1953c, pp. 264-265, pl. 61, figs 1-4, pl. 62, figs 1-4; 1967c, pp. 191-193,

fig. 83; Tokioka \& Nishikawa, 1977, pp. 23-26, fig. 1.

Doubtful synonym and references:

Tethyum atlanticum Van Name, 1912, p. 552, pl. 59, figs 92-93, pl. 60, fig. 96, pl. 68, fig. 135, textfig. 31.

Styela atlantica: Van Name, 1945, pp. 293-294, figs 189-191.

For other doubtful references see Van Name (1935).

Material examined: B: No. 330(M197) (part), a $25.5 \mathrm{~mm}$ long individual attached to the attachment side of a specimen of Ascidia etigo referred here to Ascidia longistriata, collection data lacking, but probably collected in "Etigo", corresponding to present Niigata Pref.

Description. Body ellipsoid, attached to substratum by wide posterovantral part. Branchial aperture situated subterminal, and the atrial close to it; both sessile. Test up to $2.2 \mathrm{~mm}$ thick, leathery and pale brown; the surface wrinkled. Many endocarps over the whole inner surface of mantle; atrial velum well developed, sprinkled with numerous fine atrial tentacles over its inner surface. Ciliated groove C-shaped opened anteriorly. About 20 branchial tentacles. Branchial formula is:

$$
\begin{aligned}
& \text { L. D. } 3 \text { (15) } 12(31) 10(30) 13(10) 6 \mathrm{~V} . \\
& \text { R. D. } 5 \text { (13) } 10(25) 11(25) 10(9) 5 \mathrm{~V} .
\end{aligned}
$$

Four or 5 stigmata per mesh in the interspace; parastigmatic vessels present. Alimentary system not so extensive, occupying less than posterior half of mantle body. Stomach occupying more than half of ventral branch of first intestinal loop; with many longitudinal plications. First loop very deep and narrow, while the second rather deep and wide with its axis passing through cardiac end of stomach (Fig. 32, A). Two gonads on each side; partly mature, ovarian eggs up to $150 \mu \mathrm{m}$ in diameter. Each gonad composed of a rather thin and elongated ovary surrounded proximally

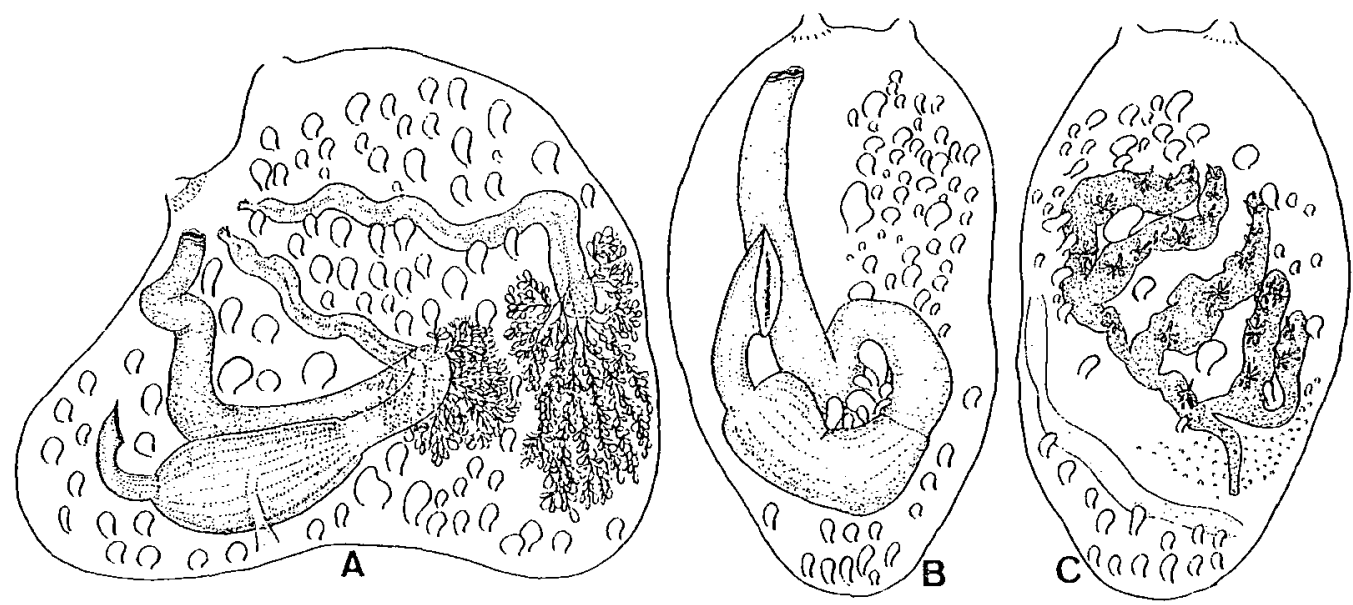

Fig. 32. A. Styela atlantica (Van Name) from Niigata Pref. (Collection B, OCUT No. 330 (M197), part), $25.5 \mathrm{~mm}$ long specimen; B. Dendrodoa aggregata (Rathke) from Mutsu Bay (B, OCUT No. 73(M388)), $29 \mathrm{~mm}$ long specimen. A \& B. left inner side of mantle body; C. right inner side of mantle body. 
with testis consisting of numerous small follicles (Fig. 32, A). Two ovaries on each side situated roughly in parallel with each other; their opening terminal, to which the aperture of vas deferens located very close.

Remarks. This specimen is consistent with the original and subsequent descriptions of $S$. atlantica, so may be assigned to this species. $S$. atlantica has so wide a geographical distribution as shown below that the species is suspected to contain two or more different taxa of specific or infraspecific ranks; in other words, the Atlantic and the Pacific population of this species might actually be different taxonomically from each other. It is also true, however, that, so far as our present state of knowledge is concerned, these two populations are quite indistinguishable morphologically from each other.

My reexamination of the type specimens of Styela sigma collected in Sagami Bay revealed that these specimens are quite similar to the above-mentioned specimen from the Japan Sea, and therefore the specimens previously identificd with $S$. atlantica. The Sagami Bay material collected by Doflein and deposited at MNB (No. ZMB 2801) consists of two specimens; the larger is $40 \mathrm{~mm}$ long $\times 27 \mathrm{~mm}$ wide and already dissected, while the smaller, $30 \mathrm{~mm}$ long $\times 20 \mathrm{~mm}$ wide with $23 \mathrm{~mm}$ long test extension, is nearly intact, and covered partly with the colony of Diplosoma mitsukurii. As the testicular follicles are present but rather inconspicuous in these specimens, they must have been overlooked by Hartmeyer. Therefore, the present specimen from the Japan Sea, together with other specimens at least from the Pacific, should be called S. sigma, even if the Pacific and the Atlantic populations are proved indistinct taxonomically from each other, because in this case $S$. sigma Hartmeyer, 1906 has the priority over Tethyum atlanticum Van Name, 1912. If verified to be distinct, the Atlantic population may safely be referred to as $S$. atlantica. Thus, the nomenclatural status of $S$. atlantica remains still open, until further comparative studies of these two taxa between different populations are made. In the present study, records of $S$. atlantica from the Atlantic are regarded as doubtful references to S.sigma.

Distribution in Japan Sea. Off Niigata Pref. (in the present study).

Distribution outside Japan Sea. In the Pacific: Sagami Bay, down to $400 \mathrm{~m}$ (Hartmeyer, 1906; Tokioka, 1953c, 1967c) and off Koshikijima Is., west off Kyushu Is., 400-450 m (Tokioka \& Nishikawa, 1977), Japan. ?In the Atlantic: off the middle United States, 62-397 fms (Van Name, 1945); SW coast of Norway, 100-150 m (Huus, 1936); Skagerrak coast of Sweden, 60-180 m (Lützen, 1965); far west off Brutagne, France, 330-430 m. (C. Monniot, 1969a; Monniot \& Monniot, 1985); around the Azores İsis, 335-355 m (C. İíonniot, 1974).

\section{Styela tokiokai n. sp.}

Styela esther: Tokioka, 1953c, pp. 266-267, pl. 60, figs 5-11; 1959a, p. 231, pl. 16, figs 30-31; Nishikawa \& Tokioka, 1975, p. 222. " $S$. esther" by Hartmeyer (1906) and Oka (1935) excluded, which is identified with Cnemidocarpa irene.

Doubtful synonym:

Styela esther: Tokioka, 1949b, pp. 52-54, fig. 9; Rho, 1971, p. 119; 1975, p. 140. 
Material examined: $\mathrm{C}-5$ (Noto-hime): 2 individuals, $24 \mathrm{~mm}$ long. $\mathrm{L}-6$ (Tsukumo Bay): 2 individuals, $16.5 \mathrm{~mm}$ and $24 \mathrm{~mm}$ long, respectively.

Type series: The two specimens which were referred to Stvela esther Hartmeyer and described in detail with fine figures by Tokioka (1953c) are designated as the type series, because his description is obviously the first reliable and sufficient description of the present new species. Of the specimens, the larger, $40 \mathrm{~mm}$ long one is chosen as the holotype, while the smaller, $35 \mathrm{~mm}$ long one as the paratype. According to the description, they were collected at Koiso in Hayama, Sagami Bay on May 17, 1930; deposited at the Biological Laboratory, Imperial Household, Tokyo and registered as Sp. No. 164.

Remarks. As already stated in the remarks of Cnemidocarpa irene above, the type specimen of Styela esther was proved conspecific with the holotype of $C$. irene, it then follows that $S$. esther should be regarded as a junior synonym of $C$. irene by the Principle of Priority. And further, the specimens collected in the Tsugaru Strait and referred to $S$. esther by Oka (1935) are also revealed to be identical with $C$. irene. These specimens from Wakasa Bay and Tsugaru Strait once assinged to S. esther are, however, distinguishable very clearly from those collected in Sagami Bay and assigned to this species by Tokioka (1953c), especially by 1) the testicular follicles that occupy the attachment surface of gonad in the Wakasa and Tsugaru specimens, instead of that is situated along nearly the whole margin of ovary in Tokioka's specimens, and 2) the existence of only a single aperture of vas deferens situated close to the opening of oviduct in each gonad in the former, instead of many short ducts of vas deferens over the mesial surface of each gonad in the latter. The difference 1) clearly shows that Tokioka's specimens are assignable to the genus Styela, but not to Cnemidocarpa, though in his specimens the testicular follicles are situated very close to the ovary as may be rather unusual in Styela. The difference 2) is of enough taxonomic significance to distinguish the Wakasa and Tsugaru specimens from Tokioka's at the specific level, even if the above-mentioned generic distinction is suspected. Thus, Tokioka's specimens from Sagami Bay should be renamed.

The occurrence of many ducts of vas deferens in Tokioka's specimens is seemingly reminiscent of Cnemidocarpa areolata (Heller) sensu stricto, but these specimens differ markedly from this species in that the ducts are very short and scattered over the mesial surface of gonad in the former, while much elongated and issuing from just around the aperture of oviduct as stated far above in this species. So far as I am aware, the opening of vas deferens in Tokioka's specimens is unique among all the species so far allotted to the genus Styela or related Cnemidocarpa. Consequently, the specimens in question will be regarded a new species of the genus Styela, to which the specific name tokiokai is proposed after $\mathrm{T}$. Tokioka who gave the first reliable description of the species. To this new species the following specimens so far called $S$. esther are assignable: that from Wakasa Bay recorded by Tokioka (1959a), those from Kii Pen. by Nishikawa \& Tokioka (1975), and further, though rather tentatively for want of information about the opening of vas deferens in the descriptions, the specimens from Tokyo Bay by Tokioka (1949b) and those from Korea by Rho (1971, 1975).

The specimens from the Japan Sea examined in the present study fall within the 
variation range of Styela tokiokai, and therefore, are easily assignable to this species. Some morphological features in the specimens are: stomach voluminous and globular, occupying nearly half or less of ventral branch of first intestinal loop; the loop deep and closed, filled with one or two endocarps; second intestinal loop more or less shallow, and in the specimens of L-6 an elongated endocarp located along the loop, its axis passing through the middle of stomach; no other endocarps; two gonads on each side, consisting each of oval to elongated ovary fringed with numerous testicular follicles; opening of the ovary terminal, up to 30 or more apertures of vas deferens over the mesial surface of ovary, arranged roughly in one or two rows, or rather randomly.

Distribution in Japan Sea. Mutsu Bay (Oka, 1935); Noto-hime, Noto Pen., 1$2.5 \mathrm{~m}$ (in the present study); Tsukumo Bay, 5-10 m (do.); Wakasa Bay (Tokioka, 1959a); ?Korean coastal waters facing the Japan Sea and Korea Strait(Rho, 1971, 1975).

Distribution outside Japan Sea. ?Tokyo Bay (Tokioka, 1949b); Sagami Bay (Tokioka, 1953c); Ago Bay, eastern coast of Kii Pen. (Nishikawa's unpublished data); Kushimoto, southern end of Kii Pen. (Nishikawa \& Tokioka, 1975); ?Yellow Sea coast of Korea (Rho, 1975).

\section{Dendrodoa aggregata (Rathke, 1806)}

(Fig. 32, B-C)

Ascidia aggregata Rathke, 1806, p. 11, pl. 130, fig. 2.

Dendrodoa aggregata: Hartmeyer, 1903, pp. 235-243, pl. 5, fig. 8.

For other synonyms see Van Name (1945).

Material examined: B (Mutsu Bay): labeled as Dendrodoa tuberculata by Oka; No. 73(M388), dredged off Asamushi Mar. Biol. Lab., by Takatsuki on Sept. 8, '26, 5 dissected individuals, 25-37 mm long, as well as 12 intact ones, $6-29 \mathrm{~mm}$ long, as the dissected specimens more or less injured, the following description was based solely on the intact ones; No. N9(M458), off Gomejima (=Kamomejima) Islet on July 10, '27 by Takatsuki, 8 intact individuals, 7-35 mm long; No. 10(M463), off Itazaki on Aug. 10, '27 by Hozawa and Kokubo, a $47 \mathrm{~mm}$ long dissected individual; all already referred to by Oka (1935).

Description. Body roughly cylindrical; both apertures situated terminal, and sessile or opening on low swellings. Test surface usually with irregular low conical protuberances, but sometimes nearly smooth; test itself more or less hardened, leathery and dark brown. Mantle and viscera brownish; numerous endocarps of various sizes over inner surface of mantle, a few to several larger ones filling first intestinal loop; atrial tentacles present. Branchial tentacles about two dozens. Ciliated groove C-shaped, opened anteriorly or laterally. Four branchial folds on each side; the formula in the $29 \mathrm{~mm}$ long specimen of No. 73 is:

$$
\begin{aligned}
& \text { L. D. } 0(16) 1(6) 1(11) 1(7) 1 \mathrm{~V} . \\
& \text { R. D. } 0(17) 1(8) 1(10) 1(10) 1 \mathrm{~V} .
\end{aligned}
$$

Visceral mass voluminous, extending to nearly the whole length of mantle body; 
posterior end of the mass occupied by the stomach lying horizontally. Stomach cylindrical and occupying two-thirds or more of ventral branch of first intestinal loop (Fig. 32 , B). Stomach plication indistinct; no pyloric coecum. Second intestinal loop rather deep, its axis passing through roughly the middle of stomach; rectum much elongated. Gonad only on the right side, consisting of 4 to 6 branches running roughly parallel to one another, united posteriorly by a common branch. Gonad composed of numerous testicular follicles distributed densely over nearly its whole free surface and the ovary situated on medullary part as well as attachment surface of gonad. Ovary opening at the posterior extremity of the common branch, with many short ducts of the testicular follicles covering free surface of gonad (Fig. 32, C).

Remarks. The present specimens are consistent with the previous descriptions of Dendrodoa aggregata (Rathke), especially that given by Van Name (1945), so the former are easily identified with this species.

Distribution in Japan Sea. Mamiya Strait, $32 \mathrm{~m}$ (Redikorzev, 1916); western coast of South Sakhalin (Skalkin, 1959); Mutsu Bay (Oka, 1935; in the present study); Korean coasts facing the Japan Sea and Korea Strait (Rho, 1971, 1975); Peter the Great Bay, 3-110 m (Redikorzev, 1916); exact localities unknown, probably off the ocast of Soviet Union, 8-105 m (Redikorzev, 1941).

Distribution outside Japan Sea. In Japan, Akkeshi Bay, Hokkaido (Tokioka, 1951a). Widely distributed in the arctic and subarctic waters, 0-707 $\mathrm{m}$ deep (Huus \& Knudsen, 1950).

\section{Dendrodoa pulchella (Verrill, 1871)}

Cynthia pulchella Verrill, 1871, pp. 98.

Dendrodoa pulchella: Huus, 1929, p. 5, figs 3-5.

For synonyms see Van Name (1945)

Material examined: None.

Remarks. Redikorzev (1916) recorded Dendrodoa adolphi (Kupffer) from the Mamiya Strait, $64 \mathrm{~m}$ deep; later Van Name (1945) synonymized this record with $D$. pulchella, and this is followed in the present study. According to Van Name, the present species occurs widely in the arctic and subarctic waters.

125a. Pelonaia corrugata corrugata Goodsir et Forbes, 1841

Pelonaia corrugata Goodsir \& Forbes, 1841, p. 138.

For synonyms see Van Name (1945).

Material examined: None.

Remarks. The taxon so far referred to as D. corrugata is here denoted as the nominotypical subspecies of $D$. corrugata because the so-called $D$. corrugata forma bursaria should be given a subspecific rank (see below).

Distribution in Japan Sea. Mamiya Strait, 20-46 m (Redikorzev, 1916); Peter the Great Bay, 0-200 m (Ostroumov \& Pavlenko, 1911; Redikorzev, 1916) 
Distribution outside Japan Sea. The arctic and subarctic waters, as well as the cold temperate waters such as the coasts of North Sea, the Skagerrak and the Kattegat in the Atlantic, and British Columbia in the Pacific, 3.5-200 m (Huus \& Knudsen, 1950).

\section{5b. Pelonaia corrugata bursaria Redikorzev, 1941}

Pelonaia corrugata forma bursaria Redikorzev, 1941, pp. 188-189, 211-212, text-fig. 14, pl. 1, fig. b.

Material examined: None.

Remarks. Redikorzev (1941) established the forma bursaria of P. corrugata for the specimens from the Japan Sea and the Sea of Okhotsk, distinguishing from the nominotypical form by the differences seen in the body shape (pyriform or sac-like in the former, "elongated cylindrical or more or less club shaped" (Van Name, 1945, p. 319 ) in the latter), the orientation of the first intestinal loop (nearly horizontal, instead of roughly vertical) and the shape of ovary (L-shaped, instead of U-shaped). These differences seem to be of certain taxonomic significance, so Redikorzev's taxon is discriminated from the nominotypical form. Following the International Code of Zoological Nomenclature, 3rd ed., Art. 45 (g), the forma bursaria is here denoted as $P$. corrugata bursaria.

Distribution in Japan Sea. Mamiya Strait, $4 \mathrm{~m}$, and Peter the Great Bay, 93$900 \mathrm{~m}$ (Redikorzev, 1941); western coast of South Sakhalin (Skalkin, 1959).

Distribution outside Japan Sea. Sea of Okhotsk, 503-1366 m (Redikorzev, 1941).

Family Pyuridae

126. Pyura vittata (Stimpson, 1852)

Limited synonymy:

Pyura vittata: Tokioka, 1953c, pp. 273-275, pl. 3, figs 3-4, pl. 66, figs 1-5; 1960b, pp. 213-215, pl. 28, figs 27-34, pl. 29, figs 35-37; 1967c, pp. 202-204, fig. 90; Rho, 1971, pp. 121-122; 1975, pp. 143-144; Kott \& Goodbody, 1980, pp. 545-546, text-fig. 22, pl. 4C; Nishikawa, 1980b, tab. $1 ; 1984 b$, p. $151 ; 1986$ b, p. 176 . C. Monniot's (1983c) reference excluded.

Material examined: B: No. 36(M360), labeled as Cynthia hemikaras by Oka, collected from Hakodate, 11 individuals, 15-38 mm long; No. 40(M557), as Cynthia vittata, off Mourajima, Mutsu Bay, on June 26, '29, a $33 \mathrm{~mm}$ long individual; No. 144(M361), as Cyrithia hemikaras, from Hakodate, 2, $15 \mathrm{~mm}$ and $25 \mathrm{~mm}$ long; No. 210(M292), as Cyntia henikaras, from Hakodate, July 2, '17, a $24 \mathrm{~mm}$ long individual. $\mathrm{C}-1$ (Hokkaido): Rishiri Is.: Kutsugata-misaki, $1-4 \mathrm{~m}$ deep, 8 individuals, 20-37 mm long; Misaki, Senposhi, 2-4 m, 2 individuals, $16 \mathrm{~mm}$ and $21 \mathrm{~mm}$ long. Rebun Is.: Kabuka Hbr, 2-3 m, 6 individuals, 20.5-31 mm long; Nishiue-domari, 1-8 m, 7 individuals, 9-30 mm long; around Neko-iwa, $0-2 \mathrm{~m}, 4$ individuals, $15-35 \mathrm{~mm}$ long. Ofuyu, 1-3 m, 17 individuals, 5-30 $\mathrm{mm}$ long. Chazu, Bikuni, 3-5 m, 3 individuals, 13-42 mm long. Yobetsu, 1-3 m, 2 individuals, $13 \mathrm{~mm}$ and $28 \mathrm{~mm}$ long. Kamomejima, Esashi, $0 \mathrm{~m}$, a $20 \mathrm{~mm}$ long individual. Yaemon-misaki, Okushirijima Is., 2-4 m, 16 individuals, 21-37 mm long. C-2 (Mutsu Bay): Hadakajima Islet, in front of Asamushi Mar. Biol. St., 1-4 m deep, 3 individuals, 18-27 mm long. C-3: Fukaura, 3-7 m, a $33 \mathrm{~mm}$ long individual. $\mathrm{C}-5$ (Noto-hime): a $9.8 \mathrm{~mm}$ long individual. $\mathrm{C}-7$ (Wakasa Bay): 2 individuals, 17.5 $\mathrm{mm}$ and $20 \mathrm{~mm}$ long. D (Tottori): several individuals. $\mathrm{M}$ (Oga): 5 individuals, 15.5-25 $\mathrm{mm}$ long, 
already listed by Nishikawa (1984b). N (Oki) : a $10 \mathrm{~mm}$ long individual, already listed by Nishikawa (1986b).

Remarks. The present specimens are consistent with the previous descriptions of Pyura vittata, especially those by Tokioka, Rho and Kott \& Goodboby. Some features seen in the present material are noted here for future revisional studies as follows: body roundish; both siphons usually more or less distinct; test surface usually coated, and sometimes also impregnated, sparsely with sand grains; test coloration varying in different specimens from pink to dark brown; the siphons of mantle body usually colored deep or orangish red; siphonal spinules needle-like, up to 100 to 125 $\mu \mathrm{m}$ long except in the specimen of $\mathrm{N}$ that is furnished with the spinules up to only $50 \mu \mathrm{m} ; 6$ branchial folds on each side; first intestinal loop deep, but rather opened, while the second more or less shallow; no swelling of the intestine discernible; a few to many endocarps on the intestine comprising the second loop except the specimen of $\mathrm{C}-5$ and the $20 \mathrm{~mm}$ long one of $\mathrm{C}-7$ lacking endocarps completely; left gonad consisting of 21 to 35 capsules and the right composed of 23 to 35 ones in the 13 to $38 \mathrm{~mm}$ long specimens from Hokkaido, Mutsu Bay, Fukaura and Oga; 20 and 13 capsules on the respective sides in the $9.8 \mathrm{~mm}$ long specimen from Noto-hime; 30 and 30 to 33 in 17.5 and $20 \mathrm{~mm}$ ones from Wakasa Bay; and 17 and 18 in $10 \mathrm{~mm}$ long one from Oki; each capsule composed of many testicular follicles over its mesial surface and ovary occupying the remainder, furnished very rarely with indistinct endocarp issuing from the surface; ovarian eggs up to $200 \mu \mathrm{m}$ or more in diameter. All the mentioned differences are here regarded as individual variations, becauses the extremes in each character are bridged by intermediate states.

According to the taxonomic revision of Pyura vittata and related species elaborated by C. Monniot (1983c), the specimens collected from the West Pacific and assigned so far to $P$. vittata firstly by Oka (1932d), followed by Tokioka and others may be assignable, though not with certainty, to the following 3 different species, $P$. karasboja (Oka, 1906), P. torpida (Sluiter, 1898) and P. albanyensis Michaelsen, 1927. These species are, according to Monniot, all distinguishable from $P$. vittata in his sense by the iridescent siphonal spinules, the swollen intestine comprising the deep second loop, and the endocarps over the intestine and gonadal capsules only in $P$. vittata; and he rightly denoted that these features are shared with $P$. curvigona Tokioka, 1950. If $P$. vittata is really conspecific with $P$. curvigona, the specimens called hitherto as $P$. vittata mainly by the Japanese taxonomists should be named otherwise. However, the type material of $P$. vittata is unavailable now (see C. Monniot, 1983c, p. 1030), and further, it seems that the variation range in each of these species in question has not yet been recognized validly; therefore, the detailed discussions on the taxonomic affiliation of the above-mentioned specimens may better be left pending for future studies. Until then, the specimens are tentatively called $P$. vittata.

Distribution in Japan Sea. Hokkaido, northerly from Rishiri and Rebun Isls southerly to Esashi and Okushirijima Is., 0-8 $\mathrm{m}$ (in the present study); Mutsu Bay, 1$4 \mathrm{~m}$ (Oka, 1935; in the present study); Fukaura, Aomori Pref., 3-7 $\mathrm{m}$ (in the present study); Oga Pen., $0 \mathrm{~m}$ (Nishikawa, 1984b; in the present study); east coast of 
Noto Pen., 0-2.5 m (in the present study); Wakasa Bay, $0 \mathrm{~m}$ (do.); Oki Isls, 47$55 \mathrm{~m}$ (Nishikawa, 1986b; in the present study); Tottori, $0 \mathrm{~m}$ (in the present study); Korean coastal waters facing Korea Strait (Rho, 1971, 1975).

Distribution outside Japan Sea. Exact distribution will be given when the abovementioned discussions are settled. The present taxon occurs widely in the West Pacific region; in the Japan and adjacent waters, it has been collected from the following localities: Tateyama (Oka, 1932d); Sagami Bay (Oka, 1906; Tokioka, 1953c); Sugashima (Oka, 1932d; Tokioka, 1949b; Nishikawa, 1980b); around Kii Pen. (Nishikawa, 1980b); Osaka Bay (Nishikawa's unpublished data); Seto Inland Sea (Oka, 1932d; Nishikawa's unpublished data); Ariake Sea (Tokioka, 1960b); Yellow Sea coast of Korea (Rho, 1975); Hong Kong (Kott \& Goodbody, 1980).

\section{Pyura sacciformis (Drasche, 1884)}

Cynthia sacciformis Drasche, 1884, p. 376, pl. 5, figs 2-3.

Pyura sacciformis: Tokioka, 1967c, pp. 197-198, fig. 86.

Halocynthia jokoboja Oka, 1906, pp. 47-48. New Synonymy.

Hyalocynthia hystrix Oka, 1930c, pp. 317-320, figs A-D. New Synonymy.

For other synonyms see Nishikawa (1980a).

Doubtful references:

Pyura michaelseni: Kott, 1964, pp. 140-141, fig. 7.

Pyura sacciformis: Kott, 1981, pp. 203 and 206, fig. 34C; 1985, pp. 321-324.

Material examined: C-1 (Hokkaido): Yaemon-misaki, Okushirijima Is., 2-4 m, a $80 \mathrm{~mm}$ long individual. C-2 (Mutsu By) : off Kaizaki, SW end of Shimokita Pen., down to $20 \mathrm{~m}, 8$ individuals, 42-64 mm long; from buoys off Moura, a $86 \mathrm{~mm}$ long individual. C-4 (Tsukumo Bay): from the buoy, $0 \mathrm{~m}$ deep, a $60 \mathrm{~mm}$ long individual, already referred to by Nishikawa (1980a). C-8 (Oki): Izanaki-ura, Nishinoshima Is., 1-3 m, 2 individulas on Polycarpa cryptocarpa kroboja, $11.5 \mathrm{~mm}$ and 15 $\mathrm{mm}$ long. $\mathrm{E}-2$ (Fukui) : 10 individuals, $38-67 \mathrm{~mm}$ long. G-4 (Wakasa Bay): 6 individuals, 20-61 $\mathrm{mm}$ long. H-1 (Tsukumo Bay): a $83 \mathrm{~mm}$ long individual, H-3 (Tsukumo Bay): 6 individuals, 33$78 \mathrm{~mm}$ long. J-1 (Wakasa Bay): a $14 \mathrm{~mm}$ long individual. L-6 (Noto Pen.): Doumi, 5-6 m, 4 individuals, 28-70 mm long; Tsukumo Bay, $10 \mathrm{~m}, 2$ individuals, $47 \mathrm{~mm}$ and $77 \mathrm{~mm}$ long. M (Oga): 3 individuals, $25-40 \mathrm{~mm}$ long, already listed by Nishikawa (1984b).

Remarks. The present specimens fall within the variation range of Pyura sacciformis shown by Nishikawa (1980a), and are easily referred to this species. In the $70 \mathrm{~mm}$ long specimen of E-3, the left peribranchial cavity contains a mass of about 70 fish eggs, up to $2.3 \mathrm{~mm}$ in diameter.

My reexamination of the holotype of Cynthia japonica Traustedt collected in Japan and deposited at ZMK proved that $C$. japonica is a junior synonym of $P$. sacciformis, as already treated as such by Nishikawa (1980a) solely on the basis of the literature. And further, the examination of the two specimens certainly assignable to the holotypes of Halocynthia jokoboja Oka and Hyalocynthia hystrix Oka, respectively, also proved to fit very well with the revisional description of $P$. sacciformis given by Nishikawa (loc. cit.), and therefore, $H$. jokoboja and $H$. hystrix are safely regarded as the junior synonyms of $P$. sacciformis. Both are kept at OCUT, and the holotype of $H$. jokoboja, $41 \mathrm{~mm}$ long, was collected from Tateyama in April, 1899 and registered as No. 338(M22), while that of $H$. hystrix, $25 \mathrm{~mm}$ long, registered as No. 242(M124) 
without no data.

Kott's (1964) record of $P$. sacciformis from Heron Is., the Great Barrier Reef, was suggested to be a possible misidentification for Pyura stolonifera (Heller, 1878) by Nishikawa (1980a, pp. 91-92). Later, Kott (1981, 1985) recorded $P$. sacciformis also from Fiji and Eastern Australia. Though these records should be noted from the biogeographical point of view, I am now rather reluctant to adopt them absolutely. Detailed comparison of Kott's specimens side by side with the Japanese $P$. sacciformis should be undertaken in the future.

Distribution in Japan Sea. Okushirijima Is:, Hokkaido, $2-4 \mathrm{~m}$ deep (in the present study); Mutsu Bay, down to $20 \mathrm{~m}$ (Oka, 1935; Nishikawa, 1980a; in the present study); around Oga Pen., 10-33 $\mathrm{m}$ (Nishikawa, 1984b; in the present study); Doumi, Toyama Bay, 5-6 m (in the present study); Tsukumo Bay, down to $10 \mathrm{~m}$ (Nishikawa, 1980a; in the present study); off Echizen-cho, Fukui Pref. (in the present study); Wakasa Bay, to $110 \mathrm{~m}$ (Hartmeyer, 1906; in the present study); Oki Isls, 1-3 $\mathrm{m}$ (in the present study); Korean coastal waters facing the Japan Sea and Korea Strait (Rho, 1971, 1975).

Distribution outside Japan Sea. According to Nishikawa (1980a), Ozika Pen.; off Sunosaki, Boso Pen., 46-49 fms; Tokyo Bay; Sagami Bay, 40-60 fms; around Kii Pen.; Osaka Bay, to $30 \mathrm{~m}$; Seto Inland Sea, 0-25 m; Nagasaki. Further, in doubt, Hong Kong (see Kott, 1985), Eastern Australia (Kott, 1964, 1985), and Fiji (Kott, 1981).

\section{Pyura lepidoderma Tokioka, 1949}

(Fig. 33)

Pyura lepidoderma Tokioka, 1949a, p. 10, pl. 5, figs 1-3.

Material examined: A (Toyama Bay): 9 individuals, $2.5-30 \mathrm{~mm}$ long, the smaller 4 found attached to Ascidia gemmata. C-1 (Hokkaido): Misaki, Senposhi, Rishiri Is., 2-4 m, a $15 \mathrm{~mm}$ long individual. C-4 (Tsukumo Bay): a $11 \mathrm{~mm}$ long individual. C-8 (Oki): Izanaki-ura, Nishinoshima Is., 1-3 m, 3 individuals, 5.5-12.5 mm long; Chinzaki, Nishinoshima Is., 1-6 m, a $10.5 \mathrm{~mm}$ long individual; all from Polycarpa cryplocarpa kroboja. H-3 (Tsukumo Bay): a $14 \mathrm{~mm}$ long individual found attached to the same species as C-8. M (Oga): 2 individuals, $7 \mathrm{~mm}$ and $12 \mathrm{~mm}$ long, already listed by Nishikawa (1984b).

Description. Body more or less flattened dorsoventrally, attached to substratum by wide ventral part; the surface divided into many rather large scale-like polygonal areas, up to $4 \mathrm{~mm}$ in long diameter. Test thin but tough, transparent and white in smaller specimens, while nearly opaque and pale yellow to brownish orange in larger specimens. Test in the inner surface of both siphons colored uniformly white to reddish orange. Siphonal armature represented by rounded scales, usually 10 $\mu \mathrm{m}$ long, but sometimes up to $16 \mu \mathrm{m}$ (Fig. 33). Tentacles 24 or more, branched in a single order. Ciliated groove simple G-shaped; 6 branchial folds on each. Many endocarps found over the inner surface of mantle, as well as on the intestine comprising ventral branch of first intestinal loop except in the specimens 


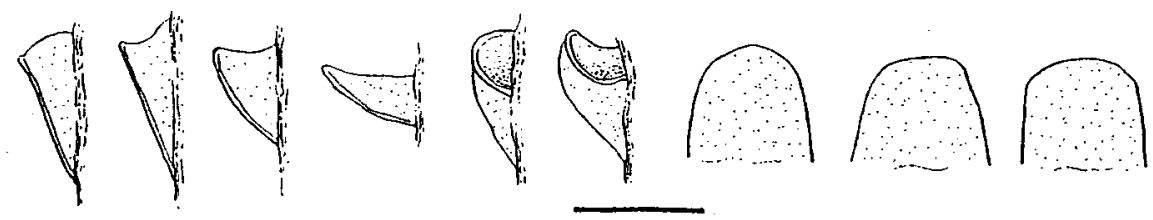

Fig. 33. Pyura lepidoderma Tokioka from Oki Isls (Collection C-8). Siphonal armature, seen microscopically from various directions. Scale indicates $10 \mu \mathrm{m}$.

of $\mathrm{C}-8$ lacking them completely. Numerous fine atrial tentacles arranged roughly in a ring. Visceral mass occupying the posteroventral half of mantle body; first loop very deep but rather wide, while the second is very shallow and widely opened. Left gonad consisting of 8 to 16 capsules, while the right of 9 to 20 ones; the $30 \mathrm{~mm}$ long individual of A (St. 21) lacked right gonad completely. Each capsule composed of testicular follicles over distal part of its free surface with ovary occupying the rest; ovarian eggs up to $200 \mu \mathrm{m}$ in diameter; a small endocarp issuing sometimes from mesial surface of the capsule only in the $19 \mathrm{~mm}$ long specimen of $A$ (St. 29).

Remarks. The complete absence of right gonad in the specimen mentioned above is a malformation. Then, the present specimens fall within the variation range of Pyura lepidoderma Tokioka shown in the previous descriptions given by Tokioka and Rho; the lack of endocarps in the above-mentioned specimens resembles the original description of this species, though its occurrence of endocarps has been noted in subsequent descriptions.

Distribution in Japan Sea. Rishiri Is., 2-4 m (in the present study); off Oga Pen., 21-33 m (Nishikawa, 1984b; in the present study); Toyama Bay, 100-1410 m (in the present study); Tsukumo Bay, down to $6 \mathrm{~m}$ (do.); Wakasa Bay (Tokioka, 1953b, 1959a); Oki Isls, 1-6 m (in the present study); Korean coastal waters facing Korea Strait (Rho, 1971, 1975).

Distribution outside Japan Sea. Kii Peninsula, $9 \mathrm{~m}$ (Tokioka, 1949a; Nishikawa, 1980b), Osaka Bay (Tokioka, 1954c), Seto Inland Sea (Tokioka, 1953a; Nishikawa's unpublished data), Ariake Sea (Tokioka, 1960b) and off Ose Zaki, Goto Isls, 65 fms (Tokioka, 1967c), Japan; East Australia (Kott, 1966, 1976; Kott (1985, p. 299) referred these records to Pyura elongata Tokioka, 1952, which seems, however, to be open to some doubt).

129. Pyura sp. cf. lignosa Michaelsen, 1908

(Fig. 34)

Pyura lignosa: Nishikawa \& Tokioka, 1976a, pp. 398-399, fig. 7, 50-52; Nishikawa, 1980b, tab. $1 ; 1982$ b, p. $204 ; 1984 a$, p. $136 ; 1984$ b, p. $151 ; 1986$ b, p. 176.

Pyura sp. aff. lignosa: Tokioka, 1970, pp. 103-106, fig. 11.

Doubtful synonym:

Pyura shiinoi Tokioka, 1949b, pp. 59-61, fig. 14. 
Material Examined: A (Toyama Bay): 5 individuals, 7-15 mm long. C-2 (Mutsu Bay): 4 individuals from Chelyosoma siboja, 5-15.5 mm long. C-3 (Fukaura) : a $11 \mathrm{~mm}$ long individual. C-4 (Tsukumo Bay): a $8.5 \mathrm{~mm}$ long individual. C-8 (Oki): Mimimimi-ura, Nishinoshima Is., 1-3 m deep, a $10.8 \mathrm{~mm}$ long individual; Chinzaki, Nishinoshima Is., $1-6 \mathrm{~m}, 3$ individuals from Polycarpa croptocarpa kroboja, 9.5-10.5 mm long. D (Tottori): 3 individuals collected in Dec., '78, 5-12 mm long. E-2 (Fukui): 11 individuals from Microcosmus hartmeyeri, 2.5-12 mm long. M (Oga): 7 individuals, 6-13 mm long, of which two are from Halocynthia hispida (ritteri-form) and Cnemidocarpa irene respectively; already listed by Nishikawa (1984b). $\mathrm{N}$ (Oki): 5 individuals, $3.5-10.5 \mathrm{~mm}$ long, the smaller three from Polycarpa maculata; already listed by Nishikawa (1986b).

Description. In life the animal appears deep reddish purple, though sometimes much paler ventrally. Body roughly ellipsoid, or much depressed dorsoventrally; attached to substratum by wide ventral side. Both siphons more or less remarkable; the branchial situated terminal, while the atrial located at the posterior onethird of body. Test surface divided into numerous small polygonal or roundish areas, usually up to $500-900 \mu \mathrm{m}$, but often to $1,250 \mu \mathrm{m}$ in long diameter; both apertures surrounded by many smaller areas. Test thin but very tough, somewhat hardened, and pale yellow to reddish pink or old rose, often deeper on the siphons. Inner surface of both siphons covered with the test variegated with 4 longitudinal lines colord bright purplish red alternating with white or pale yellow lines in the anterior (=-distal) half, while appeared uniformly whitish in the posterior (=proximal) half; further, that portion of test is furnished with minute rounded scales as siphonal armature, about $10 \mu \mathrm{m}$ or more long, quite the same as those seen in Pyura lepidoderma (see above). Mantle more or less thick and fleshy pink, sometimes with reddish tint around apertures. No endocarps over the inner surface of mantle nor the viscera; atrial tentacles indiscernible. Twelve to 20 branchial tentacles; branched only in 1 order and the branches usually minute and few in number, except the $8.5 \mathrm{~mm}$ long specimen of $\mathrm{C}-4$, furnished with the tentacles branched very rarely in two orders. Ciliated groove $\mathrm{U}$ - or $\mathrm{C}$-shaped opened anteriorly, very rarely with a short side branch on the outer margin (Fig. 34, D). Six branchial folds on each side; the formulae are:

in $8.5 \mathrm{~mm}$ long specimen of $\mathrm{C}-4$

L. D. 0 (11) 1 (8) 1 (12) 1 (12) 1 (10) 1 (3) $0 \mathrm{~V}$.

R. D. 0 (12) 1 (8) 1 (11) l (10) 1 (9) 1 (4) $0 \mathrm{~V}$.

in $12 \mathrm{~mm}$ long one of $\mathrm{D}$

L. D. 1 (12) 0 (12) 2 (14) 2 (11) 2 (12) 1 (10) $1 \mathrm{~V}$.

R. D. 1 (9) 0 (12) 0 (15) 2 (11) 2 (10) 1 ? V.

in $13 \mathrm{~mm}$ long one of $\mathrm{C}-2$

L. D. 1 (12) 1 (8) 1 (12) 1 (11) 2 (9) 2 (5) $1 \mathrm{~V}$.

R. D. 1 (11) 1 (9) 1 (13) 1 (11) 1 (10) 2 (6) $2 \mathrm{~V}$.

in $15 \mathrm{~mm}$ long one of $A$

L. D. 1 (16) 1 (14) 1 (15) 0 (15) 3 (12) 2 (9) $1 \mathrm{~V}$.

R. D. 1 (10) 1 (14) 1 (20) 0 (20) 3 (11) 2 (11) 1 V.

Alimentary system occupying most of mantle body (Fig. 34, A \& C). First intesti- 


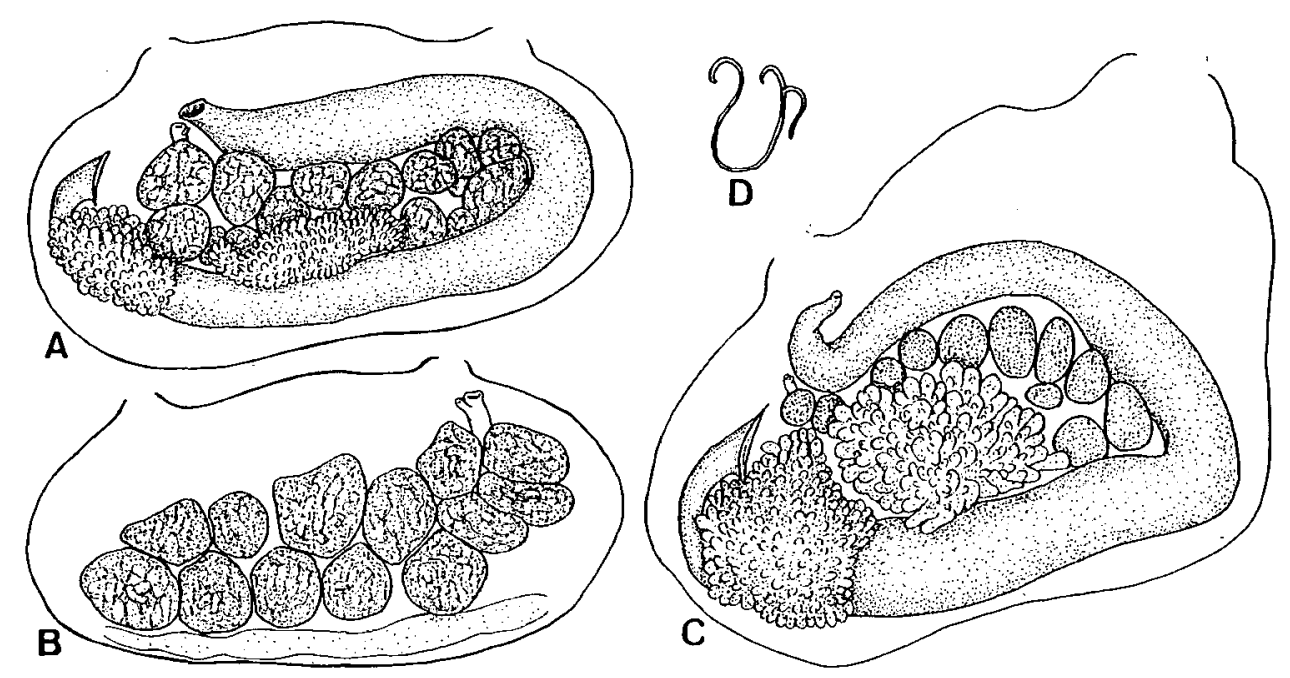

Fig. 34. Pyura sp. cf. lignosa Michaelsen. A-B. $13 \mathrm{~mm}$ long specimen from Mutsu Bay (Collection C-2); C. $6.7 \mathrm{~mm}$ long body with about $3 \mathrm{~mm}$ long posterior extension from Oga Pen. (M); D. $11 \mathrm{~mm}$ long specimen from Fukaura, Aomori Pref. (C-3). A \& C. left inner side of mantle body; B. right inner side of mantle body; D. ciliated groove.

nal loop very deep but open, while the second is virtually indiscernible; rectum very short, usually more or less tapering down to anus, and often variously curved. Liver well deveolped. Left gonad consisting of 10 to 18 (usually 12 to 14) capsules, lying straight in first loop, while the right having 10 to 21 (12 to 16) capsules, arranged nearly straight (Fig. 34, B). The capsule composed of many testicular follicles densely covering its mesial, but not lateral, surface with the ovary occupying the rest; ovarian eggs up to $250 \mu \mathrm{m}$ in diameter.

Remarks. These specimens resemble the $4.1 \mathrm{~mm}$ long specimen collected from Mindro Is., the Philippines and referred to Pyura sp. aff. lignosa by Tokioka (1970), the $16 \mathrm{~mm}$ long individual from Amami Islands, Japan and to P. lignosa by Nishikawa \& Tokioka (1976a), and the $24 \mathrm{~mm}$ long individual from Majuro Atoll and to this species by Nishikawa (1984a), especially in the tessellated surface of test appeared reddish or yellowish, the shape and size of siphonal armature (undescribed in the specimen from Amami), the course of alimentary canal, and the number of gonadal capsules. Among these specimens, however, those from the Japan Sea are different from the rest in the complete absence of endocarps in the former; in the rest the endocarps are found exclusively on the intestine and gonads. The specimens from the Japan Sea differ from the specimens from Mindro and Majuro in the lack of test projections in the Japan Sea specimens. Further, the specimens from the Japan Sea and Mindro are different from those from Amami and Majuro in the number of branchial folds on each side (6, instead of 7 in the Amami and Majuro specimens). Although these differences may be of taxonomic significance, the simi- 
larities may be so remarkable that all these specimens are conspecific with one another, although not with certainty. Thus, in this form from the West Pacific, the number of branchial folds may be varied from 6 to 7 on each side, and the test projections and the endocarps may be present or absent.

In the tessellated appearance, this form may resemble Pyura lignosa Michaelsen. This form is, however, different from the original description of $P$. lignosa by $\mathrm{Mi}$ chaelsen (1908) based on the specimens from the Pacific coast of Costa Rica especially in the siphonal armature (represented by rounded scales about $10 \mu \mathrm{m}$ or more in this form, instead of about $80 \mu \mathrm{m}$ long needles in the original description of $P$. lignosa). It seems to me that this difference is significant taxonomically. Consequently, the West Pacific form should be treated as distinct from $P$. lignosa, as already noted by C. Monniot (1983c, p. 1035); this form is here named only very tentatively as $P$. sp. cf. lignosa. The scale-like siphonal armature in $P$. sp: cf. lignosa is shared with the specimens collected in the Pacific coast of Costa Rica and assigned to $P$. lignosa by Tokioka (1972b); the smallest of Tokioka's specimens is similar to this form also in the widely opened first intestinal loop. However, Tokioka's specimens from Costa Rica are different from $P$. sp. cf. lignosa in that many endocarps are distributed over the whole inner surface of mantle in the Costa Rica specimens. Monniot \& Monniot (1967) recorded P. lignosa from off Dakar, West Africa, and C. Monniot (1983c) recorded this species also from Guadeloupe in the Caribbean Sea; their specimens are clearly distinguishable from the West Pacific form by the narrow and close first intestinal loop and deep second loop in Monniot's specimens, which resembles $P$. capensis Hartmeyer from South Africa known to have a tessellated test (see Millar, 1962a, pp. 195-196). Further affiliation of the West Pacific form will be left pending, until actual reexamination of the type and other specimens of $P$. lignosa from East Pacific, especially those described by Van Name (1945, pp. 336-338), and implied several other species with a tessellated surface.

The tessellated test, the siphonal armature represented by rounded scales, the widely opened first intestinal loop and the virtual lack of second loop seen in $P$. sp. cf. lignosa defined above are shared with the specimens collected from the Pacific coast of Japan and referred to P. lignosa by Nishikawa (1980b, 1982b). According to Nishikawa's unpublished data, these specimens, $5.5-56 \mathrm{~mm}$ long, are provided with usually 7 , but rarely 6 , branchial folds on each side, usually with a few to many endocarps on the intestine, and with the gonad consisting of far more (up to 40 or more) capsules than $P$. sp. cf. lignosa (up to 2l). In the first two features, these specimens fall within the variation range of $P$. sp. cf. lignosa such as revealed above. Further, in these specimens, the number of gonadal capsules tends to increase with growth. Thus, the specimens may be assignable to this taxon. All the mentioned features seen in P. sp. cf. lignosa, except that of test appearance, are seen in Pyura shiinoi Tokioka only recorded once from Sugashima, Kii Peninsula by Tokioka (1949b) on the basis of specimens without test; $P$. shiinoi is here included rather tentatively in the synonymy of $P$. sp. cf. lignosa. Further discussions on the delimitation of the taxon, as well as on its nomenclature, will appear elsewhere. 
Distribution in Japan Sea. Mutsu Bay, 15-20 m (in the present study); Fukaura, Aomori Pref., 3-7.m (do.); Oga Pen., down to $33 \mathrm{~m}$ (Nishikawa, 1984b; in the present study); Toyama Bay, 22-81 m (in the present study); Tsukumo Bay, 0-6 m (do.); off Echizen-cho, Fukui Pref. (do.); Oki Isls, 1-55 m (Nishikawa, 1986b; in the present study); Tottori, $0 \mathrm{~m}$ (in the present study).

Distribution outside Japan Sea. Shimoda, Izu Pen. (Nishikawa, 1982b); Kii Pen. (Nishikawa, 1980b; ?Tokioka, 1949b) and Amami Isls (Nishikawa \& Tokioka, 1976a), Japan; Mindro Is., the Philippines (Tokioka, 1970); Majuro Atoll, Micronesia, 5-13 m (Nishikawa, 1984a).

\section{Herdmania momus (Savigny, 1816)}

Cynthia momus Savigny, 1816, p. 143, pl. 1, fig. 2, pl. 4, fig. 1.

Herdmania momus: Van Name, 1945, pp. 341-344, figs 225-226.

For synonyms see Van Name (1945) and Kott \& Goodbody (1980).

Material examined: $\mathrm{C}-8$ (Oki): Ooku, Dogo Is., $3 \mathrm{~m}$, a $15 \mathrm{~mm}$ long individual; Mimimimiura, Nishinoshima Is., 1-3 m, a $9.5 \mathrm{~mm}$ long individual from Polycarpa cryptocarpa kroboja; Kuniga, Nishinoshima Is., $1-4 \mathrm{~m}$, a $24 \mathrm{~mm}$ long individual. D (Tottori) : a $24.5 \mathrm{~mm}$ long individual collected in Dec., '78. H-3 (Tsukumo Bay): a $38 \mathrm{~mm}$ long individual. I-1 (Noto-Ogi): a $88 \mathrm{~mm}$ long individual. J-3 (Wakasa Bay): 3 individuals, $19-40.5 \mathrm{~mm}$ long. $\mathrm{N}$ (Oki): 46 individuals, 4-45 $\mathrm{mm}$ long, some attached to the algae Padina sp. or Caulerpa fergusoni Murray (?).

Remarks. All the present specimens are provided with the spicules characteristic of the species. Some noteworthy features of the specimens are: seven to 11 branchial folds on each side; a thin rectangular membrane issues from the free surface of the proximal or middle part of thick short oviduct, and extending far beyond its opening located at its distal extremity; testicular follicles with many short ducts of vas deferens located over the most part of mesial surface of gonad.

Distribution in Japan Sea. Around Tsukumo Bay, 0-40 m (in the present study); Wakasa Bay, down to $40 \mathrm{~m}$ (Tokioka, 1953b, 1959a; in the present study); Oki Isls, $1-55 \mathrm{~m}$ (Nishikawa, 1986b; in the present study); Tottori, $0 \mathrm{~m}$ (in the present study); Cheju Is., Korea Strait (Rho, 1971, 1975).

Distribution outside Japan Sea. "Widely distributed in the warm waters throughout the world, including Japan" (Nishikawa, 1984a, p. 137).

\section{Herdmania mirabilis (Drasche, 1884)}

Cynthia mirabilis Drasche, 1884, p. 377, pl. 6, figs 2-7.

Herdmania mirabilis: Tokioka, 1965, pp. 125-128.

For synonyms see Kott \& Goodbody (1980).

Material examined: C-1 (Hokkaido): Chazu, Bikuni, 3-5 m, a $54 \mathrm{~mm}$ long individual. C-2 (Mutsu Bay): Kaizaki, SW end of Shimokita Pen., 15 -20 m, 2 individuals, $40 \mathrm{~mm}$ and $55 \mathrm{~mm}$ long.

Remarks. These specimens are very well consistent with the previous descriptions of this species. Several features of the specimens are: seven branchial folds on 
each side; the dorsal-most one being always the tallest, while the ventral-most one on the left very low and only seen anteriorly in the smallest specimen; the inconspicuous aperture of vas deferens situated close to the opening of oviduct. This species is here assigned to the genus Herdmania, following the opinion given by Tokioka (1965, pp. 125-128), though recent papers usually place it in the genus Pyura; for further discussion see Tokioka's paper.

Distribution in Japan Sea. Bikuni, 3-5 m (in the present study) and Otaru (Tokioka, 1967c), Hokkaido; Mutsu Bay, down to $20 \mathrm{~m}$ (Tsuchiya \& Osanai, 1978; in the present study); Wakasa Bay (Tokioka, 1959a); Korean coastal waters facing the Japan Sea and Korea Strait (Rho, 1971, 1975).

Distribution outside Japan Sea. Sagami Bay (Oka, 1906), west coast of Kii Pen. (Oka, 1906; Nishikawa, 1980b), Osaka Bay (Tokioka, 1954c), Tokushima Pref. (Oka, 1906), Usa, Kochi Pref. (Nakauchi, 1973) and Shimabara Bay, Kyushu (Oka, 1906), Japan; Hong Kong (Kott \& Goodbody, 1980); British Columbia to southern California, 0-33 fms (Ritter, 1907; Van Name, 1945; C. Monniot, 1965; Abbott \& Newberry, 1980).

\section{2a. Boltenia echinata echinata (Linné, 1767)}

Ascidia echinata Linné, 1767, p. 1087.

Boltenia echinata: Redikorzev, 1941, pp. 178-179; Van Name, 1945, pp. 354-356, pl. 2, figs 2-3, text-figs 237-241 ; Berrill, 1950, pp. 233-235; Huus \& Knudsen, 1950, p. 5; Ärnbäck-ChristieLinde, 1952, pp. 36-37; Lützen, 1959, pp. 16-17; Millar, 1959b, pp. 14-15; C. Monniot, 1965, pp. 25-26, figs 3A, 4A, 5A; Rho, 1975, pp. 147-148, pl. 10, figs 1-5. Tokioka's (1951a, 1959a) references are excluded, identified with $B$. echinata iburi.

Boltenia hirsuta: C. Monniot, 1965, pp. 27-28, figs 3B, 4B, 5B.

Pyura arctica var, ritteri: Ostroumov \& Pavlenko, 1911, pp. 20-21. Hartmeyer's (1906) Halocynthia arctica(?) excluded, identified as $B$. echinata iburi.

For other synonyms and references see Van Name (1945).

Doubtful references:

Boltenia echinata: Skalkin, 1959, p. 246; Beniaminson, 197 I, p. 319.

Material examined: None.

Remarks. In Boltenia echinata (Linné, 1767) delimited by Hartmeyer (1910; 1921, pp. 21-29; 1923, pp. 149-162), followed by many ascidian taxonomists (see, for example, Van Name, 1945), the spines over the test surface are almost always composed of the stout stem with many long branches issuing radially from its tip; the stem and branches have irregular, minute, simple spinules. According to Hartmeyer, the number of branches tends to increase gradually with growth. The animals grow larger in the arctic waters (up to $45 \mathrm{~mm}$ long or more) than that in the subarctic or cold temperate ones in the Atlantic (usually to 15 to $20 \mathrm{~mm}$ ); thus, the individuals in the arctic waters have spines bearing more branches (up to 10 or more) than those in the subarctic or cold temperate waters (to about 5). On the other hand, "Boltenia echinata forma iburi (Oka)" occurring mainly in the Japanese waters is, as stated below, covered with the spines of cold temperate type exclusively in the small- 
er specimens; larger specimens lack these spines, instead, they are covered with spines composed of slender conical stem bearing none to several short branches, all with spinules. The mentioned difference in the spines over the test surface seems to be of certain taxonomic significance, and therefore, the forma iburi is here ranked as a subspecies (only as the infraspecific taxon) of Boltenia echinata, and then so-called $B$. echinata may come to represent the nominotypical subspecies $B$. echinata echinata (Linné, 1767).

C. Monniot (1965) referred the 20 to $30 \mathrm{~mm}$ long specimens collected in the Bering Sea with the spines bearing elongated radial branches to Boltenia hirsuta (Agassiz, 1850), distinguished from the Arctic and North Atlantic B. echinata mainly by the elongated gonoduct along the rectum in $B$. hirsuta, rather than having the gonoduct opening within the first intestinal loop in B. echinata. And on the basis of this difference he suggested the possibility that his $B$. hirsuta may be oviparous, unlike $B$. echinata that has been known ovoviviparous. $B$. hirsuta was established for the specimens from the shore of Massachusettes on the Atlantic coast of North America, and therefore, the specimens from Bering should be called otherwise, even if his view is accepted. The difference seen in the gonoduct, though possibly overlooked, may be noteworthy, but in the original description of Cynthia arctica, now recognized as a junior synonym of $B$. echinata echinata, given by Hartmeyer (1899) on the basis of the specimens from the Spitzbergen and the Kara Sea, the gonoduct is drawn the same as Monniot's $B$. hirsuta. Further, among the specimens referable to $B$. echinata iburi, some have long gonoducts as seen in Monniot's B. hirsuta, but in others they are much shorter. Here, the difference in question is attributed to individual variation, of no taxonomic significance.

As distinguished by spines over the body surface, the following records of $B$. echinata are included in the synonymy of the nominotypical subspecies: those given by Redikorzev (1911a, 1916, 1941), Ostroumov \& Pavlenko (1911) and Rho (1975); Skalkin's (1959) and Beniaminson's (1971) records without any descriptions are, though only very provisionally, also included.

Distribution in Japan Sea. Mamiya Strait, $100 \mathrm{~m}$ (Redikorzev, 1916, 1941); off Sikhote-Alin, 60-106 m (Redikorzev, 1916, 194l); Peter the Great Bay, 55-200 m (Ostroumov \& Pavlenko, 1911; Redikorzev, 1911a, 1916, 1941; ?Beniaminson, 1971); ?western coast of South Sakhalin (Skalkin, 1959); Cheju Is., Korea Strait (Rho, 1975).

Distribution outside Japan Sea. Widely distributed in the arctic, subarctic and northern cold tempcratc waters in the world except around Japan; 0-162 fins deep (Van Name, 1945, p. 356).

132b. Boltenia echinata iburi (Oka, 1934)

(Fig. 35)

Cynthia iburi Oka, 1934c, pp. 695-697, figs A-B; 1935, pp. 440-442, figs 10-11.

Boltenia echinata f. iburi: Tokioka, 1960b, pp. 216-217, pl. 29, figs 42-43, pl. 30, figs 45-47; Rho, 
1971, pp. 125-126, pl. 8, figs 5-6, pl. 9, figs 6-7; 1975, pp. 148-149; Nishikawa, 1980b, tab. 1; $1984 b$, p. 151.

Boltenia echinata: Tokioka, 1951a, p. 17; 1959a, pp. 232-233, pl. 16, figs 32-37.

Halocynthia arctica(?): Hartmeyer, 1906, p. 7.

Doubtful synonyms:

Halocynthia echinata: Ritter, 1913, pp. 452-453 (part, the specimens from Alaska).

Boltenia villosa: Redikorzev, 1941, p. 179.

Material examined: A (Toyama Bay): 3 individuals, 3.8-9.5 mm long, the smaller two attached to Ascidia gemmata. C-1 (Hokkaido): Rishiri Is.: in front of the Marine Biological Station of Sapporo Medical College, Pon-misaki, 1-6 m, 2 individuals, $9 \mathrm{~mm}$ and $10 \mathrm{~mm}$; Kutsugata-misaki, $0-4 \mathrm{~m}, 3$ individuals, 5.5-25 mm; Misaki, Senposhi, 2-4 m, 16 individuals, 3-13 mm, some from Chelyosoma yezoense or Styela clava. Rebun Is.: Nishiue-domari, $1-8 \mathrm{~m}$, a $7.5 \mathrm{~mm}$ long individual from S. clava; around Neko-iwa, 1-7 m, 4 individuals, 4-9 mm long, some from $S$. clava. Ofuyu, 1-3 m, 6 individuals, 7-16 mm. Shukutsu, Otaru, 1-4 m, 4 individuals, 16-25 mm. C-2 (Mutsu Bay): Kaizaki, SW end of Shimokita Pen., 15-20 m, a $7.1 \mathrm{~mm}$ long individual. C-4 (Tsukumo Bay): a $20 \mathrm{~mm}$ long individual. C-8 (Oki): Chinzaki, Nishinoshima Is., 1-6 m, 3 individuals from Polycarpa cryptocarpa kroboja, 8-15 mm long. D (Tottori): a $5.5 \mathrm{~mm}$ long individual collected in Dec. '78. E-1 (Wakasa Bay): a $14 \mathrm{~mm}$ long individual. L-6 (Tsukumo Bay): 2 individuals from Halocynthia hispida, $5.8 \mathrm{~mm}$ and $9.5 \mathrm{~mm}$ long. $\mathrm{M}(\mathrm{Oga}): 2$ individuals, $15 \mathrm{~mm}$ and $16 \mathrm{~mm}$ long, already listed by Nishikawa (1984b).

Remarks. Body is usually ellipsoid, but sometimes flattened dorsoventrally; attached to substratum by wide ventral side. Of the specimens from Hokkaido, the individuals $10 \mathrm{~mm}$ or shorter are densely covered by "cactus"-like spines, up to 2.5 or $3 \mathrm{~mm}$ long, each composed of a thick stem part with 3 to 6 elongated branches issuing mainly from its tip (Fig. 35, A-C); the other, larger specimens have spines which include up to $6 \mathrm{~mm}$ long pointed shaft bearing at irregular intervals many
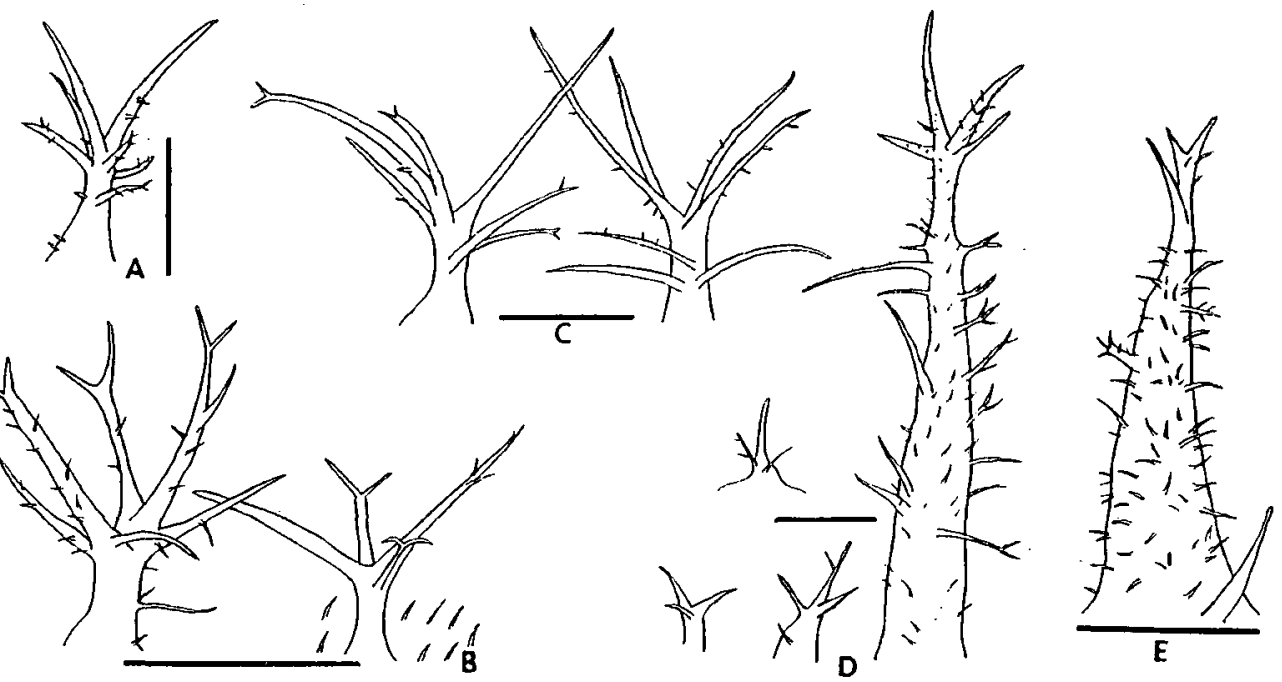

Fig. 35. Boltenia echinala iburi (Oka). Spines over the test surface. A. $7.5 \mathrm{~mm}$ long specimen from Rebun Is. (Collection C-1); B. $6 \mathrm{~mm}$ long individual from Rebun Is. (do.); C. $9 \mathrm{~mm}$ long one from Rebun Is. (do.); D. $14 \mathrm{~mm}$ long one from Obama City (E-1); E. $9.5 \mathrm{~mm}$ long specimen from Tsukumo Bay, Noto Pen. $(\mathrm{L}-6)$. Scales indicate $1 \mathrm{~mm}$. 
short side-branches, that are quite similar to the spines of B. echinata iburi (Oka) described by Oka (1935, fig. 10), but also including smaller spines assignable to the "cactus" type. In both cases, the surface of the test including the spines is always covered densely or sparsely with fine simple spinules. All of the specimens in the present material except those from Hokkaido, 3.8 to $20 \mathrm{~mm}$ long, are quite similar in having both the large "iburi"- and small "cactus"-like spines (Fig. 35, D-E). Up to about 20 tentacles. Six (in smaller specimens) or 7 (in larger ones) branchial folds on each side. An elongate, irregularly lobed gonad on each side, often very voluminous when mature: the left gonoduct situated along the rectum, opening close to the anus except in those from Pon-misaki, Hokkaido (C-1) which have the gonoduct recurved anteriad (=opposite to the anus) near the middle of stomach. In the specimens from Pon-misaki, numerous hatched larvae, $125 \mu \mathrm{m}$ in trunk length were discerned in the peribranchial cavity, they had two pigment flecks.

All these specimens except the smallest ones from Hokkaido are consistent with the previous descriptions of "Boltenia echinata $\mathrm{f}$. iburi", now denoted as B. echinata iburi. The smaller specimens from Hokkaido are here regarded as the growing individuals of this subspecies, rather than as representing the nominotypical one.

The specimens, as long as $10 \mathrm{~mm}$, from Akkeshi on the Pacific coast of Hokkaido and referred to $B$. echinata by Tokioka (195la), and the $6 \mathrm{~mm}$ long specimen from Hakodate, referred doubtfully to Halocynthia arctica by Hartmeyer (1906) and then moved to B. echinata by Hartmeyer (1923), all have a dense covering of "cactus"like spines over the body surface. These specimens will be here considered as the growing $B$. echinata iburi, rather than allotted to the nominotypical subspecies, though of course the latter view might not be impossible. Ritter (1913) referred "three small specimens from Loring, Alaska" to Halocynthia echinata with some hesitation, because there were few spines "presenting the regular ring of crowning secondary spines so characteristic of echinata", while "a majority - resemble more closely the single axis spines of $H$. villosa (=Boltenia villosa (Stimpson)) -- than the radical spines of echinata". Ritter's specimens resemble $B$. echinata iburi from outside Hokkaido and further, the specimens in question may, though not mentioned in his description, lack the peduncle; this peduncle may be typical of $B$. villosa occurring the Pacific coast of North America (see Van Name, 1945, pp. 356-358). Therefore, these specimens are classified, though only very provisionally, to $B$. echinata iburi in the present study, which may suggest the close kinship between this subspecies and $B$. villosa. $B$. villosa was once recorded from the Japan Sea by Redikorzev (1941); the specimens are ail attached to the substratum by the very small area of test, though lacking a complete peduncle. This attachment may possibly have been caused by the substratum rich in small crevices. Some specimens may have the spines typical of $B$. villosa, that are quite similar to those of the subspecies iburi, though he made no references to the structure. Consequently, Redikorzev's will be tentatively included here.

Distribution in Japan Sea. ?Exact localities unknown, but probably off the coasts of Soviet Union, 36-99 m (Redikorzev, 1941); Rishiri and Rebun Isls, Ofuyu and 
Otaru, 1-8 $\mathrm{m}$ (in the present study), as well as Hakodate (Hartmeyer, 1906), Hokkaido; Mutsu Bay, down to $20 \mathrm{~m}$ (Oka, 1934, 1935; in the present study); Oga Pen., $10 \mathrm{~m}$ (Nishikawa, 1984b; do.); Toyama Bay, 22-100 m (in the present study); Tsukumo Bay, to $10 \mathrm{~m}$ (do.); Wakasa Bay (Tokioka, 1959a; in the present study); Oki Isls, 1-6 $\mathrm{m}$ (in the present study); Tottori, $0 \mathrm{~m}$ (do.); Korean coasts facing the Japan Sea and Korea Strait (Rho, 1971, 1975).

Distribution outside Japan Sea. Akkeshi (Tokioka, 1951a) and the coast of "Iburi" province (Oka, 1934c), Hokkaido; off the western coast of Kii Pen., 100-200 m (Nishikawa, 1980b); Seto Inland Sea (Nishikawa's unpublished data); Ariake Sea (Tokioka, 1960b); ?Loring, near Ketchikan, Alaska (Ritter, 1913).

\section{Boltenia transversaria (Sluiter, 1904)}

Halocynthia transversaria Sluiter, 1904, pp. 48-49, pl. 11, figs 1-4.

Boltenia transversaria: Tokioka, 1960b, pp. 217-218, text-fig. 2, pl. 29, fig. 44, pl. 30, figs 48-52.

Cynthia transversaria var. manaarensis Herdman, 1906, pp. 312-313, pl. 3, figs 20-24. New Synonymy.

Material examined: $\mathrm{N}$ (Oki): a $14.5 \mathrm{~mm}$ long individual, already listed by Nishikawa (1986b).

Remarks. This specimen closely resembles the previous descriptions of $B$. transversaria (Sluiter), differing in that the specimen lacks the renal sac such as described by Tokioka, though instead, the heart is clearly discernible in the specimen. I feel that Tokioka might have mistaken the heart for the renal sac. This specimen from Oki is clearly in this species. Brief morphological notes on the present specimen are as follows: body flattened laterally; both siphons distinct but short; atrial velum present but narrow, without any tentacles; 6 branchial folds on each, 7 to 16 vessels on each fold and 1 to 3 ones between two folds; rectum attached directly and firmly to the branchial sac; testicular follicles occupying the attachment surface of gonad.

Cynthia transversaria var. manaarensis Herdman seems indistinguishable from $B$. transversaria, and are regarded as a synonym of the latter.

Distribution in Japan Sea. Oki Isls, 30-45 m (Nishikawa, 1986b; in the present study).

Distribution outside Japan Sea. Ariake, Japan (Tokioka, 1960b); Yellow Sea coast of Korea (Rho, 1975) ; Banda Sea, 0 m (Sluiter, 1904); Gulf of Manaar, Sri Lanka, $10 \mathrm{fms}$ (Herdman, 1906).

\section{Boltenia ovifera (Linné, 1767)}

Vorticella ovifera Linné, 1767, p. 1319.

Boltenia ovifera: Savigny, 1816, pp. 88-89, 140-141, pl. 1, fig. 1, pl. 5, fig. 1.

For synonyms see Van Name (1945).

Material examined: None.

Distribution in Japan Sea. Western coast of South Sakhalin (Skalkin, 1959).

Distribution outside Japan Sea. According mainly to Hartmeyer (1923, pp. 138- 
149), North Pacific boreal waters, the Chukchi Sea, the east and west coasts of Greenland and Baffin, Hudson Bay, as well as Atlantic boreal waters of North America, 4-270 fms.

\section{Halocynthia aurantium aurantium (Pallas, 1787)}

Ascidia aurantium Pallas, 1787, p. 240, pl. 7, fig. 38.

Halocynthia aurantium: Hartmeyer, 1903, pp. 195-200.

Halocynthia aurantium subsp. typica Kott, 1969a, pp. 81, fig. 2, 11-12.

For synonyms see Kott (1969a).

Material examined: B (Hokkaido): No. 76(M96), labeled Cynthia superba by Oka, a $67 \mathrm{~mm}$ long individual collected from Yoichi in Sept. '05 by Matsuyama. C-1 (Hokkaido): in front of Marine Biological Station of Sapporo Medical College, Pon-misaki, Rishiri Is., 1-6 m deep, a 90 mm long individual; Kabuka Hbr, Rebun Is., $5 \mathrm{~m}$, a $103 \mathrm{~mm}$ long individual.

Remarks. There are 3 gonads on each side in the smaller two specimens, but the largest one has 4 on the left and 3 on the right. This feature in the present specimens place them in Halocynthia aurantium subsp. typica defined by Kott, that should be denoted here as $H$. aurantium aurantium (see International Code of Zoological Nomenclature, 3rd ed., Art. 47a).

The material collected from "Koreas Kyst" and assigned to Cynthia fyriformis (Rathke) by Traustedt (1885) was described as having T-shaped spicules in the test and mantle; later, the material was treated as Halocynthia aurantium forma koreana by Hartmeyer (1903). Unfortunately the material is now lost at UZMK (Rasmussen, person. commu.), so the true nature of the spicules remains unknown.

Distribution in Japan Sea. Mamiya Strait, $25 \mathrm{~m}$ (Redikorzev, 1916); Olgi Bay, Sikhote-Alin, $8 \mathrm{~m}$ (Redikorzev, 1941); Peter the Great Bay, 10-100 m (Ostroumov \& Pavlenko, 1911; Redikorzev, 1916, 1941; Beniaminson, 1971, 1976); western coast of South Sakhalin (Skalkin, 1959); Rishiri and Rebun Isls, 1-6 m and Yoichi (in the present study), as well as Otaru (Tokioka, 1967c), Hokkaido; probably the Japan Sea coast of Korea (Traustedt, 1885).

Distribution outside Japan Sea. In the Japanese waters, Akkeshi (Tokioka, 1951a), Nemuro (Nishikawa's unpublished record) and several localities of Hokkaido (Oka, 1906); further, according to Kott (1969a), Okhotsk and Bering Seas, Bering Strait, Alaska to Puget Sound, 10-180 m.

\section{Halocynthia roretzi (Drasche, 1884)}

(Styela?) Cynthia roretzii Drasche, 1884, pp. 376-377, pl. 5, figs 4-8, pl. 6, fig. 1 .

Halocynthia roretzi: Oka, 1906, pp. 37-39.

Material examined: B: No. 13(M428), labeled by Oka as Cynthia sp. juv., 2 individuals collected off Noheji, SW part of Mutsu Bay, Apr. 22, '26 by Kokubo and Kamata, $3.5 \mathrm{~mm}$ and $6 \mathrm{~mm}$ long; No. 234(M412), as Cynthia sp. juv., 4 individuals collected off Wakinojawa, NW part of Mutsu Bay, Apr. 9, '26 by Hozawa and Kokubo, up to $3.5 \mathrm{~mm}$ long; No. 223(M294), as Cynthia roretzi var. ivamiana, an intact $33 \mathrm{~mm}$ long individual from Takahama, Wakasa Bay, Oct. 26, '13. C-1 (Hok- 
kaido): Kabuka Hbr, Rebun Is., $5 \mathrm{~m}$, a $110 \mathrm{~mm}$ long individual; Chazu, Bikuni, 3-5 m, 6 individuals, 48-90 mm long; Shukutsu, Otaru, 1-4 m, 6 individuals, 29-90 mm long; Kamomejima Islet, Esashi, 3-7 m, 6 individuals, $26-90 \mathrm{~mm}$ long; the same locality, $1 \mathrm{~m}$, a $4 \mathrm{~mm}$ long juvenile from undersurface of boulder; Yaemon-misaki, Okushiri Is., 2-4 m, a $85 \mathrm{~mm}$ long individual. C-2 (Mutsu Bay): Kaizaki, SW end of Shimokita Pen., 15-20 m, a $25 \mathrm{~mm}$ long individual; from buoys off Moura, 4 individuals, $4.5-42 \mathrm{~mm}$ long. $\mathrm{C}-4$ (Tsukumo Bay) : from buoys, a $45 \mathrm{~mm}$ long individual. G-1 (Oga): 2 individuals, $70 \mathrm{~mm}$ and $81 \mathrm{~mm}$ long. $\mathrm{M}(\mathrm{Oga}): 10$ individuals, $15.5-63 \mathrm{~mm}$ long, already listed by Nishikawa (1984b). N (Oki): a $7 \mathrm{~mm}$ long juvenile, already listed by Nishikawa (1986b).

Remarks. The $10 \mathrm{~mm}$ or less long specimens in the present material differ from the larger ones easily referable to Halocynthia roretzi, in the body surface wholly subdivided into numeous polygonal areas, many of which bear a slender spine, up to 1.5 $\mathrm{mm}$ long, in the smaller specimens; the spines are distributed most densely around apertures. As the smaller specimens are quite the same as the juvenile of $H$. roretzi that had been reared at Asamushi by T. Numakunai of Tohoku Univ., and kindly sent to me, they are safely assignable also to this species.

Numakunai \& Hoshino $(1973,1974)$ and Numakunai et al. (1981) divided Hal. roretzi inhabiting Mutsu Bay into 3 types, A, B and C, primarily by the difference in the season and time of spawning, and further, though not always so reliably, by the different shapes, sizes and density of the papillae over the surface. On the basis of the mentioned external features only, all the larger specimens in the present material except those of $\mathrm{C}-1$ from Hokkaido, are assignable tentatively to the type $\mathrm{C}$, while those from Hokkaido to B. Also on the basis of these features, previous records of this species are here classified into the above-mentioned 3 types as shown below, so far as adequate information is available in the records.

According to the measurements given by Rho (1971) on the 300 individuals, 100 from each of 3 localities on the Korean coast, the papillae in the larger specimens may be more numerous but shorter in those from more northern locality; observations on the spawning season and time in the Korean animal, with special reference to the different external appearances, are highly expected.

Distribution in Jaban Sea. Zooltoi Rok inlet on the coast of Sikhote-Alin region, $0 \mathrm{~m}$ (Redikorzev, 1941). Peter the Great Bay, 10-15 m (Redikorzev, 1941; Beniaminson, 1971, 1976). Hokkaido: Kabuka, Rishiri Is., 5 m, Shukutsu, Otaru, 1-4 m, Chazu, Bikuni, 3-5 m, Kamomejima Islet, Esashi, 1-7 m, and Yaemon-misaki, Okushirijima Is., 2-4 m, all assignable to type B (in the present study); Wakkanai and Otaru, to A (Numakunai \& Hoshino, 1982); Otaru (Oka, 1906; Tokioka, 1967c, probably to C); Hakodate (Traustedt, 1885; Oka, 1906). Tsugaru Strait (Traustedt, 1885, probably to G). Mutsu Bay, down to $20 \mathrm{~m}$, inhabited by all 3 types (see above) (Oka, 1906, 1935; Tsuchiya \& Osanai, 1978; in the present study). Honshu: Aomori Pref., to type C (Numakunai \& Hoshino, 1982); Oga Pen., to 62 $\mathrm{m}$, to $\mathrm{C}$ (Oka, 1906, 1926; Nishikawa, 1984b; in the present study); Sado (Tokioka, 1962a); Tsukumo Bay, $0 \mathrm{~m}$, to $\mathrm{C}$ (in the present study); Noto Pen., to C (Numakunai \& Hoshino, 1982); Wakasa Bay (Tokioka, 1953b; in the present study, to $\mathrm{C}$ ); Oki Isls, 40-55 m (in the present study). Korean coasts facing the Japan Sea and Korea Strait, excluding the Ullung-do Is. and the southern coast of Cheju Is. (Rho, 
1971, 1975).

Distribution outside Japan Sea. Sanriku coast (=roughly the northeastern part of Honshu district facing the Pacific Ocean) (Oka, 1906; 1926c, to C; Tokioka, 1953c, to A, according to Numakunai et al., 1981; Numakunai \& Hoshino, 1982, to G); off Fukushima Pref., down to $50 \mathrm{~m}$, to G(?) (Fisheries Experimental Station of Fukushima Pref., 1981); off Nakaminato, Ibaraki Pref. (Nishikawa's unpublished data); Tokyo Bay (Hartmeyer, 1906, though this record was doubted by Oka, 1926c); Sagami Bay, to $17 \mathrm{~m}$ (Hartmeyer, 1906; Oka, 1906; Tokioka, 1953c, to C); Osaka Bay (Tokioka, 1951b, 1954c); Seto Inland Sea, to G (Oka, 1926c; Numakunai \& Hoshino, 1982; Nishikawa's unpublished data); off Goto Isls, west of Kyushu, $64 \mathrm{~m}$, to $\mathrm{C}$ (Millar, 1975). Further, according to Tokioka (1953c), the present species occurs in "the coast of Shantung Peninsula in North China".

\section{Halocynthia hispida (Herdman, 1881)}

Cynthia hispida Herdman, 1881, p. 61.

Halocynthia hispida: Kott, 1952, pp. 283-285, figs 130-136.

For synonyms see Kott (1969a).

Material examined: A (Toyama Bay): 3 individuals, $16-25 \mathrm{~mm}$ long, the smaller two found attached to Microcosmus multitentaculatus. B: No. 53(M108), labeled by Oka as Cynthia igaboja, Hakodate, Mar. '05, a $65 \mathrm{~mm}$ long individual; No. 61(M357), as Cynthia ritteri, Oshoro, a $78 \mathrm{~mm}$ long individual; No. 93(M539), as Cynthia igaboja, Wajima, Ishikawa Pref., July '28, 3 individuals, 47-64 mm long; No. 273(M230), as Cynthia ritteri, Zenibako, Hokkaido, Mar. 23, '12, a $33 \mathrm{~mm}$ long individual; No. 328(M548), as Cynthia igaboja, Togi, Ishikawa Pref., '26, a $36 \mathrm{~mm}$ long individual. C-1 (Hokkaido): Chazu, Bikuni, 3-5 m, 2 individuals, $43 \mathrm{~mm}$ and $73 \mathrm{~mm}$ long. C-3: 4 individuals, 42$70 \mathrm{~mm}$ long. C-8: Okinoura, Dogo Is., 3-6 m, a $57 \mathrm{~mm}$ long individual; Chinzaki, Nishinoshima Is., 1-6 m, 2 individual, $63 \mathrm{~mm}$ and $92 \mathrm{~mm}$ long. E-1: a $18 \mathrm{~mm}$ long individual from Polycarpa maculata. E-2: 6 individuals, 43-70 mm long. F-3: a $36 \mathrm{~mm}$ long individual. G-4: a $23 \mathrm{~mm}$ long individual. $\mathrm{H}-1: 2$ individuals, $85 \mathrm{~mm}$ and $110 \mathrm{~mm}$ long. $\mathrm{H}-3:$ a $20 \mathrm{~mm}$ long individual. L-6: 3 individuals, 40-114 mm long, from Tsukumo Bay, while a $80 \mathrm{~mm}$ long one from Doumi. L-11:3 individuals, 66-76 mm long. M (Oga): 16 individuals, 11-97 mm long, already listed by Nishikawa (1984b).

Remarks. All the present specimens fall within the variation range of Halocynthia hispida defined by Kott (1969a), who rightly synonymized $H$. hilgendorfi (comprising "ritteri"-, "owstoni"- and "igaboja"-forms) and several related species with this. Some morphological features in the specimens are as follows: test surface covered with the spines composed of a slender shaft of various lengths, $10 \mathrm{~mm}$ or longer, and several (issuing from the top of short shaft) to many (from the sides of longer shafts) branches; the entire surface having numerous fine spinules, up to $500 \mu \mathrm{m}$ or rarely $1 \mathrm{~mm}$ long; longer spines are confined to aperture regions, but shorter ones usually covering the surface in the specimens of B (No. 61 and a $47 \mathrm{~mm}$ long one of No. 93), $\mathrm{C}-3, \mathrm{C}-8, \mathrm{E}-2$ (a $68 \mathrm{~mm}$ long one), $\mathrm{H}-1, \mathrm{~L}-6$ (3 ones, 80 to $114 \mathrm{~mm}$ ) and $\mathrm{M}$ ( 8 ones, 40 to $97 \mathrm{~mm}$ ), referable to the so-called "ritteri"'-form; but both longer and shorter spines covering the surface in the specimens of A, B (No. 53, 2 larger ones of No. 93, Nos. 53, 273 and 328), E-1, F-3, G-4, H-3, L-11 and M (3 ones, 11 to 
$18 \mathrm{~mm}$ long), assignable to so-called "igaboja"-form; further, the rest of the material denoted as "owstoni"-form representing an intermediate state in the arrangement of spines between the above-mentioned two forms; many endocarps over the inner surface of mantle; ciliated groove $\mathrm{C}$-shaped opening anteriorly, with both horns rolled in several times in larger specimens; 7 to 10 branchial folds on each side, the ventralmost often rudimentary; rectum attached firmly to the branchial sac; each gonad consisting of 3 to 17 branches.

I reexamined the type material of $H$. hispida, represented by a single $60 \mathrm{~mm}$ long specimen, that was collected in the Bass Strait, 38-40 fms deep, described by Herdman (1882) and deposited at BMNH (No. 1887:2:4:69-70). The features of the holotype are: body surface provided wholly and densely with spines composed of a stout shaft as short as $200 \mu \mathrm{m}$ with several branches issuing from its top, as well as with simple spinules, up to $200 \mu \mathrm{m}$ long; exclusively around apertures are the spines with a slender shaft, up to $2 \mathrm{~mm}$ long, bearing many fine branches; many endocarps over the inner surface of mantle; ciliated groove G-shaped with both horns rolled in about 2 times; 10 branchial folds on the left and 11 ones on the right; rectum attached firmly to branchial sac; left gonad consisting of 7 branches, while the right of 3 . In the surface appearance, the type specimen of $H$. hispida resembles very well the "ritteri"-form mentioned above, though the spines are much smaller in the type. This resemblance, as well as the occurrence of the specimens of various arrangements of test spines in the Australian population as shown by Kott (1969a), validates Kott's synonymy of the Japanese $H$. hilgendorf $i$ with Australian $H$. hispida, though later Kott (1985) wrongly abandoned it.

These various manners of arrangement of the spines in different specimens are here regarded as an individual variation. It should be noted here that the only animal referable clearly to so-called "igaboja"-form of $H$. hispida has been hitherto recorded from the "Oregonian" region on the Pacific coast of North America (see Van Name, 1945, pp. 362-363; Abbott \& Newberry, 1980, pp. 212-213). Young $(1985,1986)$ revealed that the "igaboja"-form are protected against the predation by the gastropod Fusitriton oregonensis (Redfield) by the stiff spines of test. In that region, according to Young (personal communication), the "ritter"'-form is probably absent, and even the areas devoid of the predatory gastropod are inhabited exclusively by the animal armed with long spines. In the Oregonian population of $H$. hispida, therefore, it may possibly be that the "ritteri"-form had already been eliminated by the gastropod predator. On the other hand, however, $F$. oregonensis occurs also in Japanese waters, where both the "igaboja"- and the "ritleri"-forms are found. As the detailed ecology, especially the feeding habits, of the gastropod in Japan are still unknown, further discussions should be left pending here. Yoshioka (1982) showed that spine formation on the zooid walls of a bryozoan Membranipora membranacea (L.) is induced by two nudibranch predators, Corambe pacifica MacFarland et O'Donoghue and Doridella steinbergae Lance, but this probably is not true of the test spines of $H$. hispids.

Distribution in Jafan Sea. Otaru (Oka, 1906), Zenibako, Oshoro and Bikuni, 
3-5 $\mathrm{m}$ (in the present study) and Hakodate (Traustedt, 1885; in the present study), Hokkaido; Tsugaru Strait (Oka, 1935); Mutsu Bay, down to $18 \mathrm{~m}$ (Oka, 1935; Tsuchiya \& Osanai, 1978; in the present study); Fukaura, Aomori Pref., 3-7 m (in the present study); around Oga Pen., to $62 \mathrm{~m}$ (Nishikawa, 1984b; in the present study); Sado Is. (Tokioka, 1962a); Toyama Bay, 1380-1410 m (in the present study); Nanao, $5 \mathrm{~m}$ (do.); Tsukumo Bay, to $10 \mathrm{~m}$ (do.); Wajima (do.); Togi, western coast of Noto Pen. (do.); west off the estuary of Kuzuryu River, 82-86 m (do.); off Echizen-cho, Fukui Pref. (do.); Wakasa Bay, to $110 \mathrm{~m}$ (Tokioka, 1959a; in the present study); Oki Isls, 1-6 $\mathrm{m}$ (in the present study); Korean coastal waters facing the Japan Sea and Korea Strait (Rho, 1971, 1975).

Distribution outside Japan Sea. Japan: Hachinohe and Kinkazan (Oka, 1906), Onagawa (Hartmeyer, 1906), Sagami Bay, 100-300 m (Oka, 1906, 1926d; Tokioka, 1953c); the mouth of Suruga Bay (Oka, 1932); Kii Pen., 2-5 m (Tokioka, 1949b; Nishikawa, 1980b); Seto Inland Sea (Nishikawa's unpublished data); Kagoshima Bay (do.). British Columbia to Southern California, very low intertidal to $165 \mathrm{~m}$ (see Abbott \& Newberry, 1980). South and West Australia, 5 fms-676 m (see Kott, 1969a; and Kott, 1972a, b, 1975, 1976, 1985; Millar, 1963). New Caledonia (Vasseur, 1967a). Sri Lanka, 6-9 fms (Herdman, 1906).

\section{Halocynthia igaguri Tokioka, 1953}

(Fig. 36)

Halocynthia igaguri Tokioka, 1953a, pp. 20-22, fig. 13; Kott, 1969a, pp. 81 and 85; Nishikawa, 1986b, p. 176.

Material examined: $N$ (Oki): 4 individuals, $5-10.5 \mathrm{~mm}$ long, the smaller 2 found attached to the body surface of Microcosmus hartmeyeri, already listed by Nishikawa (1986b).

Description. Body roughly ellipsoid elongated longitudinally, attached to substratum by thin but wide test projections issuing from the posterior end of body (Fig. 36, A). The surface densely covered with spines armed with minute spinules (Fig. 36, B); the spines up to $2 \mathrm{~mm}$ long around apertures or to $2.5 \mathrm{~mm}$ in the larger specimens, while to $1.3 \mathrm{~mm}$ or to $1.5 \mathrm{~mm}$ long respectively in the smallest one. Branchial and atrial vela well developed. Branchial tentacles about 16, branched in 1 order; the branches very rarely provided with minute projections. Ciliated groove C-shaped opened anteriorly (Fig. 36, E). Six or 7 branchial folds on each; the ventral-most one usualiy discerned only anterioriy; the formula in the $9 \mathrm{~mm}$ long specimen is:

$$
\begin{aligned}
& \text { L. D. } 0(14) 1(15) 1(15) 1(16) 1(2+) 1(9) 1 \mathrm{~V} . \\
& \text { R. D. } 1(11) 1(15) 1(14) 1(13) 1(13) 1(13) 1 \text { (4) } 0 \mathrm{~V} .
\end{aligned}
$$

Three to 4 stigmata per mesh between each fold. Many endocarps over the whole inner surface of mantle. Visceral mass occupying most of posterior half of mantle body (Fig. 36, C), or far less. First intestinal loop very deep, while the second more 


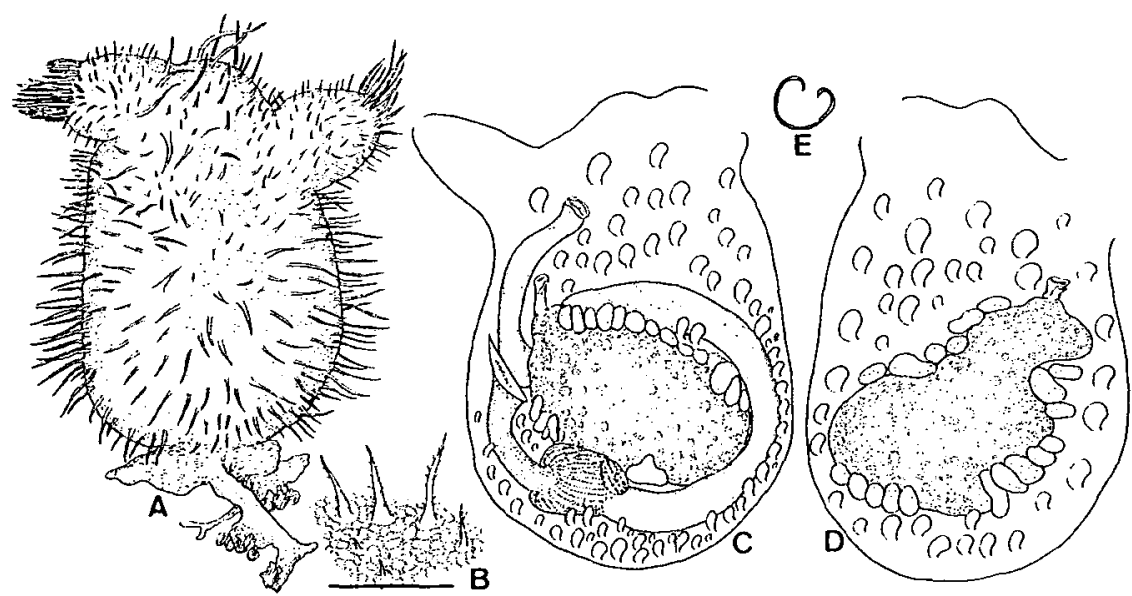

Fig. 36. Halocynthia igaguri Tokioka from Oki Isls (Collection N), $9 \mathrm{~mm}$ long specimen. A. whole body; B. enlarged view of a part of test surface in the middle of body, scale indicates $1 \mathrm{~mm}$; C. left inner side of mantle body; D. right inner side of mantle body; E. ciliated groove.

or less deep; rectum elongated along the dorsomedian part of branchial sac and firmly attached to it. Only a single gonad on each side; its anterior-most part on the left situated across the intestine near the bottom of second loop (Fig. 36, C). Gonad voluminous when fully mature and composed of the ovary fringed with many testicular follicles (Fig. 36, C-D); apertures of gonoducts situated terminally; ovarian eggs up to $200 \mu \mathrm{m}$ in diameter.

Remarks. The internal features of these specimens, especially the existence of a single gonad on each side, resemble that of Halocynthia turboja (Oka) described below, but these specimens are easily distinguishable from $H$. turboja by the stalked body and lack of large spines over the surface in $H$. turboja. However, these specimens are similar to the original and only description of $H$. igaguri Tokioka based on a single specimen from Mukaishima, Seto Inland Sea. The only exception is that this holotype has two gonads on the left and one on the right, while these specimens from the Japan Sea have one gonad on each side. According to Nishikawa's unpublished data, the two specimens collected in Iyo Sound of the Seto Inland Sea and referable to this species have a single gonad on each side. Consequently, Tokioka's holotype may better be regarded as an aberrant individual, rather than as distinct taxonomically from the animal with a single gonad on each side. Thus, the specimens from the Japan Sea are identified with H. igaguri.

Distribution in Japan Sea. Oki Isls, 35-55 m (Nishikawa, 1986b; in the present study).

Distribution outside Japan Sea. Seto Inland Sea, down to $12 \mathrm{~m}$ (Tokioka, 1953a; Nishikawa's unpublished data). 
139. Halocynthia turboja (Oka, 1929) comb. nov.

Podocynthia turboja Oka, 1929a, pp. 94-96, figs A-B; Tokioka, 1953b, pp. 29-31, text-fig. 2, pl. 1, fig. 3.

Material examined: A (Toyama Bay): 6 individuals, 14-21 mm long. B: No. 33(M532), labeled by Oka as Podocynthia rubra, Wajima, in Apr., '28, a single individual.

Remarks. These specimens fit the previous descriptions of Podocynthia turboja Oka, especially the detailed one given by Tokioka (1953b). Some morphological features in the present specimens are as follows: body $14 \mathrm{~mm}$ long $\times 10 \mathrm{~mm}$ wide to $21 \mathrm{~mm} \times 14 \mathrm{~mm}$, with the stalk 15 to $72 \mathrm{~mm}$ long and up to $5 \mathrm{~mm}$ or more thick; the stalk with rooty processes in the middle in some specimens, in addition to the usual ones near the posterior end; spines around the apertures are up to $1 \mathrm{~mm}$ long; test surface divided into small polygonal areas, each of which bears a single spinule, up to 300 to $500 \mu \mathrm{m}$ long in the body proper, while to 200 to $300 \mu \mathrm{m}$ in the peduncle; branchial and atrial vela very well developed; tentacles about 20, branched in 2 orders; ciliated groove C-shaped opened anteriorly, with both horns rolled in; 8 branchial folds on each, the ventral-most one discerned only anteriorly, except the smallest specimen that has 8 folds on the left, but 7 on the right; dorsal lamina represented by a series of fine languets; liver divided into large cardiac and small pyloric parts, the cardiac part furnished with longitudinal plications, while the pyloric composed of small lobes arranged somewhat irregularly with their surface coated with minute follicular papillae; rectum elongated, attached firmly to the branchial sac; a single gonad on each side, fully mature.

Tokioka (1953b) noted that in the type specimens of $P$. turboja, the dorsal lamina consists of a somewhat broad membrane with deeply serrated margin, but his new specimens had a lamina composed of fine languets. The latter feature of the lamina is shared also with the specimens examined here, which shows that this feature is not unusual in $P$. turboja. To clarify the true nature of their dorsal lamina, reexamination of the type specimens was planned; the specimens are kept at OCUT, but their mantle body had deteriorated to such a state as to be impossible to describe. At any rate, the above-mentioned difference seen in the dorsal lamina may be of not enough taxonomic significance to justify a specific gap. And, as already claimed by Tokioka (1953b), the existence of stalk and a single gonad on cach side in the present species cannot be treated as of generic importance; the presence of one gonad on each side is shared with Halocynthia igaguri stated above. Therefore, the genus Podocynthia is safely amalgamated into Halocynthia.

Distribution in Japan Sea. Toyama Bay, 74-1410m (in the present study); Wajima (do.); Obama Bay, Wakasa Bay (Tokioka, 1953b).

Distribution outside Japan Sea. Sagami Bay, 59-100 fms (Oka, 1929a).

140. Microcosmus hartmeyeri Oka, 1906

Microcosmus hartmeyeri Oka, 1906, pp. 49-50; Tokioka, 1953c, pp. 287-289, pl. 74, figs 1-5, pl. 75, 
figs 1-7; 1959a, p. 234; Nishikawa, 1980b, tab. 1; 1982b, p. 204; 1986b, p. 176.

Microcosmus polymorphus: Herdman, 1882, pp. 133-134, pl. 14, figs 7-8, without synonymy.

Doubtful reference:

Microcosmus polymorphus: Hartmeyer, 1906, p. 3, fig. 1.

Material examined: A (Toyama Bay): 2 individuals, $7 \mathrm{~mm}$ and $30 \mathrm{~mm}$ long. C-8 (Oki): Chinzaki, Nishinoshima Is., I-6 m, 4 individuals, $20.5-136 \mathrm{~mm}$ long. E-2: a $140 \mathrm{~mm}$ long individual. L-6: a $90 \mathrm{~mm}$ long individual from Ushitsu. $\mathrm{N}: 2$ individuals, $50 \mathrm{~mm}$ and $115 \mathrm{~mm}$ long, already listed by Nishikawa (1986b).

Remarks. All these specimens conform well to the previous descriptions of $M$. hartmeyeri, especially the detailed one given by Tokioka (1953c). This includes many important features such as; the external appearance, the shape of siphonal spinules, that of ciliated groove, the number of tentacles, the existence of 7 branchial folds on each side, the arrangement of endocarps, and the shape and position of gonads. The only exception is that the siphonal spinules are up to $100 \mu \mathrm{m}$ long in these specimens, instead of 150 to $170 \mu \mathrm{m}$ long in the descriptions. This difference seems of little taxonomic significance, so these specimens are referred to this species.

A specimen collected from sandy bottom of Bass Strait, 38-40 fms deep, referred to $M$. polymorphus Heller by Herdman (1882) and deposited at BMNH (registered as No. 1887-2-4-46,), was available for my reexamination. The specimen, $106 \mathrm{~mm}$ long and already dissected, is similar to the Japanese $M$. hartmeyeri Oka, differing only in that the siphonal spinules are much shorter (25 to $50 \mu \mathrm{m}$ long) in the specimen than in $M$. hartmeyeri ( $100 \mu \mathrm{m}$ or more), and transparent and brownish in the specimen, instead of nearly opaque and white in $M$. hartmeyeri. These differences may be of certain taxonomic significance. Therefore, the present specimen from Bass Strait is here included in the synonymy of $M$. hartmeyeri somewhat tentatively. $M$. hartmeyeri is easily distinguishable from the specimens of $M$. polymorphus Heller inhabiting European waters (its type locality being the Mediterranean Sea) by the siphonal armature lacking pointed terminal in $M$. polymorphus (see C. Monniot, 1962, pp. 410412). On the other hand, Herdman's $M$. polymorphus from Bass Strait was considered by Kott (1985, pp. 353-356) to be a synonym of $M$. propinquus Herdman, 1882. If it is ture, $M$. hartmeyeri should be regarded as a junior synonym of $M$. propinquus. According to Kott (1985, p. 356), however, "the type species (probably should be read as 'specimens') of $M$. propinquus and $M$. polymorphus have been examined and are found to be conspecific with one another". This statement introduces confusion into the distinciton between $M$. polymorphus and $M$. harmeyeri. To avoid further taxonomic confusion, it should be stressed here that $M$. hartmeyeri remains valid. The specimens collected in Sagami Bay and assinged to $M$. polymorphus by Hartmeyer (1906), was also suspected to be $M$. hartmeyeri Oka, because the specimens were described as having 7 branchial folds on each side. However, Hartmeyer's description lacks the information about such diagnostic features as siphonal armature and gonad, so the reexamination of his specimens, supposedly housed at MNB, was planned, but they are now absent from the museum (Kühlmann, person. commu.). Here Hartmeyer's record will be included, though only tentatively, in the synonymy 
of the Japanese $M$. hartmeyeri. $M$. hartmeyeri are similar to $M$. sabatieri Roule from the Mediterranean Sea described by C. Monniot (1962) in the large body, the shape and size of siphonal armature and the branchial sac with 7 folds on each. Detailed comparisons, especially of the gonadal features are needed between these species and related ones.

Distribution in Japan Sea. Toyama Bay, 22-30 m (in the present study); Ushitsu, cast coast of Noto Pen., 6-8 m (do.); off Echizen-cho, Fukui Pref. (do.); Wakasa Bay (Tokioka, 1959a); Oki Isls, 1-55 m (in the present study).

Distribution outside Japan Sea. Tateyama, southern end of Boso Pen. (Oka, 1906); Sagami Bay, down to $150 \mathrm{~m}$ (Hartmeyer, 1906; Tokioka, 1953c; Nishikawa, 1982 b) ; around Kii Pen., 1-70 m (Nishikawa, 1980b); Bass Strait, 35-40 fms (Herdman, 1882).

\section{Microcosmus multitentaculatus Tokioka, 1953}

Microcosmus multitentaculatus Tokioka, 1953a, pp. 22-23, fig. 14; 1953b, pp. 31-32, text-fig. 3, pl. 1, fig. 4; 1959b, pp. 234-235, pl. 18, figs 48-49; 1960b, pp. 215-216, pl. 29, figs 38-41; Rho, 1971, p. 125, pl. 10, figs 1-7; 1975, p. 147; Nishikawa, 1984b, p. 151. C. Monniot's (1965) reference excluded.

Material examined: A (Toyama Bay): 5 individuals, 14-57 mm long. B: all labeled by Oka as Microcosmus japonicus: No. 96(M529), off Oono, Kanazawa on July 18, '28, 4 individuals, 26-60 $\mathrm{mm}$ long; No. 102(M527), Wajima, Ishikawa Pref., July, '28, 6 individuals, 38-66 mm long; No. 109 (M528), Togi, western coast of Noto Pen., '26, 5 individuals, 34-39 mm long. E-1: 3 individuals, 22-27 mm long. E-2: 12 individuals, $31-51 \mathrm{~mm}$ long. G-4: a $77 \mathrm{~mm}$ long individual. I-1: a 17 $\mathrm{mm}$ long individual. L-6: 6 individuals, 19-28 mm long, from Doumi. M (Oga): 2 individuals, $28 \mathrm{~mm}$ and $34 \mathrm{~mm}$ long, already listed by Nishikawa (1984b).

Remarks. All these specimens resemble the original and subsequent descriptions of $M$. multitentaculatus Tokioka, especially in such features as: 7 branchial folds on each side of the sac, the arrangement of endocarps, and the shape (roundish in outline on the right) and position of gonads. Other features of these specimens are: siphonal spinules slender and conical, quite similar to those described in $M$. hartmeyeri, up to 60 to $100 \mu \mathrm{m}$ long; branchial and atrial vela more or less developed, the atrial bearing on its inner surface fine simple tentacles rather sparsely; rectum attached firmly to branchial sac; ovarian eggs up to $150 \mu \mathrm{m}$ in diameter. In the specimens of B (Nos. 96 and 109), the testicular follicles are distributed densely over the alimentary canal except the liver and rectum, as already shown in this species by Tokioka (1953b, i 1960b).

C. Monniot (1965) once referred the specimens from the West Indies to M. multitentaculatus, but recently they were identified with $M$. anchylodeirus Traustedt, 1883 on the basis of the reexamnination of the type material (see C. Monniot, 1983c, pp. 1037-1038). These two species are, as rightly remarked by him, quite similar to each other especially in the shape of gonads, and are barely distinguishable solely by the branching of the tentacles (in up to 3 orders in $M$. multitentaculatus, instead of to 3 to 5 orders in $M$. anchylodeirus). Detailed discussions regarding the conspecificity 
of these two species will be left pending for future studies. The rounded right gonad seen in these species resembles that of $M$. claudicans (Savigny, 1816) previously recorded from European waters (see, for example, Berrill, 1950; C. Monniot, 1962), but these two species are distinct from $M$. claudicans in the number of branchial folds on each side ( 7 in these species, instead of 8 or 9 on the left and 7 or 8 on the right in $M$. claudicans, according to Berrill).

Distribution in Japan Sea. Oga Pen., 10-52 m (Nishikawa, 1984b; in the present study); Toyama Bay, 22-1410 m (in the present study); around Noto Pen., down to $40 \mathrm{~m}$ (do.); off Echizen-cho, Fukui Pref. (do.); Wakasa Bay, to $110 \mathrm{~m}$ (Tokioka, $1953 \mathrm{~b}, 1959 \mathrm{~b}$; in the present study); Korean coastal waters facing Korea Strait (Rho, 1971, 1975).

Distribution outside Japan Sea. Seto Inland Sea (Tokioka, 1953a); Ariake Sea (Tokioka, 1960b).

\section{Hartmeyeria orientalis Oka, 1929}

Hartmeyeria orientalis Oka, 1929d, p. 351, figs A-C.

For other synonyms see Tokioka (1967c).

Material examined: None.

Remarks. As claimed by Nishikawa (1982b, p. 210), the present species may be closely related, or might be conspecific with $H$. triangularis Ritter (see below); detailed considerations will appear elsewhere in the future.

Distribution in Japan Sea. Nanao Bay, eastern coast of Noto Pen., 20 m (Tokioka, 1949a); Moji, the northern end of Kyushu (Tokioka, 1967c); South Sakhalin (?) (Oka, 1929d).

Distribution outside Japan Sea. Sagami Bay, 25-30 m (Tokioka, 1953c; Nishikawa, 1982b); Matoya Bay, $7 \mathrm{~m}$ (Tokioka, 1949a); off Wakayama Pref., down to $80 \mathrm{~m}$ (Nishikawa, 1980b); Kagoshima Pref. (Tokioka, 1967c).

143. Hartmeyeria triangularis Ritter, 1913

Hartmeyeria triangularis Ritter, 1913, pp. 461-463, pl. 33, figs 8-13.

Material examined: None.

Distribution in Japan Sea. Mamiya Strait, $22 \mathrm{~m}$ deep (Redikorzev, 1941).

Distribution outside Japan Sea. Aleutian Isls, 9-12 fms (Ritter, 1913).

Molgulidae

144. Eugyra glutinans (Möller, 1842)

Cynthia glutinans Möller, 1842, p. 94.

Eugyra glutinans: Verrill, 1872, pp. 213 and 289. 
For synonyms see Van Name (1945), Tokioka (1965) and Nishikawa (1984b).

Material examined: B: No. 309(M556), labeled by Oka as Eugyrioides asamusi, off Yunoshima Islet, Mutsu Bay on June 23, '29, 25 individuals, 6.0-15.3 mm long. M (Oga): 226 individuals, 2.2$18.8 \mathrm{~mm}$ long, already listed by Nishikawa (1984b).

Remarks. The Japanese waters are known to be inhabited by the specimens distinguishable from so-called Eugyra glutinans (=Eugyrioides glutinans) only by the number of gonad (a single one only on the right in the specimens, instead of a single one on each side in so-called E. glutinans). The specimens were once called "Gamaster japonica Oka", but later rightly referred to E. glutinans by Tokioka (1965). To $E$. glutinans thus redefined, all the specimens examined in the present study are safely assigned. Among them, those from the Stns A-11, -13 and -19 of the collection $\mathrm{M}$ each have a single gonad only on the right. The specimens from the St. C-1 of M, as well as those of the collection B have a single gonad on each side; the left gonad occupies the first intestinal loop rarely with the distal (=orifice) part of gonad on, though never across, the intestine forming the bottom of the second loop.

Distribution in Japan Sea. Mamiya Strait, 3-9 m (Redikorzev, 1941). Japan: Mutsu Bay (Oka, 1930a, 1935; in the present study); off Oga Pen., 29-62 m (Nishikawa, 1984b; in the present study); Nanao Bay, 5-44 m (Tokioka, 1949a). Peter the Great Bay, 46-108 m (Redikorzev, 1911 a, 1916, 1941).

Distribution outside Japan Sea. Japan: Sagami Bay, $200 \mathrm{~m}$ (Oka, 1934b; Tokioka, 1953c); Tanabe Bay, 7-40 m, and Matoya Bay, 6-11 m, Kii Pen. (Nishikawa, 1980b) ; Osaka Bay (Hartmeyer, 1914; Tokioka, 1954c); Seto Inland Sea (Tokioka, 1953a). According to Van Name (1945, p. 434), "most of the records of this species are within or near the Arctic Circle and extend from the Murman coast westward, including northern Norway, Jan Mayen, Iceland, and southwestern Greenland (Baffin Bay)", and ranging, though uncertainly, "southward along the Labrador Coast"; further, recorded from the Aleutian Isls, as well as California and Lower California; 9-1805 $\mathrm{m}$ deep. Later this species was recorded also from the Bering and Okhotsk Seas, $60 \mathrm{~m}$ (Redikorzev, 1941), and off Newfoundland, $42 \mathrm{~m}$ and ?408-412 $\mathrm{m}$ (Millar, 1970).

145. Eugyra communis Nishikawa, 1984

Eugyra communis Nishikawa, 1984b, pp. 154-157, fig. 2.

Material Examined. J-3: a $5 \mathrm{~mm}$ long individual.

Remarks. The present specimen conform well to the original description of this species.

Distribution in Japan Sea. Oga Pen., 45-59 m (Nishikawa, 1984b); off Uchiura Bay, Wakasa Bay, $49.2 \mathrm{~m}$ (in the present study).

Distribution outside Japan Sea. Unknown. 
146. Eugyra extrorsa Nishikawa, 1984

Eugyra extrorsa Nishikawa, 1984b, pp. 152-153, fig. 1.

Material examined: None.

Distribution in Japan Sea. Oga Pen., 29-32 m deep (Nishikawa, 1984b).

Distribution outside Japan Sea. Unknown.

\section{Pareugyrioides japonica (Oka, 1929)}

Eugyrioides japonicum Oka, 1929c, pp. 170-172, figs A-B.

Pareugyrioides japonica: Nishikawa, 1984b, pp. 157-158, fig. 3, with synonymy.

Material examined: None.

Distribution in Japan Sea. Hakodate, Hokkaido (Oka, 1929c); off Oga Pen., 45-59 m (Nishikawa, 1984b).

Distribution outside Japan Sea. Unknown.

\section{Pareugyrioides dalli (Ritter, 1913)}

Eugyrioides dalli Ritter, 1913, pp. 441-443, pl. 33, figs 1-3.

Pareugyrioides dalli: Hartmeyer, 1914, p. 22.

Pareugyrioides japonica: Redikorzev, 1916, pp. 47-52, text-fig. 8, pl. 1, fig. 5, pl. 4, fig. 4; 1941, pp. 168-169. New Synonymy.

Pareugyrioides bostrychobranchus Redikorzev, 1941, pp. 169-171 and 209, text-figs 1-2, pl. 2, fig. 1. New Synonymy.

Material examined. None.

Remarks. Redikorzev (1916, 1941) allotted the specimens from the Japan Sea and Okhotsk Sea to Pareug.rioides japonica Hartmeyer, though not to P. japonica (Oka) (see above). As already suggested by Nishikawa (1984b, p. 158), however, Redikorzev's specimens are quite distinct from the type of $P$. japonica Hartmeyer that are now treated as a junior synonym of Eugyra glutinans; instead, the specimens are closely allied to $P$. dalli (Ritter). Further, Redikorzev's specimens resembles $P a$ reugyrioides bostrychobranchus Redikorzev thus far recorded once from the Bering and Okhotsk Seas by Redikorzev (1941). The exception is that there are much less secondary infundibula in these specimens than in $P$. bostrychobranchus, and that the ovary is covered only very slightly (on the right) or barely (on the left) with the testicular follicles in the former, instead of nearly completely in the latter. However, both Redikorzev's specimens and $P$. bostrychobranchus obviously fall within the variation range of $P$. dalli (Ritter) previously recorded from the Bering Strait and the Bering Sea, shown in the previous descriptions given by Ritter (1913) and Van Name (1945) and by the information acquired by my reexamination of some of Ritter's specimens collected from Kyska Harbor and deposited at NMNH (USNM Nos. 5678, 5764 and 5781). Thus, the specimens referred erroneously to $P$. japonica 
Hartmeyer by Redikorzev are assigned to $P$. dalli (Ritter), and at the same time, $P$. bostrychobranchus Redikorzev is regarded as a junior synonym of $P$. dalli.

Distribution in Japan Sea. Peter the Great Bay, 15-200 m deep (Redikorzev, 1916, 1941).

Distribution outside Japan Sea. Okhotsk Sea, $100 \mathrm{~m}$ (Redikorzev, 1941); Bering Sea, 5-32 fms (Ritter, 1913; Redikorzev, 1941); Bering Strait, 5 fms (Van Name, 1945).

\section{Molgula xenophora Oka, 1914}

(Fig. 37)

Molgula xenophora Oka, 1914, pp. 457-458, figs 15-16.

Molgula (Molgula) interrupta Tokioka, 1953c, pp. 294-295, text-fig. 24, pl. 79, figs 1-8. New Synonymy.

Molgula interrupta: Rho, 1975, p. 152, pl. 11, figs 6-9; Nishikawa, 1982b, p. 204.

Doubtful reference:

Molgula (Molgula) xenophora: Tokioka, 1967c, pp. 222-224, fig. 101.

Material examined: B: No. 279(M194), labeled by Oka as Molgula xenophora, Izumozaki, Niigata Pref., on Jan. 20, ' 10 by Nakamura, 2 individuals, $25 \mathrm{~mm}$ and $26 \mathrm{~mm}$ long; No. 281 (M193), as Molgula xenophora, the same data as No. 279, a $33 \mathrm{~mm}$ long individual. F-2:3 individuals, 20-29 $\mathrm{mm}$. K-2: 4 individuals, $18-26 \mathrm{~mm}$.

Remarks. The three specimens in collection B (deposited at OCUT) obviously represent the type series of Molgula xenophora Oka, though not clearly designated as such by Oka himself, because his original description says "Fundnotiz. Japanisches Meer, bei Idsumozaki, Prov. Echigo (Coll. M. Nakamura); 3 Exemplare" (p. 458). The following are additions to the original description: the test surface with numerous dense fine filamentous processes, gathering sand grains or shell fragments thickly, as well as "vollständig erhaltener Muschelschalen" of the bivalve Limopsis tajimae Sowerby (?) (identified by K. Takenouchi); test very thin, nearly transparent and colorless, never impregnated with foreign matter; the mantle musculature (Fig. 37, A) similar to that of $M$. interrupta (Tokioka, 1953c, pl. 79, figs 2-3 and 5); muscle bundles apparently divided into small pieces colored pinkish brown, but closer examination reveals that the pieces of the same bundle are usually interconnected by nearly transparent fine white fibers, such fibers also covering the neural complex (Fig. 37, A); 13 or 14 tentacles, the larger and smaller ones alternating almost regularly; and branched into 2 , or rarely 3 orders; ciliated groove $\mathrm{C}$-shaped opening to the right (Fig. 37, D); the branchial formula of the well-preserved $26 \mathrm{~mm}$ long specimen is:

$$
\begin{aligned}
& \text { L. D. } 1 \text { (13) } 1 \text { (14) } 1 \text { (15) } 1 \text { (15) } 1 \text { (12) } 1 \text { (11) } 1 \text { (8) } 0 \mathrm{~V} . \\
& \text { R. D. } 2 \text { (13) } 1 \text { (13) } 1 \text { (14) } 1 \text { (13) } 1 \text { (13) } 1 \text { (12) } 1 \text { (10) } 0 \mathrm{~V} .
\end{aligned}
$$

Five transverse vessels, between each of which are found 2 infundibula under each fold; liver plicated longitudinally (Fig. 37, B), lacking completely any minute lobules 

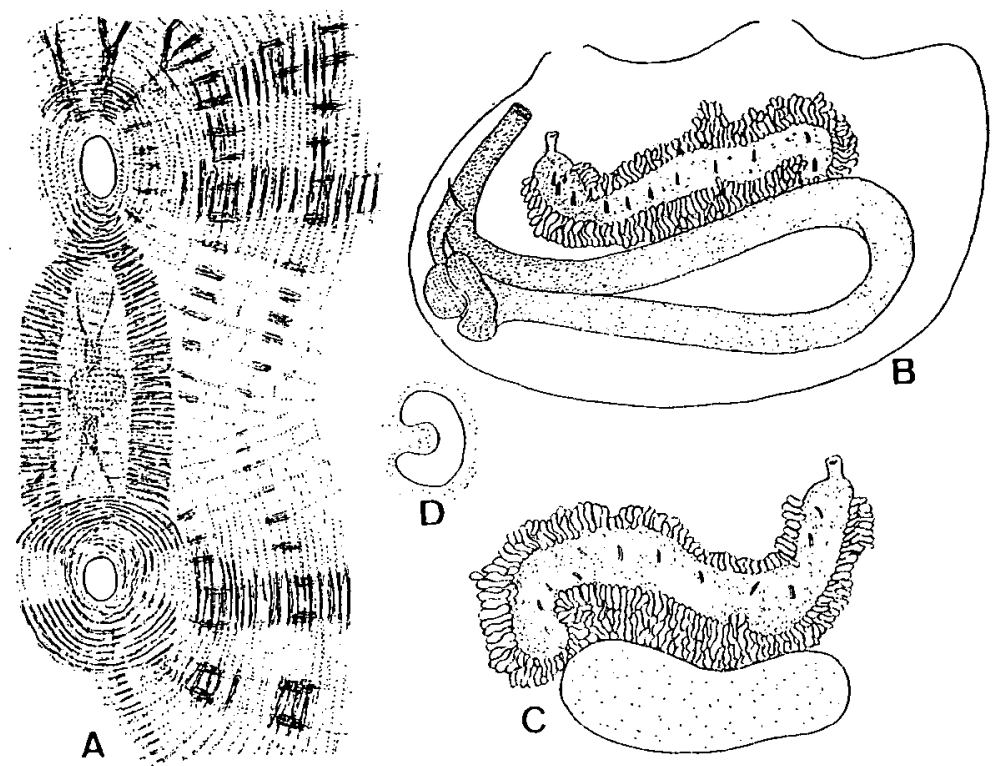

Fig. 37. Molgula xenophora Oka from off Niigata Pref. (Collection B, OCUT No. 279 (M194)), $26 \mathrm{~mm}$ long specimen. A. dorsal part of mantle body, from outside; B. left inner side of mantle body; C. gonad and renal sac on the right side; D. ciliated groove.

over the surface; rectum attached firmly to branchial sac; minute sperm ducts dis-cernible over the mesial surface of ovary (Fig. 37, B-C), 12 on each gonad in the $26 \mathrm{~mm}$ long specimen, while 9(?) on the left and 12(?) on the right in the $33 \mathrm{~mm}$ long one; ovarian eggs up to $175 \mu \mathrm{m}$ in diameter.

The specimens from $\mathrm{F}-2$ and $\mathrm{K}-2$ resembles the type specimens. The $\mathrm{F}-2$ and $\mathrm{K}-2$ specimens have 14 to 16 tentacles branched in 2 or 3 orders; 4 to 12 sperm ducts are observed on the left gonad, while 11 to 20 on the right; gonad is empty.

As mentioned above, the mantle musculature of Molgula xenophora resembles $M$. interrupta Tokioka; these two also have the same shape of ciliated groove, branchial structure and size and position of gonads. As Tokioka's original description lacks information on detailed features of the test surface, the divided pieces of muscle bundles and the sperm ducts, the paratype specimens of $M$. interrupta deposited at SMBL (Type Nos. 115-116) were examined; the $28 \mathrm{~mm}$ long specimen registered as No. 115 was chosen out of 3 type specimens of BLIH Sp. No. 113, collected from SW of Amadaiba, 300-350 m deep on July 11, '37, while the $33 \mathrm{~mm}$ long one of No. 116 was one of 7 specimens of BLIH Sp. No. 6, from W. of Amadaiba on July 26, '35. In these paratypes, the test surface has fine dense filaments carrying sand grains. Although the mantle body of the larger specimen is very much deteriorated, that of the smaller has inconspicuous fibers interconnecting small pieces of each muscle bundle as discerned in $M$. xenophora; and 8 (on the left) or 9 (on the right) sperm ducts are found over the mesial surface of ovary. Thus, $M$. interrupta is re- 
garded as conspecific with, and further, by the Principle of Priority, a junior synonym of, $M$. xenophora. The specimens collected from the Korean coast facing Korea Strait and identified as $M$. interrupta by Rho (1975), as well as those from Izu Pen. and referred also to this species by Nishikawa (1982b), share many important features with $M$. xenophora, and therefore, these records are included in the synonymy. Many specimens collected from Hakodate and allotted to $M$. xenophora with detailed description by Tokioka (1967c) are distinguishable from $M$. xenophora delimited here by the muscle bundles radiating from the siphons interrupted rather rarely in the former, instead of very frequently in the latter, the neural complex covered completely with thick muscle fibers continuously across the intersiphonal area, instead of such thick fibers apparently interrupted above the complex, the ciliated groove opened posteriorly, instead of to the right, and the liver furnished with minute lobules, instead of free from such lobules. These differences may be of certain taxonomic significance, but Tokioka's record from Hakodate is here included in the synonymy of $M$. xenophora only provisionally.

The mentioned features seen in Tokioka's specimens from Hakodate, except that of the liver, might remind me of $M$. siphonalis Sars (==M. septentrionalis Traustedt) so far recorded mainly from arctic waters (see, for example, Redikorzev, 1916, pp. 9498; Ärnbäck-Christie-Linde, 1928, pp. 28-30; Van Name, 1945, pp. 377-379; C. Monniot, 1969b, pp. 219-221) and $M$. lapidifera Redikorzev from the Okhotsk Sea (see Redikorzev, 1941, pp. 175-177 and 210-211). Comparisons should be made between these species and Tokioka's $M$. xenophora from Hakodate.

Distribution in Japan Sea. ?Hakodate (Tokioka, 1967c); Izumozaki, Niigata Pref. (Oka, 1914; in the present study); Tsushima Strait, 62.5-118 $\mathrm{m}$ (in the present study); Cheju Is., Korea Strait (Rho, 1975).

Distribution outside Japan Sea. Sagami Bay, 200-400 m (Tokioka, 1953c); off Inatori, near Shimoda, Izu Pen., 92-100 m (Nishikawa, 1982b).

150. Molgula celebensis Millar, 1975

(Fig. 38)

Molgula celebensis Millar, 1975, pp. 323-325, fig. 102.

Material examined: A (Toyama Bay): a single individual, the body $21 \mathrm{~mm}$ long $\times 15 \mathrm{~mm}$ wide, the branchial siphon $10 \mathrm{~mm}$ long, while the atrial $24 \mathrm{~mm}$.

Description. Body oval in outline and flattened laterally; its anterior end provided with elongated siphons situated adjacently (Fig. 38, A). Test soft, gelatinous, transparent and colorless; with numerous short hairy processes carrying small fragments of molluscan shells and polychaete tubes except both siphons, whose surface is much wrinkled transversely and covered sparsely with filamentous algae instead of test processes. Branchial aperture surrounded by 6 protuberance, simple or bifid (Fig. 38, B), while the atrial nearly smooth-edged. Mantle very thin and transpar- 


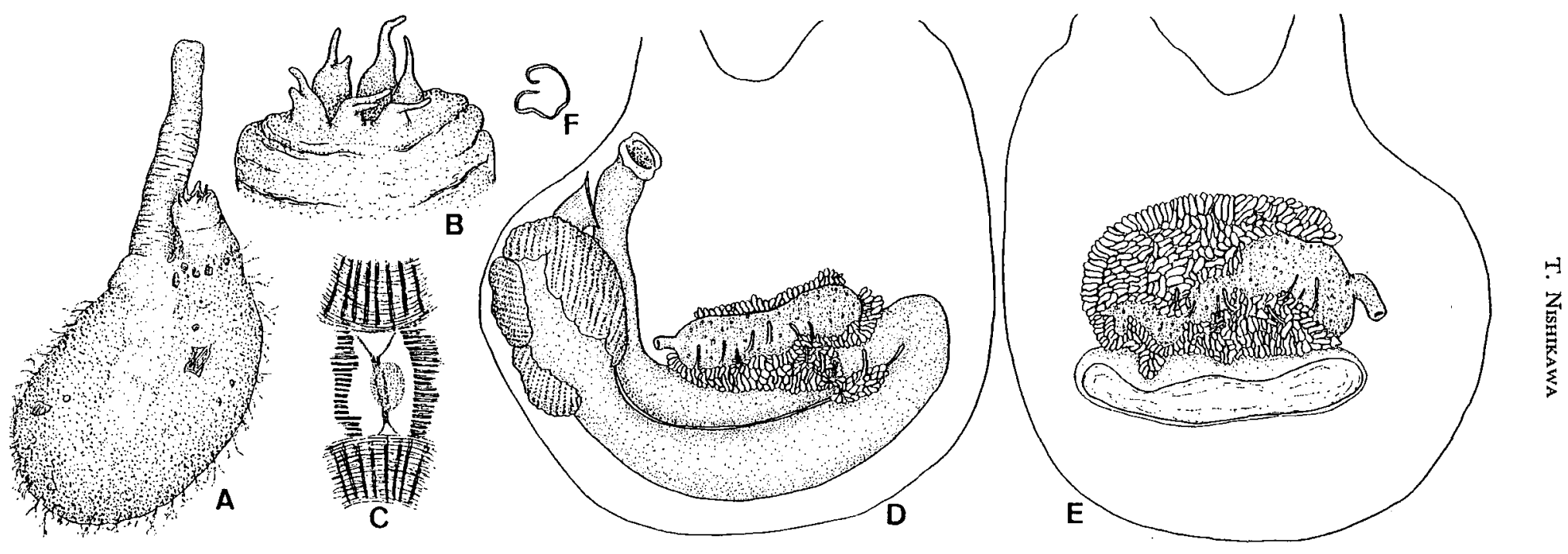

Fig. 38. Molgula celebensis Millar from Toyama Bay (Collection A). $21 \mathrm{~mm}$ long specimen. A. whole body; B. enlarged view of the branchial aperture; C. mantle musculature of the intersiphonal area, from outside; D. left inner side of mantle body; $E$. right inner side of mantle body; F. ciliated groove. 
ent; the musculature consisting of fine circular fibers and about 24 thick radial bundles confined to each siphon (Fig. 38, C.D). Intersiphonal area has 2 longitudinal rows of short transverse muscle bundles separated by a small muscle-free zone above the neural complex (Fig. 38, C). Branchial siphon terminal, the atrial subterminal; branchial aperture 6-lobed, the atrial 4-lobed. Tentacles 18, the larger and smaller ones alternating regularly; branched in 2 orders. Giliated groove C-shaped opening to the right, with both horns curled in (Fig. 38, F). Seven branchial folds discernible on each side; the formula is:

$$
\begin{aligned}
& \text { L. D. } 0(7) 0(12) 0(10) 0(14) 0(10 \text { ?) } 0(12) 0(8) 0 \mathrm{~V} . \\
& \text { R. D. } 0(13) 0(14) 0(16) 0(12) 0(13) 0(12) 0(12) 0 \mathrm{~V} .
\end{aligned}
$$

Nine transverse vessels, between each of which are seen two transverse rows of infundibula, their tip usually divided into two apexes. Dorsal lamina taller than the branchial folds; its margin usually smooth, though slightly undulated at places. Visceral mass occupying roughly the posterior half of mantle body; first intestinal loop very deep, narrow and closed, leaving no space within, while the second rather shallow and widely opened with its axis passing through the pyloric end of stomach. Stomach oval and covered on its anterior and posterior surface by the liver plicated longitudinally or obliquely (Fig. 38, C). Rectum attached firmly to branchial sac; anal margin bi-lobed. A single gonad on each side; fully mature. Left gonad composed of an elongated ovary situated within second intestinal loop along the ventral branch of intestine, with the short oviduct terminally and directed dorsoposteriad; ovary fringed wholly with testicular follicles. Additionally, some follicles extend across the intestine along the ovary rather extensively into first intestinal loop (Fig. $38, \mathrm{C})$. On the right the ovary elongate, situated along anterior margin of renal sac lying horizontally, with the oviduct curved posteriad, and almost wholly margined and partly covered with testicular follicles (Fig. 38, E). Short sperm ducts issuing from the mesial surface usually of the follicles, but rarely of the ovary; 11 on the left and 9 on the right.

Remarks. This specimen conforms well to the original description of Molgula celebensis Millar based on two specimens, $10 \mathrm{~mm}$ and $12 \mathrm{~mm}$ long respectively, from the Celebes and Java Sea, 30-35 $\mathrm{m}$ deep, mainly in the test furnished with hairy processes, the mantle musculature inclusive of that on the intersiphonal area, the shape of ciliated groove, the number of branchial plications, the general course of alimentary canal, and the generai features of gonads. However, this specimen differs from $M$. celebensis in the siphons much longer in the former than the latter, the number of tentacles (18, instead of 8 ), that of longitudinal vessels on each fold ( 7 to 16 , instead of 1 to 9), the first intestinal loop without space, instead of "open at the apex", and the number of sperm ducts (9 or 11 , instead of 1 or 3 ). Among these differences, some might be attributable to the change with growth, such as those seen in the number of tentacles and the vessels on the fold, or possibly that of sperm ducts, while others be of some taxonomic significance. However, the striking similarity seen especial- 
ly in the mantle musculature and the position and structure of gonads suggests the conspecificity of the specimen from the Japan Sea and those of $M$. celebensis from the West Pacific region. Thus, the specimen from the sea is identified with this species.

The position and structure of gonads in $M$. celebensis thus defined, especially the testicular follicles on the left across the intestine and entering the first loop, resembles $M$. macquariensis Kott from subantarctic waters (Kott, 1954; C. Monniot, 1978; Millar, 1982b). M. celebensis is distinguishable from $M$. macquariensis only by the number of longitudianl vessels between folds (almost nothing even in the larger specimens in $M$. celebensis, instead of up to 3 to 5 in $M$. macquariensis).

Distribution in Japan Sea. Toyama Bay, $31 \mathrm{~m}$ deep (in the present study).

Distribution outside Japan Sea. Makassar, Celebes, $35 \mathrm{~m}$ and the Java Sea, $30 \mathrm{~m}$ (Millar, 1975).

\section{Molgula tectiformis n. sp.}

(Fig. 39)

Doubtful synonym:

Molgula calvata: Millar, 1975, pp. 322-323, fig. 101. Excluded are the original and most subsequent descriptions of $M$. calvata by Sluiter (1904) and Kott (1952, 1964, 1985).

Type series: The holotype (SMBL Type No. 369), $31 \mathrm{~mm}$ long, and the fourteen paratype specimens (NSMT Pc-1099), 2.0-26.5 mm long, were chosen from among 164 individuals collected by me on Aug. 21, 1980, from buoys, or the body surface of Styela clava Herdman growing on them, placed off Moura, near Asamushi, Mutsu Bay (collection G-2). The single, $16.5 \mathrm{~mm}$ long individual collected off Kaizaki, SW end of Shimokita Pen., Mutsu Bay, 15-20 m deep, on Aug. 20, 1980 by $\mathrm{me}$, is also designated as a paratype (NSMT $\mathrm{Pc}_{\mathrm{c}}-1100$ ).

Description. Body roughly ellipsoid and slightly elongated longitudinally, or nearly globular and more or less flattened laterally. Both siphons almost sessile and situated terminally. In specimens longer than $11 \mathrm{~mm}$, including the holotype, body surface nearly completely covered by large or small prominences and minute papillae, as well as partly with epiphizoonts such as hydrozoans, bryozoans, bivalves, Diplosoma mitsukurii and some unidentified didemnids; also short fine filaments are borne on the apparent attachment side (the posterior or ventral part of body). In specimens, $11 \mathrm{~mm}$ or shorter, however, the surface nearly smooth and usually devoid of any prominences except around apertures, but covered wholly by short fine filaments. Test rather thick, rather tough leathery, translucent (in the larger specimens) or more or less transparent (in the smaller ones), and white; fleshy pink to pale purplish brown mantle body seen obscurely or clearly through the test. A few specimens had one or more bivalves of Musculus sp. embedded in the test. The mantle body surface covered with minute projections in various densities and distributions in different specimens. Both siphons distinct; the branchial terminal and the atrial subterminal; each aperture 4-lobed with serrated margin. Branchial velum less developed, while the atrial more or less extensive. Mantle musculature consisting of a network of fine muscle fibers densely and evenly distributed over nearly the 


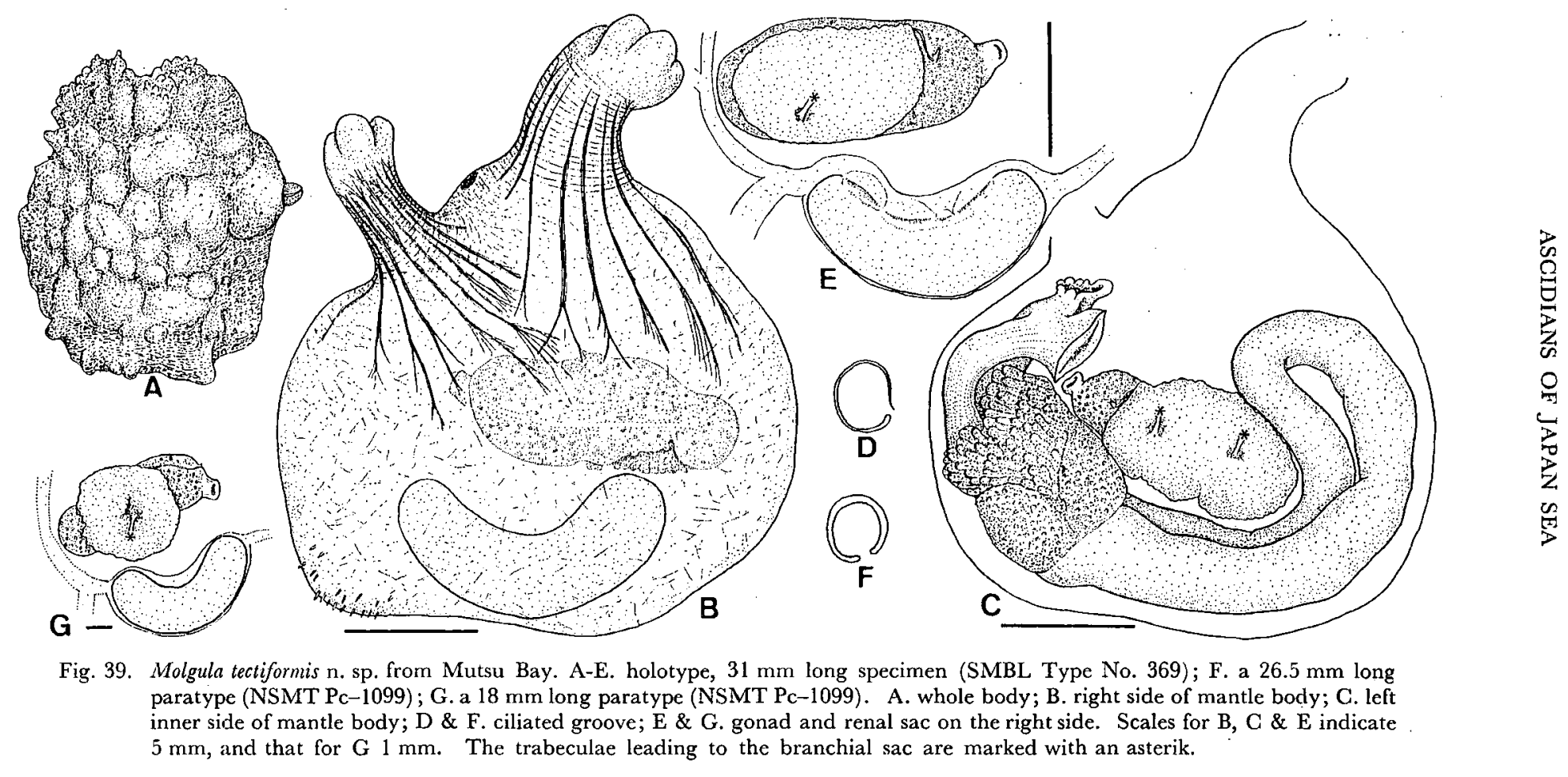


entire mantle body including the intersiphonal area, with 12 or more thick bundles radiating from the siphons and extending ventrally to roughly anterior one-third of the body on each side (Fig. 39, B). Up to 24 tentalces, of various sizes; branched in 1 (in the $13.5 \mathrm{~mm}$ or shorter specimens) or 2 (in the rest) orders. Ciliated groove C-shaped opened usually posterolaterally to the left (Fig. 38, D) or very rarely posteriorly (Fig. 39, F), except in the smallest ( $2 \mathrm{~mm}$ long) specimen that has the groove as an elongated oval orifice. The basic structure of branchial sac in all individuals of the type series are quite similar. Seven branchial folds on each side; no longitudinal vessels in the interspaces, each fold represented by only 2 vessels in the larger specimens, but some folds have a single vessel in the $6.5 \mathrm{~mm}$ or shorter specimens. A single longitudinal vessel is seen on the dorsal-most fold on each side in $6.5 \mathrm{~mm}$ long specimens, or the dorsal- and ventral-most two folds on the left and the dorsal-most two and the ventral-most one on the right in $4.9 \mathrm{~mm}$ long one; or all the seven folds on each side have a single vessel in $3.5 \mathrm{~mm}$ long one. Further, in the smallest, 2 $\mathrm{mm}$ long specimen the branchial sac has only 5 (on the left) or 6 (on the right) longitudinal vessels. In the holotype, 9 longitudinal rows of infundibula on each side, of which the dorsal- and ventral-most rows are free from vessels; infundibula well developed under the folds (vessels), while nearly flat in the rows without vessels; and 6 transverse rows of infundibula under each fold, apex of each infundibulum divided into two summits dorsally, while the summit further subdivided into two or more ventrally; stigmata nearly straight exclusively between longitudinal rows, interrupted frequently and bridged with fine parastigmatic vessels. In the smaller specimens, subdivision of the summits of infundibula tending to be rare, and the dorsal-most longitudinal row of infundibula sometimes obscure. In the $21.5 \mathrm{~mm}$ long specimen, the dorsal-most longitudinal row on the right side is accompanied posteriorly with a fine and short longitudinal vessel(?); further, in the $26.5 \mathrm{~mm}$ long one, several middle folds on the right side disappearing anteriorly, but instead, an additional fold represented also by 2 longitudinal vessels discerned between the ventral-most ordinary fold and the endostyle anteriorly; these anomalies found in no other specimens. Dorsal lamina tall and smoothly edged. Visceral mass occupying far more than posterior half of mantle body (Fig. 39, C); liver plicated on the cardiac surface but minutely papillated on the pyloric (Fig. 39, C) or wholly papillated; first intestinal loop very deep and narrow, with its bottom third curved sharply dorsad, the second loop is rather deep but rather widely opened, with its axis passing through roughly the anterior third of first loop; rectum short, parallel to and fused to the anterior end of oesophagus, never attached to branchial sac, opening roughly at the level of oesophageal opening. A single gonad on each side; when mature, the left one fills the second loop nearly completely. Right gonad situated anterior and parallel to the large renal sac which is concaved dorsally with its anteroventral tip along the proximal (= antiorifice) third of gonad (Fig. 39, B-C). Both gonads in the $4.9 \mathrm{~mm}$ or shorter specimens from off Moura, and the left one in the $16.5 \mathrm{~mm}$ long specimen from off Kaizaki are very small and immature, but all other specimens have large and fully mature gonads. Mature gonad composed of an elongated, oval ovary, filled with 
eggs, up to about $150 \mu \mathrm{m}$ in diameter, with a terminal oviduct. Thick masses of minute testicular follicles cover the proximal three-fourths or more of mesial surface of ovary (Fig. 39, C \& E); in some specimens, the masses situated on the wide central part of ovary (Fig. 39, G). One or 2 trabeculae often issuing from the mesial surface of tesis. Attachment surface of gonad always occupied nearly completely by the ovary. A fine vas deferens usually passing along the testis between its anterodorsal corner and the short upright duct on the ovary; the duct located apart from oviduct (Fig. 39, G \& E); exceptionally, in the right gonad of $18 \mathrm{~mm}$ long specimen, the vas deferens running off from the testis, over the ovary and reaching the short duct situated close to oviduct (Fig. 39, G). In the immature gonad, about 8 testicular follicles arranged radially over the middle one-third of mesial surface of elongated ovary.

Remarks. In the filamentous projections of test, the mantle musculature, the ciliated groove, the structure of the branchial sac, and the position and structure of gonads, the Mutsu Bay specimens are similar to the original description of Molgula calvata Sluiter, 1904 based upon a single, $16 \mathrm{~mm}$ long specimen collected from the reef of Saleyer (=Salajar) Island, south of the Celebes. However, my reexamination of the holotype deposited at ZMA (No. Tu 690.1; see Spoel, 1969, p. 183) revealed that it has, in addition to the described 2 gonads, an additional small roundish one situated partly in the opened bottom of the first intestinal loop and partly on the dorsal branch of the loop; this oviduct is short, straight, and located on the intestine, directed anteroventrally. The apparently mature gonads consist each of an elongate ovary with a terminal oviduct, and a thin mass of a few (in the third gonad) to many small testicular follicles; the testis covering the mesial surface of ovary only slightly (in the additional one) or moderately (in the other two). The fine vas deferens reaches the short but thick erect duct situated on the ventral (in the former) or anterior (in the latter) margin of ovary. Consequently the testis in Sluiter's specimen is much smaller than those from Mutsu Bay. Further, in Sluiter's specimen, the rectum somewhat elongated along the dorsal part of branchial sac and firmly attached to it, while the rectum short and never attached to the sac in the Mutsu Bay specimens. These differences are certainly of taxonomic significance, so the specimens from the Japan Sea are regarded as distinct from $M$. calvata Sluiter. Of course, the possibility cannot be totally ruled out that the occurrence of the additional gonad in Sluiter's specimen may be an anomaly or a malformation, and if it is true, the specimen would be conspecific with those from Mutsu Bay. In the present study, however, these specimens are not treated as such for fear of future taxonomic confusion. However, the mature specimen collected from Jolo Island, the Philippines, $27 \mathrm{~m}$ deep and referred to $M$. calvata by Millar (1975) seems to be similar to those from Mutsu Bay in many significant features including the extensive testis composed of numerous follicles (the vas deferens was undetectable in Millar's $M$. calvata). Differences include: series of short transverse muscle bundles present on "the median part of the upper anterior and midventral portions" of mantle body, 
including the intersiphonal area only in Millar's $M$. calvata, the left gonad occupies only a small part of the second loop in Millar's, instead of a major portion in the Mutsu Bay specimens, and that the animal may apparently live buried within the coral sand in Millar's, while attached to hard substrata in the Mutsu Bay specimens. These differences might possibly be of some taxonomic significance, so Millar's $M$. calvata is here regarded only very provisionally as conspecific with the Mutsu Bay spemens. On the other hand, the specimens collected from Australia and referred to $M$. calvata by Kott $(1952,1964,1985)$ are clearly distinguishable from all the abovementioned specimens mainly by the gonad in Kott's $M$. calvata composed of a tubular ovary "fringed by small, dendritic testicular lobes in the body wall around its distal end and extending over the sides of the ovary" with the "testicular ducts extend(ing) over the surface of the ovary into numerous (but not so plentiful in Kott's (1964) specimens) and small upright tubes" (Kott, 1952, p. 297), though 1 to 3 male openings on "only the surface of the ovary" in the smaller specimens (Kott, 1985, p. 371).

In the number of branchial folds, the course of alimentary canal and the position and structure of gonads, the specimens from Mutsu Bay resemble the previous descriptions of $M$. appendiculata Heller, 1877, $M$. simplex Alder et Hancock, 1870 and $M$. socialis Alder, 1848 recorded thus far from European waters (see, for example, C. Monniot, 1969, pp. 239-241; pp. 201-202; and pp. 197-201, respectively), as well as $M$. hodgsoni Herdman, 1910 sensu Monniot \& Monniot (1983, p. 99) from the antarctic waters (see, for example, Ärnbäck-Christie-Linde, 1938). The specimens from Mutsu Bay are, however, easily distinguishable from the latter 4 species mainly by the arrangement of longitudinal vessels on the branchial sac (only 2 on each fold in the Mutsu Bay specimens, instead of much more vessels in the 4 species).

Thus, these specimens from Mutsu Bay are regarded as a new species, for which the specific name tectiformis is proposed after the tectorial disposition of the testis over the ovary. "Molgula sp." in Colombera et al. (1987, pp. 41-42) is this new species.

Distribution in Japan Sea. Mutsu Bay, 0-20 m deep (in the present study).

Distribution outside Japan Sea. ?Jolo Is., the Philippines, $27 \mathrm{~m}$ deep (Millar, 1975).

\section{Molgula hozawai Oka, 1932}

Molgula hozawai Oka, 1932g, pp. 518-520, figs A-B.

Molgula pugetiensis: Oka, 1930a, p. 168.

Doubtful synonym:

Molgula martensii: Kott \& Goodbody, 1980, pp. 548-549, fig. 24, without synonymy.

Material examined: $\mathrm{J}-1: 4$ individuals, $4.0-12.7 \mathrm{~mm}$ long.

Remarks. All the present specimens fall within the variation range of Molgula hozawai Oka shown by Nishikawa (1981), to be easily identified with this species. The features of these specimens are: both vela well developed, forming funnel-like structures within the siphons; ciliated groove as a longitudinal slit; gonads mature 
in the larger 3 specimens (5.0-12.7 $\mathrm{mm}$ long), ovarian eggs up to $150 \mu \mathrm{m}$ in diameter, and testicular follicles well developed, assignable to Type w of Nishikawa (1981); some to many tailed larvae, 200 to $225 \mu \mathrm{m}$ in trunk length, in the peribranchial cavity in these specimens.

When establishing a new species Eugyrioides asamusi, Oka (1930a) wrote that the material collected in Mutsu Bay by the staff of the Asamushi Marine Biological Station in 1926-1929 contained two species of Molgulidae, one referable to Molgula pugetiensis Herdman thus far recorded from the North Pacific, and the other to this new species. So far as I am aware, Oka had referred to $M$. pugetiensis in Mutsu Bay only once. Later in 1935, he published a monograph on the simple ascidians of Mutsu Bay; in the report, only two species of Molgulidae were described, Molgula hozawai and Eugyrioides asamusi. Consequently it seems that Oka's $M$. pugetiensis is $M$. hozawai. At present, there is no bottle labeled $M$. pugetiensis at OCUT, although this does not necessarily mean that the collection orginally lacked specimens so labeled. Judging from the original description of $M$. pugetiensis given by Herdman (1898), this species is extremely similar to $M$. hozawai and has a similar number of branchial plications, course of alimentary canal, and the shape and position of gonads. In the present study, therefore, Oka's record of $M$. pugetiensis from Mutsu Bay is included in the synonymy of $M$. hozawai. $M$. pugetiensis known from the NE Pacific is easily distinguishable from $M$. hozawai especially by the gonad being composed of a central ovary fringed wholly by many testicular follicles (see Van Name, 1945) in contrast to that of $M$. hozawai.

The approximately $15 \mathrm{~mm}$ long specimen collected from Hong Kong, $1 \mathrm{~m}$ deep, and referred to Molgula martensii Traustedt by Kott \& Goodbody (1980), then moved to $M$. ficus (Mcdonald, 1859) by Kott (1985), resembles $M$. hozawai in external appearance, well developed vela, branchial structure, course of alimentary canal, and the position and structure of gonads. The only difference is the ciliated groove; in the Hong Kong specimen the groove is U-shaped opened anteriorly, with "the right horn turned out", while usually simple longitudinal slit but rarely C-shaped opened posteriorly in $M$. hozawai. This minor difference might be somewhat significant, but this is doubtful. Therefore Kott \& Goodbody's $M$. martensii is here regarded with only minor reservations as conspecific with $M$. hozawai. The synonymization of the mentioned specimen from Hong Kong with $M$. martensii or $M$. ficus by Kott \& Goodbody (1980) and Kott (1985) respectively, is not adopted here, because the specimen is slightly different from the other specimens assigned to these species by these authors, in the detailed structure of testis. In this structure, on the other hand, $M$. hozawai is quite similar to $M$. mollis Herdman, 1899 thus far recorded from Australia (see Kott, 1985, pp. 380-382), although M. hozawai is distinguishable from $M$. mollis especially by the number of longitudinal vessels on the fold ( 3 to 7 in $M$. hozawai, instead of 2 or 3 in $M$. mollis). Beyond doubt, however, these species are closely related to $M$. hozawai, and therefore, the extensive taxonomy of the species concerned, including some other related ones (see Nishikawa, 1981, pp. 342343), should be achieved in future. 
Distribution in Japan Sea. Mutsu Bay (Oka, 1930a, 1932g, 1935); Wakasa Bay, about $3 \mathrm{~m}$ deep (in the present study); Tottori, $0 \mathrm{~m}$ (Nishikawa, 1981).

Distribution outside Japan Sea. Gobo, western coast of Kii Pen., $3 \mathrm{~m}$ (Nishikawa, 1980b, 1981); Osaka Bay, 2 m (Nishikawa, 1981); Kagoshima Bay, 1.5-2 m (Nishikawa's unpublished data).

\section{Molgula oligostriata Tokioka, 1949}

Molgula oligostriata Tokioka, 1949a, p. 15, pl. 7, figs 4-7; Nishikawa, 1984b, pp. 159-160, fig. 4.

Material examined: None.

Distribution in Japan Sea. Nanao Bay, $28 \mathrm{~m}$ (Tokioka, 1949a); off Oga Pen., 29-42 m (Nishikawa, 1984b).

Distribution outside Japan Sea. Matoya Bay, 12 m (Tokioka, 1949a).

\section{Molgula eobia Redikorzev, 1941}

Molgula eobia Redikorzev, 1941, pp. 174-175 and 210, text-fig. 5, pl. 2, figs 2-3; Skalkin, 1959, p. 246 (erroneously spelled as lobia).

Material examined: None.

Remarks. According to the original description: body is roughly globular, 29 to $41 \mathrm{~mm}$ in height and 24 to $44 \mathrm{~mm}$ in width; the surface smooth; test of various thickness and consistency in different specimens, ranging from $2 \mathrm{~mm}$ and cartilaginous to $11 \mathrm{~mm}$ and gelatinous; ciliated groove horseshoe-shaped, opened posterolaterally to the right; dorsal lamina smoothly edged; 7 branchial folds on each, each fold accompanied with 5 to 10 longitudinal vessels underlain by small infundibula, while the interspaces devoid of the vessels, but pierced only by minute stigmata, roundish or oval in outline and arranged roughly spirally; first intestinal loop very deep and narrow, with its bottom remarkably bent dorsad; second intestinal loop deep but rather wide, its axis passing through the middle of first loop; a single elongated gonad on each, the left situated within second loop along the intestine comprising the dorsal branch of the loop, while the right closely along the large renal sac; gonad consisting of a central ovary fringed with testicular follicles, the border between these two obscure; oviduct elongated and thin, but vas deferens unobserved. As the features of mantle musculature and the vas deferens are still unknown, detailed discussion is impossible now, regarding the relationship of the present species with others of the genus Molgula.

Distribution in Japan Sea. Peter the Great Bay, $84 \mathrm{~m}$ (Redikorzev, 1941); western coast of South Sakhalin (Skalkin, 1959).

Distribution outside Japan Sea. Beringa Is. of the Komandorskie Isls, Bering Sea, mediolittoral (Redikorzev, 1941). 


\section{Molgula redikorzevi Oka, 1914}

Molgula redikorzevi Oka, 1914, pp. 446-448, figs 3-4; Redikorzev, 1916, pp. 66-68, text-fig. 10, pl. 4, fig. 7; Tokioka, 1951a, pp. 19-20, figs 14-15.

Material examined: None.

Remarks. In the separation of ovary and testis, $M$. redikorzevi resembles $M$. retortiformis Verrill, 1871 previously recorded widely from the arctic and subarctic waters (see, for example, Van Name, 1945). M. redikorzevi is, however, very easily distinguishable from $M$. retortiformis mainly by the 7 branchial folds on each in $M$. retorifformis, instead of only 5 in $M$. redikorzevi. On the other hand, Ärnbäck-ChristieLinde (1928) considered $M$. redikorzevi as a synonym of $M$. griffithsii (MacLeay, 1825), because in $M$. griffithsii, "the position and relation of the testes to the ovary are highly variable" (p. 50), such as shown by an extreme represented by some specimens collected in the Canadian arctic region, that have the testis separated from the ovary, which resembles $M$. redikorzevi. Though enough attention must be paid to this important opinion, such intermediate states of gonad between $M$. redikorzevi and usual $M$. griffithsii, as shown by her (1928, text-fig. 6), are very few. In the NW Pacific, these two species have been clearly distinguished from each other; therefore, $M$. redikor zevi is regarded here as a good species, distinct from $M$. griffithsii.

Distribution in Japan Sea. Off Sikhote-Alien, $46^{\circ} 12.45^{\prime} \mathrm{N}$ and $138^{\circ} 15^{\prime} \mathrm{E}, 100 \mathrm{~m}$ deep, as well as $45^{\circ} 20^{\prime} \mathrm{N}$ and $137^{\circ} 15^{\prime} \mathrm{E}, 99 \mathrm{~m}$ (Redikorzev, 1916).

Distribution outside Japan Sea. Okhotsk Sea including Amurskiy liman, 6-40 m (Redikorzev, 1916); Kamtschatka, 40-43 fms (Oka, 1914); Akkeshi Bay (Tokioka, 195la); off Nemuro, on the Hokkaido coast facing the Pacific Ocean (Nishikawa's unpublished data).

\section{Molgula griffithsii (MacLeay, 1825)}

Cystingia griffthsii MacLeay, 1825, p. 541, pl. 19.

Molgula griffithsii: Ärnbäck-Christie-Linde, 1928, pp. 47-54, text-figs 5-6, pl. 1, figs 1-6.

For synonyms see Van Name (1945).

Material examined: None.

Distribution in Japan Sea. Mamiya Strait, $44 \mathrm{~m}$ (Redikorzev, 1941); off the Sikhote-Alien, $46^{\circ} 12.45^{\prime} \mathrm{N}$ and $138^{\circ} 15^{\prime} \mathrm{E}, 100 \mathrm{~m}$ (Redikorzev, 1916); western coast of South Sakhalin (Saklkin, 1959; erroneously spelled as griffitschii).

Distribution outside Japan Sea. Widely spread in arctic and subarctic waters, 2$408 \mathrm{~m}$ deep, including the Okhotsk Sea.

\section{Molgula hartmeyeri Oka, 1914}

(Fig. 40)

Molgula hartmeyeri Oka, 1914, pp. 455-456, figs 13-14. 
Material examined: $N$ (Oki): a $15 \mathrm{~mm}$ long individual, already listed by Nishikawa (1986b).

Description. Body ellipsoid; surface coated wholly, densely and thickly with sand grains, up to $2 \mathrm{~mm}$ in thickness; siphons indistinct. Test very thin, soft but rather tough, transparent and colorless; its surface densely covered by fine and short filaments gathering sand grains. Mantle musculature consisting on the siphons of fine circular fibers and many radial bundles, on the intersiphonal area of two longitudinal rows of short fine transverse fibers interrupted along the median line by a musclefree zone above the neural complex. On the remaining larger part of the body, the musculature composed of about 24 thick bundles radiating from each siphon to the middle of body, each bundle divided into two or three pieces at regular intervals; and many series of short pieces of transverse muscle bundles, the series apparently converging to siphons and becoming obscure posteriorly; mantle also including many muscle fragments scattered over posteroventral region of the body (Fig. 40, figs. A-C). Mantle body surface partly covered by dense yellow pigment granules. Tissue of unknown nature observed densely in the mantle over the ventral half of the body and extending dorsally into narrow areas between thick bundles
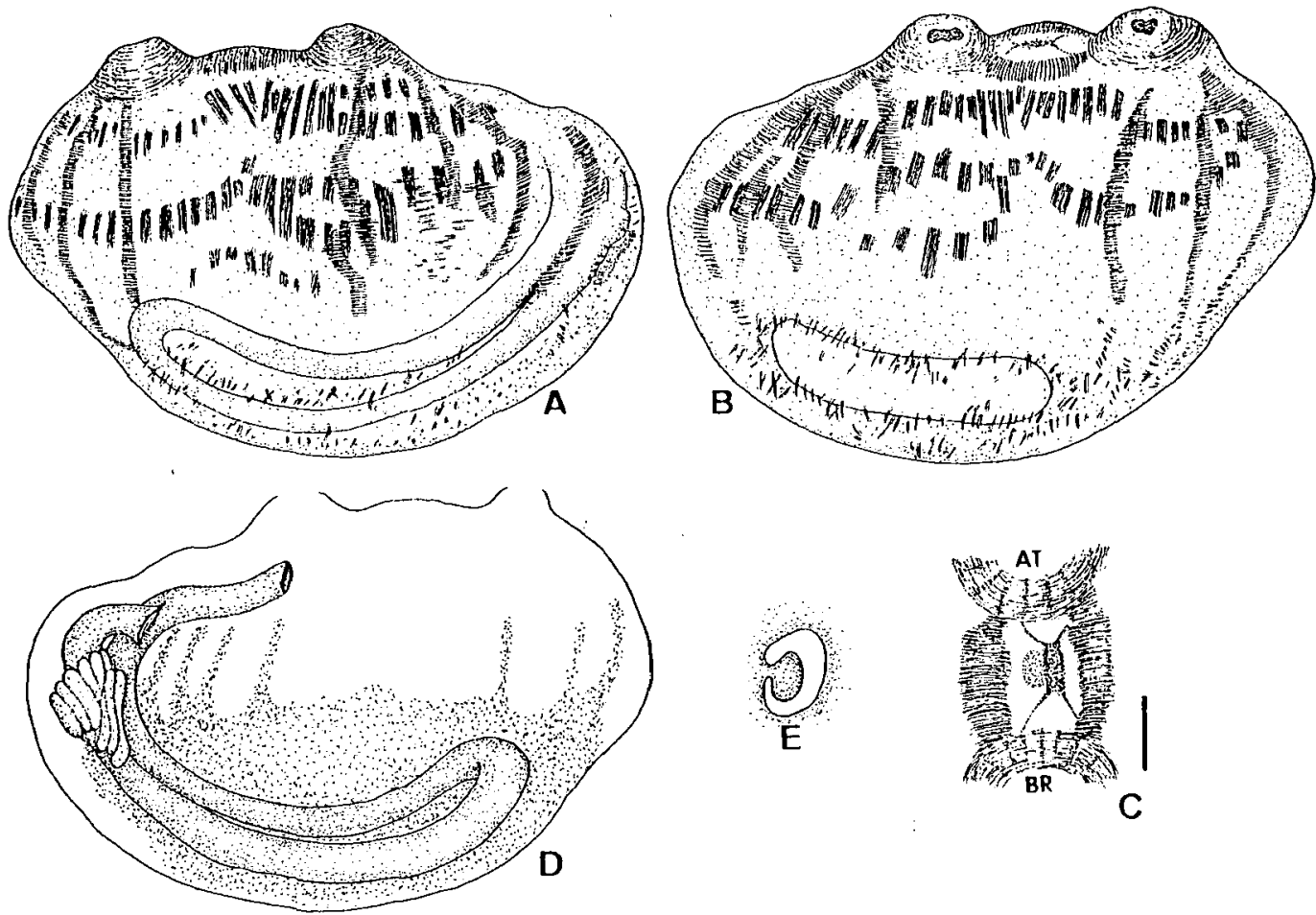

Fig. 40. Molgula hartmeyeri Oka from Oki Isls (Collection N), $15 \mathrm{~mm}$ long specimen. A. left side of mantle body; $B$. right side of mantle body, pigmentation over the surface of mantle body is not drawn in A \& B, in order to show the musculature clearly; C. intersiphonal area, from outside (AT: atrial siphon, BR: branchial siphon); D. left inner side of mantle body; E. ciliated groove. Scale indicates $1 \mathrm{~mm}$. 
converging to siphons (Fig. 40, A-B). Both vela present but not well developed. Ciliated groove C-shaped opened to the right (Fig. 40, E). Tentacles 14, the larger and smaller ones alternating almost regularly; branched in 2 orders. Dorsal lamina as a low and smoothly edged membrane. Seven branchial folds on each; the formula is:

$$
\begin{aligned}
& \text { L. D. } 0(10) 0(14) 0(14) 0(14) 0(14) 0(12) 0(7) 0 \mathrm{~V} . \\
& \text { R. D. } 0(13) 0(13) 0(14) 0(14) 0(14) 0(12) 0(9) 0 \mathrm{~V} \text {. }
\end{aligned}
$$

Five transverse vessels; 7 longitudinal rows of infundibula on each side, about 12 infundibula under each fold ventrally, with 8 dorsally; apex of infundibulum sometimes divided into two summits; stigmata bridged with fine parastigmatic vessels, and nearly straight in the interspaces. First intestinal loop much elongated, very deep and narrow, while the second very shallow; liver plicated; rectum elongated along dorsomedian line of branchial sac and attached firmly to it (Fig. 40, D). Neither gonads, gonoducts nor gonopores discernible.

Remarks. This specimen agrees well to the original and single description of Molgula hartmeyeri Oka, only except that the gonads in $M$. hartmeyeri may be replaced by the tissue of unknown nature in this specimen. In $M$. hartmeyeri, according to that description, the gonad on each side is hermaphroditic and diffuse, consisting of "unzähligen kleinen Hoden- und Ovarialfollikeln --, die durcheinander gemischt liegen" (p. 456), while in this specimen, such "Follikeln" are unobserved. I tried to investigate the details of the "Follikeln", but Oka's specimens had been lost at OCUT. I now feel inclined to doubt whether Oka correctly described the gonadal tissue, and consider the true nature of the "Follikeln" as still unknown. Thus, the present specimen from Oki is identified with $M$. hartmeyeri.

$M$. hartmeyeri is quite similar to $M$. xenophora Oka (see above), differing only in the gonads diffused or indiscernible in $M$. hartmeyeri, instead of comprising compactly distinct ovary and testis in $M$. xenophora. The gonads(?) seen in $M$. hartmeyeri might possibly be due to malformation, or some kind of deterioration from the gonads seen in $M$. xenophora. If this is accepted, the former species may be regarded as a senior synonym of the latter by the page precedence. Further discussions on this problem remain pending here until the appropriate specimens are obtained.

Distribution in Japan Sea. Oki Isls, 30-35 m deep (Nishikawa, 1986b; in the present study).

Distribution outside Japan Sea. Goto Isls, west of Kyushu (Oka, 1914).

\section{Rhizomolgula japonica Oka, 1926}

Rhizomolgula japonica Oka, 1926b, p. 176.

Material examined: None.

Remarks. This species was proposed by Oka (1926b) without any significant description nor the information about the exact locality, saying only as "the genus 
Rhizomolgula is also represented in the Japanese Ascidian fauna by a new species, which I propose to name $R h$. japonica. It is easily distinguishable from the previously known species of the genus in having a pair of gonads, one on each side of the body". The latter of the cited sentences can be regarded as a definition of the taxon that $R$. japonica denotes, and therefore, the name may be treated as available, not as nomen nudum. Later, Oka (1927e, p. 484, fig. 932) himself gave a detailed description and figure of external appearance of this species, with the reference to the locality as "the Japan Sea and northern parts of the Pacific". Unfortunately, the specimens concerned are not kept at OCUT now. Since then, no new records of this species have been given, so far as I am aware, except that of Chin (1934, p. 488) from Amoy, South China. According to his brief description, the specimens from Amoy have 4 branchial folds on each side; unfortunately, I have not yet reexamined the specimens. Judging from Oka's (1926b) statement, however, R. japonica has 6 folds on each side, because "the previously known species of the genus" (Oka) are all known to have 6 folds (see, for example, the diagnosis of the genus given by Hartmeyer, 1903, p. 167; Redikorzev, 1916, p. 127), and he mentioned no difference in this feature between "the species" and $R$. japonica. Consequently, Chin's specimens are not attributable to $R$. japonica; rather, it seems that they might possibly be referable to Hartmeyeria orientalis Oka. Thus, the exact locality of $R$. japonica remains still unknown, and therefore, the species is included in the ascidian fauna of the Japan Sea rather tentatively.

(to be continued) 